\title{
EXPLORING COLLEGE FOOD INSECURITY: A QUALITATIVE CASE STUDY \\ OF THE PERSPECTIVES OF THE UNIVERSITY OF CENTRAL MISSOURI FOOD PANTRY CLIENTELE
}

\author{
A Dissertation Proposal \\ presented to \\ the Faculty of the Graduate School \\ at the University of Missouri-Columbia \\ In Partial Fulfillment \\ of the Requirements for the Degree \\ Doctor of Educational Leadership and Policy Analysis \\ by \\ MICHAEL VERDERAIME \\ Dr. Sandy Hutchinson, Dissertation Supervisor \\ MAY 2020
}


(C) Copyright by Michael Verderaime 2020

All Rights Reserved 
The undersigned, appointed by the dean of the Graduate School, have examined the dissertation entitled

\title{
EXPLORING COLLEGE FOOD INSECURITY: A QUALITATIVE CASE STUDY OF THE PERSPECTIVES OF THE UNIVERSITY OF CENTRAL MISSOURI FOOD PANTRY CLIENTELE
}

presented by Michael Verderaime a candidate for the degree of Doctor of educational leadership and policy analysis, and hereby certify that, in their opinion, it is worthy of acceptance.

\author{
Dr. Sandy Hutchinson
}

Dr. Barbara N. Martin

Dr. Steve Ritter

Dr. C. Joseph Schott 


\section{ACKNOWLEDGMENTS}

This is dedicated to my first teacher, my nonna who from her kitchen table ignited my passion for education and instilled in me the importance of a good pot of sugu. I would like to thank all of the people who agreed to participate in this study. Without your willingness and honesty this project would not have been possible. I am truly grateful to Beth Rutt and her staff at the Student Recreation and Wellness Center for not only caring about their community, but for opening their practice for my study.

Additionally, I would like to extend my gratitude to my parents. To my mom, for teaching me an uncanny need to organize information. To my dad for pushing me to read and to always give my best effort. And to my brother for his support through these three years. This opportunity would not have been possible without my mother and father-inlaw, Marilyn and David Norfleet. Thank you for your encouragement, kindness, and love.

A sincere thank you to my mentor and friend, Dr. Sandy Hutchinson. Many students find that one teacher who changes their lives in elementary school. I had to wait until I was 40 years old, but you were well worth the wait. To my dissertation committee, especially Dr. C Joseph Schott. I appreciate your guidance, and scholarly thought, but most importantly your friendship.

Thank you to my three boys, Salvatore, Enzo, and Giovanni. I could not have truly understood the importance of this document without the constant interruptions to play. Lastly, but most importantly, thank you to my wife Kacey. For the late nights, the early mornings, the lack of sleep, the extra work, the patience, the debt, and the sacrifices, I am eternally grateful. Thank you for believing in me and for leading me into becoming a better father, husband, and man. I love you. 


\section{TABLE OF CONTENTS}

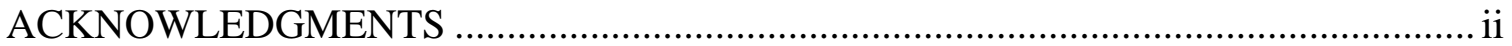

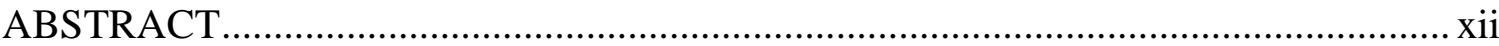

SECTION I: INTRODUCTION TO THE BACKGROUND OF THE STUDY ……........ 1

Introduction to the Background of the Study ........................................................... 2

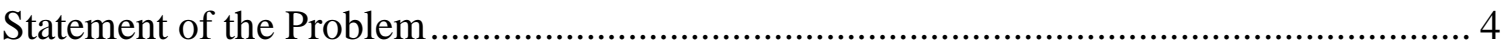

Existing Gap in the Literature ............................................................................... 5

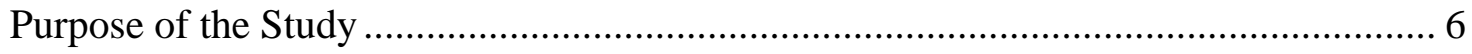

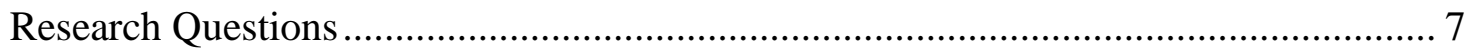

The research questions guiding this study are: …………...................................... 7

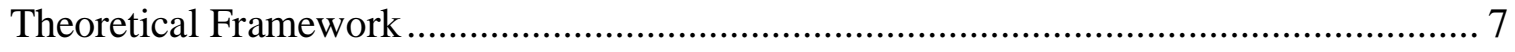

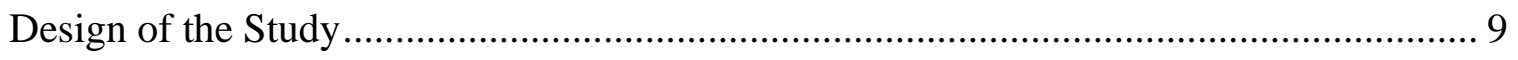

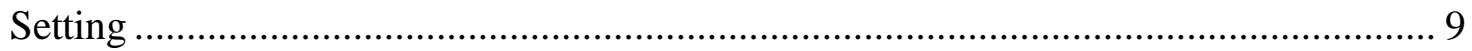

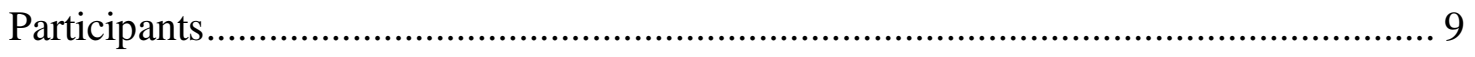

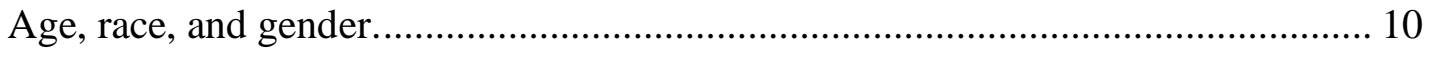

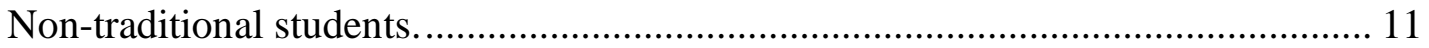

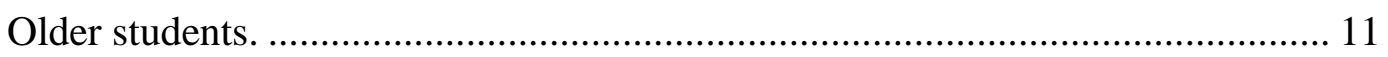

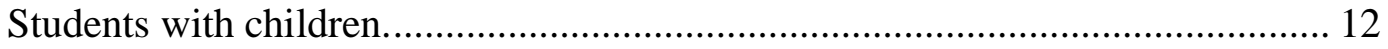

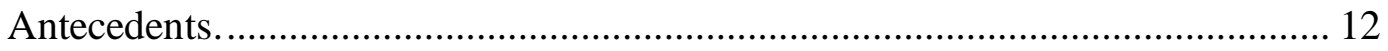

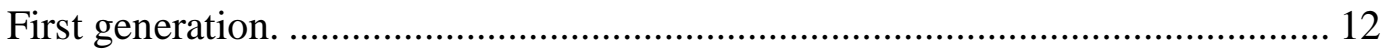

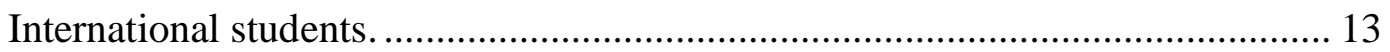

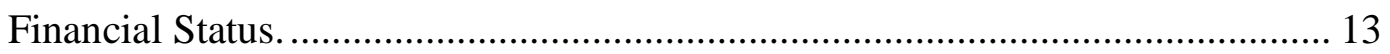

Federal Pell Grant recipients.......................................................................... 13 


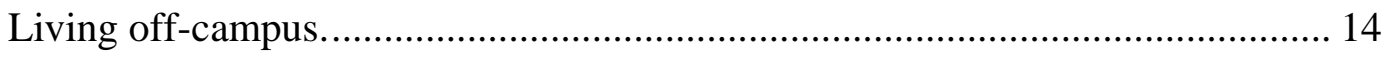

Table 1: Demographic Chart for Study Participants ............................................... 15

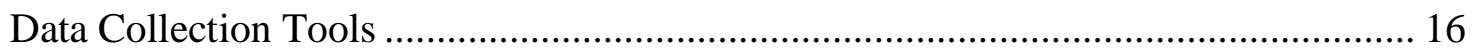

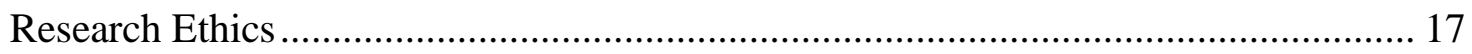

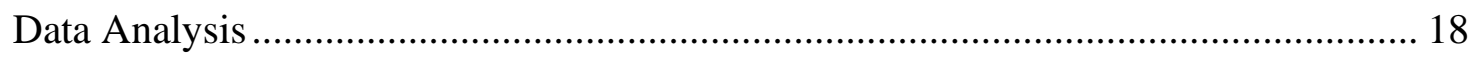

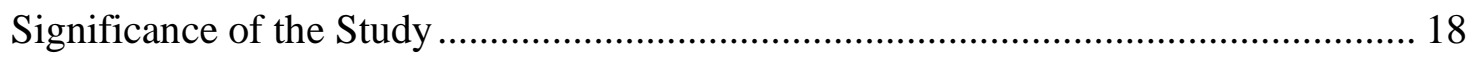

Assumptions, Trustworthiness, and Limitations........................................................... 20

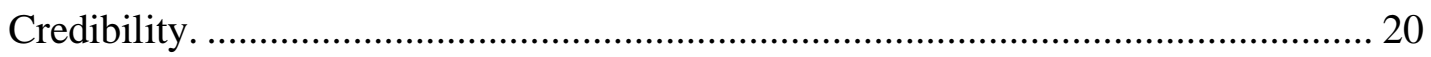

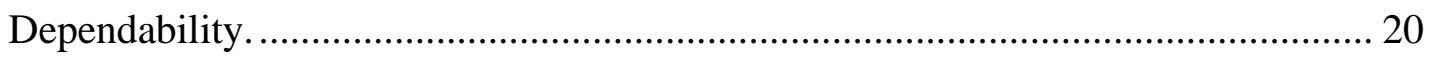

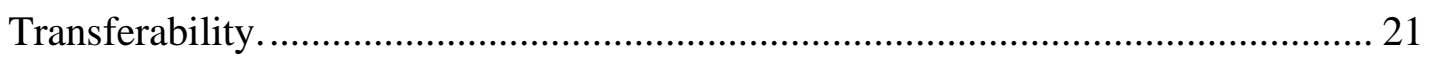

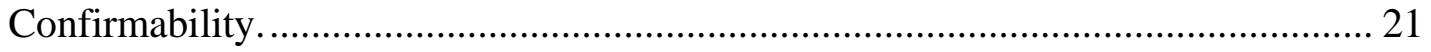

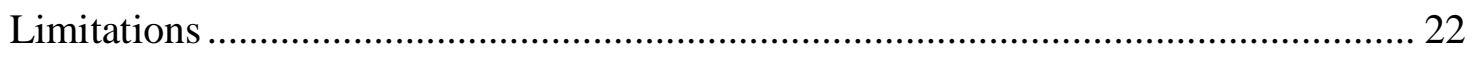

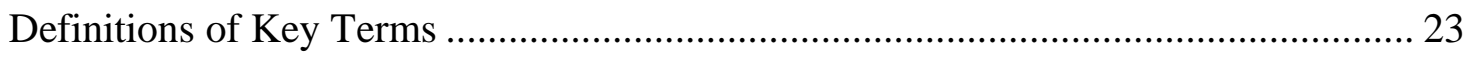

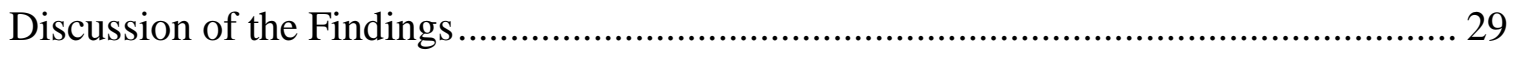

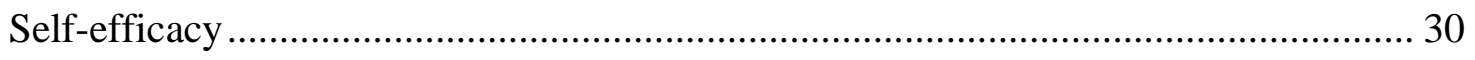

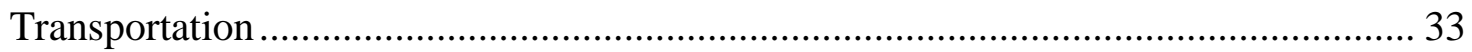

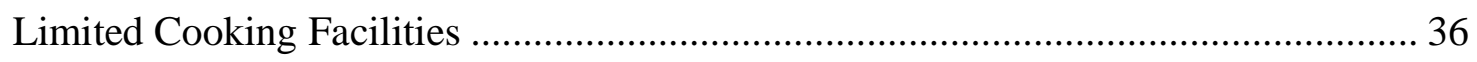

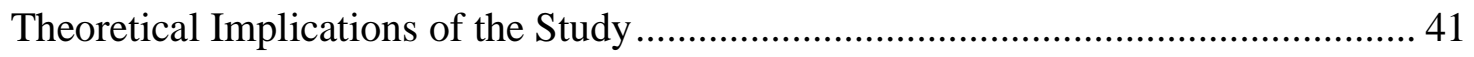

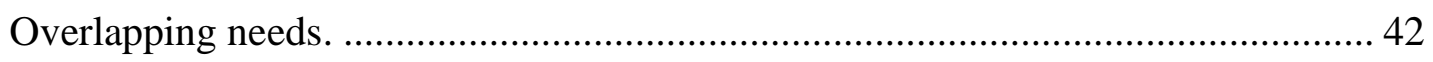

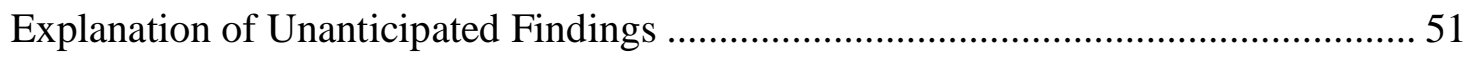

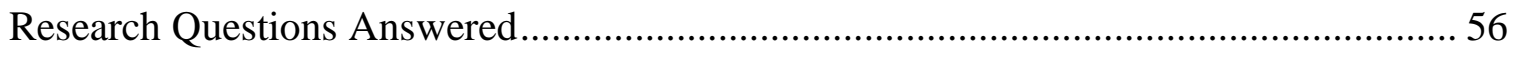

RQ1: What are the perspectives of UCM food pantry clients? .....................................56

RQ2: What UCM food pantry services are most significant to clients?...................... 62 
RQ3: What additional food pantry services would be beneficial to its clients? .......... 66

Implications for Practice (Recommendations for educators) ................................... 71

Building a Culturally Responsive Food Pantry ..................................................... 71

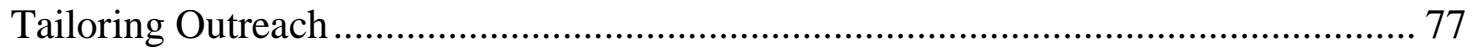

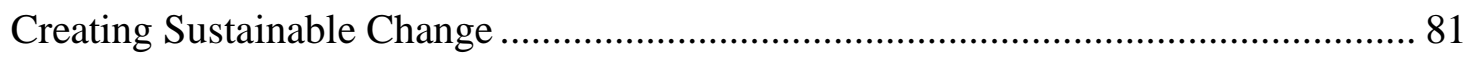

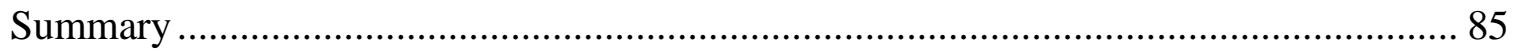

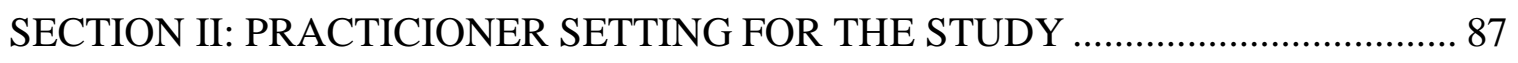

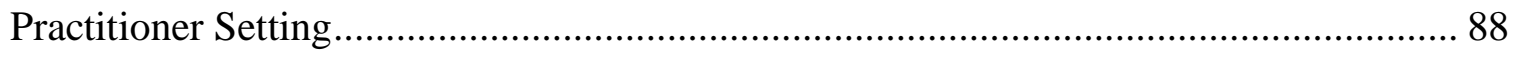

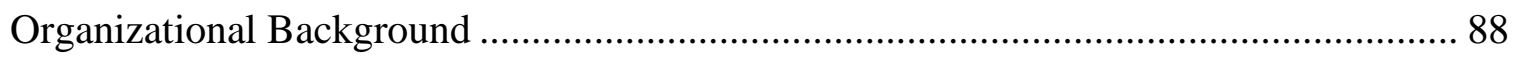

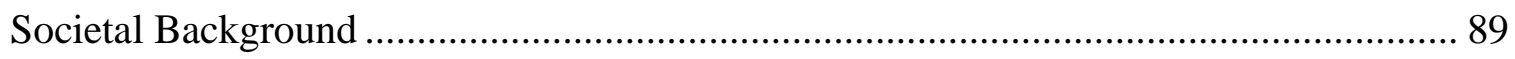

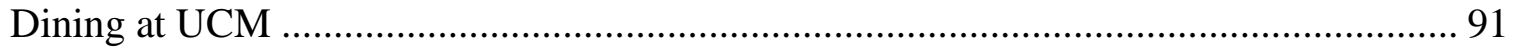

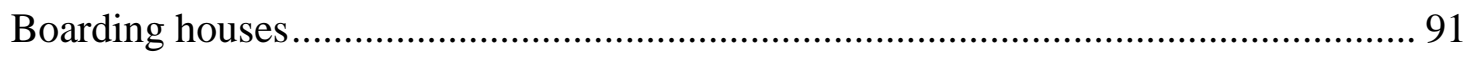

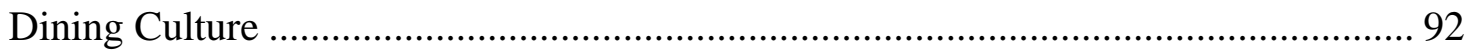

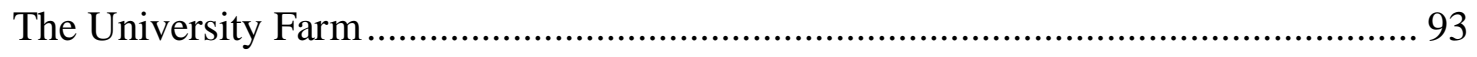

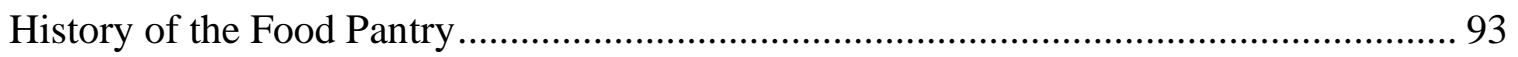

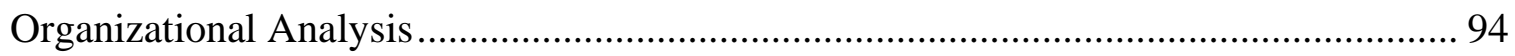

Analysis of the Campus Cupboard through the Structural Frame ............................. 94

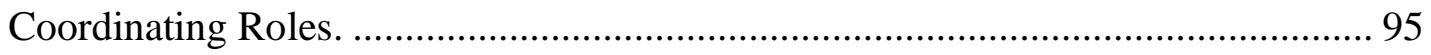

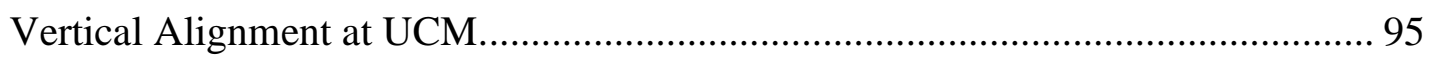

The Middle Line (Mintzberg, 1979/2005).................................................... 96

The Technostructure (Mintzberg, 1979/2005).............................................. 97

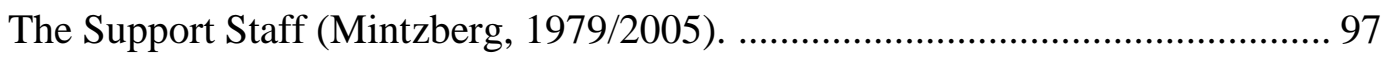

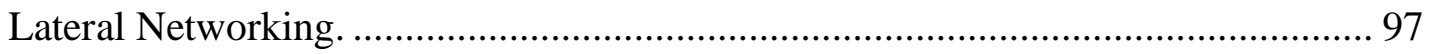




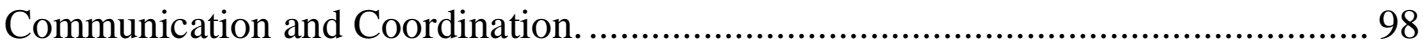

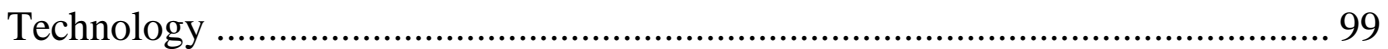

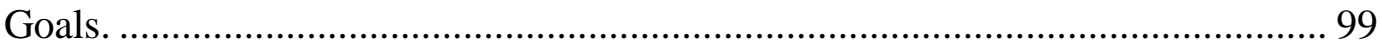

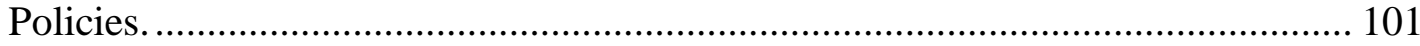

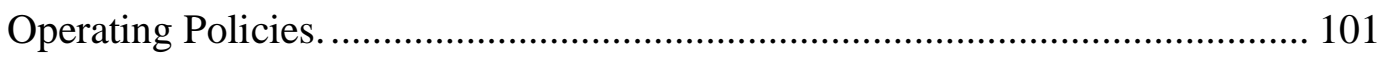

Decision Making Policies. ............................................................................... 102

Participation Policies. ............................................................................. 103

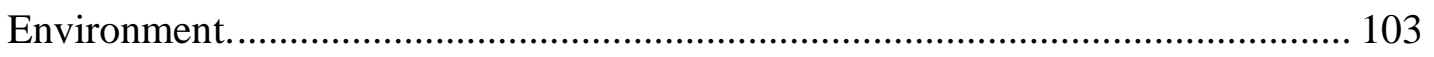

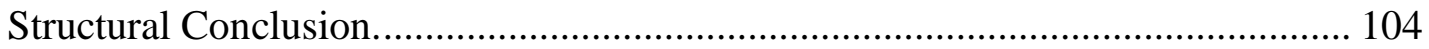

Analysis of the Campus Cupboard through the Symbolic Frame ............................ 105

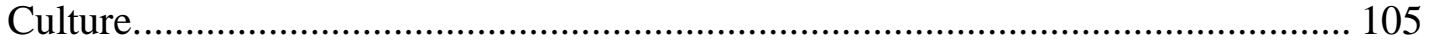

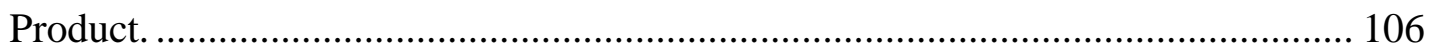

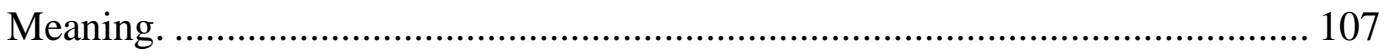

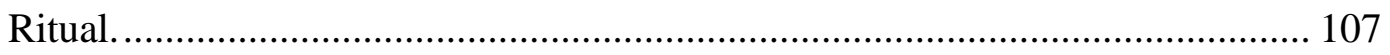

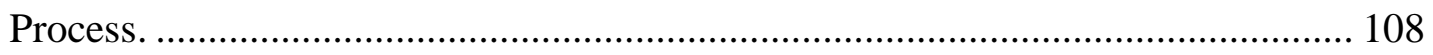

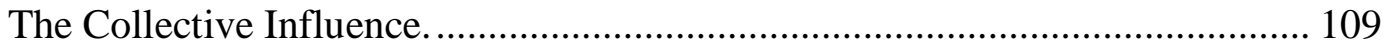

Battling perceptions. ..................................................................... 110

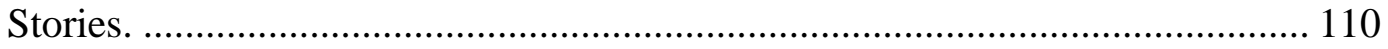

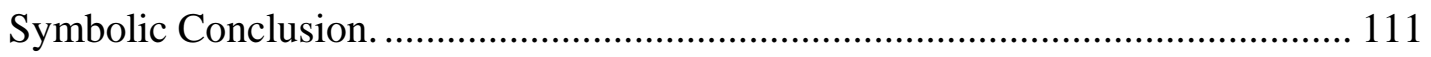

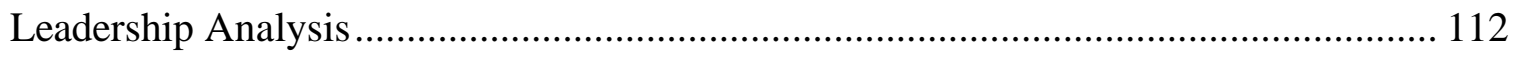

Antecedent Conditions .............................................................................. 112

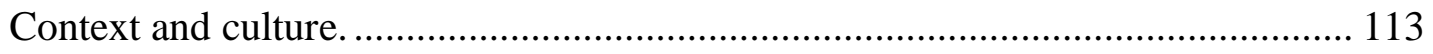

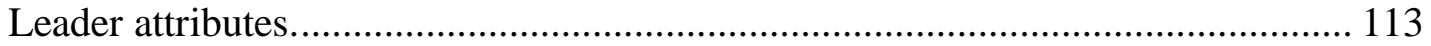




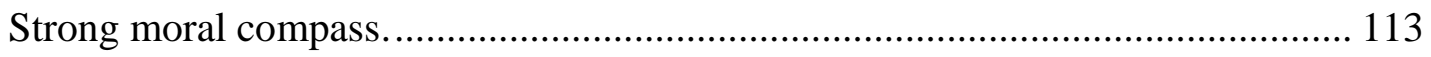

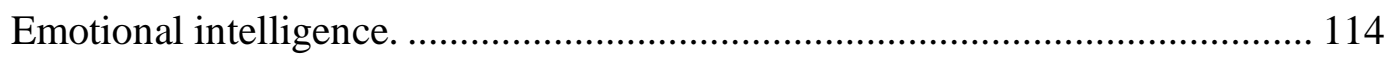

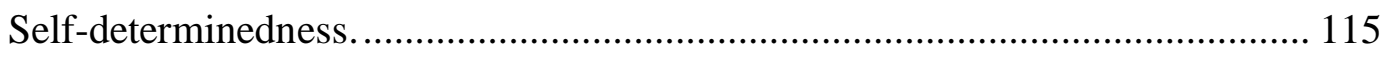

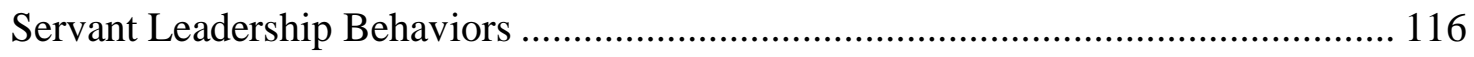

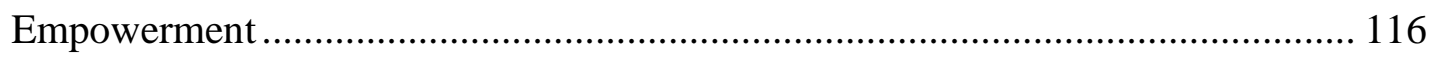

Creating value for the community. ..................................................................... 117

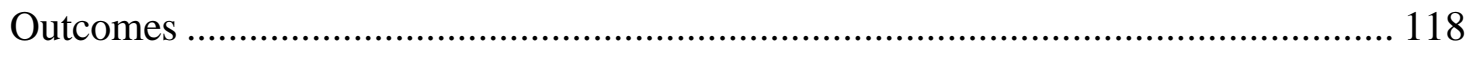

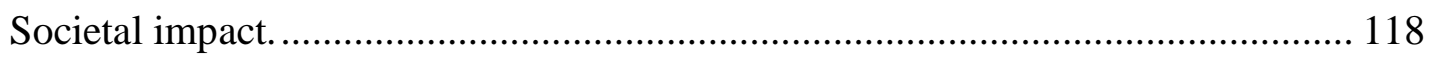

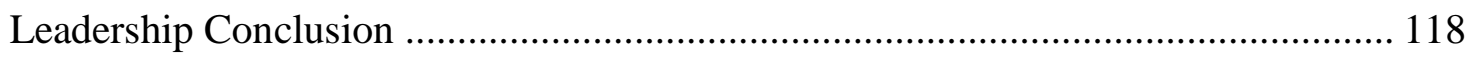

Implications for Research in the Practitioner Setting .................................................... 119

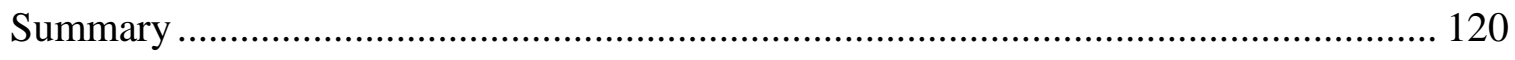

SECTION III SCHOLARLY REVIEW FOR THE STUDY ………………………... 123

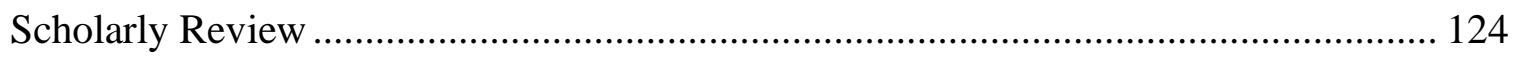

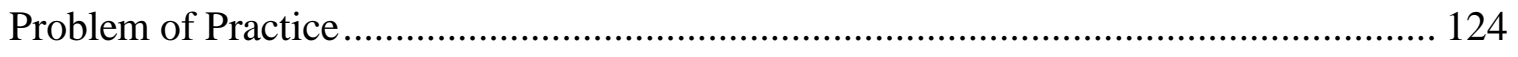

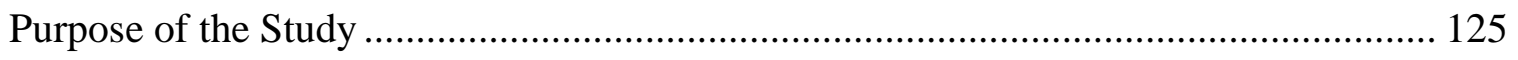

Theoretical Framework: Human Motivational Theory ………...................................... 126

Summary and Evolution of the Theory ............................................................... 126

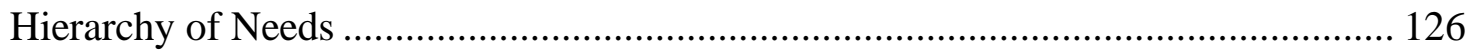

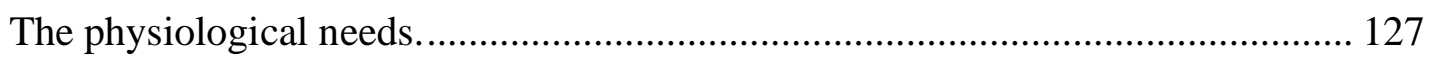

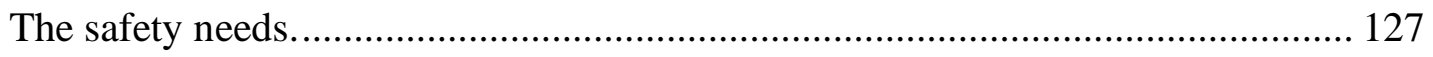

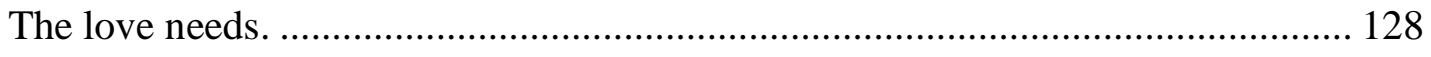

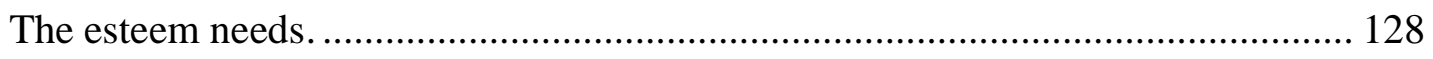

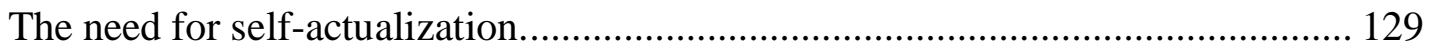


Self-transcendence.

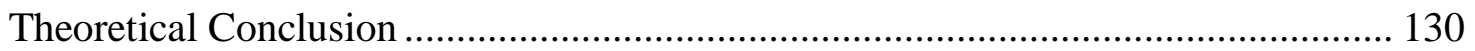

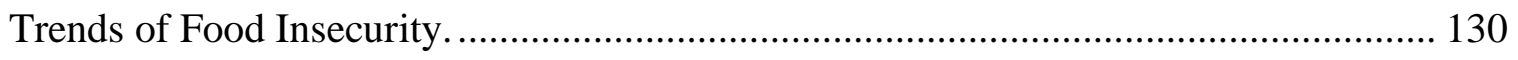

National Demand ……….................................................................................. 130

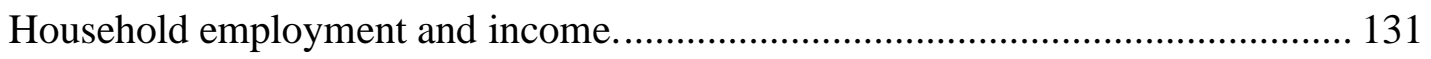

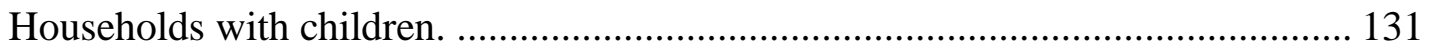

Race

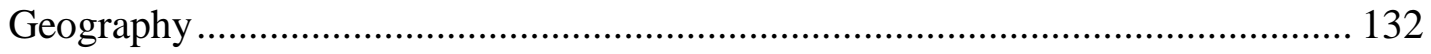

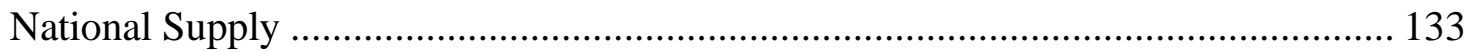

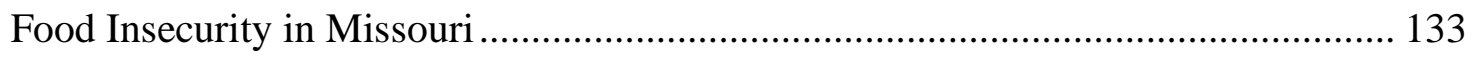

Johnson and Jackson County, Missouri................................................................... 134

Food Insecurity Among College Students ............................................................... 136

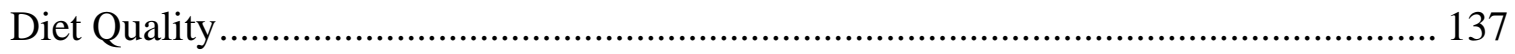

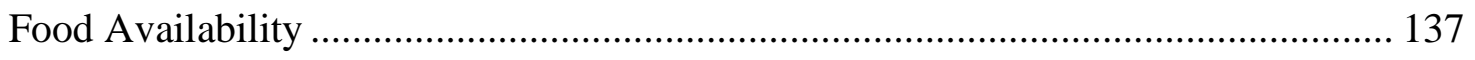

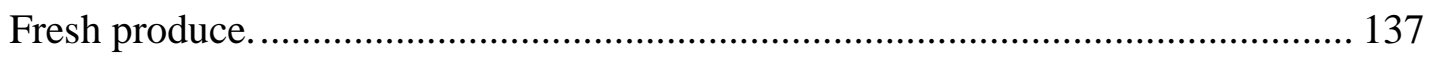

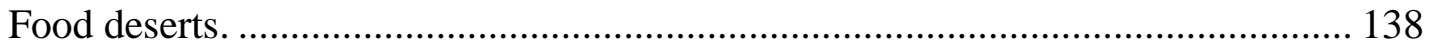

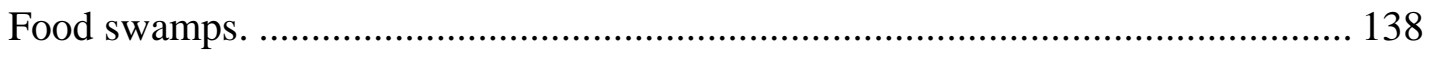

Vending machine health. .................................................................................. 139

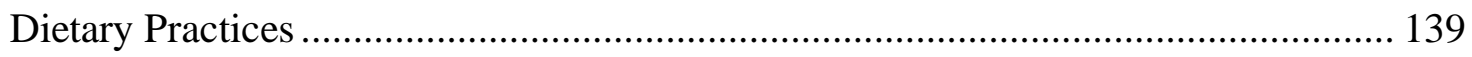

Meal frequency and portion size....................................................................... 139

Students, Hunger, and College................................................................................. 139

The History, Prevalence, and Organization of Campus Based Food Pantries ................ 140

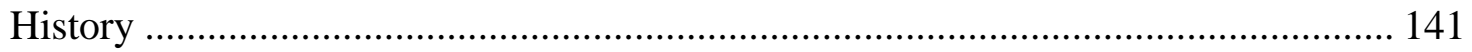




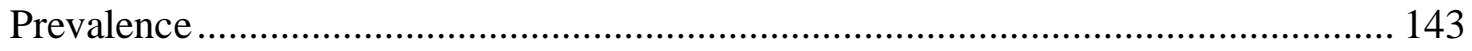

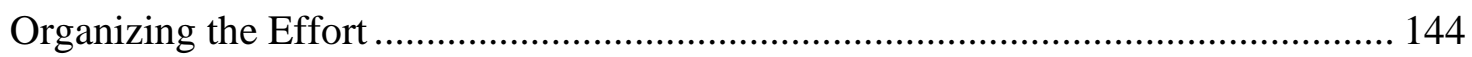

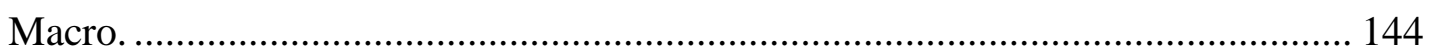

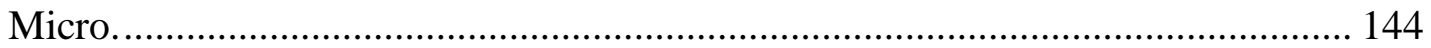

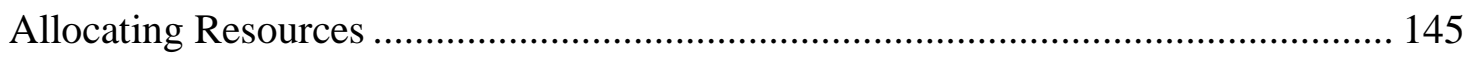

Food distribution.

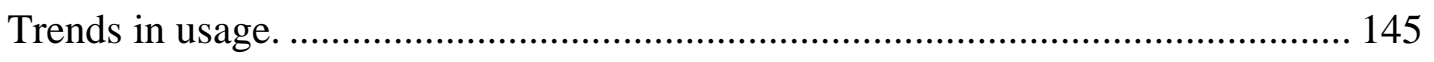

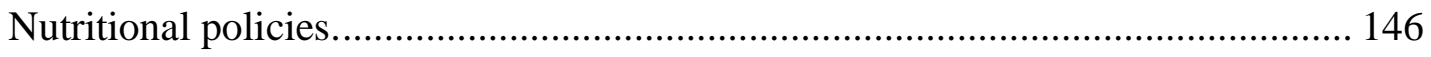

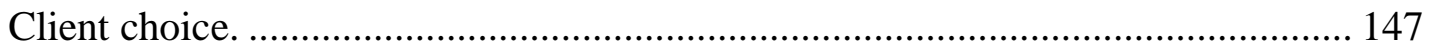

Addressing Food Insecurity at Postsecondary Institutions .......................................... 148

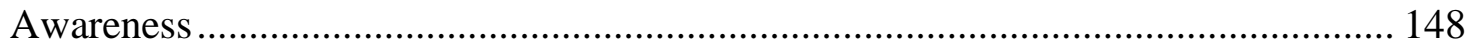

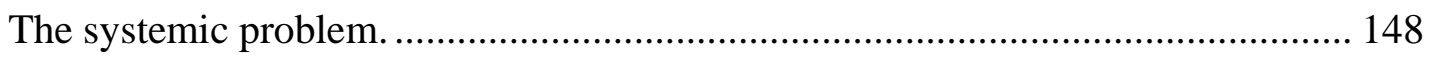

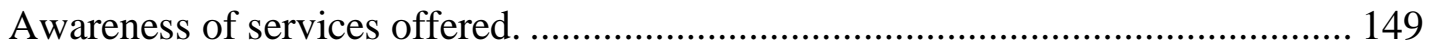

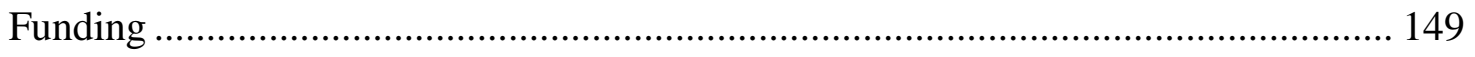

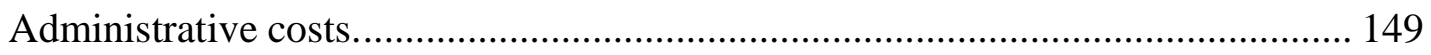

Accessibility to emergency support................................................................... 150

Innovative advances in support................................................................... 150

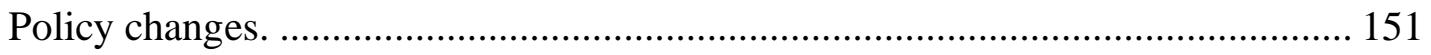

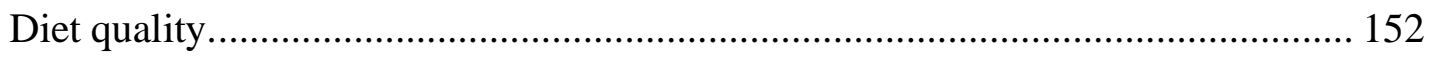

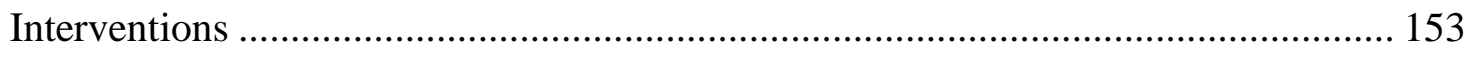

Enhancing college campus food environments...................................................... 153

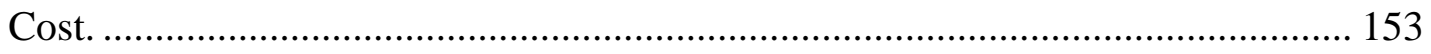

Educational nudges improving diet quality. ...................................................... 154 


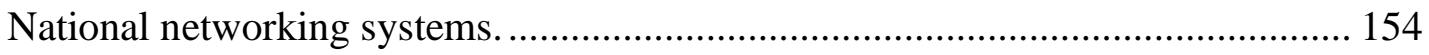

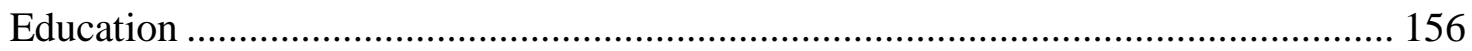

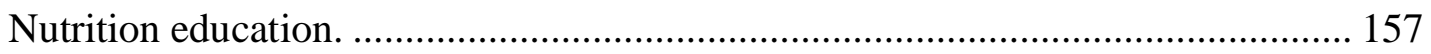

Nutrition classes and programming. …………………....................................... 157

Dietary expertise associated with food pantries.................................................. 157

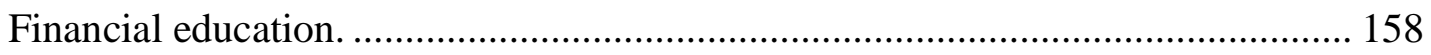

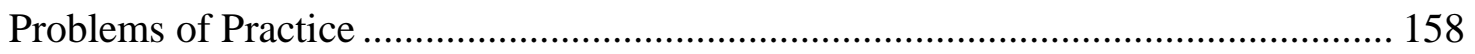

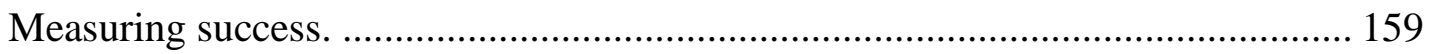

Usage

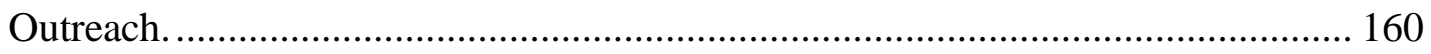

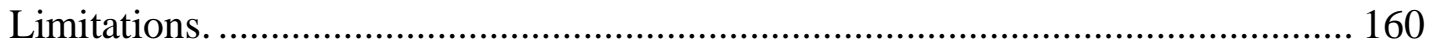

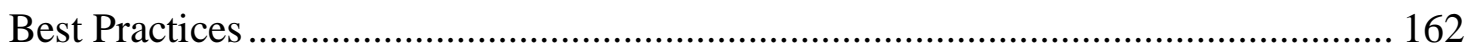

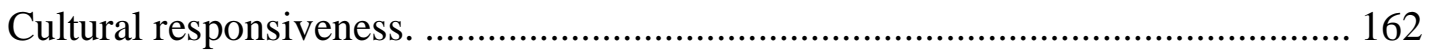

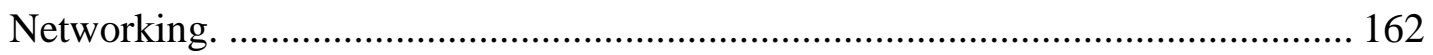

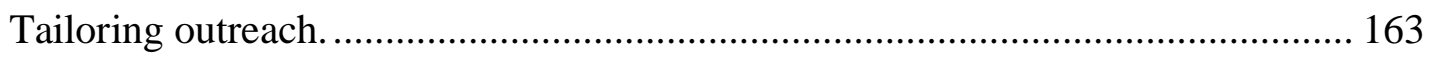

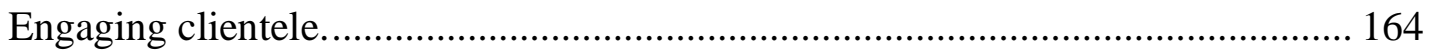

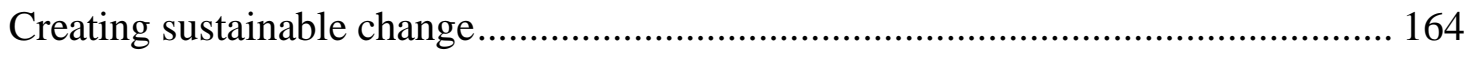

Advocating for policy improvement................................................................. 165

SECTION IV CONTRIBUTION TO PRACTICE..................................................... 167

SECTION V CONTRIBUTION TO SCHOLARSHIP ............................................. 192

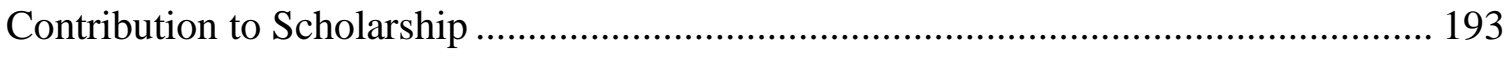

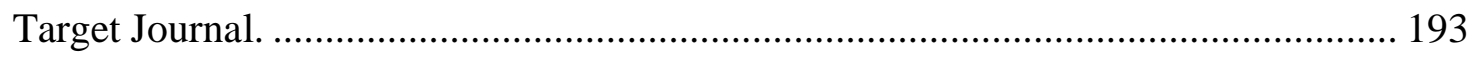

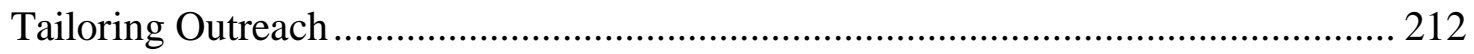




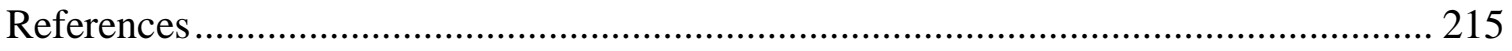

SECTION VI SCHOLARLY PRACTITIONER REFLECTION ……........................ 234

Becoming a Scholarly Practitioner ……………………....................................... 235

APPENDIX A INTERVIEW QUESTIONS: STAFF/ VOLUNTEERS ......................... 261

APPENDIX B INTERVIEW QUESTIONS: FOOD PANTRY CLIENTELE ............... 263

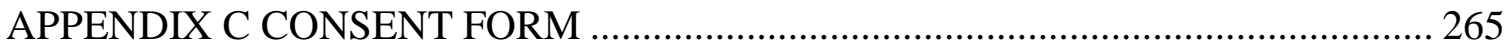

APPENDIX D PERMISSION TO CONDUCT RESEARCH....................................... 267

APPENDIX E RECRUITMENT SCRIPT ……………………………………….... 268

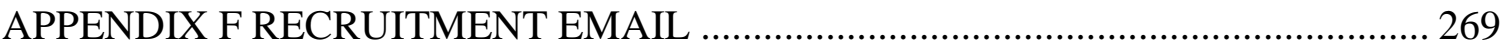

APPENDIX G RESEARCH QUESTIONS ASSOCIATED WITH ………………...... 270

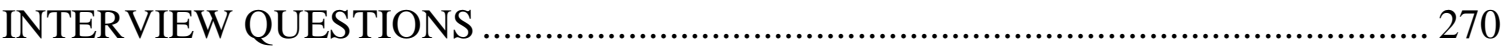

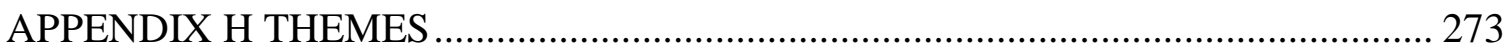

Theme 1: UCM students are balancing multiple responsibilities with a variety of

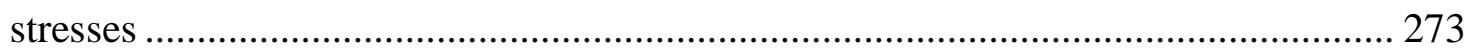

Theme 2: The Campus Cupboard clients also shared an array of successful strategies

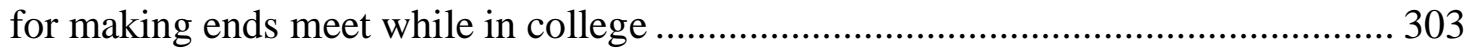

Theme 3: The reasons people use the Campus Cupboard vary from individual to individual

Theme 4: Clients care about what the food and services the Campus Cupboard offers as well as their experience while they are in there 343

Theme 5: Although the campus cupboard is focused on clientele, the volunteers and staff are the Campus Cupboard's greatest asset. 
Exploring college food insecurity: A qualitative case study of the perspectives of the University of Central Missouri Food pantry clientele

Michael Verderaime

Dr. Sandy Hutchinson, Dissertation Supervisor

\begin{abstract}
Insufficient resources undermine postsecondary educational experiences and delay credit attainment for many college students (Goldrick-Rab, Baker-Smith, Coca, Looker, \& Williams, 2019). To examine the efficacy of existing interventions, such as a campus food pantry, the researcher conducted a series of interviews with a crosssection of volunteers, staffed leaders, and food pantry clients. The study produced 5 significant themes. 1) UCM students are balancing multiple responsibilities with a variety of stresses; 2) The Campus Cupboard clients shared an array of successful strategies for making ends meet while in college; 3) The reasons people use the Campus Cupboard vary from individual to individual; 4) Clients care about the food and services the Campus Cupboard offers as well as their experience while they are in there; 5) The volunteers and staff are the Campus Cupboard's greatest asset. They represent a variety of skills, abilities, knowledge, perspectives and resources for the cupboard and their clients. The recommendations focused on three core capacities that are critical for the Campus Cupboard. Specifically, to address the dietary struggles students face in higher education, as well as the living costs associated with schooling, this study constructs its recommendations focusing on 1) Building a culturally responsive food pantry; 2) Tailoring its outreach; and 3) Creating sustainable change.
\end{abstract}




\section{SECTION I:}

INTRODUCTION TO THE BACKGROUND OF THE STUDY 


\section{Introduction to the Background of the Study}

Food insecurity negatively affects students at the University of Central Missouri (UCM) (Wisconsin HOPE Lab, 2018). There is a growing disparity between the purpose of higher education and successfully removing the barriers that inhibit students from fully experiencing the benefits of a college experience. Although federal policy has made tuition for higher education more affordable, many college students do not know from where their next meal is coming.

Current research argues that academic institutions should address food insecurity among college students. As a result of the research, the national conversation regarding food insecurity associates hunger with poorer academic achievement and degree attainment which undermine investments in higher education (Broton \& Goldrick-Rab, 2017; Broton, Weaver, \& Mai, 2018; Goldrick-Rab, Richardson, \& Hernandez, 2018; Morris, Smith, Davis, \& Null, 2016; Patton-López, López-Cevallos, Cancel-Tirado, \& Vazquez, 2014). The increasing number of emerging campus food pantries highlights the growing prevalence of food insecurity among college students. However, "despite growing awareness of food insecurity and hunger on college campuses, [college] food insecurity is faceless, has no standard image, and is often silent" (Henry, 2017, p. 9). Under these circumstances, food insecurity poses a specific problem to institutions because it is difficult to tell who is being affected. Qualitative studies uncover insufficient resources, time, transportation, and kitchen facilities contribute to inadequate consumption and poor diet quality among college students (Henry, 2017).

In response to the challenge of food insecurity, an array of food assistance programs has been developed and, consequently, has become an important part of the 
social safety net. Nevertheless, the role of these programs, especially the Supplemental Nutrition Assistance Program (SNAP), (formerly known as the Food Stamp Program), has increased over the past 20 years as non-food assistance programs have declined.

Most research yields results based on sociodemographic information, specifically concentrating on grouping their findings by gender, household employment, and income, households with children, and race (Chaparro, Zaghloul, Holck, \& Dobbs, 2009; Goldrick-Rab, Richardson, \& Hernandez, 2017; Morris et al., 2016; Patton-López et al., 2014). Although organizational demographic trends are important in recognizing those suffering from food insecurity, an additional way to understand the severity of food insecurity in the United States is by considering the national support system dedicated to food insecurity.

The weight of food distributed is often used to not only communicate the immensity of the support system, but to define the extent of the need as well. As the largest network in the United States, Feeding America distributes over 3.3 billion pounds of food and grocery items through 202 food banks in all 50 states, Puerto Rico, and Washington DC each year (Feeding America Annual Report, 2018).

Even though there is no question that emergency food relief is available and reaching a broad sector of the communities in need, some scholars question the effectiveness of current programs. For example, Jablonski, McFadden, and Colpaart (2016) argued there is very limited evidence that the utilization of community food assistance programs, which are distinct from government sponsored programs like SNAP, reduce food insecurity. Private and non-profit organizations represent the front line of service, providing a non-threatening and culturally friendly method of access for the 
vastly diverse needs of its clientele. According to Weinfield et al. (2014), "sixty-two percent of partner agencies are faith-based organizations or located in a religious institution, but agencies also include numerous other nonprofit or private organizations, community action programs, and state or local government agencies" (p. 158).

\section{Statement of the Problem}

Insufficient resources not only undermine postsecondary educational experiences but delay credit attainment for many of today's college students (Goldrick-Rab, BakerSmith, Coca, Looker, \& Williams, 2019). Although federal policy has made tuition more attainable, there is still a growing concern regarding the purpose of the barriers that inhibit student success in higher education. The policies intended to increase access to higher education are now at the center of an intense national debate. Generally speaking, scholars are advancing arguments to examine the inequality in higher education, as well as considering living costs and the struggles 21 st century college students face to make ends meet (Broton et al., 2018).

The problem is University of Central Missouri (UCM) students who lack resources for food struggle to learn at the same capacity as other students. Insufficient resources not only undermine postsecondary educational experiences, but delay credit attainment for many of today’s college students (Goldrick-Rab, Baker-Smith, Coca, Looker, \& Williams, 2019). While evidence of this relationship between hunger and student success has been well established, the literature reflects very little about the perceptions of students who rely on college food pantries. 


\section{Existing Gap in the Literature}

Current research argues the importance of academic institutions addressing food insecurity, and existing scholarship supports that food insecurity is associated with adverse outcomes including poorer academic achievement and attainment, undermining investments in higher education (Broton \& Goldrick-Rab, 2017; Goldrick-Rab et al., 2018; Morris et al., 2016; Patton-López et al., 2014). The growing number of food pantries emerging on college campuses indicates the increasing extent of food insecurity among college students, but knowing who is being affected poses a complex problem (Henry, 2017).

The difficulty in identifying who is at risk of food insecurity among college students lies in the vast number of variables contributing to the problem. Although students today are financially and ethnically more diverse than ever before, researchers agree that some college students are at higher risk of basic needs insecurity than others (Goldrick-Rab et al., 2018; Goldrick-Rab et al., 2019). In the national discussion, research is typically limited by a narrow population sample. For example, most research concentrates on a specific institution, state-wide data report, or certain schools within a specific region. There are many factors contributing to food insecurity that align with the changing demographics defining college students today. However, the exact number of students suffering from food insecurity, as well as the degree of hunger from which they are suffering, is still largely the topic of conversation.

The sheer complexity of college food insecurity makes it difficult to define sustainable solutions. Time, transportation, self-efficacy, and poor kitchen facilities contribute to inadequate food consumption, as well as poor diet quality among college 
students. What remains to be explored are the perceptions and needs of college students who are clients of campus food pantries (Henry, 2017; O’Neill \& Maguire, 2017)

\section{Purpose of the Study}

Although college campus food pantries are providing emergency support for food insecure students, long-term solutions are needed to support the changing demographics of today's college student. An important point to consider is that today's typical student is not a recent high school graduate who lives in a dormitory and is supported by his or her parents. In fact, Dubick, Mathews, and Cady (2016) indicated that less than one in four students could be categorized as having parents who are able to pay all of their college expenses. Therefore, colleges must prepare themselves towards alleviating the needs of college students in poverty. In addition, because hunger may be a sign of deeper troubles for today's college student, investigating the perspectives of college campus food pantry clientele is an important step towards understanding students' needs (Dubick, Mathews, et al., 2016; Goldrick-Rab et al. 2018).

Understanding the national trend in college food insecurity helps clarify a growing local concern. Over the past several years, there has been a substantial increase in the use of the food pantry at UCM. Significantly, in 2015 there were 123 people served; however, in 2017 that number jumped to 1,247 people (UCM Campus cupboard stats, 2018). This dramatic increase indicates a need to understand the systematic issue at hand. It is imperative that research be conducted to explore the perspectives of food pantry clientele in order to identify the needs associated with those students facing a hunger crisis at UCM. Therefore, the purpose of this qualitative study will be to explore the perspectives of food pantry clientele at UCM. In an effort to identify additional 
services that can be offered to support students at UCM, the perspectives of Campus Cupboard clientele will generally be defined by how the clients interpret their experiences, how they construct their worlds, and what meaning they attribute to their experiences (Merriam \& Tisdell, 2016).

\section{Research Questions}

The research questions guiding this study are:

1. What are the perspectives of UCM food pantry clients?

2. What UCM food pantry services are most significant to clients?

3. What additional food pantry services would be beneficial to its clients?

\section{Theoretical Framework}

This study was grounded in Human Motivational Theory. Developed from Maslow's hierarchy of needs, this study referred to both the original model as well as revised versions of the theory. Later versions of Human Motivational Theory argued that multiple needs can exist at any given time (Bridwell \& Wahba, 1976; Karasar \& Baytemir, 2018; Koltko-Rivera, 2006; Oved, 2017).

The earliest and most widespread version of Maslow's hierarchy is based on his 1943 and 1954 models in which Maslow classifies basic human needs in a logical hierarchy and relates these needs to general behavior (Koltko-Rivera, 2006; A.H. Maslow, 1943). In addition, his proposal structured needs by their probability and appearance (Bridwell \& Wahba, 1976a). The original models include five motivational levels, in order: physiological needs, safety needs, love needs, esteem needs, and selfactualization needs. Maslow's later work includes a sixth motivational level, known as self-transcendence (Koltko-Rivera, 2006). Current research argues for a transformation 
from the original model to a revised version that builds upon the pinnacle of selfactualization as self-transcendence (Kenrick, 2017; Oved, 2017). For the purpose of this theoretical review, both models will be included.

Part of the reason Maslow's Human Motivation Theory has maintained its appeal for close to a century is that it provides both a theory of human motivation as well as classifying basic human needs in a logical hierarchy that relates these needs to general behavior. Maslow's proposal structured needs by their probability and appearance (Bridwell \& Wahba, 1976a). Throughout the 20th Century, the field of evolutionary psychology widely accepted the view that there were primary drives and secondary drives. To clarify, the basic notion is that primary drives, such as hunger and thirst, are present early in life and provide the foundation for later secondary drives that are learned via simple conditioning principles. Today, psychologists understand that regardless of their order, at the core of Maslow's theory of motivation are two important ideas: (a) there are multiple and independent fundamental motivational systems and (b) these motives form a hierarchy in which some motives have priority over others (Kenrick, Neuberg, Griskevicius, Becker, \& Schaller, 2010).

Many considered Maslow's theory to be ahead of his time. Later studies in the field focused on the inherent problem that a lesser need must be resolved before one can address a subsequent need (Kenrick, 2017; Oved, 2017). These studies ultimately produced additional models of the theory. In addition, these models incorporated evolutionary psychology as well as a dynamic hierarchy that allows needs to overlap at the same time instead of adding an additional level to the pyramid. 


\section{Design of the Study}

This qualitative case study focused on the process, meaning and understanding of food insecurity of the pantry clientele at UCM. The researcher will be the primary instrument of data collection and will rely on an inductive analysis process (Creswell, 2014; Merriam \& Tisdell, 2016).

\section{Setting}

This is a qualitative case study of the food pantry clientele on the UCM campus located in Warrensburg, MO. As of the Fall of 2018, there were approximately 11,487 students, which included 9,300 undergraduate students and 2,187 graduate students. The undergraduate student body consists of $45 \%$ male, $55 \%$ female, $21 \%$ minority, and $2.5 \%$ international students. Domestic students came from 46 states. The graduate student body consists of $37 \%$ male, $63 \%$ female, $13 \%$ minority, and $19 \%$ international students. There are 658 undergraduate and graduate international students from 55 different countries (Chen, 2018, p.i).

\section{Participants}

According to the literature, a large portion of the most vulnerable food insecure student populations are those who are non-traditional and those who are housing insecure (Broton \& Goldrick-Rab, 2017; Dubick, Mathews, et al., 2016; Goldrick-Rab \& Broton, 2016; Goldrick-Rab et al., 2018). Because the population can be sampled directly, the researcher employed single stage sampling of participants who identify with any of the following criteria associated with students who struggle with food insecurity (Creswell, 2014). 
Age, race, and gender. Although frequently coupled with other

sociodemographic variables like race and gender, there is consensus among scholars that age is a sociodemographic variable highly correlated with food insecurity (Hagedorn \& Olfert, 2018; Hanbazaza, Ball, Farmer, Maximova, \& Willows, 2016). Using data from campus-based food pantries scholars determined that users were $50 \%$ more likely to be graduate students. However, students younger than 25 who are enrolled in four-year institutions are less likely to be food insecure than their two year institution counterparts (Broton et al., 2018; Farahbakhsh et al., 2017). A recent study reported rates of basic needs insecurity are "higher for marginalized students, including African Americans, students identifying as LGBTQ, and students who are independent from their parents or guardians for financial aid purposes" (Goldrick-Rab et al., 2018, p. 2).

A high number of minority students not only suffer from higher levels of food insecurity but experience it more frequently. The severity of food insecurity among minorities in comparison to non-minorities varies across the country. To illustrate the current trend, a City University New York study reports minorities experience food insecurity at a rate 1.5 times that of non-minority students. Likewise, a national study indicates $57 \%$ of Black or African American students reported food insecurity compared to $40 \%$ of non-Hispanic white students. Regardless of race, students who lived in food insecure homes before attending college, students at two-year institutions working more than 20 hours a week, and students at urban universities tend to report higher levels of food insecurity (Blagg, Gundersen, Schanzenbach, et al., 2017; Broton et al., 2018; Freudenberg et al., 2011; Morris et al., 2016). Three studies in particular contend women use campus based food pantries at a higher rate than males but, like age and race, 
sociodemographic data do not indicate food insecurity, but rather suggest correlation (Hanbazaza et al., 2016; Paola \& DeBate, 2018; Twill et al., 2016; Zizza et al., 2008).

Regardless of race, students who lived in food insecure homes before attending college, students at two-year institutions working more than 20 hours per week, and students at urban universities tend to report higher levels of food insecurity (Blagg, Gundersen, Schanzenbach, et al., 2017; Broton et al., 2018; Freudenberg et al., 2011; Morris et al., 2016).

Non-traditional students. Because access to higher education is broader than ever before, both two and four-year institutions are no longer serving a homogeneous student clientele. Today, first generation college students, international students, older students, and students with children are what have been called non-traditional, and although more prevalent and successful than ever, they are at the same time more vulnerable to food insecurity.

Older students. Because older students do not typically live in college dormitories, they do not access traditional college dorm meal plans the way younger students do. Cafeteria meal plans are a main contact point for students to access food on college campuses; however, research is revealing that "college meal plans may be too expensive for students looking to cut corners on the expense of overall college overhead" (Brown, Dresen, \& Eggett, 2005, p. 446). It is important to understand how students perceive, experience and cope with food insecurity, but also to explore opportunities to address food insecurity by improving food literacy among different types of college students. Because students older than 30 are more likely to be food insecure than their 
non-student counterparts, only addressing meal plans as a one size fits all solution presents a limited scope (Blagg, Gundersen, Whitmore Schanzenbach, \& Ziliak, 2017).

Students with children. Likewise, students with children were also disproportionately likely to experience food and housing insecurity. According to the most recent study, students with children experience higher rates of food insecurity (53\%) as compared with those who do not have children (Goldrick-Rab et al., 2019). On the brighter side, though, among students who are classified as food insecure-with hunger, students with children are the most likely to have used food stamps (Broton et al., 2018; Farahbakhsh et al., 2017; Goldrick-Rab et al., 2018; Hanbazaza et al., 2016).

Antecedents. Several factors that may affect a student's trajectory during college. As Patton-López et al. (2014) explained, food insecurity among college students may signal previous trajectories of disadvantages and shape future trajectories into adulthood. However, antecedent events such as economic shock, family separations, divorces, medical emergencies, loss of employment, legal troubles, transferring schools, and coming from homeless situations increase the likelihood of trajectories that may lead students to being more vulnerable to living in poverty and not completing their education (Broton et al., 2018; Freudenberg et al., 2011; Gaines et al., 2014; Goldrick-Rab et al., 2018; Henry, 2017; McArthur et al., 2018; Patton-López et al., 2014).

First generation. Studies examining a variety of institution types found lowincome, first-generation students were more likely to be food insecure than not food insecure. Dubick et al. (2016) found that $56 \%$ were food insecure in comparison to $45 \%$ of students who had at least one parent who attended college. Arguably, first generation 
students leave higher education at higher rates than students who have neither of these risk factors.

International students. Despite having many factors that increase vulnerability to food security, international students have received little attention when, in fact, international students are highly vulnerable to food insecurity. In addition, they face additional challenges including higher tuition, cultural and language barriers, unfamiliar cuisine, and visa restrictions that limit employment opportunities (Farahbakhsh et al., 2017; Hanbazaza et al., 2016; Watson, Malan, Glik, \& Martinez, 2017; Zein, Mathews, House, \& Shelnutt, 2018).

Financial Status. On a similar note, the association of financial status with food security suggests student financial factors play a greater role in the risk of food insecurity than demographic characteristics (Gaines et al., 2014). Food insecurity may be a product of both socioeconomic and demographic factors, but the adequacy of financial resources students can access is an essential factor in food insecurity. For example, financially independent students who make under $\$ 20,000$ a year, students who work 20 or more hours a week, students with poor health, and those receiving Pell-Grants are certainty among disadvantaged students. With this in mind, students receiving governmental financial support are likely to report very low food security, while the presence of familial financial support or alternative financing is found to be negatively associated with food insecurity.

Federal Pell Grant recipients. In the largest national study conducted on food insecurity among college students, Goldrick-Rab et al. (2018) emphasized, "neither financial aid nor employment is a sufficient buffer to prevent students from going hungry 
or even homeless" (p. 23). However, most scholars find that Pell Grant recipients are more likely to report higher levels of food security as well as utilize campus food pantries. Some studies found $30 \%$ to $75 \%$ of their sample populations receive Pell Grants, take out student loans, or both, in order to finish their education.

Living off-campus. Living off-campus influences the prevalence of food insecurity. In fact, those who live in off campus living arrangements displayed higher prevalence of food insecurity compared to those who lived on campus. The academic year, access to a car, and diet quality was also of significance in relation to living offcampus (Broton et al., 2018; Chaparro, Zaghloul, Holck, \& Dobbs, 2009; Hagedorn \& Olfert, 2018; McArthur, Fasczewski, Wartinger, \& Miller, 2018; Mirabitur, Peterson, Rathz, Matlen, \& Kasper, 2016).

The following chart displays demographic questions that were adapted from conclusions drawn from the literature review. Because a large portion of the most vulnerable food insecure student populations are those who are non-traditional, and those who are housing insecure, questions were created to explore international student status, type of study, employment, access to dining halls, on-campus or off-campus housing and living arrangements (Broton \& Goldrick-Rab, 2017; Dubick, Mathews, et al. 2016; Goldrick-Rab \& Broton, 2016; Goldrick-Rab et al. 2018). 
Table 1: Demographic Chart for Study Participants

\begin{tabular}{|c|c|c|c|c|c|c|c|c|c|c|c|}
\hline \multirow[b]{2}{*}{ Participant } & \multicolumn{2}{|c|}{ Status } & \multicolumn{2}{|c|}{ Work } & \multicolumn{2}{|c|}{ Meal Plan } & \multicolumn{2}{|c|}{ Housing } & \multicolumn{3}{|c|}{ Living Arrangements } \\
\hline & Graduate & Undergraduate & Employed & Unemployed & $\begin{array}{l}\text { Meal } \\
\text { Plan }\end{array}$ & $\begin{array}{r}\text { No } \\
\text { Plan }\end{array}$ & $\begin{array}{c}\text { On } \\
\text { Campus }\end{array}$ & $\begin{array}{c}\text { Off } \\
\text { Campus }\end{array}$ & Dorm & Apartment & House \\
\hline Charlotte & & $\mathrm{X}$ & $\mathrm{X}$ & & $\mathrm{X}$ & & $\mathrm{X}$ & & $\mathrm{X}$ & & \\
\hline Charles & & $X$ & $X$ & & & $X$ & & $X$ & & $X$ & \\
\hline Colton & & $\mathrm{X}$ & $\mathrm{X}$ & & & $\mathrm{X}$ & & $\mathrm{X}$ & & $\mathrm{X}$ & \\
\hline Chase & & $\mathrm{X}$ & $\mathrm{X}$ & & & $\mathrm{X}$ & & $\mathrm{X}$ & & & $\mathrm{X}$ \\
\hline Christopher & & $\mathrm{X}$ & $\mathrm{X}$ & & & $\mathrm{X}$ & & $\mathrm{X}$ & & & $\mathrm{X}$ \\
\hline Christina & & $\mathrm{X}$ & $\mathrm{X}$ & & & $\mathrm{X}$ & $\mathrm{X}$ & & $\mathrm{X}$ & & \\
\hline Carol & & $\mathrm{X}$ & $\mathrm{X}$ & & & $\mathrm{X}$ & & $\mathrm{X}$ & & $\mathrm{X}$ & \\
\hline Cali & & $\mathrm{X}$ & & & $\mathrm{X}$ & & $\mathrm{X}$ & & $\mathrm{X}$ & & \\
\hline Cole & & $\mathrm{X}$ & & $\mathrm{X}$ & $\mathrm{X}$ & & $\mathrm{X}$ & & $\mathrm{X}$ & & \\
\hline Clayton & & $\mathrm{X}$ & $\mathrm{X}$ & & & $\mathrm{X}$ & $\mathrm{X}$ & & & $\mathrm{X}$ & \\
\hline Colleen & & $\mathrm{X}$ & $\mathrm{X}$ & & & $\mathrm{X}$ & $\mathrm{X}$ & & & $\mathrm{X}$ & \\
\hline Chloe & & $\mathrm{X}$ & $\mathrm{X}$ & & & $\mathrm{X}$ & & $\mathrm{X}$ & & & $\mathrm{X}$ \\
\hline Caroline & & $\mathrm{X}$ & $\mathrm{X}$ & & $\mathrm{X}$ & & $\mathrm{X}$ & & $\mathrm{X}$ & & \\
\hline Clarissa & & $\mathrm{X}$ & & $\mathrm{X}$ & & $\mathrm{X}$ & $\mathrm{X}$ & & & $\mathrm{X}$ & \\
\hline Carly & $\mathrm{X}$ & & & & & $\mathrm{X}$ & & $\mathrm{X}$ & & & \\
\hline Carmyn & & $\mathrm{X}$ & $\mathrm{X}$ & & & $\mathrm{X}$ & & $\mathrm{X}$ & & & $\mathrm{X}$ \\
\hline Celeste & & $\mathrm{X}$ & $\mathrm{X}$ & & & $\mathrm{X}$ & & & & & \\
\hline Violet & & $\mathrm{X}$ & $\mathrm{X}$ & & & & $\mathrm{X}$ & & $\mathrm{X}$ & & \\
\hline Veronica & & $\mathrm{X}$ & $\mathrm{X}$ & & & & & $\mathrm{X}$ & & & $\mathrm{X}$ \\
\hline Valerie & & $\mathrm{X}$ & $\mathrm{X}$ & & & & $\mathrm{X}$ & & $\mathrm{X}$ & & \\
\hline Vanessa & & $\mathrm{X}$ & & $\mathrm{X}$ & & & $\mathrm{X}$ & & $\mathrm{X}$ & & \\
\hline Virginia & & & $\mathrm{X}$ & & & & $\mathrm{X}$ & $\mathrm{X}$ & & & $\mathrm{X}$ \\
\hline Virgil & & & $\mathrm{X}$ & & & & $\mathrm{X}$ & $\mathrm{X}$ & & & $\mathrm{X}$ \\
\hline Steve & & & $\mathrm{X}$ & & & & & & & & \\
\hline Sam & & $\mathrm{X}$ & $\mathrm{X}$ & & & $\mathrm{X}$ & & $\mathrm{X}$ & & $\mathrm{X}$ & \\
\hline Sophia & $\mathrm{X}$ & & $\mathrm{X}$ & & $\mathrm{X}$ & & & $\mathrm{X}$ & & $\mathrm{X}$ & \\
\hline Simon & & & $\mathrm{X}$ & & & & & & & & \\
\hline \multicolumn{12}{|c|}{ International Participants: } \\
\hline Cindy & & $\mathrm{X}$ & $\mathrm{X}$ & & & $\mathrm{X}$ & & $\mathrm{X}$ & & & $X$ \\
\hline Cynthia & $X$ & & $X$ & & & $X$ & & $X$ & & $X$ & \\
\hline Cayden & $X$ & & & $X$ & & $X$ & & $X$ & & $X$ & \\
\hline Carter & $X$ & & $X$ & & & $X$ & & $X$ & & & $X$ \\
\hline Victoria & & $\mathrm{X}$ & & $\mathrm{X}$ & & & $X$ & & $X$ & & \\
\hline Stanley & & $\mathrm{X}$ & $\mathrm{X}$ & & & $\mathrm{X}$ & & $\mathrm{X}$ & & & $X$ \\
\hline
\end{tabular}




\section{Data Collection Tools}

The researcher interviewed 33 participants who represented a variety of the above variables, including a balanced population of males and females; however, due to availability, adjustments were expected and made until saturation was met. Specifically, the population sample consisted of five food pantry staff members, seven volunteer staff members, and 21 food pantry clients.

The researcher began by locating a few key participants who easily met the criteria the researcher established for participation in this study. The researcher contacted these participants utilizing three primary methods of contact. First, the director of the Campus Cupboard informed any participants of this study and put those interested in the study in touch with the researcher. Likewise, as a volunteer in the Campus Cupboard, the researcher requested interviews. Second, the researcher solicited volunteers through small business card size advertisements. This two-fold approach involved placing announcements and brochures, including the researcher's contact information, around areas of the campus to advertise the study. All communication tools had the researcher's contact information, so that participants could initiate contact. Lastly, the researcher connected with the remainder of the participants using the common form of network sampling Merriam and Tisdell (2016) referred to as network, chain, or snowball sampling. This sampling strategy allowed individuals to connect the research with other participants. Specifically, the researcher employed this sampling method to avoid unethically contacting participants.

The researcher used Maslow's Theory of Human Motivation to create various data collection tools used within this study, including questions for interviews (Bridwell 
\& Wahba, 1976; Karasar \& Baytemir, 2018; Koltko-Rivera, 2006; Maslow, 1943; Oved, 2017). The researcher asked questions that identified the unique needs and perspectives of the food pantry clientele, potential clients, and key stakeholders, specifically highlighting problematic barriers to student academic success due to food insecurity (Fink, 2017). In doing so, the data were able to answer all the research questions.

\section{Research Ethics}

To ensure ethical practice, this study received Institutional Review Board (IRB) approval and participation was strictly voluntary. The researcher provided participants with consent forms reminding them of their voluntary status. For individuals who agreed to participate in an interview, the researcher obtained permission to record the session. Because data were collected not only through semi-structured interviews, but observations as well, the researcher recognized his role and the extent to which he was a participant in this study. Specifically, he acknowledged how his presence during the observations may have regulated participants' behavior. For example, taking notes at a particular time or in a particular fashion may have subtly communicated to the participants. Similarly, the researcher recognized how even his mere presence could affect the climate of the setting (Merriam \& Tisdell, 2016). Therefore, the researcher took strict precaution to limit the disruption of the environment.

If respondents were willing to participate in the interview, they were asked to contact the researcher to ensure all participation was voluntary. In addition, snowball sampling and nomination techniques were employed (Creswell, 2014). In an effort to evoke conversation clarity and comfortability, interviews lasted no longer than 60 minutes (Creswell, 2014; Krueger \& Casey, 2015). Participants were asked a series of 
open-ended questions, while allowing time for discussion and follow-up questions. Finally, the researcher ensured participant confidentiality and privacy.

Utilizing the most common tools for data collection in qualitative research, this study employed interviews, observations, and document review. The researcher therefore knew the participants and anonymity was not possible. As a result, the researcher assured participants that their identities would not be revealed to the reader and the raw data collected would not be released to any third party (Patton, 2008).

\section{Data Analysis}

Due to the qualitative nature of this study, data analysis began with the consideration of any pre-existing data, such as historical information on the UCM pantry usage, and continued during data collection (Merriam \& Tisdell, 2016). Interviews and observations occurred until saturation was reached, the researcher anticipated at least 25 interviews, but saturation occurred at 33 total interviews. An open-coding process was used to construct themes of recurring categories (Creswell, 2014). To ensure accuracy, reliability and validity, the researcher triangulated data through interviews with the food pantry clientele, volunteers and employees; observations; and documentation review. Additionally, the observations and interviews were composed of open-ended questioning techniques. Collectively, the three forms of data collection were in an attempt to collect thick, rich, and descriptive data (Creswell, 2014; Merriam \& Tisdell, 2016). The themes were then linked to the theoretical framework and research questions.

\section{Significance of the Study}

This case study provides a unique analysis of the food environment at the University of Central Missouri. From a broad perspective, it contributes to practical 
application for policy makers and educational leaders who are calling for diverse solutions to be developed for unique problems such as food insecurity (Bruening et al., 2016). One practical application is developing an understanding of perspectives of UCM students who currently use the UCM Campus Cupboard, thereby providing valuable data for a greater understanding of their needs.

Because food insecurity on college campuses has intrinsic importance affecting a wide variety of academic successes for students and educators alike, this study provides a unique perspective on the barriers between emergency food programs and students. Since campus food pantries often serve as a connection point to long-term accessible food programs like SNAP and WIC, food pantries are helpful in decreasing food insecurity among college students (Bruening et al., 2016).

Food insecurity among college students is an important public health concern that may have implications for not only academic performance and retention, but also for the mental, physical and emotional health of students (Payne-Sturges, Tjaden, Caldeira, Vincent, \& Arria, 2018). The spectrum of current literature covers students' well-being and their academic performance. University life represents a transformational experience; however, a prevailing attitude is that "universities place too much importance on academic performance and research efforts and not enough on prioritizing struggling students and a holistic student experience" (Watson, Malan, Glik, \& Martinez, 2017, p. 136). Some critics argue "by identifying students who are facing housing and food difficulties, colleges and universities can intervene, potentially increasing retention, persistence, social, and emotional outcomes for this vulnerable student population" (Silva et al., 2017, p. 296). Universities that measure food insecurity among their students will 
be better positioned to advocate for policy changes at state and federal levels regarding college affordability and student financial assistance (Payne-Sturges et al., 2018).

\section{Assumptions, Trustworthiness, and Limitations}

The nature of qualitative case studies presents different obstacles to the researcher. Specifically, the challenge to qualitative approaches is to produce plausible, robust research and to demonstrate rigor (Ryan, Coughlan, \& Cronin, 2007). Particularly, within this case study, the researcher focused on responsible conduct, systematic investigation, and scientific integrity (Horner \& Minifie, 2011). Ryan et al. (2007) argued the researcher needs to identify the criteria used and the reader should be able to clearly follow each step of the research process. Addressing the limitations to the study followed a common criteria used to evaluate qualitative research studies: credibility, dependability, transferability, and confirmability (Lincoln \& Guba, 1985).

Credibility. Because researchers can place more confidence and credibility in their claims if there is corroboration of evidence across data sources, methods, theories, and or analysis processes (Newcomer \& Hatry, 2015), the design and data collection process utilized the triangulation of data sets in order to demonstrate credibility in the findings. Additionally, aspects of the structure, process, and practice of interviewing were directed toward the goal of minimizing the effect the interviewer and the interviewing situation had on how the participants reconstructed their experience (Seidman, 2013).

Dependability. Establishing trustworthiness in qualitative research is critical in demonstrating research Lincoln and Guba (1985) described as credible, dependable, confirmable, and that produces transferable findings. Qualitative samples are often small, but this did not pose a problem as the researcher was not attempting to generalize the 
findings (Ryan et al., 2007). Demonstrating trustworthiness allows the researcher to provide detail about the elements of this study and its execution that the researcher can control. In order to demonstrate trustworthiness, the researcher explained how the execution of this research supports the different elements of establishing trustworthiness as identified by Lincoln and Guba (1985). For example, the researcher can control a systematic data collection and analysis process.

Transferability. Even though Stake (1995) argued case study research occurring within a bounded system will not produce transferable findings, there are still implications for this work at other institutions. Specifically, the findings can provide implications. As a result, transferability is achieved when readers feel as though the story of the research overlaps with their own situation and they intuitively transfer the research to their own action (Tracy, 2010). Likewise, the systematic process of how the researcher collected the data as well as the execution of the study can be reproduced and may generate similar findings.

Confirmability. Establishing confirmability after credibility, transferability and expendability are achieved required the researcher to demonstrate how conclusions and interpretations have been reached. In this specific case study the researcher was specifically concerned with establishing findings clearly derived from the data (Ryan et al., 2007).

The researcher took steps to help ensure the work's findings were the result of the experiences and ideas of the informants, rather than the characteristics and preferences of the researcher. For example, triangulating data was emphasized in this context to reduce the effect of investigator bias (Shenton, 2004). Additionally, the researcher relied on 
member checking as one of the most instrumental ways to confirm the findings (Newcomer \& Hatry Harry, 2015; Ryan et al., 2007; Shenton, 2004).

Lastly, engaging in continuous reflexivity throughout the process also contributed to the confirmability of this study. Particularly, the researcher employed a reflective process in the following two ways. First, the researcher provided thick-rich description and used multiple data collection points to support the findings as well as warrant indepth methodological descriptions, which sustained integrity in the research results (Shenton, 2004). Likewise, because Patton (2008) associated objectivity in science with the use of instruments that are not dependent on human skill and perception, acknowledging the researcher's bias, beliefs or assumptions prior to beginning the study contributed to the confirmability. Specifically, the researcher assumed people were honest during the interview process (Shenton, 2004). Ultimately, providing thick rich description, including findings regardless of how they fit in the data, and using multiple data collection points, to support the findings limited the researcher bias.

\section{Limitations}

The limitations presented below outline the elements of the study that were more difficult for the researcher to control. One of the critiques of case study research is that the findings emerge within a bounded system and thus are not necessarily transferable (Shenton, 2004). Additionally, because the participants in this study have particular identities and experiences, the findings that were developed based on their experience should not be used to apply to all students who experience food insecurity. Scholars and administrators should look to the implications section of this study to discern what structural dynamics and barriers are at play and may be relevant to their own institution. 
This would be more useful than applying findings directly to the experiences of students with food insecurity at their institution. Moreover, because this is case study research and the study was developed within a bounded system, it would be difficult to confirm findings if the study were replicated at a different institution or with a different student population. Surely other dynamics, experiences, barriers, and challenges would occur; all of which would be important to examine in other research studies about college students who experience food insecurity.

Participant perception of the researcher may have also impacted what they did and did not share, making it difficult to confirm the findings. It is possible that a completely different researcher with different identities or affiliations (or lack thereof) to the institution would have been received differently by participants, therefore altering any findings. Finally, because the researcher conducted research at an institution where he was also a student, and where the researcher introduced himself to participants as such, it was possible that participants did not disclose potential contextual information that they might have disclosed to researchers who had no affiliation to the institution. Participants may have assumed that there were things the researcher may have known or was aware of as an insider of the institution and although this reflective exercise demonstrates reflexivity in this research process (Lincoln \& Guba, 1985), there are potential instances where the researcher could have elicited more information from participants and did not because of this relationship to the institution.

\section{Definitions of Key Terms}

Beneficiaries. Typically, people receiving emergency food relief are referred to as recipients or beneficiaries (Vaterlaus, Cottle, Patten, \& Gibbons, 2018). 
CAN Criteria. The CAN approach is an effort to make healthier foods appear more convenient, attractive, and normal to select. The approach is built on the idea that nudges are better at encouraging healthier food than food prohibitions and restrictions (Nikolaus et al., 2018; Wilson, 2016)

Capacity. Capacity refers to resources available for carrying out organizational intent regarding nutrition (Campbell, Ross, \& Webb, 2013).

Consumer Nutrition Environment (CNE). The Consumer Nutrition

Environment (CNE), includes characteristics such as price, promotions, placement, range of choices, freshness, and nutritional information, that reflect the factors that influence patrons' food selections (Nikolaus et al., 2018).

Cost of attendance. The federal government requires every college and university to state a sticker price, known as the institution's cost of attendance (COA) (Kelchen, Goldrick-Rab, \& Hosch, 2017).

Culture. In this study, culture relates to the practices and perspectives of the staff, leadership, management and clientele. This includes their advertising, location, hours of operation, statements of organizational intent regarding nutritious food inventory, and stakeholder buy-in or support (Campbell et al., 2013).

Emergency Food Network (EFN). The EFN is described by Feeding America, the nation's leading domestic hunger-relief charity, as a sector of the food system that utilizes donations of food and money from corporations, government funding, private donations, and local and national distribution networks to serve over 25 million food insecure Americans every year. The EFN consists of over 200 food banks that glean, purchase, store, and distribute foods to subsidiary emergency food programs (EFPs) 
including food pantries, soup kitchens, and shelters (Campbell, Hudson, Webb, \& Crawford, 2011).

Emotional eating. Emotional eating has been defined as eating in response to emotional cues, often as a coping response to negative emotions (Bennett, Greene, \& Schwartz-Barcott, 2013).

Food insecurity. In the United States (US), food insecurity is defined as the limited or uncertain availability of nutritionally adequate and safe foods or limited or uncertain ability to acquire acceptable foods in socially acceptable ways. Originally referred to as food insufficiency, food insecurity was first addressed in 1990 as part of the National Nutrition Monitoring and Related Research Act, which mandated that a standardized food security measurement be created. Many agencies define food insecurity as having limited or uncertain access to nutritious, safe foods necessary to lead a healthy lifestyle. Other agencies refer to food insecurity as not having enough money to buy enough food (Broton et al., 2018; Cady, 2014; Dubick, Mathews, et al., 2016; Freudenberg et al., 2011; Gaines, Robb, Knol, \& Sickler, 2014; Goldrick-Rab et al., 2018; Paola \& DeBate, 2018; Twill et al., 2016).

Food insecurity with hunger. When the issue is specifically not enough food to maintain oneself physically, the term food insecurity with hunger is used (Cady, 2014).

Food insecurity without hunger. The term food insecurity without hunger indicates times when the issue is lowered caloric intake, lack of food variety, and lower quality of food. People with marginal food security may worry about food, but do not change their diets. People with low-food security make changes in the quality of the food 
they eat, and people with very low-food security reduce their food intake and experience hunger (Cady, 2014; O’Neill \& Maguire, 2017).

Food pantries. Food pantries are a type of food assistance service that collects food donations from the community and redistributes food to those in need at no cost. A food pantry (food shelf) is a community-specific food assistance program that provides free food to clients who have difficulty accessing food (Wilson, 2016a; Zein et al., 2018).

Food security. Food security exists when people have physical, social, and economic access to sufficient, safe and nutritious food to meet their dietary needs and food preferences for an active and healthy life. Importantly, people with high food security do not report limited access to food. In addition, the US Department of Agriculture (USDA) refers to food security as the state in which all members of a household have access to food throughout the year (Coleman-Jensen, Gregory, \& Singh, 2018; Gallegos, Ramsey, \& Ong, 2014; O’Neill \& Maguire, 2017; Wilson, 2016).

Heat or eat dilemma. Individuals who are food insecure often put the purchasing of food at the end of their priority list. This is a reality that has been described as the "heat or eat dilemma" (Hanbazaza et al., 2016).

Homelessness. Homelessness means that a person is without a place to live, often residing in a shelter, an automobile, an abandoned building or outside (Goldrick-Rab et al., 2018). However, for the purpose of this study, homelessness will be defined as both sheltered and unsheltered living circumstances. This definition will include the most common forms of homelessness which incorporate being formally or informally thrown out of the home; not having a place to sleep at night; or staying in abandoned buildings, cars, or other places not meant for human habitation (Broton \& Goldrick-Rab, 2017). 
Household food insecurity. Household food insecurity is defined as the limited or uncertain availability of nutritionally adequate and safe foods and limited or uncertain ability to acquire acceptable foods in socially acceptable ways. Food insecure households are ones in which members ate less food than desired, skipped meals, or lost weight because of the inability to purchase food. Individuals who struggle with food insecurity may depend on a number of governmental programs, such as the Supplemental Nutrition Assistance Program (SNAP, formerly Food Stamps) or the Special Supplemental Nutrition Program for Women, Infants, and Children (WIC), and nongovernmental food programs (Patton-López et al., 2014; Wilson, 2016a).

Housing insecurity. Individuals who report any housing related challenge. Specifically, housing insecurity includes a broader set of challenges such as the inability to pay rent or utilities or the need to move frequently (Broton \& Goldrick-Rab, 2017; Goldrick-Rab, Richardson, \& Hernandez, 2017).

Pantry users. For this particular study, pantry users will be defined as individuals having ever visited the food pantry for obtaining food.

Self-sufficiency. Self-sufficiency is broadly defined as holding a paying job or being in a state of well-being, with limited reliance on welfare benefits (Martin, $\mathrm{Wu}$, Wolff, Colantonio, \& Grady, 2013).

SNAP. Supplemental Nutrition Assistance Program. "SNAP provides nutrition benefits to supplement the food budget of needy families so they can purchase healthy food and move towards self-sufficiency" (US Department of Agriculture, 2019). 
Syndrome. A group of symptoms that consistently occur together, or a condition characterized by a set of associated symptoms. Likewise, a characteristic combination of opinions, emotions, or behaviors.

WIC. Special Supplemental Nutrition Program for Women, Infants, and Children (WIC). "Provides federal grants to states for supplemental foods, health care referrals, and nutrition education for low-income pregnant, breastfeeding, and non-breastfeeding postpartum women, and to infants and children up to age five who are found to be at nutritional risk" (US Department of Agriculture, 2019)

\section{Discussion of the Findings}

As previously mentioned, this study was conducted to explore the perspectives of food pantry clientele within the community of The University of Central Missouri. The final section of the dissertation restates the research problem and reviews the major methods used in the study. The major segments of this section summarize the findings and discuss their implications. Pseudonyms are used to protect the confidentiality of the interviewees.

Student well-being and academic performance are frequently discussed and researched concerns that span the spectrum of current literature, but little attention has been paid to the perceptions and needs of college students who are clients of campus food pantries (Henry, 2017; O’Neill \& Maguire, 2017). The data reported in this study illustrate the perspectives of food pantry clientele at UCM through qualitative inquiry grounded in Maslow's Theory of Human Motivation.

The present findings add to the ample evidence from U.S. post-secondary campuses that college food insecurity is an important public health concern that may 
have implications for not only academic performance and retention, but also for the mental, physical and emotional health of students (Broton \& Goldrick-Rab, 2017; Chaparro, Zaghloul, Holck, \& Dobbs, 2009; Gaines, Robb, Knol, \& Sickler, 2014; Henry, 2017; McArthur et al. 2018; Morris, Smith, Davis, \& Null, 2016; Payne-Sturges, Tjaden, Caldeira, Vincent, \& Arria, 2018).

The growing number of food pantries emerging on college campuses indicates the increasing extent of food insecurity among college students, but the sheer complexity of college food insecurity makes it difficult to understand the individual perspectives and distinct needs of those being affected (Henry, 2017). The relationship of the current study to previous research will follow the national conversation's suggestions that time, transportation, self-efficacy, financial resources, and poor kitchen facilities contribute to inadequate food consumption, as well as poor diet quality among college students (Dubick et al. 2016; S. Goldrick-Rab et al. 2018; Henry, 2017; O’Neill \& Maguire, 2017).

\section{Self-efficacy}

Being able to balance properly a healthy lifestyle with the academic, social, and financial demands of university life requires developing skills in both financial planning and food management (Gaines et al. 2014). The present study confirms self-reliance to be a necessary skill for coping with the stress of college. In fact, the study revealed a broad spectrum of abilities regarding financial management, budgeting for groceries, and preparing meals. On one end of the spectrum clients recognized their own shortcomings and lack of experience. For example, Clarissa confessed: 
The cooking class was not much of anything. She'd like hand out some recipes and then it might turn out well. I remember screwing up the Alfredo sauce, so we just had butter noodles. I wasn’t prepared for really cooking. My mom has really not had me cook things before, she usually does it. Probably for the best, in case I screw up dinner. These findings from the current study run parallel to researchers who have indicated that food insecurity is largely the result of financial constraints and/or lack of financial and food management skills. In fact, other studies reported very similar experiences. According to Watson et al. (2017), "Few students mentioned learning about food and nutrition as part of their K-12 education" (p. 135). Comparatively though, students who reported the ability to track expenses, and the ability to cook for themselves were more likely to indicate being food secure (Brown et al. 2005; Gaines et al. 2014; McArthur et al. 2018).

Also, participants who demonstrated superlative self-efficacy, both in a sense of financial management and cooking ability. Particularly, a young man named Charles, explained, "I'll try to cook something on Monday that can at least last me until Wednesday, and so this week I made chili... and I made that mostly out of stuff that I've got out of the Campus Cupboard."

When considering the same client's ability to budget and prepare meals for himself, this study found evidence to support the research from Matthews et al. (2016) calling for improving practical advice and experiences that support skill development (e.g.,, meal planning, using leftovers, lists of staple foods and equipment, and simple recipes for living on their own), could improve students' self-efficacy. To illustrate, Charles admitted, 
I actually do not find it too hard to make stuff out of things I find at the panty. So, each week they kind of offer some things you can make stuff out of. So they offer a bunch of canned vegetables and everything, they have some rotisseries chickens, they have bagels and all of that, but one of the main things I do is I grab rotisserie chicken and I'll end up having some vegetables and depending on what they have in there that might vary, so say that it could be potatoes and this last time I went, it was a couple of weeks ago, and they had potatoes, and I ended up making biscuits and gravy... Yea, it cuts down that grocery bill a bit. They had chili beans a couple of weeks ago, and I had a can of tomato sauce in the house already and they also had a cooked beef, and I used a food processor that I got from the thrift store and chopped it up a bit more fine, so it's easier to be in the chili

Specifically, Matthews, Doerr, and Dworatzek (2016) suggest these mastery experiences could be offered through formal channels such as student health services or extension, or informal channels such as peer education programs. To encourage uptake of these skills, additional concepts such as goal setting and self-monitoring could also be taught.

Specifically, an interesting educational nexus can be drawn between differing client perspectives regarding the desirability of the items found in the Cupboard. For example, clients who lack the same practicality or cooking experience as Charles see less potential in the same available food items. To illustrate, a different client critiqued the same selection in the Cupboard, "It's a lot of green beans, peas, and then maybe some pasta, and you can't really do much with that, and I can't necessarily have a bowl of 
green beans." As a result, this study was able to draw a similar conclusion as Byker Shanks (2017) who argued that by "simultaneously enhancing the food pantry environment and enriching the self-efficacy of food pantry clients makes more nutritious foods more accessible and more desirable" (p. 575).

\section{Transportation}

This study supported several previous authors' claim that lack of transportation adds additional hardships for students having difficulties navigating food insecurity. Zizza et al. (2008) argued students without transportation or money to purchase healthier food options off campus were left to face hostile food environments on campus. Many participants either directly stated their own trouble with transportation or were very cognizant of the problem surrounding the campus. Specifically, Caroline highlighted:

Because there is no public transport in Warrensburg, you have a lot of students using it who don't have cars. Because it's groceries that they can get on campus without being up charged, because they have, it's not even groceries at the bookstore, but they have like little cereal cups but not like the boxes of cereal, but that stuff is like so up charged. Because it's convenience, so it's nice because it's close and it's on campus for students who don't have cars.

Although it is widely accepted that transportation affects food security; specifically drawing on evidence from this study, many international students at the University of Central Missouri frequently experience inequality in accessing recognizable food. Sophia warned:

I'll address that it's not always that there's a lack of funds, I think that sometimes it's a lack of transportation as well. Like there are other barriers that really go into 
people struggling... our international student population come with very little funds, but even if they have the funds, you come to a new place and then you don't know anybody and therefore how do you find rides to get places.

Warrensburg is small but walking places is still, you have to make a lot of time to do that, and then carrying as much as you... So, it's a lot of navigating, so that would be a lot of navigating for an individual. So, I think that that is something that is also important to keep in mind.

This theme of international students and rides came up quite frequently, and although the staff and volunteers were aware of the situation, the added struggle is important in shaping the understanding of someone using the Campus Cupboard. Sophia explained:

Like I've always had a car, and I've always had a way to get places, but if I didn't have a car, would I be able to keep my job, would I be able to go get things for myself. Like, that would be pretty challenging, and then to add on top of that, coming to a completely new culture, in a new place where you don't know anybody to reach out to and get support from.

It was interesting to hear first-hand an international student, Cindy, unpack how she is navigating the conditions:

Um, yeah. Okay yeah, before I got a car, when the school was on break. And you know I don't think they're open those times, and I had to walk all the way to Walmart to get food, I can't forget that day, it was a sad day for me. And it was soo cold, it was during December, and I didn't travel, I didn't go anywhere, and it was so cold, all my friends were not around, I was just like oh my god, I'm 
starving. I had to walk all the way to Walmart. I wore a lot of coats, sweatshirts and everything. It was so bad that day. When I came home, you know I was happy, food is really good.

Speaking to the importance of transportation, this study found that international students were working together to not just find rides, but to overcome the intersectionality of lacking transportation as well as geographical and cultural isolation. Cynthia explained, 'It's an Indian What's App group so those guys who have car, they reply that we are available, and we go with them." This collaboration demonstrates a working theoretical mechanism entitled, Jobs to be done theory, that when applied to rural food pantries explains some of the international students' stress caused by living in a rural area away from the comforts of a cosmopolitan cultural center (Vaterlaus et al., 2018). For example, Cindy remarked:

Of course, sometimes when I want to go to Kansas City to get African stuff, like some people just ask me for a ride, like can I go with you? And if I take all of us to the place, so if we can all get it here, and it's not only me, like the Indians who, and the other people and the other cultures.

Inconsistent access to adequate food is particularly challenging in the rural areas of the United States because people may experience difficulty finding transportation to grocery stores, have fewer grocery stores available, pay higher food prices, and experience less variety and decreased freshness of available food (Vaterlaus et al. 2018). Ultimately, this not only adds culture shock to the struggles of living in a rural community, but also adding the stress of living in the food swamp environments prevalent on college campuses. In the end, helping clients at least understand that there 
were informal groups that could help them maybe even more than food the pantry could offer. Vaterlaus et al. (2018) contended a similar point: "To progress toward hiring a service, rural food pantry customers need to be aware of services" (p.1900).

\section{Limited Cooking Facilities}

What is evident from this study is that even though students may be food insecure, limited cooking facilities prohibit complete access to the food available within the Campus Cupboard. For example, Caroline emphasized:

I used to live in Ellis, the kitchen there, Ellis is like a horseshoe, and there's like three separate building, and there's one kitchen, and that building can house up to 900 students, so all 900 students share one kitchen.

Several other studies reported similar instances. For example, Henry (2017) found that students who lived in the dorms noted that they do not have the proper kitchen appliances to store and cook food:

Without a refrigerator or stove, they were limited in the types of food they could prepare. One participant noted that she wished to purchase healthier foods, but finances and a lack of proper refrigeration were the major barriers to buying unprocessed, whole or natural foods, such as vegetables and fruits

In connection to Henry (2017), participants in this current study similarly viewed the common misunderstanding surrounding college food insecurity as the accepted 'normal' around campus. For example, Sam argued, "I think that kids who are actually going hungry here at school, are just looked at as just a normal college kid, and I think that's not good." Likewise, Charles referred to the common perception that college students are supposed to struggle, but also pointed out the gravity of the situation: 
So, it's kind of made into a joke, so it's always the running gag about how college students, how they live off of ramen noodles and stuff like that, and I mean it's funny but at the same time it's really true, because it's like a lot of college students can't afford to go to the grocery store every week, and by the time they're at the end of waiting for an influx of money, say it's from getting paid from their jobs or from money from their parents per say, they might actually just be living off of Spam and Ramen noodles a home.

The lack of kitchen facilities leaves students with little options outside of the more expensive meal plans. In a large statewide study focusing on the University of California system, Watson et al. (2017) indicated students lacked access to kitchen space to prepare food to supplement meal plans or cook with friends. This is ultimately problematic for several reasons. First, it leaves students with less healthier options like microwaveable food or processed high sugar snacks. Sam indicated:

When I worked there, and I would go, I would just kind of see it as a way to just get snack stuff, just a way to get stuff in my dorm where if the dining hall was closed, I could just munch on something. I would never take like big bulky like proteins and like actual meals because I had a mini-fridge and a microwave. So, it's not like I could cook actually. So, I was just getting like cupcakes, I would get the chips and I would get the cereal because I could always eat dry cereal. This phenomenon was not isolated to the present study; in fact other authors pointed out similar findings. For example, "from the perspective of some volunteers and staff members in the study, clients choose items to address hunger before their nutritional or health needs" (Cooksey-Stowers et al. 2019, p.11). Although there are kitchens for use 
on campus, one conclusion that can be safely drawn is that the limited kitchen facilities within the dorms at UCM are adding to the rising floodwaters within the food swamp environment. Cali acknowledged, "We have one kitchen in the building. It's supposed to have two, but the other one, the oven broke, and there's like nothing else in there, so it's no point." Christina agreed, "You have to go downstairs and check out items, like pots and pans, and if someone else is there then you have to wait. It's hard to cook anything."

These findings not only coincide with previous literature but help us better appreciate the range of obstacles food insecure clients face while in school. Additionally, Gaines et al. (2014) asserted that individuals scoring higher on the measure of resource adequacy, but not cooking self-efficacy, were less likely to be food insecure. So, in other words, students just having access to adequate kitchen facilities improved their ability to establish food security. This was no more evident than when one client, Cali noted, "That is my favorite thing, but I don't know how to make grilled cheese in my dorm.”

\section{Time}

There is growing recognition that university students facing food insecurity are greatly hindered by their lack of time. Ironically, instant noodle meals, like Ramen Noodles, have become a symbol of college food insecurity. In the United States, the trend is so well known that often university students are jokingly referred to as being on the Ramen Noodle Diet. This idea is so widespread though, it is even supported by Australia's National Noodle Day held in recognition of the reliance on instant noodles as a mainstay of student diets (Gallegos et al., 2014). In the current study, students overwhelmingly expressed lack of time as a leading cause of stress and in many cases revealed unhealthy choices to compensate. As an illustration, Violet confirmed, "I will 
get like \$2 McDonald's sandwiches. I just eat at my dorm or in my car, depending on how much time I have." With this in mind, the current study's findings point to similar evidence found throughout the literature. For example, Tam et al. (2017) even reported convenience as a higher determinant of food-purchasing behavior than cost.

In addition to adding stress, many participants in this study reported time restrictions as their specific reason for skipping meals. Christopher added:

I've skipped a lot of meals just because I'm busy doing something... I'll probably just eat once for like the whole day.... most of the time I'm in class around the times I should be eating, so I try whenever I wake up to get breakfast, I try to squeeze some type of lunch in there. Dinner is probably my hardest one, just because it's past classes, it's past work

Of course successfully managing time can reduce stress, but in examining college food insecurity Watson et al. (2017) reported students felt, "overwhelmed or time restricted and thus were less able to balance their resources with their nutritional needs" (p. 135).

The idea of overwhelmed and stressed students not performing well in academic situations is a commonly accepted norm within education; however, pinpointing the exact origin of the stress will be useful in providing support. Specifically, in this study, several participants expressed their high stress levels caused by busy schedules; however, in the following example, Violet explains how her scheduling demands cut out her already limited time to eat, and even less time to prepare meals:

Sometimes, I don't even have time or like I'm barely struggling to even get to McDonalds, and then get to work. I have a class that gets out at 2:30, and that day 
I start work at 3, and I usually have to be there like 10 min. early, so I just like have to be leaving and getting out of class, and that class gets out late sometimes, most times actually. I mean, somedays I forget to eat, and I don't have time to eat. Other days like about a weekish $[\mathrm{sic}]$ ago, I had work at 6 in the morning then class at 9 , then I had to work on doing a quiz in between classes. Then I went to my next class and then I had to go to work and then I had a sorority event, and then I had to do some more quizzes and start working on writing a paper, and there was barely any time to eat so I think I ate twice that day. I didn't eat breakfast, I had like chicken nuggets for lunch and then I just snacked on popcorn when I was doing my homework.

This important example identifies the prominent role "time" plays in determining food insecurity and ultimately student success. Zizza et al. (2008) agreed: "competing demands for individuals time and energy, such as the increased need to work more than one job, not only may reduce the time available to study but also may contribute to fewer meals" (p. 1911).

Of note, Broton et al. (2018) indicated a specific consideration for women: "Females [participants], those who are currently employed, and four-year college students were especially likely to indicate that they do not have enough time to eat because of a busy schedule (p.10). Interestingly enough, all of the women in this study, regardless of citizenship, living arrangements, and student status confirmed very similar perspectives. Specifically, Carmyn summarized the general thought, "so like I wake up late and I don't have a time to cook a lot, then I cook a can of soup for lunch, or like a PB and $\mathrm{J}$ for dinner, stuff like that, anything that works." Violet agreed: 
I mean, I have had to go without eating before for like writing a whole paper and I don't have time to stop writing to go get food, I've had days where I have $\$ 12$ in my bank account until Friday, it is Tuesday, I have to portion my money and where it goes...

Although there could be a difference between men and women experiencing food insecurity in college, the bottom line is simple. Having the time to take care of oneself plays a large factor in determining food insecurity.

In conclusion, the discussion has reviewed the findings of this study against a specific three-folded pattern. In general, the pattern is one or more of consistently specific conditions (i.e, lack of time, self-efficacy, kitchen facilities, and lack of transportation) overlapping one or more certain demographic characteristics (e.g. firstgeneration college student, Pell Grant Recipients, international students, etc.). Ultimately, two or more attributes overlay and produce a syndrome effect that corrodes one's ability to provide sufficient nutrition for themselves. There is sufficient evidence to argue that the root causes of food insecurity, as driven by the perspectives taken from this study, define the problem as a syndrome. Specifically, because the way time factors itself into food insecurity, identifying the lack of or abundance of opportunities to access food makes it an especially potent syndrome for college students. Therefore, recommendations constructed from this perspective will be more sustainable.

\section{Theoretical Implications of the Study}

As introduced in Section 1 and explained in Section 3, Maslow's Human Motivation Theory provided the theoretical lens through which the study explored food insecurity at the University of Central Missouri. Although Maslow structured primary 
drives and secondary drives in a hierarchal structure, later research argues multiple needs could exist simultaneously (Bridwell \& Wahba, 1976; Kenrick, Neuberg, Griskevicius, Becker, \& Schaller, 2010) Analyzing the findings through the lens of Human Motivational Theory draws three key conclusions. First, overlapping needs and motivational drives exist for the Campus Cupboard Community. Second, the university can play a strong role in the success of the Campus Cupboard. Third, social groups and community are an important piece of establishing a sustainable approach to alleviating student hunger needs. Ultimately, the bigger idea behind analyzing food insecurity at UCM through Maslow's human motivational theory sparks the understanding that food insecurity exists because of consistently occurring symptoms and can be characterized as such. Additionally, because multiple needs can exist simultaneously, understanding the role social circles and communities play in humans' social development and protection is a key piece of the puzzle. Likewise, human motivational theory can shed light on the stronger role universities can play in improving the situation.

Overlapping needs. Current theoretical research criticizes Maslow's assumption that lower needs must be satisfied before a person can achieve their full potential (Mcleod, 2017). In fact, recently scholars suggested self-actualization is not separate from lower social motives, but intimately linked to the need for esteem (Krems, Kenrick, \& Neel, 2017a; Mcleod, 2017). This concept is important in analyzing distinct behaviors found in the current study. For example, Carter, an international student and food pantry client, illustrated one such common behavior:

I spend my money on clothes, and party [laughter] mostly we do party every Friday. Pine Street and sometimes we do party at home. We invite friends. It is 
kind of fun. In India it is different, we are social, here it is different, the culture. Rents, and party and clothes. Not only rent.

Understanding how clients can simultaneously exist within two competing levels of Maslow's original theory is difficult with the misunderstanding that Maslow's Hierarchy works as a structurally rigid concept. On one hand, some food pantry clients illustrated this dichotomy by explaining their expenses included climbing gear, phone bills, and Apple Music, Spotify, Hulu and Netflix subscriptions. Other clients, like Christina, explained how their financial priorities supported self-esteem and selfactualization activities such as her sorority, but still relied on the Campus Cupboard to acquire food. Specifically, she noted, "we have a lot of like dress stuff we have to do like buy outfits, oh yeah, we have to pay our sorority bills each month." Be that as it may, Kenrick (2011) helpfully explained that sometimes basic needs and priorities blur together and move in synchrony with one another. Ultimately, Sophia clarified this very point:

I will say that it is really easy to see how somebody behaves in one part of their lives, and create an assumption based on that behavior or based on how they are in that moment, but we never know what they're going through... it's just like very limiting to put someone into just one classification and say based on this you don't deserve any help, or you shouldn't be getting this help because you behave this way. I think that is really unfortunate to have such a limited view.

In fact, just because someone is hungry, or lacking any other need for that matter, does not mean that they cannot simultaneously achieve. On a similar note, Mcleod (2017) dryly argued, "many creative people, such as authors and artists (e.g. Rembrandt and Van 
Gough) lived in poverty throughout their lifetime, yet it could be argued that they achieved self-actualization" (p. 7). Ultimately, the Cupboard serves a wide variety of individuals. In addition, as Valerie noted some are, "just trying to stay healthy to begin with and be able to have all of their basic needs provided for," and others, like Christopher who honestly admitted, "I wouldn't say I'm struggling for it [food]". The difficulty in using the pyramid model of Human Needs to explain the findings of this study is that it does not allow multiple needs to exist at the same time. One client, Carly, brilliantly deduced:

I have two jobs, and I'm a billion miles from home. So, I mean just because you aren't doing the same thing I'm doing, or I'm not doing the same thing you're doing, doesn't mean that it's not there for both of us.

Accordingly, this study acknowledges the understanding of the notion that people must be understood in terms of their internal as well as their external context (Peterson \& Park, 2010).

The societal role of the university. Satisfying needs is often seen as an individual's responsibility; and even though Maslow focused on the individuals, Tay and Diener (2011) establish that need fulfillment has to be achieved at the societal level as well. Interestingly, these findings can help interpret the societal role the Cupboard plays within the UCM social system. To be sure, Cole summarized that providing food just may be one way to help community members better participate within the UCM organization:

Like I said we don't know who can and can't afford things on the dining plans, but there might be people who are spending quite a bit on rent and their just 
education in general, that they might not have a lot of money for extra food or extra snacks. So, this is a great resource from the university to give back a little bit.

From a broader perspective, this concept clearly defines the system at hand. For example, Morris et al. (2016) emphasize:

the increasing number of first-generation college students, coupled with the rising costs of tuition and enormous student loan debt, may have a significant impact on food security for current and future students. Students who are financially constrained to pay for college may be limited in other resources as well. Providing food assistance programs and services to students with financial limitations may be a critical component to building a healthy university environment. (p.381) In addition, applying a theory of human motivation to college communities helps interpret the empowering role food pantries play on campuses. For example, Tay and Diener (2011) assert, "the society in which one lives has strong associations with whether a person's basic and safety needs are met" (Tay \& Diener, 2011, p. 363). Importantly, from this perspective, the results from basic needs assessments like those used by the Wisconsin Hope Lab to evaluate food insecurity at the University of Central Missouri can be explained. To clarify, Steve unpacked the Campus Cupboard's role in addressing basic human needs:

Well, I think what the Campus Cupboard provides is that outlet you know, you're going to be, we understand your needs, we're taking care of people's needs, not just their wants. You know, when you look at the old psychologist, "Maslow's Hierarchy of Needs" you know the food clothing and shelter, and you know that 
is, we're going to try and make sure, that if those components are not addressed, how are we going to expect them to have success in other areas of their academic pursuits, so I think looking at the clientele again, like I said, there's a larger need than just the want, well I want a soda, but these people need sustenance because of their situations, so we do not want anyone to feel like they're not being taken care of, and that's a holistic approach that we take here on campus.

So, ultimately needs assessments become more about the ability of the university and of student support systems in meeting the basic needs of its students. Tay and Diener (2011) supported this argument:

the society in which one lives has strong associations with whether a person's basic and safety needs are met, but a more modest relation with whether one's psychosocial needs are met. Because nations strongly influence people's basic needs but more modestly influence their psychosocial needs, this helps explain why life evaluations — which are linked to basic needs — are more dependent on one's society, whereas positive feelings are more dependent on personal factors. (p. 363)

As college education becomes more accessible through federal grants, the university's role in providing those basic needs becomes increasingly more important. For example, Caroline summarized this point:

UCM serves a lot of low income, first generation, and minority students, so that's who we cater to, so a lot of those students do take student loans out, and like student loans don't pay for these extra things. Like student loans don't pay for your grocery bill every month, and so people don't understand that 
Because these needs may be more prevalent than ever, human development theorists can help explain why the nation has seen an increase in college food pantries emerging across the nation. In many ways these food pantries are a response to one of Maslow's original arguments recognizing that, "the peaceful, smoothly running, 'good' society ordinarily makes its members feel safe enough from wild animals, extremes of temperature, criminals, assault and murder and tyranny" (Maslow, 1943, p. 379) and therefore, "in a very real sense, he no longer has any safety needs as active motivators. Just as a man no longer feels hungry, a safe man no longer feels endangered" (Maslow, 1943, p. 379). In the same light, today's threats like food insecurity in college may be efficiently addressed on a societal level through basic life-skills. Watson et al. (2017) argue:

Food-related issues became more salient in college, and they expressed the need for the university to provide additional food education and training. Many students wanted to learn to budget and cook simple nutritious meals. They were frustrated with intellectually knowing the "right choice" but not having the skills or resources to act on that knowledge. Students identified the transition from living in university residence halls to living off campus as a critical time to receive this instruction. (p. 136)

The role of the university is changing as today's college students move more and more away from the traditional 18-23-year-old who lives in the dorms and has parents and family structures that can support their education. College societies are now defined more than ever before by non-traditional, older, first-generation, international students, 
single parents, and Federal Pell Grant students. As society evolves, so does the role of universities and their support for college food pantries.

The importance of social groups and community. Human motivational theory clarifies our perspective of the effects a community can have on individuals' basic needs, especially for college students living in this transitional period of life, because human beings are sensitive to cues of social rejection and they respond to such cues using some of the same neural circuits used to register physical pain. There are great benefits to social groups including extensive sharing of resources, and knowledge, almost an insurance policy in hard times (Kenrick, 2011). As an explanation, Christina laid out her priorities, "Grades, first always. Relationships. Between like your [sorority] sisters and your family. That's like one of the reasons you're in a sorority, to meet people who share the same interest." Those relationships are so important that in explaining her financial priorities, Christina described how she supports the financial burdens of her sorority by visiting the food pantry. Markedly, "We have a lot of like dress stuff we have to do like buy outfits, oh yeah, we have to pay our sorority bills each month." Human development theorists categorize this contradiction of thought by suggesting, "A person can gain wellbeing by meeting psychosocial needs regardless of whether his or her basic needs are fully met” (Tay \& Diener, 2011, p. 363). Building upon this point, I would argue these basic physical needs like food, clothing, and shelter seamlessly extend to affect the psychosocial well-being and ultimately can produce physiological effects.

In fact, other scholars even suggest that improving well-being may be the result of not only an overlapping human needs model, instead of the traditional hierarchy chart, but also the students' social life. To demonstrate, Tay and Diener (2011) argue, 
"Socialization uniquely shapes the causes of well-being for each person and in each culture" (p. 354). Drawing a conclusion from the findings in this study, this concept rings true with the community the Campus Cupboard is creating and its influence over the well-being of its members. In fact, Steve explained one specific pattern of growth within the community that speaks to the Cupboard's positive impact:

Over the past few semesters, or the last year or so is what we have seen is we've had an increase in staff members using our facility. We did open the campus cupboard to any of our staff, and with the times being kind of tough, we have seen that and you know, they're very, very, again, understanding of hey, this is very important for us, so not only are we taking care of the student body, but some of our staff members here on campus also have access to that facility.

Actually, this community-influenced phenomenon has been the topic of study for many human motivation theorists. For example, Bridwell and Wahba (1976) examined results from needs satisfaction questionnaire studies designed to test the idea that need satisfaction should decrease going up in Maslow's need hierarchy. They found that, "either self-actualization or security are the least satisfied needs, and social needs are the most satisfied" (Bridwell \& Wahba, 1976, p. 518). Applying this finding to the current study implies that, "the respect of others, learning new things, and supportive social relationships are fundamental universal needs that do not require secondary pairing with more basic needs to influence subjects' well-being (Tay \& Diener, 2011, p. 354).

One result of this connection may even explain the importance social groups and acceptance play in this period in college students' lives, but more importantly why 
evaluating the climate of the community is an important piece of the staff's goals. For example, Sophia outlined:

So, evaluating needs regularly is really important and like food insecurity is definitely one of those, but probably just like normalizing just that people struggle with food insecurity and people struggle with mental wellness and like other really big factors in their lives, and saying that like that's okay. Like it's okay that you're struggling with this and then endorsing programs like the Campus Cupboard and endorsing things like the mental fitness classes that they have on campus and just making those a really big part of the campus culture, and like people are okay to seek out those services whenever they do feel like that need comes up, or they feel or students feel comfortable talking to administrators about those things versus feeling ashamed that that's something that they need when that's literally, like I said, we all have something we struggle with at some point. Normalizing, creating culture, or establishing a community thus creates the opportunity and environment for members to fulfill their most basic of human needs. Tay and Diener (2011) go on to argue that a person can gain wellbeing by meeting psychosocial needs regardless of whether his or her basic needs are fully met. Applied to this study, it is easy to see how scholars argue that through this normalization students are more likely to see the programs as a student resource (Cooksey-Stowers et al. 2018; Dubick, et al. 2016; Twill, Bergdahl, \& Fensler, 2016). In the end, Collen expressed her approval of the Cupboards work, "every school should have one. More places should donate to the local food pantries 


\section{Explanation of Unanticipated Findings}

Two unanticipated findings within the study warrant additional discussion. The first was gleaned from an interview with a Campus Cupboard client who works as a community advisor in the on-campus residency halls. The second was the surprise revelation that many food pantry clients had unlimited meal plans. These unexpected findings emerged organically from the interview process and as such do not constitute a flaw in the research design. They will be discussed in the following section.

The community advisor situation. This study's findings echo previous literature's claims that intersecting demographic statistics as well as common situational hardships intensify the inability to access the daily recommended number of nutritious calories for many of today's college students. Not only have many authors written in detail about the demographics and the hardships, but also have examined cases where students discussed "key areas in which the university was not addressing their needs: inadequate financial aid allocations, unaffordable housing costs, inflexible meal plans, high food costs on campus, and lack of opportunities to learn life skills, including financial and food literacy" (Watson et al. 2017, p. 136). This study adds to that claim by referring to the employees working in campus positions.

Although the point of campus employment was brought to the study's attention by a community advisor, this discussion extends to those students working less than 20 hours a week. First, an overwhelmingly number of client participants reported working in on campus positions less than 20 hours a week. In fact, most clients reported similarly to Chase who complained, "I have a 20 hour a week job, but I don't work 20 hours often, like 10-15 hours." This scheduling poses a specific problem because not only are they not 
making enough money to be food secure, but also their shortage of hours prevents them from accessing The Supplementary Nutrition Assistance Program (SNAP). Although SNAP is the most prominent support for food, several scholars have taken note of this paradox, "undergraduates without children usually must work at least 20 hours per week to receive it (Goldrick-Rab et al. 2018, p.17). Therefore, students struggling to meet their basic needs are prevented from finding reprieve in this federally directed program. Likewise, the Community Advisors may find themselves facing additional hardships due to their employment. For example, because they are responsible for the needs of residents in the dormitories, they must remain within their buildings during their shifts. These shifts can extend over weekends, and with limited dining hall plans, there is not enough funding to last the entire semester. One client outlined the issue: I have a meal plan but it's provided by University Housing, and this is the first year they've done it, but all students at UCM now who live in the residence halls, they all have all access plans, which means they have unlimited swipes, so students who live on campus will do that, except for CA's because we get a partial meal plan, and it's provided by University Housing and you can like pay to upgrade, but it's really expensive, so most of us don't. So, I have 80 swipes this semester, which is about five a week, so five times a week I can go to the dining hall, and then I think we get $\$ 100$ dining dollars, or it may be $\$ 150$, because they changed our meal plans. So, they've improved them from what they were the past few years. 
Limiting the Community Advisors' meal plans poses an additional problem for these employees because they cannot leave the campus and the kitchen facilities are extremely limited. She goes on to explain,

You have to really plan your meals out. But again, other students don't have this problem because they all have access plans. So, CA's have kind of become the gap here, because we don't have that, so we have to compensate.

These findings support Watson et al. (2017) who disputed universities academic and research focus at the cost of the well-being of its students. Specifically, citing those students forced into "choosing meal plans based on their financial means and not on nutritional needs" (p. 136). Caroline continued, “There's like a huge gap and we're kind of just left here without." Ultimately, community advisors are paid for their work, but also provide a valuable service to the university. Watson et al. (2017) made a compelling point that can be translated to not providing Community Advisors with healthier meal plans as, "negatively [affecting] their sense of belonging at the university (p. 136).

Clients with meal plans still using the cupboard. This study found evidence to support Dubick et al. (2016) who reported that almost half of all meal plan enrollees in the study still experienced food insecurity. Likewise, in this study several of the participants reported having purchased a meal plan; however, at the time of this study, all freshman and sophomore students living on-campus were required to purchase a meal plan. Therefore, the majority of freshman and sophomores visiting the Cupboard ultimately had some type of required meal plan. Another reason some students with meal plans visited the cupboard was due to the monotony of the dining hall menus or perceived value of the dining halls caused some participants to avoid the dining halls all together. 
For example, Vanessa complained, “I don't always like their food or their options, I think that their meal plans are very overpriced." Similarly, other students, like Chris mentioned the less desirable routine choices:

I know the dining halls are not the best, I don't know if you've seen them, but sometimes the food is just not right. It doesn't really taste the best, it might not be the healthiest option out there, but definitely if there were more healthier options, if it wasn't consistently the same stuff that would be really nice.

Findings from this current study add to previous literature's debate on the effectiveness of college dining halls, especially the quality and accessibility of nutritious items. Other clients referenced the overwhelming amounts of unhealthy choices in the dining halls. For example, Colton explained, "You're bombarded by all these options... and it becomes annoying, and that's when the high carbs, and the grease catches up to you."

Lastly, the time of year affected the amount of money students had left on their meal cards and would increase the number of visits to the Cupboard by students who had meal plans. For example, Christina disclosed, "Last year I went like once a week [to the Cupboard], but it's that time of the year where we're all broke." Interestingly enough this study supported findings from two key studies. First, McArthur et al. (2018) reported, "Two of the most frequently reported reasons for their worsening food security concerned financial constraints, i.e., the monetary value of their meal card ran out too soon and they lacked money to buy food" (p. 974). Likewise, Watson et al. (2017) found students purchased the most limited meal plan because it was the cheapest option. Specifically, 
this study uncovered similar stories of students relying on visits to the Cupboard because their meal plans ran out at the end of the semester. For example, Charlotte disclosed:

People who do not have like an unlimited meal plan at the dining hall it is something that they can use to their advantage, so they are not spending all of their meals at once, or only eating pizza for the rest of their lives. In conclusion, meal plans are a method of accessing food, but without proper knowledge, and resources they can be unsuccessful in helping maintain the proper nutrition. 


\section{Research Questions Answered}

The research questions were answered by collecting and analyzing the various perspectives from staff, volunteers and clients of the Campus Cupboard. Pseudonyms were used to protect the confidentiality of the participants. The following section answers the research questions that guided the study:

1. What are the perspectives of UCM food pantry clients?

2. What UCM food pantry services are most significant to clients?

3. What additional food pantry services would be beneficial to its client?

\section{RQ1: What are the perspectives of UCM food pantry clients?}

Regardless of how clients viewed their own need, one point everyone had in common was that they were extremely grateful for the service. The general feeling of gratitude defined their need for what the Cupboard offers. One client declared, "the best thing the cupboard has done for me is being able to provide me with food to eat to get me by most of each week." Likewise, because some participants depended so greatly on the Campus Cupboard, it drew universal respect. Another client stated, "The Campus Cupboard means to me to be an outlet food source. Meaning that on a trip that I make there I know that I will most likely walk away with something to eat for the week."

\section{Participants are balancing a variety of stresses and obligations with their education}

Research Question One of this study sought to identify the outlooks of UCM food pantry clients struggling to meet their basic needs as a means to understand their situations and gauge additional services that can be offered to support students at UCM. Farahbakhsh et al. (2017) reported that despite students indicating good mental and physical health, they could still experience life stress due to food insecurity. The 
conversations with staff, volunteers, and clients unveiled a variety of stress causing agents including self-care, social life, busy schedules, academic demands, lack of family financial support, and limited transportation. Additionally, participants identified a variety of financial responsibilities surrounding their day-to-day struggles that defined their experiences leading them to use the Campus Cupboard. These financial obligations included fixed living expenses; purchasing food; added costs of owning a vehicle, like insurance and gas; phone bills; and entertainment subscriptions. The interview questions used to collect the data for this study are rooted in Maslow's Theory of Human Development and can be found in the appendices.

With the pressure of meeting graduation requirements, maintaining scholarships, repaying financial debt, and being away from home, many clients expressed feeling overwhelmed, specifically commenting on their difficulty managing stress. As a natural consequence of busy schedules, insufficient meal plans, bad spending habits, poor kitchen facilities, and lack of transportation, many clients defaulted to focusing their stress around accessing food.

Conversely, for some, these same stresses overlap with the all-you-can eat style cafeterias, abundant fast food restaurants, and unhealthy vending machine options that are all notorious to college campuses. Participants also revealed unhealthy snacking, various social demands like Greek life, and lack of physical activity as contributing to an almost syndromic food insecurity that ultimately compromises student health.

\section{Successful Strategies already in use}

Many participants already employ successful strategies for making ends meet and reducing stress. A common perspective among the clients using the food pantry is their 
successful strategies for navigating the food environment. Clients expressed several methods for saving money, buying food, and ultimately lowering stress. For example, budgeting and financial management, relying on support systems, self-reliance and prioritization of goals, and using established resources ranked among the most commonly reported methods of coping, and aligned flawlessly with the literature regarding successful implementation strategies for students struggling with food insecurity.

Budgeting and financial management. Some clients make ends meet by balancing a job with their student course loads. While many clients reported working less than 20 hours a week through campus employment, others work two or three jobs off campus to earn money for school. These particular situations are significant because they highlight a portion of the population who do not qualify for federal aid either due to parent income, do not meet the required 20-hour employment qualification for SNAP, or they have international student status which prevents them from holding employment outside of the university.

Additionally, some participants have various ways of monetarily coping with stress. For example, some participants prioritized managing their finances, some clients thoughtfully budgeted their money for the month while other participants relied on summer work to sustain them throughout the school year.

Quality Diets and Meal Prepping. Some participants reported successfully lowering stress by purchasing an individualized meal plan from the university. One client in particular even went back to purchasing a meal plan after moving off campus. A majority of participants with meal plans found that being able to personalize meal plans 
aided in lowering stress. Similarly, for students living off campus, sharing grocery expenses and prepping for meals were also ways participants reported lowering stress.

Support Systems. Many clients confessed to relying on friends and family as well as creating relationships with staff members. In some instances, clients reported bonding over the common goal of navigating the food environment together. This goal took the form of sharing responsibilities for cooking, grocery shopping, or even visiting the food pantry together. Some clients reported their family helping them financially, or with groceries as well. One support system important to note was the non-formal international student groups that help one another with rides to different grocery stores, or the city to visit international markets. Families also played a large role in supporting many of the participants in this study through financial support, food supplements, or support or even lending a friendly ear between classes, the idea of having someone for basic moral support was helpful for lowering participants' stress levels. Likewise, participants also reported relying on faculty and staff to help them manage stress.

Self-Reliance and Prioritizing. Additionally, many clients expressed selfreliance as a skill for coping with stress, while others submitted that managing their expectations about being a poor college student helped them navigate the financial hardships of college life. Others mentioned prioritizing their goals and responsibilities helped reduce their stress. However, one student left no doubt that self-reliance fueled by motivation is a powerful mechanism for success. Specifically, Cindy concluded, "You know once you're determined to do something, you definitely find a way to cope."

Using Established Resources. The university offers a very large variety of resources that many of the clients were well aware. Specifically, participants reported 
taking advantage of academic, nutritional, economic, health and wellness, emotional, and veteran services. In fact, many participants acknowledge the Campus Cupboard as a resource provided to students to help them manage their nutrition. Staff, volunteers, and clients alike indicated the Campus Cupboard provided free and convenient assistance for students struggling with nutrition just like the tutoring center or writing lab would help students struggling with academics or writing.

\section{How clients use the cupboard depends on a variety of conditions}

Clients have diverse backgrounds and needs that shape how they view the Cupboard as well as how they engage with the food pantry. Under those circumstances, participants indicated that among those with severe need, some clients supplement their grocery budget with the cupboard, and others are looking for different ways to make ends meet. Likewise, the pantry helps navigate other obstacles than just food insecurity. In the end, the Campus Cupboard is a free and convenient resource, and participants in this study feel there is no judgment or stigma in using the pantry. An additional point of clarity is that many participants felt it was difficult to ask for help. Because it is difficult to categorize or define what constitutes need, the Campus Cupboard exists to serve everyone. Sometimes participants' backgrounds defined their need. For example, several clients expressed a deep seeded need for any kind of support. As Charles explained, "So, it's not all college students have a great, I would say connection to like their home and everything so like they might not have a foundation that they're coming from, like once they get here, and sometimes you just got to do what you got to do to make sure that you make it by." On the other hand, other clients did not rely on the pantry but used it to supplement their food budget with the groceries they find in the Cupboard; even planning 
their grocery shopping around what they could not find at the Campus Cupboard. Yet, there are also students who have financial support, can afford meal plans, and are looking for snacks to supplement their existing diet. In the end, most clients, whether they were students or staff, were looking for different ways to make ends meet. Because defining the obstacles people have to overcome differs for everyone, for some the Campus Cupboard helps clients save money on food so they can use that resource elsewhere, while others are simply getting to eat because of the Campus Cupboard.

\section{The Value of the Cupboard}

As themes emerged in the process of interviewing clients, staff, and volunteers it became evident that many people acknowledged the difficulty behind asking for help: "rarely is somebody going to come to you about it, I'm sure. And it's going to be hard to probably spark up a topic.” However, observing the consistently long lines of people waiting to use the Campus Cupboard suggest there is a high need for its services.

Specifically, speaking to the mindset of someone in need, Sophia made the case, "I think that it's likely that the individuals who are going to the cupboard are in a head space or a mindset that they are more willing to seek out services and support, because that is a really hard thing to do." The bottom line is the clients recognize the efforts of the Campus Cupboard in removing those barriers. Sophia continued, "I mean it takes a lot of courage to step up and ask people for assistance and to go and do that. I would say that there is probably a lot of people on campus who really need us, but they think other people probably need it more, or it's just a really, really embarrassing thing for them to think that they need help but they don't want to go and show everyone that they need help." With this in mind, clients view the Cupboard as a valuable resource because the 
staff empowers the clients to not have to ask for help, because they know they can rely on the Cupboard.

\section{RQ2: What UCM food pantry services are most significant to clients?}

Research Question Two explored the services that are most significant to the Cupboard's clients. As a result, several significant themes emerged surrounding the

products and services the pantry offered. Specifically, convenience and nutritional value; the freshness and variety of available products; the supply of soup; the food recovery program; personal hygiene products; opportunities for volunteers; clarity in communication; and a non-judgmental environment to be the most significant features of the Campus Cupboard.

Convenience and Nutritional Value. Although most participants understood working strictly with donations makes it difficult to control the items that come into the food pantry, many participants placed importance on the nutritional value of the food in the Cupboard, but readily chose convenience over higher nutritional value. In fact, most participants emphasized looking for food that does not take long to prepare or can stretch through the week, even though those items may lack quality nutrients. For example, one client indicated items with higher sugar levels like spaghetti or processed food like canned vegetables were "not the healthiest food, but man, it lasts." Additionally, one staff member noted the higher prices for healthier food might drive clients' choice: "I've noticed that when we have chicken and that kind of stuff in the pantry, they tend to go fast, like people really want those, so I'm guessing that people really don't want to spend money to buy those. 
Freshness and Variety of Food. The freshness of the products is important to the all the participants in this study; however, because the food pantry supplies options that are generally close to their expiration dates when they are donated, it makes keeping fresh produce very difficult. As a result, even though volunteers and staff prioritized checking the expiration dates of the products, many participants still expressed a concern surrounding the actual expired goods on the shelves. Specifically, many clients reported not grabbing the produce that looked bad. Bread, fruit, vegetables, milk, cheese, and some dining hall recovery products were items that drew the most concern.

Soup. The most popular item in the Cupboard, and perhaps the most talked about, was canned soup. Many, if not all of the participants mentioned soup and because of its popularity, one staff member even mentioned the importance of keeping more cans of soup in stock: "What the students want are their soups, the soups, that's the simplest thing, but we don't get enough of those. I know that for a fact, because when we get soups it's gone. They go so quick and we have a limit, one soup per person, but it just flies off the shelves." Perhaps the convenience of storage and cooking explains its popularity: "soups or ramen noodles or easy macs or quick things that you can just throw in a microwave." Clients living both on and off campus agreed, and it generally is a healthier option when comparing its nutritional value to its convenience.

The Food Recovery Program. In addition to the longevity value of food, the participants placed significance on the food recovery program. On one hand participants really found benefit in the collaborative project with Sodexo, while on the other hand the partnership received harsh criticism. For example, some clients purposefully watched the menu of the dining halls, so they knew when to visit the Campus Cupboard and 
appreciated the variety of easy to make food, while others expressed discontent for the repackaged foods: "like, if you don't swipe in the dining hall, it's like $\$ 10$ or $\$ 13$ otherwise. It's like it's not worth it, we're not the biggest fans of the Sodexo food."

Personal Hygiene Products. The Campus Cupboard provides more than food. From time to time the donation boxes from Harvesters or Walmart contain personal hygiene products like toothbrushes, toothpaste, soaps, shampoos, etc. Many participants indicated these items have an indirect effect on freeing up resources for purchasing food. One client's comment is very representative of how these items impact the community especially "for people who can't get off campus and they need this sort of thing, so maybe like some shampoo or conditioner or something like that. Or, if again for low income people who can't afford like some notebooks or stuff like that." In the end nonfood items were of great significance to the clients.

Opportunities for volunteers. Many of the volunteers are motivated by philanthropic requirements from their courses, specifically the university's nursing program's Culture and Sustainability in Health course. So, in addition to providing food and resources for students in need, the Campus Cupboard also provides a place for community members needing or wanting volunteer hours. As a result, many volunteers took pride and joy in their ability to help people within the campus community. Providing the opportunity to serve is a significant piece of this community:

I work at a hospital so I could have just volunteered there, and did my normal thing, but it doesn't really mean anything then. I really think it helps people, and obviously I want to be a nurse, so I want to help people, and me being able to do that drives me to want to do it, motivates me. 
Communication. Another theme of significance Research Question Two produced was the importance behind communication. There were two specific areas that participants indicated communication was important, specifically internal communication between volunteers and staff, and then external communication between the Campus Cupboard and its clients. The importance of communication emerged as a theme specifically surrounding the confusion on the hours of operation, days the Cupboard was open, and policies on how many items clients could take. Additionally, many participants alluded to the fact that the need for these resources is much larger than those who currently use the cupboard and communicating the Cupboard's existence and need was important for both clients and potential donors.

No judgment or stigma. Another significant service the Cupboard offers its clients is the dignity of a judgment free environment. Almost every participant agreed that the feeling of not being judged or looked down upon was attractive to its clients. Many participants already acknowledged the societal norm of a penny-pinching college lifestyle, but one aspect of the Cupboard that was significant to clients, employees and volunteers alike was creating a community that does not look down on people for trying or struggling with resources. One client pointed out the bottom line about using the Cupboard, “...it doesn't mean that you're not trying. Like, I have two jobs, and I'm a billion miles from home. So, I mean just because you aren't doing the same thing I'm doing, or I'm not doing the same thing you're doing, doesn't mean that it's not there for both of us." 


\section{RQ3: What additional food pantry services would be beneficial to its clients?}

Research Question Three focused on what additional food pantry services would be beneficial to its clients. The participants indicated that the Cupboard is there to serve the staff and faculty and appreciated the work it does for their community. Specifically, the themes that emerged surrounding this topic were: Increasing availability; addressing the size and location; adding culturally perceptive items; offering more fresh fruits and vegetables, increasing access to affordable fresh raw food; and creating strategic partnerships through advocacy and outreach.

Increasing Availability. Because of the academic demands, busy schedules, and stress, many of the clients expressed interest in expanding the Campus Cupboard's days and hours. Specifically, when prompted some clients went back to mentioning the freshness of the products. This is an important aspect of their perspective, because the Cupboard is only open only three days a week, Cayden suggested organizing an effort to distribute the fresh produce before it goes bad:

Also, if possible, call out to students to come around for pick up on items that have less validity time before they go bad, in between when the pantry is closed, this has to be monitored to achieve. If it can be allowed up to twice in a week and also more of the perishable things out for those who want more so as not to get bad in the pantry without anyone having them.

Although there were different points of view surrounding the preferred hours of the Campus Cupboard. Clients emphasized that the limited hours of operation significantly affected the freshness of the food: 
Like they have vegetables down there, but again, they could be getting close to going bad, like the bread sometimes like molds within a couple of days. And you can only get them within a week, so by the time things get old, you can't even get more food and they're open weird hours of the week.

Additionally, the clients complained that the Cupboard was only open during the evening hours and that made it difficult for students with night classes to access. While some had conflict with the current hours, some found no issue, and others were confused on when the Cupboard was actually open. Although the business hours during the school year posed some conflict for clients, individual schedules made the first come first serve policy difficult for some clients. More importantly, holidays and vacation breaks posed the most significant difficulty for clients who truly depend on the Cupboard.

Size and location. In addition to the hours, improving the location and increasing the physical size of the Campus Cupboard would be beneficial to its community. Several clients indicated difficulty in finding the food pantry and suggested its location may discourage new clients. The secluded location also bolsters the argument to improve its communication. In addition, the size of the food pantry presents similar obstacles and, as a result, many participants expressed increasing the size would also be beneficial. One staff member suggested, "if somehow, we could expand it, have a bigger place or another place, get more of a variety of food, like the rice." Volunteers also suggested a better location: “I don't think it's a great location honestly. I had no idea how to find it last year, I went with a senior to find it. It could be better, more signs, more open, but, it's a spot, so..." 
Additionally, the size and location also have implications for the location of the items within the pantry. For example, Stanley argued the location of items within the cupboard could make a difference. Specifically, he argued, "Really just categorize everything like a vegetable section, meat section, variety of meats, and then like some stuff that is just for fun, make it like a smaller section maybe set certain limits on that."

Education. Many participants in this study also stressed a need for learning how to navigate food insecurity through improving their ability to cook and manage their finances. Specifically, those students with higher levels of cooking experience and knowledge saw raw ingredients as more of a useful item than those who did not know how to cook. Thus, with an arguably higher level of cooking knowledge, the items found within the cupboard can open more possibilities. Other suggested methods of educating the Campus Cupboard Community took forms that are more modern. For example, Charlotte furnished one exiting idea: "Well, this is still food, but like some meal kits, so if people did want to start cooking, either purchase or get one of those meal kits." Other clients suggested just connecting with existing efforts that are already being offered within the Student Recreation and Wellness Center like health classes that address nutrition and cooking. Additionally, because education can take many forms, some clients traced food insecurity back to cooking knowledge. For example, Charles suggested:

So, something that they could do is offer a simple cook book, and I would not know exactly how to go about that, but I would say that is something around 15 to 20 pages and has a variety of simple and healthy meals, the kind that students 
could make and they could offer that with every cloth bag that they hand out for students.

Culturally recognizable items. Throughout the study participants indicated the need for produce and dry goods that would be easily stored, and culturally recognizable to the large population of international students that use the Cupboard's services. Specifically, participants made requests for dried rice, Indian "pulses" like dried lentils, legumes, mung beans, black-eyed peas, lentils, pigeon peas, adzuki beans, moth beans, and kidney beans. There were other African produce items like the tuber, or yam, that students travel to larger cities to purchase. Halal meats were also suggested to support Muslim students who have difficulties finding these products in the dining halls.

More fruits and vegetables. Likewise, participants expressed access to more fresh fruits and vegetables would be beneficial. Either specifically finding these items from the dining halls or from local donations, all participants, domestic and international students alike felt fruits and vegetables were important for their diets. Chloe argued, "Fruits are not cheap, and they taste amazing, and I like vegetables, I love vegetables, but fresh vegetables are not cheap, and it's hard to get them fresh too." Many clients expressed very similar points of view and suggested broader access to fresh fruits and vegetables would be a beneficial addition to the food pantry.

Increasing access to affordable fresh raw food. In addition to the actual food that the Cupboard provides, some clients specifically mentioned an interest in transforming or adding a small marketplace to the cupboard in addition to free food. Charlotte added: 
Just because it can be very hard to get to other locations if you did want produce and you can't get off campus, or if it was cheaper on campus because a lot of college students are very low-income people.

Specifically, participants suggested offering items that were of little cost, not to make profit, but to improve the food environment on campus. Others mentioned altering the dining hall "to go" option to include quicker services. Lastly, bedroom furnishing, winter clothing, and educational supplies were also addressed as options of services that would be beneficial to add to the Pantry.

\section{Creating strategic partnerships through advocacy and outreach. Several}

volunteers as well as staff members believed advocating for their clientele by providing thoughtful outreach programs and useable products would benefit the Campus Cupboard. For example, adding guides or more personable relationships between the Cupboard and the clients. Likewise, strategically using technology, as Virgil argued, to dial in, "systems and community communication channels to effectively target and communicate with students. And the two-way communication will know what their means are and is there a way to dial in that the campus is covered more effectively." Additionally, participants spoke to the importance of the Cupboard's connection with the UCM Faculty to help reach out more effectively to students and community members in need. Virgil concluded, "You know relationships are the wellspring of all of humanitarian service. And, I think that there's probably an opportunity to look at local stores, local farmers. I think that there's probably an opportunity to serve as and interact more with the students," ultimately arguing for stronger connections on a more personal level with individual students and tailoring outreach to individuals. 


\section{Implications for Practice (Recommendations for educators)}

The focus of the recommendations will center around three core capacities of the Campus Cupboard, as the results of this study demonstrate the Cupboard is a critical ally for many students fighting to learn at the same capacity as their fellow students. This study derived its conclusion and made its recommendations from the perspectives of students who rely on the college food pantry to avoid delaying graduation due to insufficient resources (Goldrick-Rab, Baker-Smith, Coca, Looker, \& Williams, 2019). Specifically, to address the dietary struggles students face in higher education as well as the living costs associated with schooling, this study constructs its recommendations focusing on (a) building a culturally responsive food pantry, (b) tailoring its outreach, and (c) creating sustainable change.

\section{Building a Culturally Responsive Food Pantry}

Accommodating alternative eating patterns shows respect for clientele while increasing effectiveness, but more importantly, it reflects cultural responsiveness. Providing culturally recognizable food for students is just one strategy that can build human dignity, maximize access and affordability of healthy foods, and provide an environment which assists students in achieving the best possible physical and academic outcomes (Gallegos et al. 2014). One specific example would be offering easily storable rice, beans, and lentils. These products are not only culturally recognizable and healthy but are largely sought after by international students. In fact, students revealed traveling to the city to purchase these items. For example, Cynthia shared:

Basmati rice is something Indian students would appreciate. Like, in the Walmart we have limited options for vegetables. In India we have lots of options for 
vegetables, but here we have limited options, so if we want to eat something Indian vegetables, then we have to go to the Indian store in Lee's Summit, and then buy from there.... If they can keep some Indian stuff there like wheat flour, rice flour, and some Indian pulses.

Regardless of the cultural variances, the common thread is the distance these students are willing to travel to not just have a taste of home, but to grasp a sense of dignity while living abroad. For example, Cindy unpacked her perspective:

Rice, yes. We eat rice a lot in Africa. Where I come from in Nigeria, we eat beans, but it's like peas. Not beans, it's like peas, like a lentil. We eat something back at home called a yam. Yam is a tuber. It's like potato but a bigger version of a potato. It's big, really big, so we cook that and eat it with egg, so it's my favorite meal. I drive all the way to Kansas City to get it in an African store. Staff also shared a similar perspective from the point of view of an international student. Again, rice serves as a universally important item:

Well, bags of uncooked rice would be super helpful, even dry noodles might be helpful. Because in general Asians all rely on rice a lot, so I'm still thinking that rice would be super helpful.

Considering the wide variety of cultural backgrounds from which clients come is only part of a series of strategies scholars are calling for that maintain human dignity. (Gallegos et al. 2014). Understanding the international communities that food pantries serve including affordability, health, and the development of cooperation with both the private and public sector will strengthen community university partnerships. 
Specifically, the researcher recommends building a connection with the international stores in the greater Kansas City area. At the same time, current literature argues that food pantries with a clear way of communicating information to clients include clear written messages in multiple languages responding to client need in a culturally sensitive way (Cooksey-Stowers et al. 2018; Gallegos et al. 2014; Nikolaus et al. 2018). Furthermore, posting signs in multiple languages connects the Campus Cupboard to the university's commitment to diversity as well as their core value of meeting the needs of all students through community:

Central Missouri encourages acceptance and respect of individuals with differing values, ideas, beliefs, abilities and life experiences. The university promotes good citizenship, a sense of civic responsibility, global awareness and an appreciation for human diversity at all levels (“UCM mission and vision,” 2019).

Networking. Fighting hunger is generally limited by unforeseen obstacles that are oftentimes overcome by the creativity of a multidisciplinary approach. Networking with a wide variety of volunteers, organizations, and ideas often creates incredible solutions to problems at hand.

Volunteers. There is a diverse range of philanthropic organizations around the UCM campus that offer a wide variety of skills, time, and resources that would enhance the capability of the Campus Cupboard. One recommendation would be extending the network of volunteers to include a variety of organizations around campus. For example, this study found the majority of volunteers during the time frame of the study were nursing students fulfilling required community service hours for one of their courses. 
These individuals represent just one group of many who are not just fulfilling requirements, but rather want to make a difference. Steve confirmed:

We do have a volunteer group that volunteer and stuff, and they have a belief in what we're doing and you can see the passion that hey, helping others help themselves, I mean in our student trainings and things I have often said, you know if you're helping all the people around you get what they want then you'll truly have everything you've ever wanted in the end game, so helping people get what they want and helping them get to where they want to be, that's the ultimate goal. Arguably, there are more organizations whose missions align with the purpose of the Campus Cupboard and whose members would bring a great deal of knowledge and support to the effort. Ultimately this study recommends extending the network of volunteers to create a wider web of time, talent, and campus wide buy-in.

Organizations. On a national level current scholarship recommends food and nutrition practitioners and their food pantries connect to the Healthy Food Bank Food Hub to attain additional information about healthy food distribution, nutrition education, innovative partnerships and models, as well as tools and resources for changing the food pantry food supply (Byker Shanks, 2017; Goldrick-Rab \& Broton, 2013; Noltemeyer et al. 2012; Silva et al. 2017)

Similarly, scholars highlight the resourcefulness of The College and University Food Bank Alliance, which aligns partnerships within colleges and their communities to support food pantry clients. These larger organizations have incredible reach and this researcher would recommend exploring additional opportunities with them in order to 
strengthen the existing relationship with Sodexo or other local food vendors to better address the needs of food insecure students (Broton \& Goldrick-Rab, 2016).

Numerous participants in this study commented on the limited amount of fresh fruits and vegetables the Cupboard was able to provide. Many also politely proposed that they would like to see more. For example, Cali suggested "I don't know how well this would work, but like fresh fruits and vegetables and stuff. I'm not sure they could do that because on weekends, I don't know if they're open on weekends I don't know.”

On a local level, several scholars recommend expanding the relationship with Farm to Food Bank programs that connect food banks with local produce through gleaning, discounted purchasing, or donations of excess fruits and vegetables (Byker Shanks, 2017). However, because UCM already has a strong connection with organizations like Harvesters, this study recommends connecting clients with the local mobile food pantries for clients to access free produce. In fact, pantries as well as individuals can access produce through the following mobile pantries, which are a valuable networking resource to supply clients. Their website is harvesters.org where clients can click on to 'get help'.

Connecting clients to free vegetables and produce can be done in a variety of ways. For example, organizing transportation for clients, car-pooling, or simply posting the information in a variety of languages outside the pantry. Participants frequently critiqued the pantry's lack of available information. For example, Vanessa argued "It [the pantry] could be better, more signs, more open, but, it's a spot." Specific information on how clients can find access to more food will be a powerful addition to the pantry. 
A slightly more in-depth process of physically supplying more fresh and perishable foods would require changes in equipment as well as food storage and handling practices, but is well worth the effort to address diet-related health issues of food pantry clients (Byker Shanks, 2017). Some items from Harvesters require a .16 per pound handling fee but would allow greater access to shelf stable food during low donation times. However, by increasing space for perishable food storage, the Cupboard could access Harvesters' Hard Seven. Specifically, 30-pound crates of at least two or three items that include hard vegetables like sweet potatoes, white potatoes, onions, cabbage, citrus, carrots and onions. Additionally, increasing the storage capabilities for fresh produce would increase the ability to regularly supply produce picked up from grocery stores such as melons, cantaloupes, apples, oranges, and grapes. These suggestions provide an additional safety net for students and could be strengthened with ongoing community/university partnerships. However, other strategies also need to be considered in order to meet the remit of maintaining human dignity.

In the short time, creating lists of how long different items are still good after the expiration dates would help clarify the confusion clients share. For example, some items are good for a couple months after their best by date, but other things (pumpkin pie filling, e.g.) is good for up to years after their date. Explaining the difference in best buy dates and good through dates would help educate the clients on choosing items.

Ideas. Ultimately, schools are a great place to connect students with other services, so some scholars stress intensifying their relationships with social service and medical agencies to promote student well-being. Other colleges create low cost or interest free programs to alleviate stress from textbooks or loan delays (Goldrick-Rab \& Broton, 
2016). The bottom line is that strengthening referrals to additional community resources like SNAP benefits or employment centers that are better suited to address economic instability will improve the economic situations for many clients. Additionally, campus career services may be able to assist with employment opportunities. On a similar note, UMass Boston even helped establish the Massachusetts Homeless Post-Secondary Students Network in an effort to assist students experiencing housing insecurity and chronic poverty on college campuses (Byker Shanks, 2017; Goldrick-Rab \& Broton, 2013; Noltemeyer et al. 2012; Silva et al. 2017).

\section{Tailoring Outreach}

Studies reveal that almost 90 percent of students participating in campus food banks are still food insecure despite measures to alleviate the stress (Farahbakhsh et al. 2017; Freudenberg et al. 2011; Hagedorn \& Olfert, 2018). Meeting the individual needs of clients requires a community centered approach focused on three specific outreach agendas: Consistently identifying clients' needs, making individual food recommendations, and improving education. Because outreach is dependent on the surrounding communities, creative approaches and flexibility will be required to find success.

First, in order to identify needs, Cady (2014) suggested short-term action should include developing assessments to determine the prevalence and severity of food insecurity in addition to barriers and specific populations who are being disproportionately affected. Although the Wisconsin HOPE Lab has already conducted a detailed campus-wide study, additional inquiries and engagement with clients will create a deeper connection with those individuals the Cupboard wants to reach (Crutchfield \& 
Maguire, 2018). Because scholars recognize that food insecurity is rarely an isolated condition but rather a sign of much deeper financial hardship, involving other campus resources to help communicate the availability of the Cupboard to their communities would be helpful in identifying needs. For example, because clients are already aware of the variety of services UCM provides its students, placing points of access to needs assessments in other offices would enhance communication. As such, Cayden noted, "UCM has services in place that are accessible for dealing with stressors, student engagement, student counseling, student accessibility, mental health and the GISS office." As a result, this study suggests simple two-way lines of communication through social media like Twitter, Facebook, Snap Chat, etc.

Individual food recommendations. Because college students have a range of knowledge and skill regarding financial budgeting, nutrition, and self-efficacy, food pantries are focusing on non-traditional ways to enhance student support. Some scholars advocate for meeting individual clients needs by providing food recommendations based on dietary restrictions, health needs, and access to food preparation equipment (CookseyStowers et al. 2018; Gallegos et al. 2014; Nikolaus et al. 2018).

One recommendation would be adding a nutritional rating system and incorporating educational nudges like in grocery stores such as a traffic light color-coded system or star systems, where more stars indicate healthier items. Not only would this increase the role volunteers play within the pantry, but it would also be a quick way to communicate nutritional value of the food item. However, there is some debate regarding which intervention to use, especially when keeping in mind the dignity of clientele. Other 
scholars advocate for an even more subtle approach where healthier food appear more convenient, attractive, and normal to select (Cooksey-Stowers et al. 2018; Wilson, 2016).

Because many clients have limited kitchen facilities and lack time to prepare meals, simple food donations to the Campus Cupboard are not the most effective. Therefore, one innovative idea is to organize a one-day fund-raiser where staff and students can donate to the pantry through dining dollars and meal swipes directly from campus dining halls (Broton et al. 2018; Goldrick-Rab \& Broton, 2013). This way Campus Cupboard users can gain access to actual meal-swipe cards and dine in the cafeteria at their convenience.

Improving education. Of course, education plays a large role in the discussion of outreach. Some scholars recommend voucher and transportation interventions, as well as cooking classes and methods for addressing clients with dietary health concerns. For example, many students wanted to learn to budget and cook simple nutritious meals. Specifically, Vanessa suggested:

I mean it's always beneficial to have a nutritionist. And just like learning more about what you eat, but I think just like overall they do a fairly decent job of getting a wide variety of foods. I'm trying to think of the My Plate. I'm pretty sure they have everything.

White hallway walls. Clients wait in line in a long narrow hallway leading down a slight ramp and around a left-bending corner in front of the Campus Cupboard. As a result, this study recommends transforming that waiting area into an incredible classroom space. Ultimately, this recommendation has several projected benefits which include reducing the amount of time clients spend making choices in the actual food area, as well 
as improving self-efficacy and cooking skills. Specifically, including a large visible list of the items currently available in the pantry would help clients make choices ahead of their time in the pantry. Second, installing a monitor for students to watch educational cooking programs, specifically "Struggle Meals" with Chef Frankie Celenza who has shown interest in specifically working with The UCM Campus Cupboard to help educate clients struggling with cooking.

QR codes. Similarly, creating a repository of instructional videos and information regarding products found within the cupboard will teach clients different recipes and uses for food items. This can easily be done with the knowledge and skills of the food pantry volunteers and staff and strategically placed in the cupboard, but also on the Campus Cupboard's website. Volunteer couple Virgil and Virginia recommended:

If they have a communication channel or a little barcode or something there that just said, Hey, this item can be made in five ways, click on this to get a couple of recipes that can be done in five or 10 minutes. Because again, students don't have time to sit around and make a whole bunch of things. Like we've learned this with our missionaries, right? So, we sent them off to Brazil or Idaho or wherever they've gone, you know, they run 14 to 18 -hour days, missionaries where they got to stay, they got to stay healthy, so they can't just eat out or, you know. And so how do you give them recipes that are quick, easy, simplified, but still give them nutrition? That's what these college students need in my opinion. College may be a critical time for developing food literacy, as many students reported that they were new to experiencing food insecurity. Additionally, improving food literacy could help address the widely held student perception that healthy food is 
more expensive (Watson et al. 2017). Ultimately, the most renowned voices in the field plead for a similar multi-sector approach that includes private support and public benefits to help students and their families get enough to eat (Broton et al. 2018; Goldrick-Rab \& Broton, 2013).

\section{Creating Sustainable Change}

Some strategies to change the conversation regarding food insecurity focus on education, self-efficacy and community building; however specifically engaging the volunteers and strategically communicating with the clients will help address root causes of food insecurity and also strategically link community services to people in need. Additionally, improving the face of the Campus Cupboard is also important, as some scholars call for a rebrand of food pantries by connecting them with sources of wellness instead of need (Campbell, Hudson, Webb, \& Crawford, 2011; El Zein, Mathews, House, \& Shelnutt, 2018; Hanbazaza, Ball, Farmer, Maximova, \& Willows, 2016; Martin, Wu, Wolff, Colantonio, \& Grady, 2013; Matthews et al. 2016; Nikolaus et al. 2018).

Engaging volunteers and staff. Campbell et al. (2013) reported that only 41 percent of food banks indicated they had access to nutrition expertise, and in addition, only a third indicated that they had someone with nutritional expertise to provide volunteers with nutrition training. This study recognizes that employing a full-time nutritionist would be costly but recommends empowering the volunteers who are studying to be nutritionists or nurses to provide additional support to clients. For example, many food pantries utilize nutritionists to track food inventory or procure food from donors, but they are seldom asked to develop written nutrition policies or educate donors. In addition, food pantries cannot always accommodate for medical conditions or 
food allergies. Providing education to donors about foods that are needed or encouraging monetary donations versus food donations may prove beneficial (Campbell et al. 2013; Goldrick-Rab \& Broton, 2016; Vaterlaus et al. 2018).

Strategic Communication. While several interventions suggest coupling interventions in pantries with vouchers or referrals for clients with a lack of reliable transportation or cooking equipment (Cooksey-Stowers et al. 2019), an additional consideration would be strategically marketing the communication or adverting. Caroline indicated the need for improvement, "I guess the need to advertise better with their new hours, because nothing has frustrated me more than going there, and then they're not open." As a result, this study establishes several means to communicate information to clients besides the outdated website.

Additionally, there is a second implication for communication within this system. Exclusively, the food pantry clients communicate their demographic information to the Cupboard when they swipe their ID Cards at the food pantry. While the investigator acknowledges food insecurity solutions should be discreet, protect student confidentiality, and work to alleviate stigma associated with food insecurity by raising awareness on campus (Henry, 2017), there are several ways to strategically respond to those individuals and similar individuals who are at equal or higher risk of suffering from food insecurity.

Reception of financial aid is positively associated with food insecurity, indicating that this variable may be considered as a signal of overall need (i.e. those who do not use financial aid are at an advantage in terms of overall resource availability). To illustrate, Dubick, Matthews, et al. (2016) found, "seventy-five percent of students suffering from 
food insecurity reported receiving some form of financial aid, 56 percent reported working while going to school, and 61 percent reported taking advantage of benefit programs like SNAP” (p. 31). The same may also be true regarding receipt of food assistance and budgeting behaviors (Payne-Sturges, Tjaden, Caldeira, Vincent, \& Arria, 2018). Specifically, this study suggests exploring options for non-intrusive, but strategic advertising to students who may benefit from the cupboard.

Include the pantry as part of new faculty orientation. Many campus tour guides lead incoming students and their families past the Campus Cupboard. The stop on the tour impresses many of the potential students. Several clients, like Sam indicated:

They told me about it on my visit, so when I toured campus they brought us down and showed us the Cupboard and I would come to the rec a lot and if it was open that day, I would be like oh, yea the Cupboard is open so I would just run in and grab something.

However, because clients also mentioned the relationships between faculty and staff, this study recommends including the Cupboard as part of new faculty orientation (Twill et al. 2016). This will advertise its existence to instructors who interact with students daily, but also will connect the Cupboard with another potential resource and volunteer.

Leadership structure. An additional aspect of sustaining change for the future is confronting the current leadership model. Due to the rapid growth in users as well as the increasing number of visits to the Campus Cupboard, the current leadership model prevents efficiently addressing the changing needs of the community. Establishing a leadership team or board of directors will accommodate the evolving food pantry goals as well as clients' difference in needs. The bottom line is that it is essential to establish a 
leadership model that will continue the director's vision after her retirement. More specifically, the director, Beth Rutt, was able to establish a system of networking and coalition building to establish the Campus Cupboard throughout her tenure; however, continuing to navigate the political arena will become vital if the Cupboard is to remain in effect after her retirement (Bolman \& Deal, 2013). Establishing a team consisting of various stakeholders from the community will aid in the Cupboard's ability to "shape purpose in response to a demand or an opportunity placed in their path" (Bolman \& Deal, 2013, p. 108). Options to consider are food pantry staff, student health clinic representative, tutoring center representative, counseling center representative, Greek Life Council representative, faculty, staff (including community advisors and food service employees) and community members.

\section{Suggestions for additional research}

With the aim of improving on the research practices used in the present study the researcher calls for specifically employing focus groups to gather opinions. Several clients expressed an interest in interviewing with their friends and the potential for gathering clues and insights as to how the Campus Cupboard is perceived in a safe, comfortable place with people like themselves, which may yield richer data (Krueger \& Casey, 2015b). Likewise, future research should explore best practices for engaging clients and healthcare professionals (e.g., dietitians, nutrition educators, nurses, and physicians) in the development of nutrition interventions targeting food pantry clients (Cooksey-Stowers et al. 2018). Although several researches have called for the involvement of additional professionals, connecting the Campus Cupboard's services to the health clinic would arguably improve its ability to serve the community. 
Cady (2014) suggested short-term assessments to determine the prevalence and severity of food insecurity in addition to barriers and specific populations who are being disproportionately affected. Similarly, the researcher would suggest conducting specific research to develop short wellness checks to quickly evaluate community wide needs or assess individual needs. Creating short surveys or questionnaires, like client-feedback venues at the Campus Cupboard, or even as simple as a web-based suggestion system would be beneficial to leaders making decisions for the UCM food pantry. Finally, to increase funding from the university, the researcher argues, "future studies should examine delayed graduation, discontinuous enrollment, and attenuation of academic goals as possible consequences of food insecurity" (Payne-Sturges et al. 2018, p. 352). The Campus Cupboard on the campus of UCM has been a completely grass-root project independent of university funding; however, the syndrome creating food insecurity has now extended to such a large population of students and community members, the university will need accurate and reliable data to direct funds towards this epidemic.

\section{Summary}

A national health concern regarding hunger among college students is at the center of a growing national debate. By and large, the current literature reflects academic performance, student retention, and student health as being associated with food insecurity (Broton \& Goldrick-Rab, 2017; Chaparro et al., 2009; Gaines et al., 2014; Henry, 2017; Morris et al., 2016; Payne-Sturges et al., 2018). Consequently, scholars criticize universities for overemphasizing academic performance and research while student well-being declines (Gaines et al., 2014; Henry, 2017). In the end, simply identifying students who are facing food insecurity is only the first step in intervention. 
However, universities who prioritize struggling students by considering their perspectives will be better positioned to advocate for policy change (Payne-Sturges et al., 2018; Watson et al., 2017).

There is a limited, but growing, body of research surrounding food insecurity among college students. Despite growing awareness, the perceptions and needs of college students who are clients of campus food pantries remain largely unknown (Henry, 2017; O'Neill \& Maguire, 2017). The purpose of this qualitative study will be to explore the perspectives of food pantry clientele at UCM through qualitative inquiry grounded in Maslow's Theory of Human Motivation. This research will identify the unique needs and perspectives of the food pantry customers or potential clients, highlighting problematic barriers to student academic success due to food insecurity (Fink, 2017). This study's significance lies in its practical application for educational leaders searching for diverse solutions to food insecurity (Bruening et al., 2016). One specific practical application is understanding UCM student perspectives who currently use the UCM Campus Cupboard in order to better meet their basic needs throughout their collegiate experience. 


\section{SECTION II:}

PRACTICIONER SETTING FOR THE STUDY 


\section{Practitioner Setting}

The relevant history of the dining experiences on the campus at the University of Central Missouri as well as the description of food insecurity leading to the need for an on-campus food pantry will provide a deeper understanding of the context surrounding the Campus Cupboard. Specifically, delineating the organizational history of UCM in conjunction with the societal, intellectual, and professional backgrounds offers a glimpse of the developments in the community, movements in academia, and the changes in the field, that offer a specific context for studying food insecurity at UCM. Likewise, in an effort to understand the organization, "as sets of practices instead of units of people, plans, and execution processes, [this organizational analysis] reveals the actual complexity of the complexities regarding organizational change" (Jansson, 2013, p. 11). Specifically, analyzing the Campus Cupboard through Bolman and Deal's (2013) structural and symbolic frames outlines the distribution of work and the coordination of communication within the organization. Additionally, this analysis will investigate the meaning behind the Campus Cupboard's work and its inherent place within the

community (Bolman \& Deal, 2013). Likewise, considering the leadership of the Campus Cupboard within its historical context will provide the setting to examine the ways in which the leaders "serve the greater good of the organization, community, and society at large" (Northouse, 2016, p. 226).

\section{Organizational Background}

Founded in 1871, UCM is located in Warrensburg, Missouri, roughly 45 miles from the Kansas City metro area. The university offers students opportunities for online, off-campus and non-credit instruction (Chen, 2018) all with the goal of, "transforming 
students into lifelong learners, dedicated to service, with the knowledge, skills and confidence to succeed and lead in the region, state, nation and world" (University of Central Missouri Fact Book, 2017). The university is composed of the following colleges: College of Arts, Humanities, and Social Sciences; Harmon College of Business and Professional Studies; College of Education; and College of Health, Science and Technology (Chen, 2018).

UCM has a diverse population of students from across the country, as well as an international program. In the Fall 2018 enrollment was 11,487 students, which included 9,300 undergraduates and 2,187 graduates (Chen, 2018). The undergraduate student body consists of $45 \%$ male, $55 \%$ female, $21 \%$ minority, and $2.5 \%$ international students. Comparatively, the graduate student body consists of $37 \%$ male, $63 \%$ female, $13 \%$ minority, and $19 \%$ international students. Students from 45 different states attend UCM (Chen, 2018).

\section{Societal Background}

Scholars acknowledge that demographic information alone does not portray the general need for support among college campuses. This is of particular importance because even though first-generation colleges students, international students, older students, and students with children are more prevalent and successful than ever, they are, at the same time, more vulnerable to food insecurity while pursuing their degrees. For example, it would not be sufficient to only examine the number of SNAP users, because it would exclude students who do not qualify for federal aid due to parent income, or because they do not work the required 20-hour employment qualification, or hold an international student status (Cady, 2014; Dubick, Matthews, et al., 2016; Freudenberg et 
al., 2011; Kelchen et al., 2017; Zein et al., 2018). Therefore, the societal background of UCM provides a more vivid picture of the vulnerable student populations.

UCM has 35 international exchange agreements with institutions worldwide, including direct partnerships with overseas universities. Currently, there are 658 undergraduate and graduate international students from 55 different countries. Comparatively, from 2014-2018 the average age of UCM students was 24 years old (Chen, 2018). Since 2014, UCM has experienced a steady decrease in first-generation college students. In 2014, 53\% of students were first-generation; however, in 2018 46.0\% of students were first-generation. The prevalence of food insecurity in 2018 was higher than the national average for households headed by Black non-Hispanics (21.8\%) and for Hispanics (18\%) (Coleman-Jensen, Rabbitt, \& Gregory, 2017). In contrast, the prevalence of food insecurity was below the national average for "White, non-Hispanic households (8.8\%); households headed by non-Hispanics of other, or multiple, races (9.9\%); and households with incomes above $185 \%$ of the poverty line $(5.8 \%)$ " (ColemanJensen et al., 2017, p. 13). The race and gender makeup of UCM students struggling with hunger is also a concern. The Wisconsin HOPE Lab (2018) study at UCM found 43\% of students to be food insecure (i.e., had low or very low food security). Broken down by race, those data appear to reflect the national trends. Specifically, $28 \%$ of black students, $15 \%$ of white students, and $13 \%$ of non-black or white students reported low food security. Alarmingly, $54 \%$ of black students, $43 \%$ of white students and $31 \%$ of other students reported not being able to afford to eat balanced meals. Analyzing the data by gender revealed similar statistics. According to the same study, 29\% of females, and $14 \%$ of males reported having very low food security. On the same page, $35 \%$ of males and 
$47 \%$ of females reported not being able to afford to eat balanced meals (Wisconsin HOPE Lab, 2018).

Likewise, current scholarship also indicates that food insecurity is most prevalent among households with incomes below $185 \%$ of the poverty threshold. As previously mentioned, Dubick, Mathews and Cady (2016) indicate that fewer than one in four students could be categorized as having parents who are able to pay all of their college expenses. It is important to note since 2014 the average age of students at UCM is 24 years old. In the same study completed by the Wisconsin Hope Lab (2018), 35\% of students had to borrow money from friends or family to help pay their bills (Wisconsin HOPE Lab, 2018). UCM students reported similar findings by age. Thirty-one percent of students over 30 years old reported very low food security, compared to $33 \%$ of $25-30$ year old students, $27 \%$ of 21 to 25 -year-old students, and $23 \%$ of 18 -20-year-old students. Since 2014, the average amount of Federal Pell Grant money at UCM is $\$ 14,914,966$ (Chen, 2018).

\section{Dining at UCM}

When UCM originally opened in 1871 there were no dormitories. Students lived in boarding houses that surrounded the university and individuals were responsible for their own food; however, most boarding houses provided dinners. In fact, there were no regular dining facilities until almost the second decade of the 1900s.

\section{Boarding houses}

Holden Hall was the first room and board facility, but it was located off-campus in the Estes Hotel. After a fire in early 1915, the university constructed several new buildings. Among the first was the all-male dormitory, Todd Hall. Yeater Hall was the 
first dormitory for women, built in 1941 (A.R. Clifford-Napoleone, personal communication, June 27, 2019).

\section{Dining Culture}

An important component of the history of dining at UCM is the stunning formality embedded within its culture. Manners for eating, collected from the university library's museum, displayed expected behavior for the dinners, including how to pass food, politely excuse oneself from the table, and conduct conversation (Food manners, 1955). The plate-served dining services lasted into the 1960 s.

When the student union and Ellis Hall opened in 1962, modern-day buffet style dining replaced table-service. The Elliot Student Union was a popular place to eat and had open dining service so many community members would go there just to eat. The dining options close to campus were also popular among the students. In the 1990s, the university signed an agreement with Sodexo and stopped producing food in-house. Since then, a variety of restaurants including a Pizza Hut, Taco Bell, Chick-Fil-A, and Steak n’ Shake have provided additional choices for students (A.R. Clifford-Napoleone, personal communication, June 27, 2019).

Today there are a variety of residential dining options available to students. Sodexo offers the Westside Market at Todd and Ellis Halls, Fitzgerald Dining Hall has allergen-free stations, along with vegetarian, vegan and gluten-free options. Students also have an opportunity to purchase different meal plans. Three primary meal plans feature

unlimited dining, guest passes, and dining dollars. A Gold Dining Plan, \$1,775, features unlimited residence hall dining, six guest passes, and \$300 in dining dollars. The Platinum Dining Plan, \$1,975 includes unlimited residence hall dining, eight guest 
passes, and $\$ 500$ in dining dollars. The Silver Meal Plan, $\$ 1,675$, provides unlimited dining, three guest passes, and \$150 in Dining Dollars per semester (Murphy, 2019).

\section{The University Farm}

The agricultural department at UCM has a long tradition of supporting students' needs at UCM. In fact, for over a century, the University's farms have donated vegetables to the campus. The UCM's school newspaper, The Normal Student, recorded the inaugural year of the UCM Farm. Originally developed for experimenting with varieties of corn, rye, barley, oats, and clovers, it also demonstrated the value of crop rotation without fertilization. Of particular noteworthiness are the ten acres of the College Farm that were devoted to raising potatoes for the poor of the county ("Normal farm makes good," 1911). Presently, the college farm donates to the Campus Cupboard; however; Beth Rutt, director of the Student Recreation and Wellness Center, recently redirected those donations to address the critical shortages at the Johnson County Food Center during the summer of 2019 .

\section{History of the Food Pantry}

The Campus Cupboard opened in October of 2013. It was developed through the collaborative efforts of the Office of Student Activities, the Department of Communication Disorders and Social Work, and the Department of Nutrition and Kinesiology, along with an Opportunity Grant from the UCM Alumni Foundation ("Campus cupboard," 2019). However, this was not the first food pantry on campus.

A little-known fact is that the 2013 opening of the Campus Cupboard is a relaunch of UCM's effort to establish a campus food pantry. In fact, the past 150 years displays a profound history of several attempts to create and sustain a food pantry at 
UCM. Reviewing archived documents within UCM's McClure Museum uncovered an extensive history of people being aware of the struggles hungry college students face while attending school. Actually, old campus newspaper headlines report addressing food concerns as early as the 1870 s. Throughout the past 150 years, support for the UCM food pantry's efforts seemed to surge particularly around times of need, such as both world wars, and the Great Depression. Additionally, there are stories relating to abundant support during the Vietnam era and Civil Rights Movement of the 1960s. In the most recent headlines, however, Harvesters, The Community Food Network of Kansas City, recognized the UCM Campus Cupboard with the 2016 Circle of Hope Network Partnership-Missouri Pantry Award (Severance-Weinert, 2016).

\section{Organizational Analysis}

Building understanding of an organization through simultaneous multiple perspectives creates a deeper understanding of the organization as an organic form, "in which needs, roles, power, and symbols must be integrated to provide direction and shape behavior" (Bolman \& Deal, 2013, p. 434). The organizational structure of the UCM Campus Cupboard, as well as its meaning in the context of food insecurity on the university's campus, can best be understood through Bolman and Deal's (2013) structural and symbolic frames. With the intention of specifically examining the practices, people, plans and process, the purpose of this organizational analysis is to combine research, experience, and context to frame the organization amid its complexities and unravel the complexity of the Campus Cupboard (Bolman \& Deal, 2013; Jansson, 2013).

\section{Analysis of the Campus Cupboard through the Structural Frame}

This individualized analysis of the UCM Campus Cupboard begins by examining 
its structural framework. Generally speaking, there are two basic concerns that center the structural design of an organization: the allocation of work and the coordination of effort (Bolman \& Deal, 2013). With this intention, the structural analysis will focus on the roles, goals, policies, communication and environment of the Campus Cupboard not only within the university but also within its community. Because of the ambiguity of food insecurity, it will be helpful to present the logistics of how resources connect to the need of hungry students.

Coordinating Roles. Allocating resources to the specific needs of food insecure students is, "coordinated in two primary ways: vertically through formal chain of command, and laterally, through meetings, committees, coordinating roles, or network structures" (Bolman \& Deal, 2013, p. 51). Understanding how this concept applies to the Campus Cupboard's practice is best accomplished by presenting both the coordination of its roles and the allocation of its work.

Vertical Alignment at UCM. UCM's bureaucratic infrastructure "coordinates and controls the work of subordinates through authority, rules and policies, and planning and control systems" (Bolman \& Deal, 2013, p. 51). A flow chart of the university's departments exhibits the Campus Cupboard under the leadership of Beth Rutt, the Director of Student Activities. Rutt directly reports to Dr. Shari Bax, the Vice Provost for Student Experience and Engagement. Dr. Bax reports to the University President, Dr. Roger Best, as well as the Board of Directors.

Financially, the term pooled coupling is an additional conceptual scheme that explains the interdependencies of the food pantry with the five principal areas of Dr. Bax's responsibilities that include student services, student auxiliary services, public 
safety, student activities and student recreation and wellness center, and the center for multiculturalism and inclusivity. In simple terms, these pooled members share common resources, but are otherwise independent (Manning, 2013; Mintzberg, 2005). The student activities budget, with donations from the UCM Foundation, generates the financial resources UCM is able to provide to the Campus Cupboard.

To delineate the structural chain of command, this analysis will employ Mintzberg's 1979 Model of The Five Basic Parts of an Organization (Mintzberg, 2005, p. 223). Formally, Rutt and Bax are charged with the overall responsibility for the Campus Cupboard; however, because of Rutt's diplomatic status within the university and community, she has artfully negotiated across boundaries to construct a small cadre of her close peers and colleagues to round out the Strategic Apex of the food pantry (Bolman \& Deal, 2013; Mintzberg, 1979/2005). This small cohort of peers and colleagues collaborate to make strategic and logistical decisions involving the food pantry, such as applying for a seminal Opportunity Grant. These original members include Ms. Jean Nuernberger (School of Human Services), Dr. Swarna Mandali (Nutrition and Dietetics), Dr. Mary McCord (Business Management) and Dr. Chuck Ambrose (Former UCM President). The current UCM President is Dr. Roger J. Best.

The Middle Line (Mintzberg, 1979/2005). Rutt has served as the Director of the Student Recreation and Wellness Center at UCM since 2003. Under her direct supervision are two assistant directors who have formal authority over their individual operations, but also serve as an informal middle line to the operating core of volunteers and graduate assistants who oversee the operations of the Campus Cupboard (Mintzberg, 1979/2005). Dan Plott is the Assistant Director of Student Activities. Kevin Smead is the 
Assistant Director of Intramural and Recreational Sports. In addition, Alice Dempsey is the accountant for Student Activities and Eliza Ridenhour is the current graduate assistant who oversees the operations of the Campus Cupboard.

The Technostructure (Mintzberg, 1979/2005). An additional structural component is the technology operations team. This group of individuals provides technical support to the Campus Cupboard by maintaining their website, advertising, and coordinating technology systems to help manage demographic information of the Campus Cupboard clientele. In addition, the technostructure also helps standardize the donation process to the university through the alumni foundation by implementing a donation button on the Campus Cupboard webpage that allows anyone to easily contribute to the mission of the food pantry.

The Support Staff (Mintzberg, 1979/2005). There are roughly 60 volunteers who work intermittently throughout the year in a variety of roles and positions. The Campus Cupboard is a popular location for Greek Life, as well as community and religious organization volunteers. As part of her managerial duties, Eliza Ridenhour directs the volunteer effort and organizes the times and hours of volunteer work.

Lateral Networking. Because the theme of hunger involves such a wide variety of people at UCM, the Campus Cupboard has become a "multicentric firm whose initiatives and strategies often emerge from many places, taking shape through a variety of partnerships and joint ventures outside the traditional hierarchy" (Bolman \& Deal, 2013, p.56). Therefore, the structural analysis will include an overview of the "horizontal linkages that supplement and sometimes supplant vertical coordination" (Bolman \& Deal, 2013, p. 56). 
Since its inception, a diverse gathering of university offices, departments, foundations, services, employees, and staff have cooperated with community and regional organizations and businesses to establish the Campus Cupboard as it stands today. Bolman and Deal (2013) specifically presented a representative model that illustrated these, "more decentralized and interactive lateral forms of coordination that are often needed to keep top-down control from stifling initiative and creativity" (p. 57). This more unofficial network creates multiple connections that allow for lateral communication to flow through meetings, committees, coordinating roles, or network structures, creating what organizational theorists call, Helgeson's web of inclusion. This multiple connection network allows people to talk freely, make decisions, touch base, and also lends to maintaining a high morale among its participants (Bolman \& Deal, 2013). Moreover, the all-channel network includes the UCM Office of Student Activities, The Department of Communication Disorders and Social Work, the Department of Nutrition and Kinesiology, The UCM Alumni Foundation, Shiloh First Baptist Church, Harvesters, Feeding America, and Sodexo Food Services. Sodexo provides food to the campus dining halls. At the end of the day leftovers are sent to the Campus Cupboard where they are repackaged in single-serving containers (Severance-Weinert, 2016),

Communication and Coordination. The informal network allows a free flow of information that drastically reduces uncertainty (Bolman \& Deal, 2013). In fact, outside of the Student Recreation and Wellness Center's weekly meetings between Rutt and the assistant directors, who discuss the food pantry among other agenda items, most of the communication regarding the Campus Cupboard is done in informal meetings, emails, phone calls, and text-messages. An example of more formal communication may be an 
email between Rutt and the Crisis Information team who may ask if a certain student is on their radar. In fact, these informal meetings and exchanges are the cornerstone of the lateral coordination that holds the Campus Cupboard in place (Bolman \& Deal, 2013). Similarly, the harmony between the vertical structure and lateral coordination of the Campus Cupboard create a flexible and polycentralized organization of trust, and common goals that allow for on-the-spot discussion, as well as the dynamic ability to practice discretion, spontaneous coordination, and interdependence among the groups (Perrow, 2009).

Technology. Structurally, the use of technology has enabled more widespread access to information like clientele demographic data, patterns in Campus Cupboard traffic, and course scheduling and shift changes. Specifically, communication technology such as email, the internet, social media, and networking groups, have provided communication across bureaucratic levels and involve a more diverse population to volunteer or to participate as clients (Manning, 2013). To illustrate, in April of 2019, 430 individuals swiped I.D. cards and made 784 visits to the pantry. As a result, hours were adjusted to be compatible with semesters, classes, as well as employee shift work (Severance-Weinert, 2016).

Goals. The Campus Cupboard is a volunteer-based, 501(c)(3) charity dedicated to alleviating hunger and financial burdens in the University of Central Missouri community. Among its charges is that the organization provides food and personal care items for its clients (“Campus Cupboard,” 2019). UCM allows for multiple goals to provide individualized instruction and preparation for their 11,000 students. In fact, "The reality of multiple goals means that the institution can adopt a new direction without 
fundamentally changing the college or university's mission and purpose" (Manning, 2013, p. 23). In a magazine article examining the Campus Cupboard, Rutt indicated one of the goals of the food pantry:

Where in Warrensburg, could you eat for $\$ 4$ a day? If you look at that as $\$ 4$ per day for five days, that's $\$ 20$ a week we've been able to put back into someone’s pocket, and for a month, it's $\$ 80$ that hasn't had to be spent on food. For an employee that's gas money to go to and from work. Or maybe they have a child who now can take piano lessons or go on a field trip. By saving one meal a day, we're affording opportunities that person would not have. (Severance-Weinert, 2016)

Although this may be one of the less visible goals of the university, Bolman and Deal (2013) argued that these less visible goals often champion character development or excellence that honor the university's visions for their graduates. On that same note, Manning (2013) added that larger institutional purposes can be achieved simultaneously because multiple, even conflicting, goals exist within the same institution. A concrete example of this in higher education is establishing longer degree programs. Economically speaking it is more salient to keep the students and their families paying into the institution; however, ethically, developing degree pathways that graduate students in four years or less connects students to the principle goal of higher education. Likewise. what appears to be chaos may actually be a symphony of synchronized efforts. Other scholarly contentions include the awareness that systematically chaotic organizations are more adaptable because they distribute their effort in several, rather than one, areas allowing numerous societal purposes to be achieved at the same time (Bolman \& Deal, 2013; 
Manning, 2013). The Campus Cupboard's discreet goal of providing for the hungry not only fits into the larger mission of the university but champions the development of its students through empathetic community involvement and selfless leadership.

Policies. Higher education policies are traditionally seen as a way of standardizing operation, limiting individual direction or helping to ensure predictable behavior (Bolman \& Deal, 2013). Structurally, these policies are in place to communicate, realign, and establish patterns; however, working in such large institutions' structural policies often sow loss of direction, lack of clarity, or confusion for overwhelmed students. For example, the process of handling student financial aid is not clear to incoming students, who end up coordinating the necessary conversations between the loan office, the financial aid office, and the registrar's office.

At times, different institutions within higher education have varying opinions regarding whether students should be considered clients, customers, or learners, and these circumstances make it difficult to determine the basic nature of the higher education client (Bolman \& Deal, 2013; Manning, 2013). The Campus Cupboard's unique acknowledgment of conflicting ideas about who the clients are, how they are to be served, and what they are to be served transforms their policies from this traditional structural perspective. Operation, participation and decision-making policies within The Campus Cupboard have been designed to create transition, develop new skills, become involved, and add psychological support to their clientele (Bolman \& Deal, 2013).

Operating Policies. The policies set in place for food process and handling are largely drafted through Harvesters and the Feeding America Network. These policies structurally guide employees' standard operating procedures, limit individual discretion, 
govern conditions of work, create time frames for decisions, and specify standard ways of handling food and relating to clientele (Bolman \& Deal, 2013; Mintzberg, 2005). For example, Campus Cupboard volunteers must first pass a food handler training course for individuals working in facilities with an overview of food safety issues, regulations, and techniques to maintain a food-safe environment. Such policies like monitoring logged temperatures or repackaging food items on stainless steel countertops assist employees in understanding how correctly handling food reduces health risks (Food Handler Training, 2019). Although there may be a tension between employee discretion and policy, by and large these guidelines are designed to minimize the risk of storing food.

Decision Making Policies. Interpreting the structure of the university organizational leadership chart, the hierarchical influence of positional power gives way to the Campus Cupboard's flattened network. Here, a variety of expertise produces strong norms and aids in identifying problems from multiple perspectives. Likewise, open channels of communication and positive attitudes support dialogue and focus problem solving (French \& Raven, 2005; Levi, 2017). Specifically, the Campus Cupboard enjoys a decentralization in their decision making, in contrast to the traditional university centralized decision making, policy standardization, and control (Manning, 2013). Although decisions like hours of operation are made after studying trends in class times and shift changes for UCM employees, the application of those policies are made in simple parking lot meetings instead of formal board rooms. This freedom from micromanagement allows Rutt and her colleagues to concentrate on defining the best ways to serve the clientele (Manning, 2013). 
Participation Policies. The success of the Campus Cupboard has drawn local media attention. In a 2016 interview, Rutt was quoted, "With Harvesters, our agreement is that no one is turned away. All they need is a university ID, and we just swipe the cards, I don't stop you at the door; there's not a lot of paperwork" (Severance-Weinert, 2016). This simple, straightforward action planning in place of performance control is designed to empower hungry students (Mintzberg, 1979/2005). Likewise, Campus Cupboard serves the University of Central Missouri campus community. Any UCM faculty and staff member or student who presents a valid UCM ID may select 10 items per week from Campus Cupboard ("Campus cupboard," 2019). The limit prompts students to be savvy shoppers, combining items in ways that provide nutrition and variety (Severance-Weinert, 2016). From a structural standpoint, governing conditions allow the food pantry to relate to their clientele and help customers engage with the expertise of key members of the community (Bolman \& Deal, 2013).

Environment. The transient nature of student populations creates a turbulent environment for the university. Frequently postponing or interrupting their attendance, enrolling in various ways, and attending more than one college or university at a time creates substantial variables for the university to monitor in its environment (Bolman \& Deal, 2013; Manning, 2013). Due to its open structure and flexible network, the Campus Cupboard has employed mechanisms such as environmental scanning to monitor what is happening in its environment to be better prepared for problems in the future (Levi, 2017; Tierney, 2012). As a result of a 2019 Wisconsin Hope Lab Study on the Basic Needs of students at UCM, it is known that about $56 \%$ of students experienced at least one form of basic needs insecurity (homelessness, housing insecurity, or food insecurity) in the past 
year. About 3.5\% experienced all three forms of basic needs insecurity. In the fall of 2017, the Wisconsin HOPE Lab collected data from 28,408 students attending 42 different four-year colleges and universities. Specifically, UCM's 43\% food insecure student population was $7 \%$ higher than the national average of the 42 schools in their study (Wisconsin HOPE Lab, 2018).

Organizational theorists argue universities are, "nonprofit and tuition dependent with relatively few sources of income, [thus] changes in the environment can have a harsh and rapid impact” (Manning, 2013, p. 19). Because environmental vulnerabilities such as these introduce complexity and anarchy into organizational structure, scholars highlight the importance of developing alliances (Hess \& Lautzenheiser, Daniel, 2012; Manning, 2013). To illustrate, UCM offers nutrition counseling; food sampling; classes in cooking; health sciences and personal finance; plus, a variety of degree programs such as dietetics, community health and nursing. Collectively, these programs make a difference in fighting food insecurity through their own unique approach and provide a concrete example of how seemingly chaotic individual efforts actually generate a harmonious energy by educational degree conferring institutions (Severance-Weinert, 2016).

Structural Conclusion. The structural framework of the UCM Campus Cupboard, like a building's framework, "both enhances and constrains what an organization can accomplish" (Bolman \& Deal, 2013, p. 47). The delicate combination of vertical coordination and lateral communication lend to the decentralization of decisionmaking (Bolman \& Deal, 2013). A simple analogy would be an inverted ' $\mathrm{T}$ ' where the hierarchal tower of the Campus Cupboard is supported by a flattened network of well- 
coordinated expertise, high-morale, and community commitment to volunteerism that help shape the roles, goals, polices, and flow of communication. Structurally, the Campus Cupboard remains buoyant within the turbulence of the university's food insecure environment, maintaining its ability to connect resources to the needs of hungry students, thus calming the rolling seas that hinder their ability to arrive safely in the port of graduation.

\section{Analysis of the Campus Cupboard through the Symbolic Frame}

This analysis of the UCM Campus Cupboard concludes with an examination of its symbolic role within the university and the Warrensburg community. Specifically, "the symbolic frame focuses on how humans make sense of the chaotic, ambiguous world in which they live" (Bolman \& Deal, 2013, p. 244). Given this understanding, this symbolic analysis will focus on the culture and symbolism behind the Campus Cupboard with the intention of "interpreting and illuminating the basic issues of meaning and belief that make the symbols so powerful" (Bolman \& Deal, 2013, p. 247).

Culture. As a starting point, the Campus Cupboard is both a product of the university and a process that defines the cultural lens through which we can view its meaning (Bolman \& Deal, 2013). The inextricably intertwined formal and informal structures of the Campus Cupboard define the relationship between the soul and ethics of UCM's culture and, in turn, affects the way it operates (Bolman \& Deal, 2013; Levi, 2017; Tierney, 2012). Culturally, the Campus Cupboard exposes UCM's core values in two ways. First, by defining the university's sense of "responsibility to enrich each student's perspective through a cumulative experience that starts with academic rigor and integrates applied learning and servant-leadership opportunities" ("UCM mission and 
vision,” 2019). Secondly, the Campus Cupboard outlines the university's ability to "[engage] students with multiple sources of learning and creating a dynamic environment that encourages individuals to find their passions and reach beyond themselves" ("UCM mission and vision," 2019). Ultimately, the Campus Cupboard exemplifies a bedrock sense of core values as, "a critical element in the long-term success of organizations" (Bolman \& Deal, 2013, p. 398).

Product. As a product, the Campus Cupboard exists as a means to its own end. Regardless of the national trends in college student food insecurity, the bottom line is that there are students within the UCM family who experience various levels of food insecurity, who borrow money to pay their bills, and who suffer from other forms of basic need insufficiency, in some cases upwards of $43 \%$ of the student population at UCM (Wisconsin HOPE Lab, 2018).

In a recent interview, Rutt pointed to the university-wide unity and pride that the Campus Cupboard has inspired, "Although more than 300 colleges now are active members of the College and University Food Bank Alliance, UCM was one of the earlier institutions to provide this service" (Severance-Weinert, 2016, p. 9). Because food insecurity affects college communities in such a variety of ways, its solutions are often significantly ambiguous. It is in these undefined moments where "lack of clarity is apparent and the point is less to try to clarify the situation than simply exist with it" (Tierney, 2012). The Campus Cupboard represents the deeper issues of faith, purpose, compassion and concern for others which is the "ethical glue that holds a family together in a caring community" (Bolman \& Deal, 2013, p. 401). 
Meaning. The Campus Cupboard is not heavily advertised; however, most people know of its humble existence. Although a simple metaphor, its location helps shape its "unique identity and character" (Bolman \& Deal, 2013). To explain further, the Campus Cupboard is modestly located in the basement of the student recreation and wellness center. Just off of one of the basketball courts in the main facility, the cupboard has access to an outside entry door. From here, people can enter and leave without walking through the exercise equipment or intramural activities. Symbolically, it has a similar presentation to hunger on the campus of UCM. Most people know that many students are hungry, and acknowledge it, but most people just carry on about their day without having to walk through it. Its place on the campus is similar to hunger's place in the lives of many students. It is just not advertised, but it is there.

The entrance is a meaningful transition for its clients and volunteers. It reassures the community that hunger does not have to be advertised, but it conveys the message to external constituencies that struggling with hunger does not have to be hidden either. The Campus Cupboard's modest existence is important. Within the laid-back county lifestyle of its mid-Missouri surroundings, it fits right into the role of a familiar back-door friend. Where the door is always open, there is no formality of a grand entrance or bureaucratic paperwork to slow things down. Everyone is welcome, no-one is judged, and everyone knows they will be taken care of at UCM (Bolman \& Deal, 2013; Schein, 2005).

Ritual. Depending on the schedules of Sodexo and the deliveries from Harvesters, Aldi and Walmart, several deliveries are made to the Campus Cupboard every week that strongly symbolize the basic elements of the culture of this operation and shape the Campus Cupboards' unique identity and character. These weekly food deliveries require 
manpower that is difficult to find in an environment where employees are facing high turnover, tight resources, and people worrying about losing their jobs (Bolman \& Deal, 2013). In the beginning, Rutt would often unload trucks herself, but over the course of the Campus Cupboard's lifespan, it has become normal to see the assistant directors stopping their daily routines to help unload the trucks alongside grad assistants or whoever else may be there. The ritual has gained so much steam over the past years that Rutt does not need to ask anyone to help. The trucks just get unloaded (Levi, 2017). "The thing that's been really good is that we've been able to take one initiative and cross the disciplines of the campus," Rutt says. "There's lots of engagement, not just the social work department, not just dietetics, not just student activities. There's a family feel to it. It truly is a collaboration" (Severance-Weinert, 2016, p. 9). In sum, voluntarily assisting the Campus Cupboard has become a habit and a statement of belief in UCM's mission.

Process. Analyzing the symbolic process of the work behind the Campus Cupboard portrays the belief and faith of the communities that drive its cause (Bolman \& Deal, 2013). The Campus Cupboard grounds its process in providing a hand up not a hand out, which prevents a traditional and fairly common misunderstanding of philanthropy Johnson (2018) called the tin cup approach. Because it appeals to a surface level sense of good-will towards those less fortunate, Johnson (2018) denounced this perspective for the division that it creates between those that have and those that have not. "The act of helping--of being able to help--affirms the social distance between the two groups and heightens everyone's awareness of it" (Johnson, 2018). The Campus Cupboard manages to accept and honor help without highlighting disparity in prosperity. 
The Campus Cupboard possesses a unique process that displays its emotional intelligence as an entity within UCM. For example, advertising for the Campus Cupboard is personal, modest, caring, and largely informal. Sometimes it's even hard to find. A small excerpt in daily corporate style emails sent to employees mentions that if you know of any fellow co-workers and people in need here is the least restrictive environment. Additionally, flyers are sometimes posted near the building managers' time clocks in campus buildings that mention the Campus Cupboard's hours. Likewise, its reduced paperwork, demographic tracking, and the no questions asked policy demonstrates selfawareness, empathy, and relationship management skills that empower clients to advocate for themselves and transition into a position of self-sustainability (Levi, 2017).

The Collective Influence. There are several other missions and non-profit organizations clustered around the Warrensburg, MO community that provide services for people struggling with not only food insecurity, but housing insecurity and mental handicaps as well. The Campus Cupboard also works with the Warrensburg Community Food Pantry as well as other non-profits to help complement each other. For example, The Shiloh Missionary Baptist Church's Man of Harvest program offers free dinner five nights a week. The Campus Cupboard often sends kids there to eat, where they get a hot meal at no cost. Although it is difficult without transportation, the harmony between the organizations speaks to the fact that these philanthropic endeavors are "worth doing-a calling that adds something of value to the world" (Bolman \& Deal, 2013, p. 381). These opportunities to collaborate and build long-term relationships reflect the values and ethical principles that allow people the ability to see the world from the vantage point of others (Bolman \& Deal, 2013; Levi, 2017). 
Battling perceptions. One of the most difficult obstacles to overcome is the feeling of embarrassment or the social stigma behind using a food pantry's services (Farahbakhsh et al., 2017; Freudenberg et al., 2011; Hanbazaza et al., 2016; Twill et al., 2016; Vaterlaus et al., 2018). Symbolically, this poses a significant barrier to connecting students in need with the resources available. One of the criticisms Rutt and her team face is the perception that UCM does not need a food pantry. Many of these critics draw the conclusion that if students are in college, they can afford food. The traditional misconception that all college students belong to a certain social class may shed light onto why these critics believe people are using the food pantry, but do not really need it. As a result, the complex dynamic between the school, workplace, and community seem to collide with those misconceptions around the Campus Cupboard and produce consequences that include privilege and oppression. In the end, battling these perceptions creates a sense of moral urgency and social justice that compels school reformers to focus on the quality of America's universities (Hess \& Lautzenheiser, Daniel, 2012; Johnson, 2018).

Stories. For years, the Campus Cupboard has been the staging point for several stories turned legend. Communicating acts of tremendous empathy, mutual respect, and noteworthy generosity, the Campus Cupboard stories illuminate the vision of servant leadership, passion, and community engagement, which the university represents (Bolman \& Deal, 2013; “UCM mission and vision," 2019). The rich culture of the Campus Cupboard can be lost if one only examines the quarterly numbers. Thus, stories about taking groceries to hungry students who later make donations to the Campus Cupboard, and about families who donate their time to the cause are shared and passed 
down from one generation of students to the next in order to communicate core values, socialize and convey the view point of others and revitalize the culture behind the Campus Cupboard (Bolman \& Deal, 2013; Severance-Weinert, 2016).

Symbolic Conclusion. An analysis through the symbolic frame is an important perspective to consider in analyzing the role of UCM's Campus Cupboard. Operating within a large food insecure community, the Campus Cupboard carries a powerful intellectual vision and emotional message, speaking to both the mind and the heart of the Warrensburg community (Bolman \& Deal, 2013). Because the Campus Cupboard's process of fighting food insecurity among its college students and community is one of humility, service and empathy, it is an influential symbol among its clientele and is gaining a strong reputation across the campus and Missouri. Unfortunately, college food pantries also symbolize inequality in student experiences once they gain access to higher education. To that end, some scholars argue against campus-based food pantries, calling instead for reductions in tuition costs, student funding, and loan assistance. While politicians debate long-term solutions to a very real-time problem, it is essential that universities find user friendly support systems for students in need (Dubick, et al., 2016; Farahbakhsh et al., 2017; Freudenberg et al., 2011; Hanbazaza et al., 2016; Jablonski et al., 2016; Vaterlaus et al., 2018; Zein et al., 2018). Ultimately, the Campus cupboard's clever and humane approach is going to look at how the Campus Cupboard is approaching students' needs. In the end, one thing is certain: "the only way to change the outcome is to change how we see and play the game and, eventually, change the game itself and its paths of least resistance (Johnson, 2018, p. 73). For the present, the Campus Cupboard is a gamechanger in the lives of the UCM students and the university itself. 


\section{Leadership Analysis}

This leadership analysis begins by examining the servant leadership of the UCM Campus Cupboard. Overall, there are three basic elements at the heart of servant leadership: antecedent conditions, servant leaders behaviors, and outcomes (Northouse, 2016). Specifically, this leadership analysis will focus on the antecedent process of how context and culture combined with unique leader attributes lead to empowerment and the creation of value for the community that ultimately produces societal impact (Northouse, 2016). Due to the ambiguous nature of food insecurity and the turbulent environment in which it thrives, the three basic elements delineate how the Campus Cupboard impacts its community. The history of food insecurity at UCM, coupled with national trends, creates the need for servant leaders at UCM to empower others to become healthier, wiser, more autonomous, and more likely to become a servant themselves (Greenleaf, 1970).

Essentially, the UCM Campus Cupboard community is not only defined through its acts of service, but how its leadership empowers others to continue its legacy (Beck, 2014; Northouse, 2016).

\section{Antecedent Conditions}

Some people are leaders because of their position while others become leaders because of the situation (Northouse, 2016). In this particular study, food insecurity among UCM students colliding with the philanthropic culture of the university highlights the unique harmony between the context, culture, and leadership attributes that serve as the preamble to the current state of the Campus Cupboard. Likewise, there are several leaders woven into this environment whose specific attributes help connect resources to needs. In addition, the welcoming environment of the Campus Cupboard created by the 
approachability of its staff creates a positive receptivity of its role in the community, allowing it to thrive.

Context and culture. Dining at UCM has always been a part of its cultural identity. During the early 1900s, students boarding houses surrounding the university offered a plate-service dining experience for university students. It was not until the mid 1960s that the university incorporated a more modern buffet-style cafeteria. Presently, renovations to the student union have brought fast-food style options for students and offer some alternatives to the traditional dormitory meal plans.

Leader attributes. Because there are countless approaches to leadership, many scholars argue, "different types of leaders are useful in different situations" (Levi, 2017, p. 201). Upon analysis of the various leaders' responsible for navigating the Campus Cupboard, this notion holds true. Although the director of the Student Recreation and Wellness Center holds the formal position of authority, she shares leadership of the Campus Cupboard. The power behind various members of the community performing leadership functions encourages participative decision-making, emboldens developing social relations and support, and most importantly sparks empowerment (Levi, 2017). On the ground, there are several actions performed by a variety of leaders that ensure the success of this effort to reduce UCM student hunger. Within the Campus Cupboard environment, servant leadership is widespread and is often demonstrated by the attributes of a "strong moral compass, emotional intelligence, and self-determinedness" (Northouse, 2016, p. 232).

Strong moral compass. One leader attribute that defines the culture of servant leadership is the strong moral compass guiding the Campus Cupboard Community. 
Leadership from this perspective is not relegated to formal positions of authority, but rather spread out in order to develop social relations, create support and spark empowerment (Levi, 2017). An example of this notion is the presence of steady confidence in light of the critique that the pantry is misused by people who are not in need of its services. Because the Cupboard's servant leadership is constantly aware of the importance of staying grounded, they are disciplined enough to not accede to the criticism with strict policies on pantry usage. Instead, the Campus Cupboard takes advantage of these critiques to establish long-term and meaningful relationships through the practice of their values and principles (George et al., 2007). For example, the noquestions policy invites students to engage with the Campus Cupboard in a nonjudgmental fashion. As a result, the open-door policy welcomes anyone (Rutt, personal communication, August 27, 2019).

Emotional intelligence. An additional attribute of the servant leadership behind the Campus Cupboard is emotional intelligence. This holds true not only in examining Beth Rutt, but in the team of colleagues, department heads, graduate assistants, and community leaders who share leadership roles within the organization. This attribute not only distinguishes these individuals as understanding leaders, but allows them to take risks, accept feedback, learn from success and mistakes, relate effectively to others, and stay focused (Gill, 2010; Goleman, 2011; Merriam \& Bierema, 2014). Although the purpose of the food pantry is to help reduce the struggle for hungry students facing food insecurity, it takes an additional empathetic nature to provide a sense of dignity to people looking for food. This attribute is no more evident than the thought-process behind how food is packaged within the cupboard. For example, Rutt underwent several periods of 
time where clientele would not take prepared meals in the refrigerator. After listening to client feedback, she became aware of how the packaging prohibited people from seeing the food. Attesting to her humility, Rutt embraced the constructive criticism. Being selfaware enough to recognize the Cupboards impact on others, she purchased see-through lids for food containers. As a result, having the social skills to work around the criticism led to a more productive process for the Campus Cupboard (Gill, 2010; Goleman, 2011; Merriam \& Bierema, 2014).

Self-determinedness. The recent history of the Campus Cupboard grounds itself in a series of symbolic moments that, in hindsight, foreshadow the existence of the Campus Cupboard. More specifically, these flashes of self-determinedness, courage, and honesty connected the values of the community with a deeper purpose (George et al., 2007; Helland \& Winston, 2005). The recent success of the Campus Cupboard can be traced to the combined diligent efforts by the sociology, social work, and communications departments. During this planning period, Rutt served as an unknowing visionary for the pantry at a pivotal moment in its history.

Former university President Chuck Ambrose gave an initial go-ahead for the food pantry. Although Ambrose recognized the overwhelming need and grave importance within the community, due to financial constraints and cutbacks, he was unable to provide any financial support. While most people would have turned back, Rutt and her determined team used the data from the study to apply for a $\$ 5,000$ Opportunity Grant from the University Alumni Foundation. Soon after, Rutt and her team, Dr. Jean Nuernberger, Dr. Swarna Mandali, and Dr. Mary McCord, were able to transform a seldom-used catering kitchen into the Campus Cupboard as well as create a channel that 
allowed donors to give tax-deductible support through the foundation's 501(c)(3) nonprofit status (Northouse, 2016; Severance-Weinert, 2016). Rutt and her team's clear sense of goals and direction amid these set-backs defined their self-determinedness to ultimately help others become healthier, wiser, and more autonomous through their act of service (Beck, 2014; Greenleaf, 1970; Northouse, 2016).

\section{Servant Leadership Behaviors}

The servant leadership style of the Campus Cupboard concentrates on a slow transformational cultural shift which symbolizes, "the core of the servant leadership process" (Northouse, 2016, p. 233). This section of the analysis will concentrate on two behaviors its leaders display that are not only altruistic examples of empowering the less privileged, but also the foundational power of servant leadership. First, empowerment lies in the receptivity of the collective with a focus on a societal impact and, second, the value created by the Campus Cupboard improves organizational performance and follower growth (Northouse, 2016).

Empowerment. Traditionally, when scholars define empowerment in the workplace it refers to the process of giving employees more power and control over their work (Johnson, 2018). Markedly, analyzing the Campus Cupboard will extend the term to its clientele as well. Because the vertical structure and lateral network alignment of the Campus Cupboard creates opportunities for shared leadership roles with a variety of organizations, academic departments, and people, there is more flexible thinking, increased creativity and innovation (Levi, 2017). As an example, the Campus Cupboard transforms its community through acts of service (Beck, 2014). To illustrate this dynamic system, as a service to the entire campus, the Dietetic Student Association teaches 
monthly nutrition classes and organizes tasting tables outside of the pantry. By offering this service, the Campus Cupboard empowers dietetic students to share their knowledge in order to help others and, in turn, the interactions empower clientele to learn and share themselves (Beck, 2014; Johnson, 2018; Levi, 2017; Northouse, 2016).

Comparatively, a well-known legend within the Campus Cupboard community serves as another example of the way the Campus Cupboard empowers its community. The story, and for all general purposes the present-day Campus Cupboard, began with Rutt taking a small bag of groceries to a hungry student doing an internship. After some time, the student's financial situation improved, and the same student wrote a check to donate to the cause of helping others through the Campus Cupboard. Accordingly, establishing long-term and meaningful relationships through practicing the Campus Cupboard's values and principles serves as a prominent illustration of how this community empowers others to become leaders (George et al., 2007; Northouse, 2016; Severance-Weinert, 2016).

Creating value for the community. The servant leadership of the Campus Cupboard grounding their work within the larger goal of UCM creates meaning for its community. "Creating value for the community is one way for leaders to link the purposes and goals of an organization with the broader purposes of the community" (Northouse, 2016, p. 235). Specifically, the Campus Cupboard provides opportunities for students to connect with UCM's mission by encouraging students to transform into, "lifelong learners, dedicated to service" (University of Central Missouri Fact Book, 2017). Ultimately, this is important because the goal of servant leadership and the Campus Cupboard is to serve as a conduit to create more servant leaders through selfless 
service to its community. Defining success through followers' success, the servitude of the Campus Cupboard creates a caring society that puts others first (Beck, 2014).

\section{Outcomes}

Servant leadership is centered around healthy organizations that nurture individual growth, strengthen organizational performance, and produce a positive impact on their community (Northouse, 2016). On one hand, the volunteers and staff of the Campus Cupboard ground themselves in their ability to generate support and care for those struggling to make ends meet. On the other hand, hopeful thinking on the part of the Campus Cupboard's leaders generates hope in its clientele (Helland \& Winston, 2005).

Societal impact. Scholars recognize that food insecurity is rarely an isolated condition; rather, it is a sign of much deeper financial hardship. Consequently, many scholars are calling for increased attention to food insecurity among today's student populations (Cady, 2014; Dubick, et al., 2016; Freudenberg et al., 2011; Kelchen et al., 2017; Zein et al., 2018). One highly visible impact of the Campus Cupboard's servant leadership is established by the remarkable increase in its clientele. As previously mentioned, the Campus Cupboard is experiencing a 1000\% increase in visitors over a two-year span. This escalation indicates its extraordinary impact throughout this struggling population (UCM Campus Cupboard stats, 2018). Because the Campus Cupboard is thriving, it is ultimately benefiting its community.

\section{Leadership Conclusion}

From the broader perspective painted by research, context, and experience, this leadership analysis exposes the selfless leadership guiding the Campus Cupboard 
(Bolman \& Deal, 2013; Jansson, 2013). As displayed through the combined efforts of its leadership, the Campus Cupboard has concentrated on a slow-burning transformation of the campus into a philanthropic culture. Because their servant leadership style has been a grass root effort, led by the organic and altruistic determination of selfless volunteers, the Campus Cupboard continues to empower the less privileged while struggling to earn a college education (Beck, 2014; Helland \& Winston, 2005; Northouse, 2016). Likewise, the shared leadership approach behind the core value of servitude produces fruitful outcomes in the form of individualized services and opportunities in which clients can participate to not only improve their situation but foster hope.

\section{Implications for Research in the Practitioner Setting}

The national trend in food insecurity among college students helps clarify a growing local concern at UCM. Over the past several years there has been a substantial increase in using the UCM Campus Cupboard. Significantly, in 2017 the Campus Cupboard served 1,247 people (UCM Campus cupboard stats, 2018). There is a need to understand the systematic issue at hand. Food insecurity among college students is a public health concern that may have implications for not only academic performance and retention, but also for the mental, physical and emotional health of students (PayneSturges, Tjaden, Caldeira, Vincent, \& Arria, 2018). As a result, this study produces both scholarly and practical implications to impact the Campus Cupboard's services and policies, as well as overall student achievement. First, identifying the unique needs and perspectives of the food pantry customers or potential clients will highlight problematic barriers to student academic success due to food insecurity (Fink, 2017). Another implication for educational leaders searching for diverse solutions to food insecurity is 
understanding which services are most significant to Campus Cupboard clients in order to better meet their basic needs throughout their collegiate experience (Bruening et al., 2016). Exploring UCM food pantry clients' perspectives will also allow the leadership team to expand their current practices to add services that would be beneficial to its clients. Because hunger may be a sign of deeper troubles for today's college student, investigating the perspectives of college campus food pantry clientele is an important step towards improving pantry services, refining the policies supporting student access, and improving student academic achievement through food security (Dubick, et al., 2016; Goldrick-Rab, Richardson, \& Hernandez, 2018).

\section{Summary}

A multiple perspective organizational analysis provides the opportunity for a deeper diagnosis; this, coupled with an analysis of the pantry's leadership, as well as the historical background, sets the practitioner setting for this research. Combining Bolman and Deal's (2013) structural and symbolic frames exposes the architectural design allocating the appropriate resources to food insecurity on campus as well as the meaning behind the organizational culture and its central role in shaping performance (Bolman \& Deal, 2013). Specifically, the arrangement between the vertical coordination and lateral communication of the food pantry bolsters creativity and initiative and functions like an inverted ' $\mathrm{T}$ ' where the flattened network of well-coordinated expertise, morale, and volunteers support the hierarchical structure of resources. As a result, the Campus Cupboard stays afloat within the turbulence of the university's food insecure environment and supports it to connect resources to the need of hungry students. Symbolically, the Campus Cupboard communicates the philanthropic nature of the university; however, it 
also represents the disparity of college student experiences while earning their degrees. Because the Campus Cupboard's process of fighting food insecurity among its college students and community is one of humility, service and empathy, it is a powerful symbol communicating UCM's mission.

The Campus Cupboard's leadership focuses the philanthropic culture of the university through the selfless determination of countless volunteers. The servant leadership of the Campus Cupboard is responsible for providing the most basic needs to the less privileged student population who struggle to earn a college education because of food insecurity (Beck, 2014; Helland \& Winston, 2005; Northouse, 2016). The shared leadership organized behind the core value of servitude produces fruitful outcomes in the form of individualized services and opportunities in which clients can participate to not only improve their situation but, more importantly, foster hope.

Producing both scholarly and practical implications to impact the Campus Cupboard's services, policies, and overall student achievement, this research will identify the unique needs and perspectives of the food pantry clients in order to highlight the problematic barriers to student academic success due to food insecurity (Fink, 2017). Additionally, educational leaders will find diverse solutions to basic food insecurity through understanding which services are most significant to Campus Cupboard clients. Furthermore, exploring UCM food pantry clients' perspectives will allow the leadership team to expand their current practices to add services that would be beneficial to its clients (Bruening et al., 2016). In the end, one could argue that, "the only thing of real importance that leaders do is to create and manage culture and that the unique talent of 
leaders is their ability to understand and work with culture" (Schein, 2005, p. 361). The Campus Cupboard is UCM's symphonic, educational crescendo. 


\section{SECTION III SCHOLARLY REVIEW FOR THE STUDY}




\section{Scholarly Review}

Food insecurity among college students is an important public health concern that may have implications for not only academic performance and retention, but also for the mental, physical and emotional health of students (Payne-Sturges, Tjaden, Caldeira, Vincent, \& Arria, 2018). Following a general overview of food insecurity on a national level, this scholarly review examines college students who are at a greater risk of food insecurity. This review focuses on studies exploring the effects of food insecurity on students' welfare and academic performance.

\section{Problem of Practice}

University of Central Missouri (UCM) students who lack resources for food struggle to learn at the same capacity as other students. Insufficient resources not only undermine postsecondary educational experiences, but delay credit attainment for many of today's college students (Goldrick-Rab, Baker-Smith, Coca, Looker, \& Williams, 2019).

Although federal policy has made tuition more attainable, there is a growing concern regarding the barriers that prohibit student success in higher education. The policies intended to increase access to higher education are now at the center of an intense national debate. Scholars are examining the inequality in higher education, as well as considering living costs and the struggles 21 st century college students face to make ends meet (Broton et al., 2018). While evidence of the relationship between hunger and student success is well established, the literature reflects very little about the perceptions of students who rely on college food pantries. 


\section{Purpose of the Study}

Although campus food pantries are providing emergency support for food insecure students, long-term solutions are still needed. Today's typical student is not a recent high school graduate who lives in a dormitory and is supported by his or her parents. In fact, Dubick, Mathews, and Cady (2016) indicated that fewer than one in four students could be categorized as having parents who are able to pay all of their college expenses. Because of these economic hardships, colleges must gear themselves towards alleviating the needs of college students in poverty. Because hunger may be a sign of deeper troubles, investigating perspectives of food pantry clientele is an important step in addressing students' needs (Dubick et al., 2016; Goldrick-Rab, Richardson, \& Hernandez, 2018).

Understanding the national trend in college food insecurity helps clarify a growing local concern. Over the past several years there has been a substantial increase in the use of the food pantry at UCM. Significantly, in 2015 there were 123 people served; however, in 2017, that number jumped to 1,247 people (UCM Campus cupboard stats, 2018). This dramatic increase indicates a need to understand the systemic issue at hand. Thus, it is imperative that research be conducted to explore the perspectives of food pantry clientele in order to identify the additional needs associated with those students facing a hunger crisis at UCM. Therefore, the purpose of this qualitative study will be to explore the perspectives of food pantry clientele at UCM. The perspectives of food insecure clients of the food pantry will be generally defined as the outlooks of students struggling to meet their basic needs, as well as understanding additional services that can be offered to support students at UCM. 


\section{Theoretical Framework: Human Motivational Theory}

This study will be grounded in Human Motivational Theory which was developed from Maslow's hierarchy of needs (Koltko-Rivera, 2006; A.H. Maslow, 1943).

Additionally, Human Motivational Theory will provide the foundation to discuss the needs of UCM food pantry clientele.

\section{Summary and Evolution of the Theory}

Since Maslow first published his theory almost 80 years ago, it has become one of the most popular theories of motivation found in human psychology literature. The earliest and most widespread version of Maslow's hierarchy is based on his 1943 and 1954 models. The original models include five motivational levels that include in order: physiological needs, safety needs, love needs, esteem needs, and the need for selfactualization (A.H. Maslow, 1943). Current research argues for an evolution from the original hierarchy to a revised version with fluid access to a pinnacle sixth motivational level, known as self-transcendence (Koltko-Rivera, 2006). In this later model, selfactualization can be met prior to meeting other needs. For the purpose of this theoretical review, both models will be included.

\section{Hierarchy of Needs}

Part of the reason Maslow's Human Motivation Theory has maintained its appeal for close to a century is that it provides both a theory of human motives and a theory of human motivation. It classifies basic human needs in a logical hierarchy and relates these needs to general behavior. Maslow proposed structured needs by their probability and appearance (Bridwell \& Wahba, 1976a). In the 20th century, evolutionary psychology accepted the view that there were "primary drives," such as hunger and thirst and these 
primary drives, present early in life, provide the foundation for later "secondary drives" that are learned via simple conditioning principles. At the core of Maslow's theory of motivation are two important ideas: (a) there are multiple and independent fundamental motivational systems and (b) these motives form a hierarchy in which some motives have priority over others (Kenrick, Neuberg, Griskevicius, Becker, \& Schaller, 2010).

The physiological needs. "It is quite true that man lives by bread alone- when there is no bread" (Maslow, 1943, p. 6). The needs that are usually taken as the starting point for motivation theory are the physiological drives. In 1943, Maslow referred to this level of his hierarchy as the major motivation above all others. A person who is lacking food, safety, love, and esteem would most probably hunger for food more strongly than for anything else (A.H. Maslow, 1943). So essential are these needs to the theory that, seventy years later, scholars argue, "basic needs are the essential part of a body. They provide energy, light and life to all the beings" (Ghafoor, 2012, p. 1).

The safety needs. "Just as a sated man no longer feels hungry, a safe man no longer feels endangered" (Maslow, 1943, p. 8). Once people meet their basic physiological needs, Maslow suggested that safety needs become the next priority. Later research proposed the idea that human beings have motivational systems for dealing with threats, including learning associations for stimuli that threatened our ancestors. Today, modern psychologists stress religion, safety protocols, and laws that organize the world against unimageable or other dangerous occurrences to shield us from harm (Kenrick et al., 2010; Maslow, 1943; Tikkanen, 2009) and although the terms safety and security differ, the word insecurity in relation to food highlights the delicate line between them, especially when considering how people feel or react to food insecurity (personal 
communication C.J.Schott, 2019). Human flight response argues it is better to unnecessarily flee a misperceived potential threat than to mistakenly remain in a dangerous situation.

The love needs. "He will hunger for affectionate relations with people in general, namely, for a place in his group, and he will strive with great intensity to achieve this goal" (Maslow, 1943, p. 9). In his original theory, Maslow places great importance on people's hunger for affectionate relationships with others, and the importance of finding a place within social groups with the same yearning of hunger or love. Eisenberger, Lieberman, and Williams (2003) bolstered this argument by highlighting the manifestation of physical pain as a result of social rejection. Although Maslow treated the needs for love, affection, and belongingness as a single category, there is some argument as to their place on a rigid scale. Kenrick et al. (2010) suggested these social motivations differ from physiological and safety needs in that they are not absolutely necessary for personal survival. Oved (2017) highlighted their importance, citing people who have endangered their own lives by casting aside their safety needs for the chance of keeping their beloved friends, lovers or family members from harm. In sum, progressing through the hierarchy, the lines defining ultimate self-actualization become less explicit and more implicit.

The esteem needs. Maslow originally suggested these needs may be classified into two subsidiary sets. The first being the desire for strength, for achievement, for adequacy, for confidence in the face of the world, and for independence and freedom. The second set being the desire for reputation or prestige, recognition, attention, importance or appreciation. According to Maslow's original theory, satisfaction of the 
self-esteem need leads to feelings of self-confidence, worth, strength, capability and adequacy of being useful and necessary in the world (A.H. Maslow, 1943). Significantly, when the need for social approval increases, individuals' fear of being judged negatively also increases and they prefer to withdraw themselves from social environments (Karasar \& Baytemir, 2018). Therefore, a motive to solve or master novel problems is likely to facilitate the attainment of status and others' esteem, with consequent implications for reproductive fitness (Kenrick et al., 2010).

The need for self-actualization. "What a man can be, he must be" (Maslow, 1943, p. 382). Self-actualization is presented as the pinnacle of human development in this early theory. Although the manifestation of self-actualization may take many forms, Maslow argues that the emergence of self-actualization needs relies on the satisfaction of the previous physiological, safety, love and esteem needs (A.H. Maslow, 1943). Later models of motivation theory present a renovated pyramid of needs that combines ideas from Maslow's original theory and life history theory. One feature of the renovated pyramid is that what Maslow called self-actualization was removed from the top of the motivational hierarchy. Recent research suggests that self-actualization is not separate from social motives, but intimately linked to the need for esteem (Krems, Kenrick, \& Neel, 2017b).

Self-transcendence. Evolutionary psychology pushes the limits of Maslow's original model, arguing the unlikeliness that "human beings would be designed to have as their highest goal going off to play their guitar or write poetry for its own sake" (Kenrick, 2017, p.521). Current theoretical literature supports the perspective that higher motivations, such as self-actualization and self-transcendence, "can appear as the 
dominant motivations in individuals who seem not to have firmly resolved the needs for survival, safety, and so forth (Koltko-Rivera, 2006, p. 309). The reorganization of the pyramid links self-actualization with self-esteem and places self-transcendence in the form of parenting at the pinnacle of the pyramid.

\section{Theoretical Conclusion}

Many consider Maslow to be ahead of his time (Kenrick, 2017). However, the inherent problem that a lesser need must be resolved before one can address a subsequent need produced additional models of the theory. Today, evolutionary psychology incorporates a dynamic hierarchy that allows needs to overlap at the same time instead of adding an additional level to the pyramid.

\section{Trends of Food Insecurity.}

The Supplemental Nutrition Assistance Program (SNAP, formerly known as the Food Stamp Program) has increased over the past 20 years as non-food assistance programs have declined. One way to understand the level of food insecurity in the United States is by examining the usage statistics from the nation's largest network of federal aid dedicated to food insecurity. Another way to understand the problem is by recognizing whom poverty and food insecurity affects.

\section{National Demand}

The four largest programs, SNAP, the Special Supplemental Nutrition Program for Women, Infants, and Children (WIC), the free-and reduced-price National School Lunch Program (NSLP), and the free-and reduced-price School Breakfast Program (SBP), have a combined budget of almost $\$ 100$ billion (Gundersen \& Ziliak, 2018, p. 120). Specifically, over the past decade, SNAP (Supplemental Nutrition Assistance 
Program) has more than doubled its distribution of benefits. Although SNAP reaches every corner of the United States, poverty and food insecurity are still extensive across the nation.

Most research methods in the field have yielded results based on sociodemographic information. These data are important in order to focus the expanding network of regional and community-based food banks to work alongside SNAP. Most studies concentrate on grouping their findings by household employment and income, households with children, race, and geography.

Household employment and income. Household income draws a fairly defined line in the sand between households that tend to use supplemental food sources like SNAP and or food pantries and those that do not. For example, 36.8\% of households with annual incomes below the official poverty line were food insecure, compared with 5.8\% of those with incomes at or above 185\% of the poverty line (Coleman-Jensen et al., 2017, 2018). Key points such as these are important because they indicate where efforts to mitigate food insecurity through policy may be most effective.

Households with children. Substantially higher rates of food insecurity are found in households with children in comparison to households without children" (Gundersen \& Ziliak, 2018, p. 121). In 2015, "14\% of all Americans, or more than 48 million people, lived in food insecure households. Nineteen percent of all households with children experienced food insecurity" (Cafer, Chapman, Freeman, \& Rikoon, 2016, p. 1). Additionally, the United States Department of Agriculture reports that during 2017, 7.7\% of U.S. households with children (2.9 million households) were food insecure (ColemanJensen et al., 2018). Although the number of households with children affected by food 
insecurity is striking, the problem is not evenly distributed. This is because the national numbers are difficult to interpret without considering the concentration of food insecurity within certain states and counties. For example, "some counties, especially along the Texas-Mexico border, have rates above 40\%" (Craig Gundersen \& Ziliak, 2018). Two recent national studies indicated the burden for food insecurity is higher among single parent households. From these findings, single income households are at a greater risk of food insecurity than two income households (Coleman-Jensen et al., 2018, 2017).

Race. Recent reports indicate that food insecurity is most prevalent among households with incomes below $185 \%$ of the poverty threshold. According to ColemanJensen et al. (2017) (30.8\%) of the population is considered below the poverty threshold. The prevalence of food insecurity in 2018 was higher than the national average for households headed by Black non-Hispanics (21.8\%) and for Hispanics (18\%) (ColemanJensen et al., 2017). In contrast, the prevalence of food insecurity was below the national average for "White, non-Hispanic households (8.8\%); households headed by nonHispanics of other, or multiple, races (9.9\%); and households with incomes above $185 \%$ of the poverty line (5.8\%)" (Coleman-Jensen et al., 2017, p. 13).

Geography. As reported by the US Department of Agriculture, between 2015 and 2017 statistics at the state level estimated that food insecurity ranged from $7.4 \%$ in Hawaii to $17.9 \%$ in New Mexico. Noteworthy, places with higher food costs also tend to have higher levels of food insecurity (Goldrick-Rab et al., 2018). The previous years' findings indicated that across residential classifications, food insecurity was higher than the national average for households in metropolitan areas (13.8\%) and in nonmetropolitan (rural) areas (13.3\%); and lower for households in suburbs/exurbs and 
other metropolitan areas outside principal cities (9.4\%) (Coleman-Jensen et al., 2017). In the Midwest, $15.4 \%$ of households were considered food-insecure, and among those, 7.7\% were households with children (Coleman-Jensen et al., 2018).

\section{National Supply}

As the largest network in the United States, the Feeding America network distributes over 3.3 billion pounds of food and grocery items through 202 food banks in all 50 states, Puerto Rico, and Washington, DC each year (Feeding America annual report, 2017). Additionally, "we estimate that the Feeding America network is currently serving 46.5 million unique individuals in 15.5 million households annually across the United States" (Weinfield et al., 2014, p. 44). Private and non-profit organizations represent the front line of service, in an effort to provide a non-threatening, and culturally friendly method of access for the vastly diverse needs of its clientele. More than half $(62 \%)$ of partner agencies are faith-based organizations or located in a religious institution, but agencies also include numerous other nonprofit or private organizations, community action programs, and state or local government agencies" (Weinfield et al., 2014, p. 158).

\section{Food Insecurity in Missouri}

Although many scholars view the number of people using national programs like SNAP or WIC to accurately indicate the severity of food insecurity, "certain restrictions may prevent vulnerable households from qualifying. For example, in 2017, Missouri was one of 10 states that banned people with felony drug convictions from ever receiving Food Stamps" (Kaiser \& Cafer, 2017, p. 59). So, in addition to those national program 
data, statistical information from food pantries themselves can help paint a more accurate picture of the overall need.

With this in mind, The Food Bank for Central and Northeast Missouri (FBCNM) located in Columbia, MO is one of six regional food banks located around the state. In 2012, it distributed more than 28 million tons of food. 'Remarkably, the food bank's distribution poundage has increased more than $50 \%$ over the past five years" (Cafer et al., 2013, p. 3). Overall, the six regional food banks distributed nearly 90 million pounds of food to pantries throughout the state. Unfortunately, a large majority of the counties that are characterized as high need are also low performing in terms of their ability to support food insecure households. Additionally, there are not many high need/ high performing counties.

Food insecurity and hunger continue to affect all regions of the state.

Traditionally, large proportions of counties with high need are in the southern half of the state, but needs are also prevalent along the Iowa border, central regions and in St. Louis. High need areas are generally grouped with counties of high poverty levels (Cafer et al., 2013, 2016).

Johnson and Jackson County, Missouri. UCM has two different campus locations. One is located in Johnson County and the other is located in Jackson County. Although both counties are within the central Missouri region, side by side, they reflect the two extreme sides of hunger within the state. For example, Jackson County is one of Missouri's largest counties. It has a high need population, so the sheer number of people who are food insecure, eligible for a food assistance program, or currently participating in one is predictably high. Even though Jackson County is a high need county, it is also a 
high performing county in terms of readiness and ability to serve its population in need. Johnson County on the other hand, is a low need county, but comparatively a low performance county as well (Cafer et al., 2016). The Food Insecurity Rate in Johnson County is $\mathbf{1 5 . 3 \%}$, while The Food Insecurity Rate in Jackson County is distinctively higher at 17.2\% (Cafer et al., 2016). A three year average trend between 2014 and 2016 shows these two counties are above the state-wide average of 14.2\% (Food Research \& Action Center, 2019). In 2015, the participation rate of eligible persons in their local food pantries (FY 2015) was $89.0 \%$ across the state of Missouri. However, there is almost a $20 \%$ drop in the SNAP participation rate among eligible persons within in the last five years (2012-2017) (Food Research \& Action Center, 2019). According to The Missouri Hunger Atlas (2016), both Johnson and Jackson County are ranked very low for their participation rate among those eligible for food stamps. This statistic is particularly somber when it is reported that $48 \%$ of Jackson County and $35 \%$ of Johnson County are income eligible for The Supplemental Nutrition Assistance Program. The unemployment rate in Johnson County is $6.3 \%$ and slightly higher in Jackson County at 7.1\%. Again, these data bookend the state rate of $6.1 \%$. Likewise, the poverty rate (dividing the total population below the poverty level divided by the total population) in Johnson county is $16.8 \%$ and $18.7 \%$ in Jackson County. Because food insecurity and poverty are often times symbiotic, poverty is the best single predicator of food insecurity, and hunger strongly correlates with lower educational achievement, unemployment and impaired work performance (Cafer et al., 2013, 2016). 


\section{Food Insecurity Among College Students}

The prevalence of food insecurity among college students is largely unknown. In the national discussion, research is typically limited by a narrow population sample. For example, most research concentrates on a specific institution, state-wide snapshots, or certain schools within a specific region at best. In addition, due to the many factors that contribute to food insecurity along with the changing demographics that define college students today, the exact number of students suffering from food insecurity, as well as the degree of hunger from which they are suffering, is still largely the topic of conversation. To begin, despite differences in methodology or population samples, many studies find food insecurity to affect 25 to $30 \%$ of their populations (Broton et al., 2018; Gallegos, Ramsey, \& Ong, 2014). However, these statistics fall on the more conservative end of estimates. In addition, some scholars argue that, "even at their highest levels, the nationally representative estimates of food insecurity rates among households containing two-year college students are nonetheless substantially lower than those reported in some previous campus-based studies" (Blagg, Gundersen, Schanzenbach, \& Zilak, 2017, p. 4). Fundamentally, there are five studies within the United States that are widely used as benchmark research for defining the range of college students who are suffering from food insecurity on a national basis. These scholars currently outline food insecurity to affect anywhere from $25 \%$ to $50 \%$ of students in post-secondary education. This range includes both public and private two year and four-year institutions (Bruening et al., 2016; Chaparro et al., 2009; Gaines et al., 2014; McArthur et al., 2018; Patton-López et al., 2014). 
On the liberal end of the spectrum, Patton-López et al., (2014) found that food insecurity was a significant issue for more than half of college students surveyed. But regardless of whether a study yields findings that agree with the higher or lower end of the spectrum, most scholars would agree that in order to "have a better picture of the food insecurity situation across the country, it is necessary to expand the focus on college students' risk behaviors to include social and economic factors influencing a student's health, including income, employment, debt, housing costs, and food insecurity" (PattonLópez et al., 2014, p. 212). Many scholars have noted this very problem and, although the exact number is uncertain, the bottom line is that food insecurity affects many U.S. college students (Dubick, Matthews, \& Cady, 2016).

\section{Diet Quality}

Studies have shown that students with higher levels of food insecurity consumed significantly fewer fruits, vegetables, dairy, and legumes than those with non-severe food insecurity. The lack of available nutritious food is many times referred to as a food desert, while inundation of empty calories is a food swamp. Harmful food environments contribute to the role dietary quality plays on health and student success by limiting access to nutritious calories.

\section{Food Availability}

Fresh produce. Of course, transportation availability and cost coupled into the price per calorie affect healthier nutrition but, overall, few students actually meet the recommended food group recommendations. As fruits and vegetables have the highest cost per calorie, a noteworthy argument is that significantly more students with than without meal plans come closer to the dietary recommendations. As a result, current 
research argues that taste and convenience were important, but price is the primary factor that would increase access and consumption of fruits and vegetables (Farahbakhsh et al., 2017; Gallegos et al., 2014; Ha \& Caine-Bish, 2009; Handforth, Hennink, \& Schwartz, 2013; Mirabitur, Peterson, Rathz, Matlen, \& Kasper, 2016; O’Neill \& Maguire, 2017; Paola \& DeBate, 2018).

Food deserts. Campus food environments are struggling ecosystems that sometimes lie between food deserts and food swamps. Broton and Goldrick-Rab (2017) reported that 2-and 4-year college students reported some type of food-access problem or limitation. Other research shows that the unhealthy dietary practices of food insecure students can be due to food scarcity rather than lack of time and food preferences. Studies show campus food deserts can be due to insufficient meal card funds, spending habits, working appliances, and transportation (Hagedorn \& Olfert, 2018; McArthur et al., 2018; Vaterlaus, Cottle, Patten, \& Gibbons, 2018).

Food swamps. All you can eat style cafeterias provide easy access to foods high in fats and added sugars. In addition, unhealthy snacking, school and social demands, and lack of exercise also contribute to the food swamp environment. While these problems could be due to practices learned at home, students avoiding discomforts of hunger by consuming low quality diets that include easy to fix breakfast cereals, pasta, sandwiches, fried food, and junk food because they are easy to prepare, save money and satisfy hunger ultimately compromise students' health (Bemel et al., 2016; Bennett, Greene, \& Schwartz-Barcott, 2013; Broton et al., 2018; Brown et al., 2005; Hagedorn \& Olfert, 2018; McArthur et al., 2018). 
Vending machine health. Fast food and vending machines create hostile environments for students without transportation or money to purchase healthier food options off campus, adding to the food swamp environment. Zizza et al. (2008) warned the major source of energy from snacking was the sugar, sweets and beverage groups. In fact, in a recent study to identify correlates of food insecurity among students attending a rural university in Oregon, students were surveyed to see if they wanted an improvement in the variety of food offered in vending machines including hot, healthier and special diet options. In this case, researchers argue that improving variety of food by introducing healthier options would satisfy students as well as improve the on-campus food environment (Tam et al., 2017).

\section{Dietary Practices}

Meal frequency and portion size. Diet quality can also be affected by the frequency of meals as well as portion size. Some of the most common challenges involve an inability to afford to eat balanced meals, skipping meals and lack of resources or knowledge (Broton \& Goldrick-Rab, 2017; McArthur et al., 2018). Lastly, it should be noted that some scholars find that skipping meals can be associated with diets that are adequate in energy. Zizza et al. (2008) suggested that increase in meal size and the energy obtained by snacking appeared to compensate for reduced meal frequency but warned against energy intake becoming the total focus as food insecure students were still more likely to report skipping meals than food secure students

\section{Students, Hunger, and College}

University life represents a transformational experience; however, a prevailing attitude is that the universities place too much importance on academic performance and 
research efforts and not enough on prioritizing struggling students and a holistic student experience (Watson, Malan, Glik, \& Martinez, 2017). Many critics argue that "by identifying students who are facing housing and food difficulties, colleges and universities can intervene, potentially increasing retention, persistence, social, and emotional outcomes for this vulnerable student population" (Silva et al., 2017, p. 296). Additionally, Farahbakhsh et al., (2017) found that even though students may indicate excellent/ very good/good general mental and physical health; or were very satisfied/satisfied with life; they can still experience quite a bit/extreme life stress due to food insecurity. However, "Self-reported overall health status did not necessarily reflect the challenges associated with food insecurity that students faced on a daily basis. The K12 literature demonstrates a link between food insecurity and compromised academic performance" (O’Neill \& Maguire, 2017).

Examining higher education, most scholars agree that universities that measure food insecurity among their students will be better positioned to advocate for policy changes at state and federal levels regarding college affordability and student financial assistance (Payne-Sturges et al., 2018).

\section{The History, Prevalence, and Organization of Campus Based Food Pantries}

Although federal relief has largely been a product of the late 1960's, campus food pantries associated with The Feeding America Network can be traced back to the 1933 New Deal signed into effect by President Franklin D. Roosevelt. Public food programs have helped millions of Americans, but arguably the most powerful and well-known initiative has been that of the public education system. Beginning in the 1940's The Federal School Lunch Program solidified the public-school system's leadership role in 
the nutrition of students. Currently, food pantries are focusing on policies to undertake a larger responsibility in the health and nutrition of their clientele. These policies range from national health standards to individual pantry's efforts to broaden clients' options and influence healthier choices (Feeding America annual report, 2017; "Feeding America history," 2019).

\section{History}

Grocery programs, including nonprofit food pantries, account for more than $75 \%$ of programs run by agencies affiliated with Feeding America, the largest hunger-relief organization in the United States (Weinfield et al., 2014). However, federal food policy efforts date back to the mid-1930's when President Hoover established the Emergency Relief Administration (ERA), originally known as the Federal Emergency Relief Administration (FERA). In 1933, as part of U.S. president Franklin D. Roosevelt's New Deal, Congress passed The Agricultural Adjustment Act. Later this law would become known as the Farm Bill but offered subsidies to farmers in exchange for limiting their production of certain crops. The subsidies were meant to limit overproduction and surplus agricultural products were purchased from farmers in order to redistribute to people in need (Fyall \& Levine Daniel, 2018). In conjunction with the national effort towards World War II, the federal government ran an experimental food stamp program from 1939 to 1943 focusing on vouchers for commodities including basic food, but modern food stamps were not established as a permanent government program until 1964 (Fyall \& Levine Daniel, 2018). In addition, The National School Lunch Program was founded by the National School Lunch Act in 1946 as a way to provide permanent 
Federal support to long-standing efforts in some states to provide meals to school children (Ralston, Newman, Clauson, Guthrie, \& Buzby, 2008).

The second half of the 20th century brought modern change to food insecurity. The late 1960s was a turning point for poverty in America. The world's first nonprofit food bank started in 1967 just before the Citizens’ Board of Inquiry released Hunger, U.S.A. in 1968, reporting widespread malnutrition among America's poor. John Van Hengel established St. Mary's Food Bank in Phoenix, AZ as the nation's first food bank. In its first year of service, van Hengel's team of volunteers distributed 275,000 pounds of food. By 1977, food banks had been established in 18 cities across the country ("Feeding America history,” 2019). The 1970 Food Stamp Reform Bill mandated national standards of eligibility, and the Special Supplemental Nutrition Program for Women, Infants, and Children (WIC) began in 1972. In 1974, SNAP became a national program available in all counties across the nation. "Since becoming a national program, SNAP has undergone numerous changes, but its basic structure has stayed the same" (Gundersen \& Ziliak, 2018, p. 124). In 1977 California passed The Good Samaritan Food Donation Law, which limited corporate liability for food donations and allowed food banks to access private surplus food. As the number of food banks began to increase, van Hengel created a national organization for food banks. In 1979 he established Second Harvest, which was later called America's Second Harvest the Nation's Food Bank Network. In 2008, the network changed its name to Feeding America to better reflect the mission of the organization.

In 1982, the Electronic Benefits Transfer (EBT) program was piloted. The Personal Responsibility and Work Opportunity Reconciliation Act consolidated the 
TEFAP and SK-FB programs under one umbrella, and the Bill Emerson Good Samaritan Food Donation Act protected good faith food donors from civil and criminal liability on a national scale. America's Second Harvest, initially founded in 1979, became the national coordinator for food distribution (“Feeding America history," 2019; Fyall \& Levine Daniel, 2018). Under this umbrella, non-profits commonly spearhead food assistance programs such as food pantries, community kitchens, Meals on Wheels, and school backpack programs to create the largest food bank system in the nation. In fact, grocery programs, including nonprofit food pantries, account for more than $75 \%$ of programs run by agencies affiliated with Feeding America (Weinfield et al., 2014).

\section{Prevalence}

Addressing hunger in school is not a new phenomenon. Academia and hunger programs have established a long partnership dating back to the National School Lunch Act of 1946, giving light to one of the most utilized and depended on programs in the American public-school system. Today, over 75 years later, larger portions of the population are accessing higher education than ever before, and one of the fastest growing movements to combat hunger on college campuses is the development of campus food pantries. In 2009, fewer than ten campus food pantries existed; as of 2016 there were more than 350, and currently there are more than 400 (Dubick, et al., 2016; Goldrick-Rab, Richardson, \& Hernandez, 2017). The increased number of food pantries on college campuses indicates a growing concern for the well-being of our student population. Comparatively, on a national level, around 30 percent of food insecure households report participation in some type of food assistance programs. Food pantries, church programs, emergency kitchens, WIC, SNAP, infant and child care programs, or 
other private organizations often work together to provide more rounded support, but it is worth mentioning that scholars argue clients who once used pantries for short-term assistance increasingly demonstrate chronic food insecurity and long-term dependence on pantries (Coleman-Jensen et al., 2017; Dubick, Mathews, et al., 2016; Goldrick-Rab et al., 2017; Kaiser \& Cafer, 2017; Patton-López et al., 2014).

\section{Organizing the Effort}

The harmony between large-and small-scale efforts define the system of emergency food relief in the United States. Understanding the relationship between the two different approaches is an important aspect of the process of feeding the nation's hungry.

Macro. Feeding America has established several hundred hunger relief programs across the country, and these are an important part of local hunger relief efforts. Regional food banks warehouse the donated, purchased, and government foods and dispatch orders to their affiliated local agencies which include over 30,000 pantries, 4,500 emergency soup kitchens, and 3,500 emergency shelters across the nation. Feeding America has even created mobile food pantries that bring dry and refrigerated goods to provide food to clients in areas where traditional pantries may not be accessible or where certain foods are difficult to distribute. While food banks contribute over 90 million pounds of food a year to these facilities, there are an additional set of thousands of faith-based organizations and groups that provide food and resources to populations in need (Cafer et al., 2016; Campbell et al., 2013; Weinfield et al., 2014).

Micro. The organization of smaller-scale food pantries are frequently organized by client need. For example, in many food pantries, volunteers accompany clients while 
shopping in order to learn their preferences, cooking knowledge, family size, and health problems, focusing on relationships and education. Likewise, many college-based food pantries are organized in make-shift areas of campus but are still easier for students without transportation to utilize. Scholars argue that students are also more likely to see the programs as a student resource instead of a community-based program. Many times academic departments and other areas of universities donate physical items such as space, shelving and labor to help establish the services (Cooksey-Stowers et al., 2018; Dubick, et al., 2016; Twill, Bergdahl, \& Fensler, 2016).

\section{Allocating Resources}

How well the campuses are implementing services and how effective those services are in fighting food insecurity is an important aspect of the solution to food insecurity among colleges. Commonly, analyzing the allocation of resources involves analyzing the usage statistics, policies, and client choice.

Food distribution. Food pantries are community-specific organizations designed to help food assistance programs end hunger by supplying emergency food relief to clients in times of limited resources and hunger. On one end of the spectrum are pantries that do not offer choice and give fixed boxes of food, while on the other end client-choice food pantries give clients a choice of products within their limits. Because the food that pantries offer is largely donated, it can range from energy-dense and heavily processed food to nutrient dense and minimally processed items (Byker Shanks, 2017; Campbell, Hudson, Webb, \& Crawford, 2011; Wilson, 2016).

Trends in usage. Because prolonged and persistent pantry users are often times already coupled with other programs like SNAP and WIC, a common concern is that a 
high percentage of users are still considered food insecure, which in some cases is as high as $75 \%$ (Kaiser \& Cafer, 2017). In turn, this causes food pantry staff and volunteers to report concern over scarce resources and the fear of promising more than they can deliver, especially during the higher traffic times; for campus food pantries this is the beginning of terms and especially September (Cooksey-Stowers et al., 2018; Farahbakhsh et al., 2017).

Nutritional policies. Because food banks are charitable organizations, they heavily depend on the generous donations of donors to meet the needs of their clients. Since food pantries within the Feeding America System must give away food for free, food pantry directors are beginning to question whether food pantries should only distribute healthy foods, or a variety of foods, including soda and candy. This in turn makes the largest debate among food pantry scholars whether or not they should implement nutrition policies regulating the nutritional quality of foods they distribute. There is some concern regarding whether food donors would support such policies; however, most pantries reported strong commitments to the nutritional quality and the distribution of healthy foods. Their strong commitments go as far as providing information on their nutrition policies, specifying support for and referrals to government nutrition programs, including outreach activities, or advocating for legislative and community-based efforts to improve nutrition among their clients and the community at large. Likewise, other pantries demonstrate strong commitment by using ranking systems or algorithms to quantitatively score the nutritional value of the foods distributed (Campbell et al., 2013; Handforth et al., 2013). To support such commitment, there are several theory-based mechanisms to create client centered food choices revolving around 
dignity, motivation and education to build skills and resources that families can use to move towards independence. For example, Fresh Place and NEFPAT (Nutrition Environment Food Pantry Assessment Tool) are designed to provided information data and specific strategies for intervention (Martin, Wu, Wolff, Colantonio, \& Grady, 2013; Nikolaus et al., 2018).

Client choice. Client-choice food pantries are often times organized like supermarkets with nutritional information provided to help clients guide their choices. Based on current research, some scholars argue that the environment in food pantries should be thoughtfully designed to encourage clients to choose mostly whole grains, lean proteins, fruits and vegetables, and calcium-rich dairy and dairy alternate foods. Keeping client preference in mind while balancing health concerns is key. For example, in studies surveying client preference, meat/poultry/fish, vegetables and fruit were important to clients, while they expressed little or no preference for snacks, soda, and candy. In some areas, urban guests had a statistically significantly higher preference for meat/poultry/fish and soup than their rural counterparts. In other studies, rural guests had a statistically significant greater preference for beans than urban guests (Campbell et al., 2011).

Other studies indicated food pantry layout should nudge clients towards nutritious foods in each food group through strategic placement and presentation of food items as well as providing nutritional information of different foods (Byker Shanks, 2017; Campbell et al., 2011; Martin et al., 2013; Vaterlaus et al., 2018a; Wilson, 2016). With this in mind, "Personal recommendations may be important to ensure prospective food pantry customers that the permanent staff is kind, welcoming, and nonjudgmental because they are likely experiencing the vulnerability associated with whether or not they 
perceive acquiring food for their household from the food pantry as socially acceptable" (Vaterlaus et al., 2018, p. 1900).

\section{Addressing Food Insecurity at Postsecondary Institutions}

With the recent increase in college food pantries, a new conversation has emerged regarding how to best support the vulnerable population of food-insecure students, keeping in mind that the best designed food pantries should work themselves out of a job. Suggested and practiced solutions to addressing food insecurity at postsecondary institutions focus on awareness, funding, intervention, and education.

\section{Awareness}

Communities, administrators, students and families need to be aware of the large increase in the number of students suffering from food insecurity. Furthermore, understanding the systemic problem will help leaders design initiatives, interventions, and education programs to help those in need not only recognize when they need help, but to also become aware of the services that are already offered. Many institutions already have well established practices working diligently to support their students, nevertheless scholarly conversation and reflection will transform their problems into best practices (Campbell et al., 2011; Gallegos et al., 2014; Handforth et al., 2013; Wilson, 2016).

The systemic problem. Due to the potential range of costs incurred by students in seemingly similar off-campus living situations, it is difficult to understand the problem as a whole. Among students currently receiving food stamps, 63\% still reported food insecurity, suggesting that food stamps are not enough. Many scholars confirm SNAP usage among long-term pantry clients does not serve as a protective mechanism against 
emergency food needs. In fact, using SNAP numbers alone does not include the population of students who do not qualify for federal aid either due to parent income, lack of the required 20-hour employment qualification, or international student status. Scholars recognize that food insecurity is rarely an isolated condition but rather a sign of much deeper financial hardship, so many are calling for increased attention to food insecurity as a student issue among today's student populations (Cady, 2014; Dubick, Mathews, et al., 2016; Dubick, Matthews, et al., 2016; Freudenberg et al., 2011; Goldrick-Rab et al., 2018; Kelchen, Goldrick-Rab, \& Hosch, 2017; Zein, Mathews, House, \& Shelnutt, 2018).

Awareness of services offered. The number of food insecure students likely exceeds the number using food banks located on university campuses. Data on college food pantry usage estimate around 10\% were aware of the services (Freudenberg et al., 2011). Even community-based food pantries reported lacking awareness of services as a general problem. SNAP and federal programs see similar results, reporting low numbers of eligible users. Even though an important part of establishing food pantries is making sure the campus is aware of its services, word of mouth is usually the introduction. Feelings of embarrassment or the social stigma behind using a food pantry's services poses a significant barrier to connecting students in need with the resources available (Farahbakhsh et al., 2017; Freudenberg et al., 2011; Hanbazaza et al., 2016; Twill et al., 2016; Vaterlaus et al., 2018).

\section{Funding}

Administrative costs. Obtaining enough food and funding to open and maintain pantries is a large concern for many administrators of food pantries because of the 
difficulty behind arranging and maintaining contact between donors, regional hubs and individual food banks. The need for cold storages and paid staff to properly distribute products are valid concerns. Many scholars are calling for the next phase of research to investigate the characteristics of existing food banks and to identify key factors for success, including the size of the food bank, the need for registered dieticians, geographic location and connection to their communities (Handforth et al., 2013; Twill et al., 2016).

Accessibility to emergency support. Food initiatives in today's campus food pantries are largely centered around the access to emergency support by focusing on unconventional initiatives and changes in policies to improve the diet quality of their clientele. Studies reveal that almost $90 \%$ of students participating in campus food banks are still food insecure despite measures to alleviate the stress, like sharing accommodations with roommates. Today's college food banks are dedicated to improving the accessibility of available emergency support through a targeted two-fold approach: first, to provide the basic needs of students and second, to promote positive behavior with the understanding that emergency food banks are not a solution to long term food security (Farahbakhsh et al., 2017; Freudenberg et al., 2011; Hagedorn \& Olfert, 2018).

Innovative advances in support. Because college students have a wide range of knowledge and skill regarding financial budgeting, nutrition, and self-efficacy, food pantries are focusing on non-traditional ways to enhance student support. Advancing innovative support strategies will not only reduce food insecurity but will also promote academic success and economic stability. Campuses may need to consider more nontraditional ways to enhance student success by addressing the underlying causes of food 
insecurity such as unstable housing conditions, mental health issues and lack of employment (Broton et al., 2018; Martin et al., 2013; Twill et al., 2016). For example, efforts are being made to utilize social media to connect with a broader network of individuals. Some campuses are incorporating technology programs such as Swipe Hunger, where students participate in a virtual food pantry through unused or donated campus dining dollars. Other campuses now include a tour and information on campus food pantries as part of new faculty initiation training. Student in some colleges have indicated the need for mobile markets due to lack of transportation. Even passing out samples of easy-to-make nutritious recipes helps nudge diet quality as well as advertise for campus food banks (McArthur et al., 2018; Nikolaus et al., 2018; Watson et al., 2017).

Policy changes. In addition to innovative advances, large portions of the national conversation among scholars delineates the need for policy changes in three general areas regarding food insecurity among college students. These areas call for concerted efforts to change policies addressing the root causes of food insecurity, adopting policies that improve food quality, and broadening qualifications for existing federal food programs. Some scholars lean towards redesigning state and federal policies to be more inclusive of college students. A few examples include changing eligibility requirements for programs like SNAP or standardizing qualifications. Likewise, scholars argue, re-evaluating income support through cost of living allowances would address more of the root problems associated with food insecurity. Rather than creating new food banks, some scholars emphasize the need to address policy with the goal of establishing more public funding for postsecondary education and to create programs that address these root 
causes, e.g. inadequate loans, lack of well-paying youth employment, lack of financial management skills, and high tuition and compulsory fees (Farahbakhsh et al., 2017; Gallegos et al., 2014; S. Goldrick-Rab et al., 2018). In a similar manner, other scholars stipulate that food pantries should begin working with donors to help create policies limiting or prohibiting food items that are too saturated in sugar or are composed of too many empty calories, arguing that formal nutrition policies may help clientele and donors consider the importance of nutritional quality (Campbell et al., 2013).

Finally, scholars also emphasize the importance of broadening the eligibility for federal food programs, arguing that data do not adequately represent the material need on campus, underscoring the importance of interventions and policies to help economically disadvantaged students. For example, college students who are not eligible for federal aid such as food stamps, still struggle with food insecurity and have little opportunity for public assistance. These scholars urge policy makers to take steps to improve students' access to existing federal programs, including extending SNAP eligibility requirements for college students, like eliminating the 20-hour work week requirement for students not on financial aid (Chaparro et al., 2009; Dubick, Matthews, et al., 2016; O'Neill \& Maguire, 2017).

Diet quality. The discussion regarding the importance of diet quality and the role food pantries play in education has evolved greatly. From the perspective of food pantry volunteers and staff members, clients seem to choose items to address hunger before nutritional or health needs, but staff are often worried about being too overbearing with nutrition advice. Data indicate that participants were supportive of improving the nutritional value of the foods available in their food pantries. It seems that the large 
majority of both staff and clientele agreed on the need for more perishable items such as meat, poultry, and fish, not to mention more fruits and vegetables, especially tomatoes and apples. In addition, experts suggest that nutrition initiatives address meal and snacking behavior in order to improve students' diet quality. Other suggestions commonly highlighted in literature are nutrient ranking systems, clear written messages in multiple languages that indicate healthy choices, and many wanted to see more freshly cooked and prepared meals available as options (Byker Shanks, 2017; Campbell et al., 2011; Cooksey-Stowers et al., 2018; Tam et al., 2017; Zizza, Duffy, \& Gerrior, 2008).

\section{Interventions}

The range of interventions within campus food pantries are limitless, but by and large concentrate on improving the food campus food environment, nutrition, and networking practices. The majority of the interventions focus on improving the food environment and educational outreach programs.

Enhancing college campus food environments. Food pantries play a role in the food environments on college campuses; however, they sometimes go unnoticed. This may be due to the vast difference in price options for students. Scholars point out interventions to improve the food environment on college campus should emphasize diet quality through economic efficiency and education (Byker Shanks, 2017; CookseyStowers et al., 2018; Handforth et al., 2013; Tam et al., 2017; Wilson, 2016a).

Cost. In a study examining college students' food preferences on campus, the three most suggested interventions pertained to cost. Tam et al., (2017) contended the majority of respondents wanted to see, "healthier food at a lower cost and with discounts and less expensive food in general. Cost or poor value for money was the most common 
reason for respondents not purchasing food or beverages" (p.11). In addition, the high cost of fast food chains and fast food style restaurants often times found in student unions do not offer a wide selection of food choice or price options.

Educational nudges improving diet quality. In addition, economic principles of marketing can also influence campus food pantries through a technique called nudging in which clients are influenced towards certain products. In regard to educational interventions aimed at enhancing the food environment through self-efficacy, campus food pantries use nudges to make more nutritious foods more accessible and more desirable (Byker Shanks, 2017; Handforth et al., 2013). There is some debate regarding which intervention to use, especially when keeping in mind the dignity of clientele. Cooksey-Stowers et al. (2018) made the case that anyone creating a nutritional guidance system should take great care in managing the communication around discouraging foods. Because some clients are already health conscious individuals, color coded or star rating systems are a popular noninvasive approach that may help indicate healthier choices. Yet, Wilson (2016) advocated for an even more subtle approach where healthier food appears more convenient, attractive, and normal to select. Nikolaus et al. (2018) argued focusing on placement, promotion and information could lower administration costs in comparison to inventory changes or traditional education methods and be implemented with minimal effort. However, some scholars disagree all together, for example, Patton-López et al. (2014) warned against using food assistance initiatives, advocating for broader food system rights-based approaches instead.

National networking systems. There are several national networks that coordinate both social and private efforts to minimize the threat of food security; whose 
efforts and vision are continuing to expand. According to Campbell et al. (2013),

“Organizational culture of food banking, nationally, is evolving toward a more systematic and thoughtful consideration of nutritional quality" (p. 275). Feeding America coordinates food supply to every region of the country through collaboration with a variety of other organizations. For example, The Emergency Food Network (EFN), SNAP, Healthy Food Bank Hub, College and University Food Bank Alliance, and Single Stop to name some of the most prevalent. Feeding America and The Emergency Food Bank Network serve over 25 million food insecure Americans each year. The EFN Food network consists of over 200 banks that glean, purchase, store and distribute foods to smaller emergency food programs by utilizing corporate and government funding as well as private charitable donations.

There are many nationally known organizations that offer individualized services to food pantries; in an effort to make a variety of interventions more available for food pantry clienteles their range of services include networking between pantries and food distribution centers, nutrition education, counseling, and federal aid. The most widely used, or well-known interventions are: CUFBA. SNAP. The Healthy Food Bank Hub, Single Stop, and Freshplace.

To begin, the College and University Food Bank Alliance (CUFBA) was founded in 2012 and has identified over 70 campuses on which a food bank exists and is responsible for helping create The Food Bank Movement as a response to the challenges students are facing due to hunger (Cady, 2014).

The Supplemental Nutrition Assistance Program is by far the largest food assistance program in the US, providing total benefits of $\$ 68.3$ billion dollars in 2010 , 
though undergraduates without children must work at least 20 hours a week to be eligible to receive benefits and current research demonstrates its inability to prevent long term food security (Broton et al., 2018; Goldrick-Rab et al., 2018; Gundersen, 2013).

The Healthy Food Bank Hub connects area food banks and food pantries to knowledgeable information about healthy food distribution, nutrition education, innovative partnerships and models. In addition, it provides tools and resources for changing the food pantry environment as well as its supply (Byker Shanks, 2017).

Single Stop is a similar organization but connects low-income individuals and families with food pantries, shelters, health centers and job training sites. Through partnerships with organizations like Single Stop, universities can help meet the demand for nutritionally adequate food as well as connect to the existing social safety net of resources to help students with financial and nutritional stability to promote academic completion (Goldrick-Rab \& Broton, 2016).

Freshplace is a client-choice food pantry model where members not only choose their own food but meet with a project manager once a month to develop and monitor a plan to track personal goals for becoming food secure and self-sufficient. In addition, the Freshplace model offers a range of services and referrals to help members reach their goals. One of the benefits to using Freshplace is the low cost of employing one full time project manager who meets with clients to provide motivational interviewing and organize Cooking Matters classes for members (Martin et al., 2013).

\section{Education}

An ancient Chinese parable argues that giving a man a fish feeds him for a day; while teaching a man to fish feeds him for a lifetime. Through this lens, education is a 
powerful tool against hunger. There are many different methods of education that food pantries employ to empower their clientele.

Nutrition education. Education plays an integral role in aiding campus-based food pantries' mission to address student hunger. Students express frustration knowing the right choice in food but not having the skills or resources to acquire it. In some studies, students expressed interest learning to budget and cook nutritious meals. In fact one study indicated $60 \%$ of students expressed an interest in additional nutrition education programming in their institutions (Matthews et al., 2016; Watson et al., 2017).

Nutrition classes and programming. Programming and nutrition classes can take a variety of forms. Some experts encourage general nutrition courses that introduce simple recipes, assigning home cooking, tasting healthful snacks and writing health activity logs. Others recommend advice and experiences to support skill development such as using leftovers, lists of staple foods and equipment to help students improve their self-efficacy. Experiences could be offered through formal channels or in association with peer education programs (Ha \& Caine-Bish, 2009; Matthews et al., 2016).

Dietary expertise associated with food pantries. Even students in health science classes expressed difficulty in identifying correct dietary recommendations. Due to its difficulty, some scholars propose providing opportunities for dietary record keeping and goal analysis to motivate and help change behavior (Ha \& Caine-Bish, 2009; Matthews et al., 2016). Campbell et al. (2013) reported that only $41 \%$ of food banks indicated they had access to nutrition expertise and, in addition, only a third indicated that they had someone with nutritional expertise to provide volunteers with nutrition training. This poses a problem for food pantries trying to help students suffering from food insecurity. 
The role of nutritionists for pantries that can afford to staff them are also limited. For example, many food pantries utilize nutritionists to track food inventory or procure food from donors, but they are seldomly asked to develop written nutrition policies or educate donors. In addition, food pantries cannot always accommodate for medical conditions or food allergies. Providing education to donors about foods that are needed or encouraging monetary donations versus food donations may prove beneficial (Campbell et al., 2013; Goldrick-Rab \& Broton, 2016; Vaterlaus et al., 2018).

Financial education. Scholars indicate that food management skills alone may be insufficient strategies to ensure dietary adequacy and food security among students receiving financial aid. Bemel et al. (2016) made the case that every dimension of college student's health is related to their financial health in one way or another, warranting the need for financial education to be a part of entry level health education. Notably, freshman in particular indicated a need for learning opportunities that would teach them how to manage their money, make a budget, purchase nutritious affordable foods and make healthy choices. Furthermore, in addition to healthy cooking, financial budgeting classes and teaching students to apply for SNAP benefits may help students cope with food insecurity (Bemel et al., 2016; Gaines et al., 2014; McArthur, Fasczewski, Wartinger, \& Miller, 2018; Zein et al., 2018).

\section{Problems of Practice}

There are several problems of practice that thwart the effectiveness of food pantries. Measuring success, trends in usage, outreach, and restrictive policies add complications to the ambiguity surrounding the fight against hunger. Raising awareness of the specific needs food pantries and their clientele face is only part of the battle. 
Overcoming these obstacles will require a deeper understanding of the complex structure and intricate context behind individual food pantries.

Measuring success. Measuring the success of food banks is often quantified in terms of weight of food delivered to clients. The problem scholars identify with this methodology stems back to the relationship food banks build with donors. Many times, donations consist of a mixture of healthy and unhealthy food items. Current research highlights the fact that nutritional quality may not be a key consideration influencing acceptance of donations because food bank funding is associated with number of pounds an organization accepts and distributes throughout the year. Thus, focusing on pounds of food as a benchmark for success penalizes food banks that choose to eliminate heavy, but empty calories. So, eliminating items like cans of soda can drastically affect the total weight of products allocated during the year. This system, in turn, causes food pantries to accept items based on weight instead of nutritional value (Campbell et al., 2011; Handforth et al., 2013).

Usage. Through the literature, several problems related to the functionality of food pantries are important to the conversation of streamlining the fight against student hunger. To begin, low rates of student usage indicate that many students are missing out on benefits for which they would be eligible, including easy access to services like local food pantries. Low rates could be due to the perceptions many students identify as barriers to usage including lack of information on food pantry policies as well as inconvenient operating hours. Likewise, the prevalence of food insecurity is rising at such high rates, that local campus food pantries may not be able to support the need if numbers continue to increase. Finally, another barrier commonly reported was shame and stigma 
associated with using the pantry. Many students felt they needed to overcome their sense of pride before they could access the services offered by the food pantries.

Some scholars claim that food banks are not the answer to sustainable change, pleading with policy makers to establish, "more effective approaches to reduce its prevalence among students by making appropriate decisions regarding tuition costs, student funding, and loan assistance" (Hanbazaza et al., 2016, p. 574). The drastic difference between reported need and usage could be used to help market a more user friendly support system for students in need (Dubick, et al., 2016; Farahbakhsh et al., 2017; Freudenberg et al., 2011; Hanbazaza et al., 2016; Jablonski et al., 2016; Vaterlaus et al., 2018; Zein et al., 2018).

Outreach. Scholars consider the use of demographic information alone as an ineffective way of reaching students in need. In the past, eligibility for the federal Pell Grant has been the most commonly used measure of socioeconomic status among college students; however, some of its requirements, including completion of the Free Application for Federal Student Aid (FAFSA) form, excludes some low-income students and families from the program. Other studies indicate that students with sudden financial shock, such as a birth of a child, never connect with established safety-net systems of support (Broton et al., 2018; Goldrick-Rab et al., 2018; Vaterlaus et al., 2018).

Limitations. The limitations presented below outline the elements of the study that are and were more difficult for the researcher to control. One of the critiques of case study research is that the findings emerge within a bounded system and thus are not necessarily transferable (Shenton, 2004). Additionally, because the participants in this study have particular identities and experiences, the findings that are developed based on 
their experience should not be used to apply to all students who experience food insecurity. Scholars and administrators should look to the implications section of this research to discern what structural dynamics and barriers are at play and may be relevant to their own institution. This would be more useful than applying findings directly to the experiences of students with food insecurity at their institution. Moreover, because this is case study research and the study is developed within a bounded system, it would be difficult to confirm findings if the study were replicated at a different institution or with a different student population. Surely other dynamics, experiences, barriers, and challenges would occur; all of which would be important to examine in other research studies about college students who experience food insecurity in order to address the character of food insecurity and target responses effectively at other schools.

Participant perception of the researcher may also impact what they do and do not share, making it difficult to confirm findings. It is possible that a completely different researcher with different identities or affiliations (or lack thereof) to the institution would be received differently by participants, therefore altering any findings. Finally, because the researcher is conducting research at an institution where he is also a student, and where the researcher will introduce himself to participants as such, it is possible that participants have not disclosed potential contextual information that they might to researchers who had no affiliation to the institution. Participants may assume that there are things the researcher may know or is aware of as an insider of the institution and although this reflective exercise demonstrates reflexivity in this research process (Lincoln $\&$ Guba, 1985), there are potential instances where the researcher could have elicited 
more information from participants and did not because of this relationship to the institution.

\section{Best Practices}

According to an examination of the current literature, there are several practices that scholars argue efficiently impact the fight against food insecurity. These practices emerge as strong suggestions for policy makers, food pantry leaders, and volunteers to incorporate into their organizations for greater results.

Cultural responsiveness. Considering the wide variety of cultural backgrounds from which clients come is only part of a series of strategies scholars are calling for in order to maintain human dignity. In addition, developing health and financial support programs through private and public sector cooperation will help food pantries better serve their communities as well as strengthen community-university partnerships. Cultural responsiveness reflected in accommodating alternative eating patterns shows respect for clientele while increasing effectiveness. Some scholars advocate for meeting individual clients' needs by providing food recommendations based on dietary and oral health needs, medical needs and access to food preparation equipment. At the same time, food pantries that have a clear way of communicating information to clients including clear written messages in multiple languages are responding to client need in a culturally sensitive way (Cooksey-Stowers et al., 2018; Gallegos et al., 2014; Nikolaus et al., 2018).

Networking. Fighting hunger is often limited by unforeseen obstacles that are oftentimes overcome by the creativity of a multiple discipline approach. Networking with a wide variety of volunteers, organizations, and ideas often creates solutions to problems at hand. Scholars highlight the resourcefulness of many food pantries around the country. 
The College and University Food Bank Alliance operates to align partnerships within colleges and their communities to support students. These larger organizations have incredible reach. Some institutions link with school cafeterias and food vendors to support food insecure students. Other colleges create low cost or interest free programs to alleviate stress from textbooks or loan delays. Other schools have implemented a no late fee policy on tuition (Goldrick-Rab \& Broton, 2016). Ultimately, schools are a great place to connect students with other services, so some scholars stress intensifying their relationships with social service and medical agencies to promote student well-being. Some scholars recommend the key goal of food banks to be connecting and networking clientele with the appropriate services. UMass Boston even helped establish the Massachusetts Homeless Post-Secondary Students Network in an effort to assist students experiencing housing insecurity and chronic poverty on college campuses (Byker Shanks, 2017; Goldrick-Rab \& Broton, 2013; Noltemeyer et al., 2012; Silva et al., 2017).

Tailoring outreach. Tailoring outreach to meet the individual needs of clients takes on a community centered approach that may work in some areas and not in others. In order to identify needs, Cady (2014) suggested short-term action should include developing assessments to determine the prevalence and severity of food insecurity in addition to barriers and specific populations who are being disproportionately affected. Of course, education plays a large role in the discussion of outreach. Some scholars recommend nutrition rating systems, voucher and transportation interventions, as well as cooking classes and methods for addressing clients with dietary health concerns. Individual outreach is also dependent on the surrounding communities, creative approaches such as on-campus community gardens, and food recovery programs have 
been reported to create high success. Another innovative idea was a one-day fund-raiser where staff and students made monetary donations to the pantry through dining dollars from campus dining halls. Ultimately, the most renowned voices in the field plead for multi-sector approach that includes private philanthropic support and public benefits to help students and their families get enough to eat (Broton et al., 2018; Goldrick-Rab \& Broton, 2013). Until then, colleges and universities face an uphill battle that requires the creativity and support of future community leaders (Blagg, et al., 2017; Cooksey-Stowers et al., 2018; Dubick, Mathews, et al., 2016; Twill et al., 2016; Vaterlaus et al., 2018).

Engaging clientele. Besides traditional classroom educational settings, food pantries can do quite a bit to engage their clientele. Setting food pantries up like grocery stores complete with nutritional information emphasizes customer choice and dignity. Providing cards with business hours and pantry address, hours of service, website address and general health information is also an important part of advertising and encouraging community. Cornell University partnered with Feeding America to study "nudge" interventions such as sign placement and product information and found an increase in healthy selections (Feeding America Annual report, 2017). In addition, scholars consider client choice pantries optimal ways to engage clientele self-efficacy.

\section{Creating sustainable change}

Sustainable change on a budget is a difficult task. Some strategies to change the conversation regarding food insecurity focus on education, self-efficacy and community building. Organization models like FreshPlace are not only providing emergency food and helping members set goals and gain skills to address root causes of food insecurity but also strategically linking community services to people in need. Results from their 
interventions indicate members were less likely to experience very low food security compared with traditional food bank (Zein et al., 2018). In addition, influencing the campus environment through multimedia messaging, improved fruit and vegetable intake and ways to cope under stress like the promotion of physical activity has the potential to improve food swamps and unhealthy environments. Improving the face of college food pantries is also important. Some scholars call for a rebrand of food pantries by connecting them with sources of wellness instead of need. Other scholars encourage pantry tours as well as classes on financial health and budgeting as part of campus orientation days (Campbell et al., 2011; Hanbazaza et al., 2016; Martin et al., 2013; Matthews et al., 2016; Nikolaus et al., 2018). Scholars hope that models like FreshPlace in conjunction with interventions aiming to rebrand food pantries' image will, "alleviate stigma while fostering a sense of dignity in seeking food assistance" (Zein et al., 2018, p.10).

Advocating for policy improvement. Some of the more creative ideas in the fight against food insecurity are offshoot of the inefficient and slow bureaucratic efforts to change policy on the large scale. Most scholars agree that changing eligibility criteria for public social services programs like SNAP or standardizing qualifications for social services with financial aid packages in order to promote degree completion would be a large brush fix. Due to the slow turning wheels of national policy, other scholars promote more part-time jobs and more affordable meal plans. In addition, other conversations are calling for registered dietitians, social workers, and health educators, who can implement interventions and advocate for local policy to address student health concerns. In fact, updating policies to match The Food Bank of Central New York's No Soda and No Candy Donation Policy may correspond with food pantry directors' philosophies as well 
as their guests'. Data from a food preferences study indicates, "Most directors (80\%) reported that food pantries should only provide healthy foods" (Campbell et al., 2011, p. 186). In addition there are new and creative ways to innovate advances in overnight and refrigerated shipping to create mobile pantries to deliver perishable food to people in need (Campbell et al., 2011; Freudenberg et al., 2011; Goldrick-Rab et al., 2018;

Handforth et al., 2013; Matthews et al., 2016; McArthur et al., 2018). 


\section{SECTION IV}

CONTRIBUTION TO PRACTICE 


\section{Contribution to Practice}

The following presentation will be presented at the 2020 NASPA Conferences on Student Success in Higher Education.

\section{EXPLORING COLLEGE FOOD INSECURITY: \\ A QUALITATIVE CASE STUDY \\ OF THE PERSPECTIVES OF THE UNIVERSITY OF CENTRAL \\ MISSOURI FOOD PANTRY CLIENTELE}




\section{Introduction of Presenter}

Mike received an MA in education emphasizing in Spanish Language pedagogy, history and literature. While at Doherty High School he assisted in a field studies program that focused on an experiential learning environment in Colorado, Utah, New Mexico and Peru. Focusing on the natural, biological social, and political importance of water. Specifically, Mike focused on drought's role in immigration and on lower-economic communities in the West, he also helped create an international program that helped doctors with health clinics in the Peruvian Amazon.

He was hired by Colorado Community Colleges in 2010 . He continues to serve students, families, and his department as the World Language and Communication Department Chair at the Colorado Community College System. While teaching at Colorado Community College Online, Mike completed the Doctorate in Educational Leadership and Policy Analysis program through the University of Missouri in Columbia, Missouri in May of 2020.

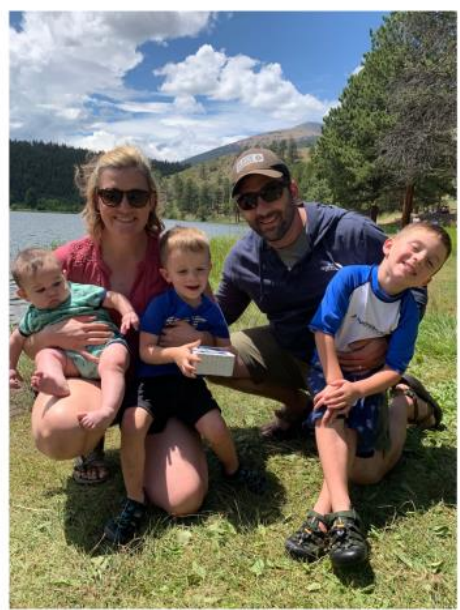

I am excited here and excited about the opportunity to speak to you today about food insecurity in college. 


\section{Overview of Topic}

- The drastic changes seen in public school lunch programs ends at high school graduation.

- Scholars currently outline food insecurity to affect anywhere from 25 to 50 percent of students in post- secondary education. This range includes both public and private two year and four-year institutions

(Bruening, Brennhofer, Van Woerden, Todd, \& Laska, 2016; Chaparro, Zaghloul, Holck, \& Dobbs, 2009; Gaines, Robb, Knol, \& Sickler, 2014; Laura Helena McArthur, Ball, Danek, \& Holbert, 2018; Patton-López, López-Cevallos, Cancel-Tirado, \& Vazquez, 2014).

As higher education becomes more accessible, the support systems that surround public schools have not followed. Scholars estimate that food insecurity affects anywhere from $25-50 \%$ of college students. 


\section{Literature Review: General Overview}

- Although the exact number is uncertain, the bottom line is that food insecurity affects many U.S. college students (Dubick, Matthews, \& cady, 2016).

So, because food insecurity is difficult to pinpoint, it may help to review some of the literature that guided this study. 


\section{Literature Review: Intercollegiate comparison}

- Food insecurity measured among both 2- and 4-year institutions is not unique to any particular region and although prevalence rates vary across institutions, food insecurity can be found at any academic institution, even students attending Ivy League universities with full financial-aid packages report going without food and struggling with hunger (Jack, 2015 as cited in (Goldrick-Rab \& Broton, 2016).

- Food Insecurity rates range from $14 \%$ at the University of Alabama, $21 \%$ at the University of Hawaii at Manoa, $25 \%$ of community college students in a national study featuring 12 community colleges, $39 \%$ at Western Oregon University, to 59\% at CUNY (Chaparro et al., 2009; Dubick, Mathews, \& Cady, 2016; Freudenberg et al., 2011a; Gaines et al., 2014).

To provide a snapshot of the current conversation I looked to the 5 biggest studies conducted on college food insecurity.

Specifically, studies in Alabama, Hawaii, Western Oregon, Wisconsin and New York are among the most cited and relevant to the conversation. 


\section{Literature Review: 2- and 4-year institutions}

- Currently it is estimated that, twenty-five percent of community college students qualify as having very low food security, compared to 20 percent at four-year schools (Blagg, Gundersen, Whitmore Schanzenbach, et al., 2017; Dubick, Matthews, et al., 2016).

- However, there does seem to be a relevant connection between types of enrollment and the potential for food insecurity.

- To illustrate, among the population of students at four-year schools, "students are significantly more likely to be food insecure while enrolled as a part-time student and when enrolled at public institutions" (Blagg, Gundersen, Whitmore Schanzenbach, et al., 2017, p. 5).

It is widely accepted that food insecurity is occurring at both two-year and four-year institutions and although it is of national importance; students at four-year schools are less likely to be food insecure than those at two-year schools.

We know the type of enrollment is more relevant than the actual institution.

The question becomes more about the degree to which food insecurity is affecting our nation's college students. 


\section{Gap in Literature}

-What remains to be explored are the perceptions and needs of college students who are clients of campus food pantries (Henry, 2017; O’Neill \& Maguire, 2017)

So, where my study enters the conversation is largely around the effectiveness of the current support systems in place to help students. 


\section{Purpose of Investigation}

- The purpose of this qualitative study will be to explore the perspectives of food pantry clientele at UCM.

- Research Question:

- What additional food pantry services would be beneficial to its clients?

Part of the importance of this study is to investigate how well the campus food pantry was meeting the needs of its clients. 


\section{Setting}

- Qualitative Case Study

- University of Central Missouri (Warrensburg, MO).

- 11, 487 Students

- 9,300 Undergraduate Students

- 2,187 Graduate Students

This qualitative case study of the food pantry clientele was completed on the University of Central Missouri campus located in Warrensburg, MO. As of the Fall of 2018, there were approximately 11,487 students, which included 9,300 undergraduate students and 2,187 graduate students. The undergraduate student body consists of $45 \%$ male, $55 \%$ female, $21 \%$ minority, and $2.5 \%$ international students. Domestic students came from 46 states.

The graduate student body consists of $37 \%$ male, $63 \%$ female, $13 \%$ minority, and $19 \%$ international students. There are 658 undergraduate and graduate international students from 55 different countries (Chen, 2018, p.i). Focusing on the process, meaning and understanding of food insecurity of the pantry clientele at UCM, the researcher was the primary instrument of data collection and relied on an inductive analysis process (Creswell, 2014; Merriam \& Tisdell, 2016). 


\section{Methodology}

- Interviews

- Observations

- Document Review

- Network, chain, or snowball sampling (Merriam \& Tisdell, 2016)

I triangulated themes between the series of interviews, documents, and observations conducted throughout the study. 


\section{Participants}

- 33 Participants

- 21 Clients ("C" Names)

- 7 Volunteers ("V" Names)

- 5 Staff Members ("S" Names)

- Missouri, US, India, China, Nigeria, and Tunisia

- (Late teens- Late 60's)

- 13 female and 9 male clients

- 7 Female volunteers- all nursing students

The 33 participants in this study were individuals consisting of five staff members, seven volunteers, and 21 clients, representing various places around Missouri, the United States, India, China, Nigeria, and Tunisia. With the exception of a few, most interviews were conducted in a large conference room on the main floor of the Students Recreation and Wellness Center on the University of Central Missouri Campus. The interviews ranged anywhere from 30-45 min. and were conducted in quite locations of the clients' choosing.

The participants ranged in age from late teens to late sixties. The clients represented various fields of study including nursing, education, construction management, math, science, aviation, and library sciences. There were 13 female clients and 9 male clients.

The seven volunteers were almost all female, with the exception of one male in his late forties. Five of the volunteers were female college nursing students, and one was a registered nurse in her late forties. Throughout the study, the clients' pseudonyms will all begin with the letter, 'c'. Likewise, volunteer names begin with the letter ' $v$ ' and staffs' names begin with the letter 's'. 


\section{Theoretical Framework}

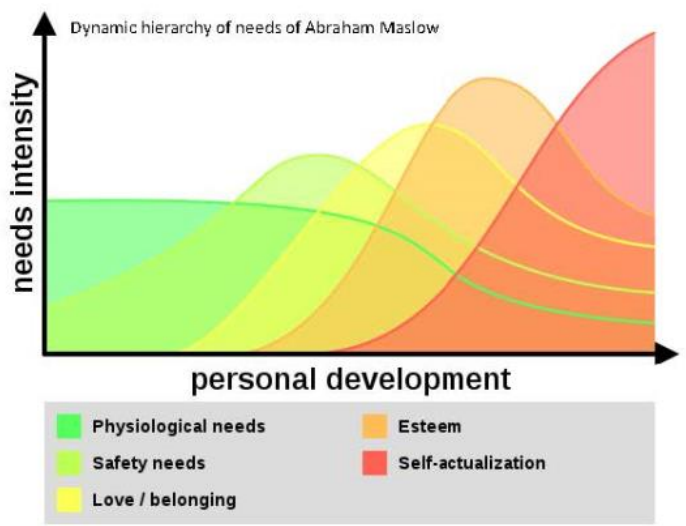

Dynamic hierarchy of needs of Abraham Maslow referring to Krech, D./Crutchfield, R. S./Ballachey, E. L. (1962), Individual in society, Tokyo etc. 1962, S. 77

Although this chart is different from the traditional hierarchical pyramid of human development needs, we are mostly familiar with, later research in the field has argued this dynamic representation of needs stresses the overlapping and progression of how humans' needs can change as well as interact with one another.

Some of the most interesting findings produce a discussion revolving around overlapping needs, the social role of the university, and the importance of social groups and community for college students. 


\section{Findings: Overview}

- Increasing availability;

- addressing the size and location;

- adding culturally recognizable items;

- offering more fresh fruits and vegetables,

- increasing access to affordable fresh raw food; and

- creating strategic partnerships through advocacy and outreach.

Because this research question specifically focused on what was missing from the Cupboard, the findings focused on how to improve the food pantry. Here are the 6 themes that emerged as a result of the study. 


\section{Improvements in Practice: Availability}

"Like they have vegetables down there, but again, they could be getting close to begin bad, like the bread sometimes like molds within a couple of days. And you can only get them within a week, so by the time things get old, you can't even get more food and they're open weird hours of the week."

-Christina (Campus Cupboard Client)

One of the most interesting questions the staff of the food pantry can answer is whether or not to incorporate charging clients for items. It is widely argued that lack of resources is only part of the factors that create food insecurity for college students. Because time, transportation, and cooking knowledge also affect food insecurity, charging for items like fresh fruits and vegetables can be an interesting option. 


\section{Improvements in Practice: Size and Location}

"If somehow, we could expand it, have a bigger place or another place, get more of a variety of food, like the rice."

-Stanley (Campus Cupboard Staff)

"I don't think it's a great location honestly. I had no idea how to find it last year, I went with a senior to find it. It could be better, more signs, more open, but, it's a spot, so..."

-Vanessa (Campus Cupboard Volunteer)

The limited hours the Cupboard is open also adds to the freshness of the items available. Increasing the times, the pantry is open could help move product more rapidly.

Because many college food pantries are temporary productions, space and location is not always ideal. In this specific case study, the rapid growth of the clients over the course of its existence is an example of how quickly the need can overwhelm the available resources. 


\section{Improvements in Practice: Education}

"So, something that they could do is offer a simple cook book, and I would not know exactly how to go about that, but I would say that is something around 15 to 20 pages and has a variety of simple and healthy meals, the kind that students could make and they could offer that with every cloth bag that they hand out for students."

-Charles (Campus Cupboard Client)

This was an incredible recommendation that was expressed several times and in several different ways. Collecting recipes and useful ideas to create a repository for students to access can help build community, but more importantly help students help one another. 


\section{Perspectives \& Products: Culturally Recognizable Items}

- Specifically, participants made requests for dried rice, Indian "pulses" like dried lentils, legumes, mung beans, black-eyed peas, lentils, pigeon peas, adzuki beans, moth beans, and kidney beans. There were other African produce items like the tuba, or yam, that students travel to larger cities to purchase. Halal meats were also suggested to support Muslim students who have difficulties finding these products in the dining halls.

Culturally recognizable items that students need to run to the city to find could also carry a small charge to cover the costs of bringing the food to the campus. 


\section{Perspectives \& Products: Fresh Produce}

"Fruits are not cheap, and they taste amazing, and I like vegetables, I love vegetables, but fresh vegetables are not cheap, and it's hard to get them fresh too."

-Chloe (Campus Cupboard Client)

Although directly connecting students to some type of meal plan is ideal, there were several options through Feeding America and specifically Harvesters that can provide access to free fresh vegetables and fruits on a weekly basis. Providing access to transportation or even just advertising these exist is a helpful addition to the pantry. 


\section{Access \& Partnerships: Affordable Produce}

"Just because it can be very hard to get to other locations if you did want produce and you can't get off campus, or if it was cheaper on campus because a lot of college students are very low-income people."

-Charlotte (Campus Cupboard Client)

Several times the idea of a fresh produce market came up. In my head I imagine a commissary like a bodega for students and staff to access affordable raw produce and healthier items to improve the food environment on campus. 


\section{Access \& Partnerships: Advocacy \& Outreach}

"Systems and community communication channels to effectively target and communicate with students. And the two-way communication will know what their means are and is there a way to dial in that the campus is covered more effectively."

-Virgil (Campus Cupboard Volunteer)

Adding guides, nutritionists or finding creative ways to create more personable relationships between the Cupboard and the clients is a great idea to improve the efficiency of the food pantry. The volunteers and staff of the campus cupboard have underutilized experience that can help create a broader range of helpful resources.

I am often reminded of the parable "give a man a fish and he'll eat for a day, teach him to fish and he'll eat for a lifetime"

In many ways college food pantries need to provide more than just free food. They need to become a hub for self-reliance and self-sustainability. 


\section{Implications and recommendations}

- Education

- Nutritional Education

- Classes and Programming

- Dietary Record Analysis and Goal Setting

- Expertise associated with food pantries

- Financial Education

- Outreach

- Cultural Responsiveness

- Networking

- Tailoring Outreach

- Engaging Clientele

- Awareness

- Creating Awareness

- Advocating for Policy Change

With the intention of moving the Campus Cupboard from a food pantry with a single perspective on service into a hub with a dynamic outreach program.

The recommendations for this study were focused on three key areas of the pantry. 


\section{The UCM Pantry: White Hallway Walls}

- Include a large visible list of the items currently available in the pantry would help clients make choices ahead of their time in the pantry.

- Second, installing a monitor for students to watch educational cooking programs, specifically "Struggle Meals" with Chef Frankie Celenza who has shown interest in specifically working with The UCM Campus Cupboard to help educate clients struggling with cooking.

The majority of the time clients spend interacting with the food pantry is spent just outside of the pantry itself. Many clients commented on the lines to enter the food pantry. This presents a unique opportunity to create a dynamic educational environment.

Specifically, the study produced two recommendations to transform this area into a learning environment. 


\section{The UCM Pantry: QR Codes}

"If they have a communication channel or a little barcode or something there that just said, Hey, this item can be made in five ways, click on this to get a couple of recipes that can be done in five or 10 minutes."

-Virgil and Virginia (Campus Cupboard Volunteers)

Most of the clients had access to phones and were holding them during their time in the pantry or outside of it. One way to help clients become more self-reliant is taking advantage of the opportunity to help clients think about the possibilities each ingredient holds. 


\section{Discussion: $\mathrm{Q}$ and $\mathrm{A}$}

What questions do you have for me?

How does this apply to your own campus?

How does our campus influence the choices we make about our health?

How would not having a grocery store near your home affect you?

What are the causes of obesity?

What does it mean to have a healthy diet?

What criteria might supermarket chains use to decide where to build stores? 


\section{SECTION V}

CONTRIBUTION TO SCHOLARSHIP 


\title{
Contribution to Scholarship
}

Target Journal. Journal of Student Affairs Research and Practice

\begin{abstract}
Insufficient resources not only undermine postsecondary educational experiences, but delay credit attainment for many of today's college students (Goldrick-Rab, BakerSmith, Coca, Looker, \& Williams, 2019). Using 33 interviews this study found stakeholders care about their experience as much as what food and services the Campus Cupboard offers. To address the struggles college students face, this study constructed its recommendations focusing on tailoring its outreach to create sustainable change.
\end{abstract} Keywords: College food insecurity, campus food pantries, campus food communities, at-risk students

\section{Introduction}

Evidence of households with children struggling to provide food for their children has led to policy reform seen in programs like free and reduced meals in schools around the country. Poverty links many insecurities and often times food is associated with housing studies. Some scholars argue that "housing instability and homelessness is an increasingly significant and persistent problem in the United States and it affects schooling outcomes at every level, including college" (Goldrick-Rab \& Broton, 2013, p. 7). However, the drastic changes seen in public school lunch programs ends at high school graduation. This is in part due to the fact that the prevalence of food insecurity among college students is largely unknown. There is a growing disparity between the purpose of higher education and successfully removing the barriers that inhibit students from fully experiencing the benefits of a college experience. Although federal policy has 
made tuition for higher education more affordable, many college students do not know from where their next meal is coming.

\section{Literature Review}

Defining food insecurity among college students proves just as difficult as defining it on a national scale. This may be due to the fact that the demographic evolution of today's collegiate population is following the changing needs of today's work force. For example, the needs of employers are different today than they were even ten years ago. In fact, "in the past 50 years, the gap in earnings between those with and without a degree has grown, making college degrees more important than ever (Pew Research Center, 2014)" (O’Neill \& Maguire, 2017, p. 34). As a result, many adults who currently make up today's work force are trying to improve their education. So much so that in the past, the term, "non-traditional college student" was once used to describe older students. Now it is not only becoming more familiar but developing to include a wide variety of students who do not meet the archaic definition of whom should attend college. This is important because higher education is becoming more accessible and, as a result, the college student population is becoming more diverse. There are more first-generation college students who, along with their families, need even more support navigating the transition to college life (Bruening et al., 2016). As many adults find themselves going back to school full time, they are joining first-generation college students who are more prevalent on today's college campuses than ever before. In addition to this cultural shift, the rising costs in tuition and expenses are causing many institutions to search for answers on how to best support this wave of students with families, as well as low-income and firstgeneration college students. What many are finding is that the demands for education are 
taking a toll. In 2014, Feeding America reported that, "ten percent of adult [food pantry] clients are seeking to increase their levels of education, with 6.7 percent in school fulltime and 3.5 percent in school part-time" (Weinfield et al., 2014, p. 88). The increased access to higher education is producing a twofold problem. First the increase in the number of first-generation college students, the rising costs of tuition, and enormous student loan debt may have significant impact on food security for current and future college students. Second, colleges are now seeing the heads of households adding the attainment of college degrees to their family responsibilities. All in all, today's college students are becoming more financially constrained to pay for college and may be limited in other resources as well (Morris et al., 2016). Under these circumstances, some college students with limited resources may be skipping meals to make ends meet (O'Neill \& Maguire, 2017). As a result, current research argues that low-income students need more support to achieve retention and graduation parity with their academic peers. Due to the nature of solutions these hardships are generating, a crucial component to building a healthy university environment may be to provide food assistance programs and services to students with financial limitations (O’Neill \& Maguire, 2017; Weinfield et al., 2014).

College food insecurity in perspective. Although there is growing recognition that university students face increasing poverty and consequent difficulties in acquiring healthy food, due to geographic and demographic variables not every study produces the same results (Gallegos et al., 2014). This creates some conversation among scholars so, in examining food insecurity among college students, it is helpful to compare their need against the need of the general population as a baseline. While most scholars agree, one study conducted at the University of Alabama found that students did not seem to be at an 
increased risk for food insecurity when compared to the general public, but acknowledged the concern regarding the lack of food assistance available to college students and the potential to create financial instability (Gaines et al., 2014). The majority of recent studies, however, find that food insecurity among college students is higher than the national average. In the United States, such little research has been done on a national scale that a study from Australia was consulted. It specifically examined the prevalence and severity of food insecurity among its local campus. Although its findings are based on a population sample that is too small to generalize to the larger population, Micevski, Thornton, and Brockington, (2014) found that food insecurity at Victorian-based Deakin University was higher among students than within the broader Australian population at 5.2 percent. Three specific studies done within the United States that compared food insecurity among college students to the general population all produced findings that indicated food insecurity among college populations was higher than the national average, similar to the Australian study (Cady, 2014; Freudenberg et al., 2011a; Hagedorn \& Olfert, 2018). "According to USDA, between 2006 and 2008, an average of 1.4 million New York City residents lived in food insecure households, about $17 \%$ of the city's population. This suggests that the prevalence of food insecurity among CUNY students (39\%) is substantially higher than among US and NYC households and adults" (Freudenberg et al., 2011, p. 5). Cady's (2014) research demonstrated food insecurity among college students is significantly higher than the general U.S. population based on USDA 2013 data. By and large, the available data suggest that the incidence of food and housing insecurity is now greater among college students than it is in the general population (K. Broton, Frank, \& Goldrick-Rab, 2014) 


\section{Methods}

\section{Setting}

This qualitative case study of the food pantry clientele was completed on the University of Central Missouri campus located in Warrensburg, MO. As of the Fall of 2018, there were approximately 11,487 students, which included 9,300 undergraduate students and 2,187 graduate students. The undergraduate student body consists of $45 \%$ male, $55 \%$ female, $21 \%$ minority, and $2.5 \%$ international students. Domestic students came from 46 states. The graduate student body consists of $37 \%$ male, $63 \%$ female, $13 \%$ minority, and 19\% international students. There are 658 undergraduate and graduate international students from 55 different countries (Chen, 2018, p.i). Focusing on the process, meaning and understanding of food insecurity of the pantry clientele at UCM, the researcher was the primary instrument of data collection and relied on an inductive analysis process (Creswell, 2014; Merriam \& Tisdell, 2016).

Data Collection Tools. The researcher interviewed 33 participants, representing a variety of the most common variables associated with food insecurity. Saturation was met after 22 clients, seven volunteers, and five staff members.

The researcher began by locating a few key participants who easily met the criteria the researcher established for participation in this study. Second, the researcher solicited participants by advertising outside the food pantry. Lastly, the researcher connected with the remainder of the participants using what Merriam and Tisdell (2016) identified as snowball sampling or a type of purposeful sampling in which individuals or participants can connect the research with other participants. This method was employed to avoid unethically contacting participants. 


\section{Participants}

The 33 participants in this study were individuals consisting of five staff members, seven volunteers, and 21 clients, representing various places around Missouri, the United States, India, China, Nigeria, and Tunisia. With the exception of a few, most interviews were conducted in a large conference room on the main floor of the Student Recreation and Wellness Center on the University of Central Missouri Campus. The interviews ranged anywhere from 30-45 min. and were conducted in quite locations of the clients' choosing.

The participants ranged in age from late teens to late sixties. The clients represented various fields of study including nursing, education, construction management, math, science, aviation, and library sciences. There were 13 female clients and 9 male clients. The seven volunteers were almost all female, with the exception of one male in his late forties. Five of the volunteers were female college nursing students, and one was a registered nurse in her late forties. Throughout the study, the clients' pseudonyms will all begin with the letter, 'c'. Likewise, volunteer names begin with the letter ' $v$ ' and staffs' names begin with the letter ' $\mathrm{s}$ '.

\section{Procedures}

The research question was answered by collecting and analyzing the various perspectives from staff, volunteers and clients of the Campus Cupboard. Pseudonyms were used to protect the confidentiality of the participants. The research question that guided the study was:

1. What UCM food pantry services are most significant to clients? 
Data collection. The researcher interviewed 33 participants who represented a variety of the above variables, including 13 males and 20 females. Interviews were conducted until saturation was met. Specifically, the population sample consisted of five food pantry staff members, seven volunteer staff members, and 21 food pantry clients. The researcher contacted these participants utilizing three primary methods of contact. First, the director of the Campus Cupboard informed any participants of this study and put those interested in the study in touch with the researcher. Second, the researcher solicited volunteers through small business card size advertisements. This two-fold approach involved placing announcements and brochures, including the researcher's contact information, around areas of the campus to advertise the study. All communication tools had the researcher's contact information, so that participants could initiate contact. Lastly, the researcher connected with the remainder of the participants using the common form of network sampling Merriam and Tisdell (2016) referred to as network, chain, or snowball sampling. This sampling strategy allowed individuals to connect the research with other participants. Specifically, the researcher employed this sampling method to avoid unethically contacting participants.

\section{Data analysis}

Due to the qualitative nature of this study, data analysis began with the consideration of any pre-existing data, such as historical information on the UCM pantry usage, and continued during data collection (Merriam \& Tisdell, 2016). Interviews and observations occurred until saturation was reached, the researcher interviewed 33 participants in total. An open-coding process was used to construct themes of recurring categories. To ensure accuracy, reliability and validity, the researcher triangulated data 
through interviews with the food pantry clientele, volunteers and employees;

observations; and documentation review. Additionally, the observations and interviews were composed of open-ended questioning techniques. Collectively, the three forms of data collection were in an attempt to collect thick, rich, and descriptive data (Creswell, 2014; Merriam \& Tisdell, 2016).

\section{Limitations}

One of the critiques of case study research is that the findings emerge within a bounded system and thus are not necessarily transferable (Shenton, 2004). Additionally, because the participants in this study have particular identities and experiences, the findings that were developed based on their experience should not be used to apply to all students who experience food insecurity. Scholars and administrators should look to the implications section of this study to discern what structural dynamics and barriers are at play and may be relevant to their own institution. Moreover, because this is case study research and the study was developed within a bounded system, it would be difficult to confirm findings if the study were replicated at a different institution or with a different student population (Creswell, 2014; Lincoln \& Guba, 1985).

\section{Findings}

Several significant themes emerged surrounding the products and services the pantry offered. Specifically, convenience and nutritional value; the freshness and variety of available products; the supply of soup; the food recovery program; personal hygiene products; opportunities for volunteers; clarity in communication; and a non-judgmental environment to be the most significant features of the Campus Cupboard. 
Convenience and Nutritional Value. Although most participants understood working strictly with donations makes it difficult to control the items that come into the food pantry, many participants placed importance on the nutritional value of the food in the Cupboard, but readily chose convenience over higher nutritional value. In fact, most participants emphasized looking for food that does not take long to prepare or can stretch through the week, even though those items may lack quality nutrients. For example, one client indicated items with higher sugar levels like spaghetti or processed food like canned vegetables were "not the healthiest food, but man, it lasts." Additionally, Stanley noted the higher prices for healthier food may drive clients' choice: "I've noticed that when we have chicken and that kind of stuff in the pantry, they tend to go fast, like people really want those, so I'm guessing that people really don't want to spend money to buy those.

Freshness and Variety of Food. The freshness of the products was important to all the participants in this study; however, because the food pantry supplies options that are generally close to their expiration dates when they are donated, it makes keeping fresh produce very difficult. As a result, even though volunteers and staff prioritized checking the expiration dates of the products, many participants still expressed a concern surrounding the actual expired goods on the shelves. Specifically, many clients reported not grabbing the produce that looked bad. Bread, fruit, vegetables, milk, cheese, and some dining hall recovery products were items that drew the most concern.

Soup. The most popular item in the Cupboard, and perhaps the most talked about, was canned soup. Many, if not all, of the participants mentioned soup and because of its popularity, Simon even mentioned the importance of keeping more cans of soup in stock: 
"what the students want are their soups, the soups, that's the simplest thing, but we don't get enough of those. I know that for a fact, because when we get soups it's gone. They go so quick and we have a limit, one soup per person, but it just flies off the shelves."

Perhaps the convenience of storage and cooking explains its popularity: "soups or ramen noodles or easy macs or quick things that could can just throw in a microwave." Clients living both on and off campus agreed, and it generally is a healthier option when comparing its nutritional value to its convenience.

Food Recovery Program. In addition to the longevity value of food, the participants placed significance on the food recovery program. On one hand participants really found benefit in the collaborative project with Sodexo while, on the other hand, the partnership received harsh criticism. For example, some clients purposefully watched the menu of the dining halls so they knew when to visit the Campus Cupboard and appreciated the variety of easy to make food, while others expressed discontent for the repackaged foods. For example, Clarissa shared, "like, if you don't swipe in the dining hall, it's like $\$ 10$ or $\$ 13$ otherwise. It's like it's not worth it, we're not the biggest fans of the Sodexo food."

Personal Hygiene Products. The Campus Cupboard does not just provide food. From time to time the donation boxes from Harvesters or Walmart contain personal hygiene products like toothbrushes, toothpaste, soaps, shampoos, etc. Many participants in the study indicated these items have an indirect effect on freeing up resources for purchasing food. Charlotte's comment is very representative of how these items impact the community especially: "for people who can't get off campus and they need this sort of thing, so maybe like some shampoo or conditioner or something like that. Or, if again 
for low income people who can't afford like some notebooks or stuff like that." In the end non-food items were of great significance to the clients.

Opportunities for volunteers. Many of the volunteers are motivated by philanthropic requirements from their courses, specifically the university's nursing program's Culture and Sustainability in Health course. So, in addition to providing food and resources for students in need, the Campus Cupboard also provides a place for community members needing or wanting volunteer hours. As a result, many volunteers took pride and joy in their ability to help people within the campus community. Providing the opportunity to serve is a significant piece of this community:

I work at a hospital so I could have just volunteered there, and did my normal thing, but it doesn't really mean anything then. I really think it helps people, and obviously I want to be a nurse, so I want to help people, and me being able to do that drives me to want to do it, motivates me.

Communication. Another theme of significance the research question produced was the importance of communication. There were two specific areas participants indicated communication was important, specifically internal communication between volunteers and staff, and then external communication between the Campus Cupboard and its clients. The importance of communication emerged as a theme specifically surrounding the confusion on days and hours the Cupboard was open, and policies on how many items clients could take. Additionally, many participants alluded to the fact that the need for these resources is much larger than those who currently use the cupboard and communicating the Cupboard's existence and need was important for both clients and potential donors. 
No judgment or stigma. Another significant service the Cupboard offers its clients is the dignity of a judgment free environment. Almost every participant agreed that the feeling of not being judged or looked down upon was attractive to its clients. Many participants already acknowledged the societal norm of a penny-pinching college lifestyle, but one aspect of the Cupboard that was significant to both clients, employees and volunteers alike was creating a community that does not look down on people for trying or struggling with resources. One client pointed out the bottom line about using the Cupboard, “...it doesn't mean that you're not trying. Like, I have two jobs, and I'm a billion miles from home. So, I mean just because you aren't doing the same thing I'm doing, or I'm not doing the same thing you're doing, doesn't mean that it's not there for both of us."

\section{Discussion}

The growing number of food pantries emerging on college campuses indicates the increasing extent of food insecurity among college students, but the sheer complexity of college food insecurity makes it difficult to understand the individual perspectives and distinct needs of those being affected (Henry, 2017). The relationship of the current study to previous research will follow the national conversation's suggestions that time, transportation, self-efficacy, financial resources, and poor kitchen facilities contribute to inadequate food consumption, as well as poor diet quality among college students (Dubick et al. 2016; S. Goldrick-Rab et al. 2018; Henry, 2017; O’Neill \& Maguire, 2017).

\section{Self-efficacy}


Being able to properly balance a healthy lifestyle with the academic, social, and financial demands of university life requires developing skills in both financial planning and food management (Gaines et al. 2014). The present study found self-reliance to be a necessary skill for coping with the stress of college. In fact, the study revealed a broad spectrum of abilities regarding financial management, budgeting for groceries, and preparing meals. On one end of the spectrum clients recognized their own shortcomings and lack of experience. For example, Clarissa confessed:

The cooking class was not much of anything. She'd like hand out some recipes and then it might turn out well. I remember screwing up the Alfredo sauce, so we just had butter noodles. I wasn't prepared for really cooking. My mom has really not had me cook things before, she usually does it. Probably for the best, in case I screw up dinner.

These findings from the current study run parallel to researchers who have indicated that food insecurity is largely the result of financial constraints and/or lack of financial and food management skills. In fact, other studies reported very similar experiences. According to Watson et al. (2017), "Few students mentioned learning about food and nutrition as part of their K-12 education" (p. 135). Comparatively though, students who reported the ability to track expenses and the ability to cook for themselves were more likely to indicate being food secure (Brown et al. 2005; Gaines et al. 2014; McArthur et al. 2018).

Also, participants demonstrated superlative self-efficacy, both in a sense of financial management and cooking ability. Particularly, a young man named Charles explained, "I'll try to cook something on Monday that can at least last me until 
Wednesday, and so this week I made chili... and I made that mostly out of stuff that I've got out of the campus cupboard.”

When considering the same client's ability to budget and prepare meals for himself, this study found evidence to support the Matthews et al. (2016) research calling for improving practical advice and experiences that support skill development (eg. meal planning, using leftovers, lists of staple foods and equipment, and simple recipes for living on their own), could improve students' self-efficacy. To illustrate, Charles admitted,

I actually do not find it too hard to make stuff out of things I find at the panty. So, each week they kind of offer some things you can make stuff out of. So they offer a bunch of canned vegetables and everything, they have some rotisserie chickens, they have bagels and all of that, but one of the main things I do is I grab rotisserie chicken and I'll end up having some vegetables and depending on what they have in there that might vary, so say that it could be potatoes and this last time I went, it was a couple of weeks ago, and they had potatoes, and I ended up making biscuits and gravy... Yea, it cuts down that grocery bill a bit. They had chili beans a couple of weeks ago, and I had a can of tomato sauce in the house already and they also had a cooked beef, and I used a food processor that I got from the thrift store and chopped it up a bit more fine, so it's easier to be in the chili

Specifically, Matthews, Doerr, and Dworatzek (2016) suggest these mastery experiences could be offered through formal channels such as student health services or extension, or 
informal channels such as peer education programs. To encourage uptake of these skills, additional concepts such as goal setting and self-monitoring could also be taught.

Specifically, an interesting educational nexus can be drawn between differing client perspectives regarding the desirability of the items found in the Cupboard. For example, clients who lack the same practicality or cooking experience as Charles see less potential in the same available food items. To illustrate, a different client critiqued the same selection in the Cupboard. "It is a lot of green beans, peas, and then maybe some pasta, and you can't really do much with that, and I can't necessarily have a bowl of green beans." As a result, this study was able to draw a similar conclusion as Byker Shanks (2017) who argued that by "simultaneously enhancing the food pantry environment and enriching the self-efficacy of food pantry clients makes more nutritious foods more accessible and more desirable" (p. 575).

\section{Limited Cooking Facilities}

What is evident from this study is that even though students may be food insecure, limited cooking facilities prohibit complete access to the food available within the Campus Cupboard. For example, Caroline emphasized:

I used to live in Ellis The kitchen there, Ellis is like a horseshoe, and there's like three separate buildings, and there's one kitchen, and that building can house up to 900 students, so all 900 students share one kitchen.

Several other studies reported similar instances. For example, Henry (2017) found that students who lived in the dorms noted that they do not have the proper kitchen appliances to store and cook food. Without a refrigerator or stove, they were limited in the types of food they could prepare. One participant noted that she wished to purchase healthier 
foods, but finances and a lack of proper refrigeration were the major barriers to buying unprocessed, whole or natural foods, such as vegetables and fruits

In connection to Henry (2017), participants in this current study similarly viewed the common misunderstanding surrounding college food insecurity as the accepted 'normal' around campus. For example, Sam argued, "I think that kids who are actually going hungry here at school, are just looked at as just a normal college kid, and I think that's not good." Likewise, Charles referred to the common perception that college students are supposed to struggle, but also pointed out the gravity of the situation:

So, it's kind of made into a joke, so it's always the running gag about how college students, how they live off of ramen noodles and stuff like that, and I mean it's funny but at the same time it's really true, because it's like a lot of college students can't afford to go to the grocery store every week, and by the time they're at the end of waiting for an influx of money, say it's from getting paid from their jobs or from money from their parents per say, they might actually just be living off of Spam and Ramen noodles at home.

The lack of kitchen facilities leaves students with little options outside of the more expensive meal plans. In a large state-wide study focusing on the University of California system, Watson et al. (2017) indicated students lacked access to kitchen space to prepare food to supplement meal plans or cook with friends. This is ultimately problematic for several reasons. First, it leaves students with less healthier options like microwaveable food or processed high sugar snacks. Sam indicated:

When I worked there, and I would go, I would just kind of see it as a way to just get snack stuff, just a way to get stuff in my dorm where if the dining hall was 
closed, I could just munch on something. I would never take like big bulky like proteins and like actual meals because I had a mini-fridge and a microwave. So, it's not like I could cook actually. So, I was just getting like cupcakes. I would get the chips and I would get the cereal because I could always eat dry cereal.

This phenomenon was not isolated to the present study, in fact other authors pointed out similar findings. For example, Cooksey-Stowers et al. (2019) found, "from the perspective of some volunteers and staff members in the study, clients choose items to address hunger before their nutritional or health needs" (p.11). Although there are kitchens for use on campus, one conclusion that can be safely drawn is that the limited kitchen facilities within the dorms at UCM are adding to the rising flood waters within the food swamp environment. Cali acknowledged, "We have one kitchen in the building. It's supposed to have two, but the other one, the oven broke, and there's like nothing else in there, so it's no point." Christina agreed, "You have to go downstairs and check out items, like pots and pans, and if someone else is there then you have to wait. It's hard to cook anything."

These findings not only coincide with previous literature but help us better appreciate the range of obstacles food insecure clients face while in school. Gaines et al. (2014) asserted that individuals scoring higher on the measure of resource adequacy, but not cooking self-efficacy, were less likely to be food insecure. Ultimately, students just having access to adequate kitchen facilities improved their ability to establish food security. This was nothing more evident than when one client, Cali, noted, "That is my favorite thing, but I don't know how to make grilled cheese in my dorm."

\section{Implications}




\section{Building a Culturally Responsive Food Pantry}

Accommodating alternative eating patterns shows respect for clientele while increasing effectiveness, but more importantly it reflects cultural responsiveness. Providing culturally recognizable food for students is just one strategy that can build human dignity, maximize access and affordability of healthy foods, and provide an environment which assists students in achieving the best possible physical and academic outcomes (Gallegos et al. 2014). One specific example would be offering easily storable rice, beans, and lentils. These products are not only culturally recognizable and healthy, but are largely sought after by international students. In fact, students revealed traveling to the city to purchase these items. For example, Cynthia shared:

Basmati rice is something Indian students would appreciate. Like, in the Walmart we have limited options for vegetables. In India we have lots of options for vegetables, but here we have limited options, so if we want to eat something Indian vegetables, then we have to go to the Indian store in Lee's Summit, and then buy from there.... If they can keep some Indian stuff there like wheat flour, rice flour, and some Indian pulses.

Regardless of the cultural variances, the common thread is the distance these students are willing to travel to not just have a taste of home, but to grasp a sense of dignity while living abroad. For example, Cindy unpacked her perspective:

Rice, yes. We eat rice a lot in Africa. Where I come from in Nigeria, we eat beans, but it's like peas. Not beans, it's like peas, like a lentil. We eat something back at home called a yam. Yam is a tuber. It's like potato but a bigger version of 
a potato. It's big, really big, so we cook that and eat it with egg, so it's my

favorite meal. I drive all the way to Kansas City to get it in an African store.

Staff also shared a similar perspective from the point of view of an international student. Again, rice serves as a universally important item:

Well, bags of uncooked rice would be super helpful, even dry noodles might be helpful. Because in general Asians all rely on rice a lot, so I'm still thinking that rice would be super helpful.

Considering the wide variety of cultural backgrounds from which clients come is only part of a series of strategies scholars are calling for that maintain human dignity. (Gallegos et al. 2014). Understanding these international communities that food pantries serve including affordability, health, and the development of cooperation with both the private and public sector, will strengthen community university partnerships.

Specifically, this study recommends building a connection with the international stores in the greater Kansas City area. At the same time, current literature argues that food pantries with a clear way of communicating information to clients include clear written messages in multiple languages responding to client need in a culturally sensitive way (CookseyStowers et al. 2018; Gallegos et al. 2014; Nikolaus et al. 2018).

Networking. Fighting hunger is generally limited by unforeseen obstacles that are oftentimes overcome by the creativity of a multidisciplinary approach. Networking with a wide variety of volunteers, organizations, and ideas often creates incredible solutions to problems at hand.

Volunteers. There is a diverse range of philanthropic organizations around the UCM campus that offer a wide variety of skills, time, and resources that would enhance 
the capability of the Campus Cupboard. One recommendation would be extending the network of volunteers to include a variety of organizations around campus. For example, this study found the majority of volunteers during the time frame of the study were nursing students fulfilling required community service hours for one of their courses. These individuals represent just one group of many who are not just fulfilling requirements, but rather want to make a difference. Valerie confirmed:

Yeah, I mean I work at a hospital so I could have just volunteered there, and did my normal thing, but it doesn't really mean anything then. I really think it helps people, and obviously I want to be a nurse, so I want to help people, and me being able to do that drives me to want to do it, motivates me.

Arguably, there are more organizations whose missions align with the purpose of the Campus Cupboard and whose members would bring a great deal of knowledge and support to the effort. Ultimately this study recommends extending the network of volunteers to create a wider web of time, talent, and campus wide buy-in.

\section{Tailoring Outreach}

Studies reveal that almost 90 percent of students participating in campus food banks are still food insecure despite measures to alleviate the stress (Farahbakhsh et al. 2017; Freudenberg et al. 2011; Hagedorn \& Olfert, 2018). Meeting the individual needs of clients requires a community centered approach focused on three specific outreach agendas: Consistently identifying clients' needs, making individual food recommendations, and improving education. Because outreach is dependent on the surrounding communities, creative approaches and flexibility will be required to find success. 
First, in order to identify needs, Cady (2014) suggests short-term action should include developing assessments to determine the prevalence and severity of food insecurity in addition to barriers and specific populations who are being disproportionately affected. Although the Wisconsin HOPE Lab has already conducted a detailed campus-wide study, additional inquiries and engagement with clients will create a deeper connection with those individuals the Cupboard wants to reach (Crutchfield \& Maguire, 2018). Because scholars recognize that food insecurity is rarely an isolated condition but rather a sign of much deeper financial hardship, involving other campus resources to help communicate the availability of the Cupboard to their communities would be helpful in identifying needs. For example, because clients are already aware of the variety of services UCM provides its students, placing points of access to needs assessments in other offices would enhance communication. As such, Cayden noted, "UCM has services in place that are accessible for dealing with stressors, student engagement, student counseling, student accessibility, mental health and the GISS office." As a result, this study suggests simple two-way lines of communication through social media like Twitter, Facebook, Snap Chat, etc.

\section{Conclusion}

The Higher Education Act (HEA) that was signed at the beginning of the 21st century is a mix of political, economic, demographic, and technological developments that are transforming K-12 and higher education and, "with the help of federal policy, narrowing the distance that has long separated the two sectors" (Loss \& McGuinn, 2016, p. 1). However, converging the two educational sectors requires the advanced understanding of the entire system as a tightly coupled infrastructure to ensure student 
success and lower attrition. As a result, some scholars are calling for, "more opportunities for work placement through university and/or community partnerships may also be effective in addressing potential income shortfalls that students might face" (Bruening et al., 2016, p.1453). In conclusion, there is a pattern behind food insecurity. Specifically, a combination of consistently specific conditions (i.e, lack of time, self-efficacy, kitchen facilities, and lack of transportation) that overlap one or more certain demographic characteristics (i.e. first-generation college student, Pell Grant Recipients, international students, etc.,) that work together produce a syndrome effect which ultimately corrodes one's ability to provide sufficient nutrition for themselves. As a result, recommendations constructed from this perspective will be a more sustainable solution to addressing the root causes of nutrient deficiency.("Hunger and poverty in Missouri: Map the meal gap," 2016) 


\section{References}

Beck, C. D. (2014a). Antecedents of servant leadership: A Mixed methods study. Journal of Leadership \& Organizational Studies, 21(3), 299-314. https://doi.org/doi: $10.1177 / 1548051814529993$

Beck, C. D. (2014b). Antecedents of servant leadership: A Mixed methods study. Journal of Leadership \& Organizational Studies, 21(3), 299-314. https://doi.org/10.1177/1548051814529993

Bemel, J. E., Brower, C., Chischillie, A., \& Shepherd, J. (2016). The impact of college student financial health on other dimensions of health. American Journal of Health Promotion, 30(4), 224-230. https://doi.org/10.1177/0890117116639562

Bennett, J., Greene, G., \& Schwartz-Barcott, D. (2013). Perceptions of emotional eating behavior. A qualitative study of college students. Appetite, 60(1), 187-192. https://doi.org/10.1016/j.appet.2012.09.023

Blagg, K., Gundersen, C., Schanzenbach, W., \& Zilak, J. P. (2017). Assessing Food insecurity on campus: A national look at food insecurity among America's college students.

Blagg, K., Gundersen, C., Whitmore Schanzenbach, D., \& Ziliak, J. P. (2017). Assessing food insecurity on campus: A national look at food insecurity among America's college students. Urban Institute, (August), 1-15. Retrieved from www.urban.org

Bolman, L. G., \& Deal, T. E. (2013). Reframing organizations: Artistry, choice, and leadership (5th ed.). San Francisco, CA: Jossey-Bass.

Bridwell, L. G., \& Wahba, M. A. (1976a). Maslow reconsidered: A review of research on the need hierarchy theory. Organizational Behavior and Human Performance, 
15(2), 212-240. https://doi.org/10.1016/0030-5073(76)90038-6

Bridwell, L. G., \& Wahba, M. A. (1976b). Maslow reconsidered: A review of research on the need hierarchy theory. Organizational Behavior and Human Performance, 15(2), 212-240. https://doi.org/10.1016/0030-5073(76)90038-6

Broton, K., Frank, V., \& Goldrick-Rab, S. (2014). Safety, security, and college attainment: An investigation of undergraduates' basic needs and institutional response. Wisconsin Hope Lab. Madison, WI. Retrieved from http://wihopelab.com/publications/APPAM.Draft.10.28.2014.pdf

Broton, K., \& Goldrick-Rab, S. (2016). The dark side of college (un)affordability: Food and housing insecurity in higher education. Change, 48(1), 16-25. https://doi.org/https://doi.org/10.1080/00091383.2016.1121081

Broton, K. M., \& Goldrick-Rab, S. (2017). Going without: An exploration of food and housing insecurity among undergraduates. Educational Researcher, 47(2). https://doi.org/10.3102/0013189X17741303

Broton, K., Weaver, K., \& Mai, M. (2018). Hunger in higher education: Experiences and correlates of food insecurity among Wisconsin undergraduates from low-income families. Social Sciences, 7(10), 1-25. https://doi.org/10.3390/socsci7100179

Brown, L. B., Dresen, R. K., \& Eggett, D. L. (2005). College students can benefit by participating in a prepaid meal plan. Journal of the American Dietetic Association, 105(3), 445-448. https://doi.org/10.1016/j.jada.2004.12.030

Bruening, M., Brennhofer, S., Van Woerden, I., Todd, M., \& Laska, M. (2016). Factors related to the high rates of food insecurity among diverse, urban college freshmen. Journal of the Academy of Nutrition and Dietetics, 116(9), 1450-1457. 
https://doi.org/10.1016/j.jand.2016.04.004

Byker Shanks, C. (2017). Promoting food pantry environments that encourage nutritious eating behaviors. Journal of the Academy of Nutrition and Dietetics, 117(4), 523525. https://doi.org/10.1016/j.jand.2016.12.020

Cady, C. L. (2014). Food insecurity as a student issue. Journal of College \& Character, 15(4), 265-271. https://doi.org/10.1515/jcc-2014-0031

Cafer, A., Chapman, D., Freeman, K., \& Rikoon, S. (2016). Missouri hunger atlas 2016. Columbia, MO. Retrieved from http://foodsecurity.missouri.edu

Cafer, A., Foulkes, M., Heflin, C., Hermsen, J., Raedeke, N., \& Rikoon, S. (2013). Coping with hunger in 2013 : Food pantry clients and households in the service region of the food bank for central and northeast Missouri. Interdisciplinary Center for Food Security (Vol. 861). Columbia, MO. Retrieved from http://foodsecurity.missouri.edu

Campbell, E. C., Ross, M., \& Webb, K. L. (2013). Improving the nutritional quality of emergency food: A study of food bank organizational culture, capacity, and practices. Journal of Hunger and Environmental Nutrition, 8(3), 261-280. https://doi.org/10.1080/19320248.2013.816991

Campbell, E., Hudson, H., Webb, K., \& Crawford, P. B. (2011). Food preferences of users of the emergency food system. Journal of Hunger and Environmental Nutrition, 6(2), 179-187. https://doi.org/10.1080/19320248.2011.576589

Campus cupboard. (2019). Retrieved June 18, 2019, from https://www.ucmo.edu/currentstudents/student-services/campus-cupboard/index.php

Chaparro, M. P., Zaghloul, S. S., Holck, P., \& Dobbs, J. (2009a). Food insecurity 
prevalence among college students at the University of Hawaii at Mānoa. Public Health Nutrition, 12(11), 2097-2103. https://doi.org/10.1017/S1368980009990735

Chaparro, M. P., Zaghloul, S. S., Holck, P., \& Dobbs, J. (2009b). Food insecurity prevalence among college students at the University of Hawaii at Mānoa. Public Health Nutrition, 12(11), 2097-2103. https://doi.org/10.1017/S1368980009990735

Chen, M. (2018). University of Central Missouri Fact Book. Warrensburg, MO. Retrieved from https://www.google.com/url?sa=t\&rct=j\&q=\&esrc=s\&source=web\&cd=1\&ved=2ah UKEwiduZSknfbiAhUMW60KHXwHDisQFjAAegQIABAC\&url=https\%3A\%2F $\% 2$ Fwww.ucmo.edu\%2Foffices\%2Funiversity-analytics-and-institutionalresearch\%2Ffactbook.pdf\&usg=AOvVaw3nqe-bvydvcUzHtDivJL_j

Coleman-Jensen, A., Gregory, C., \& Singh, A. (2018). Household Food Security in the United States in 2017. Economic Research Report Number 256. https://doi.org/10.2139/ssrn.2504067

Coleman-Jensen, A., Rabbitt, M. P., \& Gregory, C. A. (2017). Examining an "experimental" food-security-status classification method for households with children. Economic Research Service (Vol. 1945). Retrieved from www.ers.usda.gov

Cooksey-Stowers, K., Read, M., Wolff, M., Martin, K. S., McCabe, M., \& Schwartz, M. (2018). Food pantry staff attitudes about using a nutrition rating system to guide client choice. Journal of Hunger \& Environmental Nutrition, 1-15. https://doi.org/10.1080/19320248.2018.1512930

Cooksey-Stowers, K., Read, M., Wolff, M., Martin, K. S., McCabe, M., \& Schwartz, M. 
(2019). Food pantry staff attitudes about using a nutrition rating system to guide client choice. Journal of Hunger and Environmental Nutrition, 14(1-2), 35-49. https://doi.org/10.1080/19320248.2018.1512930

Creswell, J. W. (2014). Researach Design (4th ed.). Thousand Oaks, California: Sage Publications.

Crutchfield, R., \& Maguire, J. (2018). Study of student basic needs. The California State University.

Datnow, A., \& Park, V. (2014). Data-driven leadership. San Francisco, CA: Jossey-Bass.

Dubick, J., Mathews, B., \& Cady, C. L. (2016). Hunger on campus: The challenge of food insecurity for college students. CUFBA website. https://doi.org/10.5479/si.01960768.38.437

Dubick, J., Matthews, B., \& Cady, C. (2016). Hunger on campus: The challenge of food insecurity for college students. College and University Food Bank Alliance.

Eisenberger, N. I., Lieberman, M. D., \& Williams, K. D. (2003). Does rejection hurt? An fMRI study of social exclusion. Science, 302(5643), 290-292. https://doi.org/10.1126/science.1089134

Farahbakhsh, J., Hanbazaza, M., Ball, G. D. C., Farmer, A. P., Maximova, K., \& Willows, N. D. (2016). Food insecure student clients of a university-based food bank have compromised health, dietary intake and academic quality. Nutrition \& Dietetics, 74(1), 67-73.

Farahbakhsh, J., Hanbazaza, M., Ball, G. D. C., Farmer, A. P., Maximova, K., \& Willows, N. D. (2017). Food insecure student clients of a university-based food bank have compromised health, dietary intake and academic quality. Nutrition and 
Dietetics, 74(1), 67-73. https://doi.org/10.1111/1747-0080.12307

Feeding America annual report. (2017). Chicago, Illinois. Retrieved from

www.feedingamerica.org

Feeding America Annual Report. (2018). Chicago, Illinois. Retrieved from

www.feedingamerica.org

Feeding America history. (2019). Retrieved January 20, 2019, from

https://www.feedingamerica.org/about-us/our-history

Fink, A. (2017). How to conduct surveys: A step-by-step guide (6th ed.). Thousand Oaks, CA.: Sage Publications.

Food manners. (1955). Warrensburg, MO.

Food Research \& Action Center. (2019a). Profile of hunger, poverty, and federal nutrition programs. https://doi.org/10.4135/9781452276151.n284

Food Research \& Action Center. (2019b). Profile of hunger, poverty, and federal nutrition programs. https://doi.org/10.4135/9781452276151.n284

French, J. R. P., \& Raven, B. (2005). The bases of social power. In Jay M. Shafritz, S. J. Ott, \& Y. S. Jang (Eds.), Classics of organizational theory (6th ed., pp. 311-320). Belmont, CA.

Freudenberg, N., Manzo, L., Jones, H., Kwan, A., Tsui, E., \& Gagnon, M. (2011a). Food insecurity at CUNY: Results from a survey of CUNY undergraduate students. New York. Retrieved from http://web.gc.cuny.edu/che/cunyfoodinsecurity.pdf

Freudenberg, N., Manzo, L., Jones, H., Kwan, A., Tsui, E., \& Gagnon, M. (2011b). The Psychological Well-Being of CUNY Students: Results from a Survey of CUNY Undergraduate Students. 
Fyall, R., \& Levine Daniel, J. (2018). Pantries and policy Implementation: Using nonprofit priorities to understand variation in emergency food assistance. Nonprofit and Voluntary Sector Quarterly, 47(4_suppl), 11S-33S. https://doi.org/10.1177/0899764017753318

Gagliardi, J. S., Parnell, A., \& Carpenter-Hubin, J. (2018). The analytics revolution in higher education: Big data, organizational learning, and student success. Sterling, VA: Stylus.

Gaines, A., Robb, C. A., Knol, L. L., \& Sickler, S. (2014). Examining the role of financial factors, resources and skills in predicting food security status among college students. International Journal of Consumer Studies, 38(4), 374-384. https://doi.org/10.1111/ijcs.12110

Gallegos, D., Ramsey, R., \& Ong, K. W. (2014). Food insecurity: Is it an issue among tertiary students? Higher Education, 67(5), 497-510. https://doi.org/10.1007/s10734-013-9656-2

George, B., Sims, P., Mclean, A. N., George, B., Sims, P., Mclean, A. N., \& Mayer, D. (2007). Discovering your authentic leadership. Harvard Business Review, (February), 129-138.

Ghafoor, A. (2012). Active and Proactive Characteristics of Physiological Needs. Language in India, 12(7), 348-366. Retrieved from http://proxy.mul.missouri.edu/login?url=http://search.ebscohost.com/login.aspx?dire ct=true $\& \mathrm{db}=$ ufh $\& A N=88819915 \&$ site $=$ eds-live $\&$ scope $=$ site

Gill, S. J. (2010). Developing a learning culture in nonprofit organizations. Thousand Oaks, CA: Sage Publications. 
Goldrick-Rab, K., \& Broton, S. (2016). The Dark Side of College (Un) Affordability. College Teaching and Learning for Change: Students and Faculty Speak Out. Azusa, CA. https://doi.org/10.4324/9781315302393

Goldrick-Rab, S., Baker-Smith, C., Coca, V., Looker, E., \& Williams, T. (2019). College and university basic needs insecurity: A national \# realcollege survey report. Madison, WI. Retrieved from http://wihopelab.com/

Goldrick-Rab, S., \& Broton, K. (2013). Housing Instability among College Students, (October), 1-8. Retrieved from http://www.massresources.org/section8-financialeligibility.html

Goldrick-Rab, S., Richardson, J., \& Hernandez, A. (2017). Hungry and homeless in college: Results from a a national study of basic needs insecuirty in higher education. Madison, WI. Retrieved from www.acct.org

Goldrick-Rab, S., Richardson, J., \& Hernandez, A. (2018). Hungry and homeless in college: Results from a national study of basic needs insecurity in higher education. Madison, WI. Retrieved from http://homelesshub.ca/resource/still-hungry-andhomeless-college

Goleman, D. (2011a). What makes a leader? In Harvard Business Review 10 must reads on leaderhsip (Reprinted from June 1996) (pp. 1-21). Boston, Massachuttes: Harvard Business School Publishing Corporation.

Goleman, D. (2011b). What makes a leader? In Harvard Business Review 10 must reads on leaderhsip (Reprinted from June 1996) (pp. 1-21). Boston, Massachuttes: Harvard Business School Publishing Corporation.

Greenleaf, R. K. (1970). The servant as leader. Indianapolis, IN: Greenleaf Center. 
Gundersen, C. (2013). Food insecurity is an ongoing national concern. Advances in Nutrition: An International Review Journal, 4(1), 36-41. https://doi.org/10.3945/an.112.003244

Gundersen, Craig, \& Ziliak, J. P. (2018). Food insecurity research in the united states: Where we have been and where we need to go. Applied Economic Perspectives and Policy, 4O(1), 119-135. https://doi.org/10.1093/aepp/ppx058

Ha, E. J., \& Caine-Bish, N. (2009). Effect of nutrition intervention using a general nutrition course for promoting fruit and vegetable consumption among college students. Journal of Nutrition Education and Behavior, 41(2), 103-109. https://doi.org/10.1016/j.jneb.2008.07.001

Hagedorn, R. L., \& Olfert, M. D. (2018). Food insecurity and behavioral characteristics for academic success in young adults attending an Appalachian university. Nutrients, 10(3), 361 .

Hanbazaza, M., Ball, G. D. C., Farmer, A., Maximova, K., \& Willows, N. D. (2016). Filling a Need: Sociodemographic and Educational Characteristics Among Student Clients of a University-Based Campus Food Bank. Journal of Hunger and Environmental Nutrition, 11(4), 569-577. https://doi.org/10.1080/19320248.2015.1128864

Handforth, B., Hennink, M., \& Schwartz, M. B. (2013). A qualitative study of nutritionbased initiatives at selected food banks in the feeding America network. Journal of the Academy of Nutrition and Dietetics, 113(3), 411-415. https://doi.org/10.1016/j.jand.2012.11.001

Helland, M. R., \& Winston, B. . (2005). Towards a deeper understanding of hope and 
leadership. Journal of Leadership \& Organizational Studies, 12(2), 42-54.

Henry, L. (2017). Understanding food insecurity among college students: Experience, motivation, and local solutions. Annals of Anthropological Practice, 41(1), 6-19. https://doi.org/10.1111/napa.12108

Hess, F. M., \& Lautzenheiser, Daniel, K. (2012). Putting the punch in parent power. American Enterprise Institute for Public Policy Research, August(5), 1-8. Retrieved from www.aei.org

Horner, J., \& Minifie, F. D. (2011). Research ethics I: Responsible conduct of research (RCR)-Historical and contemporary issues pertaining to human and animmal experimentation. Journal of Speech, Language, and Hearing Research, 54(February), S303-S329.

Hunger and poverty in Missouri: Map the meal gap. (2016). Retrieved from http://map.feedingamerica.org/county/2016/overall/missouri/county/johnson

Jablonski, B. R., McFadden, D. T., \& Colpaart, A. (2016). Analyzing the Role of Community and Individual Factors in Food Insecurity: Identifying Diverse Barriers Across Clustered Community Members. Journal of Community Health, 41(5), 910923. https://doi.org/10.1007/s10900-016-0171-0

Jansson, N. (2013). Organizational change as practice: A critical analysis. Journal of Organizational Change Management, 26(6), 1003-1019. https://doi.org/10.1108/JOCM-09-2012-0152

Johnson, A. G. (2018). Privilege, power, and difference (3rd ed.). New York: McGrawHill.

Kaiser, M. L., \& Cafer, A. M. (2017). Exploring long-term food pantry use: Differences 
between persistent and prolonged typologies of use. Journal of Hunger and Environmental Nutrition, 12(1), 46-63.

https://doi.org/10.1080/19320248.2016.1157554

Karasar, B., \& Baytemir, K. (2018). Need for social approval and happiness in college students: The mediation role of social anxiety. Universal Journal of Educational Research, 6(5), 919-927. https://doi.org/10.13189/ujer.2018.060513

Kelchen, R., Goldrick-Rab, S., \& Hosch, B. (2017). The costs of college attendance: Examining variation and consistency in institutional living cost allowances. Journal of Higher Education, 88(6), 947-971. https://doi.org/10.1080/00221546.2016.1272092

Kenrick, D. T., Neuberg, S. L., Griskevicius, V., Becker, D., \& Schaller, M. (2010). Goal-driven cognition and functional behavior: The fundamental-motives framework. Current Directions in Psychological Science, 19(1), 63-67. https://doi.org/10.1177/0963721409359281

Kenrick, Douglads. (2011). Renovating the Pyramid of Built Upon Ancient Foundations. Perspect Psychol Sci, 5(3), 292-314. https://doi.org/10.1177/1745691610369469.Renovating

Kenrick, Douglas. (2017). Self-actualization, human nature, and global social problems. Society, 54(6), 520-523.

Kofman, F., \& Senge, P. M. (1993). Communities of commitment: The heart of learning organizations. Organizational Dynamics, 4(12), 16-19. https://doi.org/10.1016/0090-2616(93)90050-B

Koltko-Rivera, M. E. (2006). Rediscovering the later version of Maslow's hierarchy of 
needs: Self-transcendence and opportunities for theory, research, and unification. Review of General Psychology, 10(4), 302-317. https://doi.org/10.1037/10892680.10.4.302

Krems, J. A., Kenrick, D. T., \& Neel, R. (2017a). Individual perceptions of Selfactualization: What functional motives are linked to fulfilling one's full potential? Personality and Social Psychology Bulletin, 43(9), 1337-1352. https://doi.org/10.1177/0146167217713191

Krueger, R. A., \& Casey, M. A. (2015a). Focus groups: A practical gide for applied research (5th ed.). Los Angeles, California: Sage Publications.

Krueger, R. A., \& Casey, M. A. (2015b). Focus groups: A practical guide for applied research. (H. Salmon, A. Villarruuel, T. Buyan, \& P. Schroeder, Eds.) (5th ed.). Thousand Oaks: Sage Publications.

Levi, D. (2017). Group dynamics for teams (5th ed.). Thousand Oaks, CA: Sage Publications.

Lincoln, Y. S., \& Guba, E. G. (1985). Naturalistic inquiry. Newbury Park, CA: Sage Publications.

Manning, K. (2013). Organized anarchy. In Organizational theory in higher education (pp. 11-24). New York, NY: Routledge.

Martin, K. S., Wu, R., Wolff, M., Colantonio, A. G., \& Grady, J. (2013). A novel food pantry program: Food security, self-sufficiency, and diet-quality outcomes. American Journal of Preventive Medicine, 45(5), 569-575. https://doi.org/10.1016/j.amepre.2013.06.012 Maslow, A.H. (1943). A theory of human motivation. Psychological Review, 50, 370- 
396. https://doi.org/10.1037/h0054346

Maslow, Abraham H. (1943). A theory of human motivation. Psychological Review. https://doi.org/10.4324/9781912282517

Matthews, J. I., Doerr, L., \& Dworatzek, P. D. N. (2016). University students intend to eat better but lack coping self-efficacy and knowledge of dietary recommendations. Journal of Nutrition Education and Behavior, 48(1), 12-19. https://doi.org/10.1016/j.jneb.2015.08.005

McArthur, Laura H., Fasczewski, K. S., Wartinger, E., \& Miller, J. (2018). Freshman at a university in Appalachia experience higher rate of campus than family food insecurity. Journal of Community Health, (43), 969-976. https://doi.org/10.1016/j.appet.2012.09.023

McArthur, Laura Helena, Ball, L., Danek, A. C., \& Holbert, D. (2018). A high prevalence of food insecurity among university students in Appalachia reflects a need for educational interventions and policy advocacy. Journal of Nutrition Education and Behavior, 50(6), 564-572. https://doi.org/10.1016/j.jneb.2017.10.011

Mcleod, B. S. (2017). Maslow 's hierarchy of needs the expanded hierarchy of needs: (December), 1-8.

Merriam, S. B., \& Bierema, L. L. (2014). Adult learning: Linking theory and practice. San Francisco, CA: John Wiley \& Sons, Inc.

Merriam, S. B., \& Tisdell, E. J. (2016). Qualitative research: A guide to design and implementation (4th ed.). San Francisco, CA.: Jossey-Bass.

Micevski, D. A., Thornton, L. E., \& Brockington, S. (2014). Food insecurity among university students in Victoria: A pilot study. Nutrition and Dietetics, 71(4), 258- 
264. https://doi.org/10.1111/1747-0080.12097

Mintzberg, H. (2005). The five basic parts of the organization. (J.M. Shafritz, J. S. Ott, \& S. J. Yong, Eds.), Classics of organizational theory (Sixth, pp. 219-230). Belmont, CA.

Mirabitur, E., Peterson, K. E., Rathz, C., Matlen, S., \& Kasper, N. (2016). Predictors of college-student food security and fruit and vegetable intake differ by housing type. Journal of American College Health, 64(7), 555-564.

https://doi.org/10.1080/07448481.2016.1192543

Morris, L. M., Smith, S., Davis, J., \& Null, D. B. (2016). The prevalence of food security and insecurity among Illinois university students. Journal of Nutrition Education and Behavior, 48(6), 376-382. https://doi.org/10.1016/j.jneb.2016.03.013

Murphy, J. (2019). UCM announces changes in dining options as room and boards rates are set.

Newcomer, K., \& Hatry Harry, P. (2015). Handbook of practical program evaluation (4th ed.). Hoboken, New Jersey: John Wiley \& Sons, Inc.

Nikolaus, C. J., Laurent, E., Loehmer, E., An, R., Khan, N., \& McCaffrey, J. (2018). Nutrition environment food pantry assessment Tool (NEFPAT): Development and evaluation. Journal of Nutrition Education and Behavior, 50(7), 724-728.e1. https://doi.org/10.1016/j.jneb.2018.03.011

Noltemeyer, A., Bush, K., Patton, J., \& Bergen, D. (2012). The relationship among deficiency needs and growth needs: An empirical investigation of Maslow's theory. Children and Youth Services Review, 34(9), 1862-1867. https://doi.org/10.1016/j.childyouth.2012.05.021 
Normal farm makes good. (1911, October). The Normal Student, p. 1 (Volume 2).

Northouse, P. G. (2016). Leadership: Theory and practice (Seventh ed). Los Angeles: SAGE Publications, Inc.

O’Neill, M., \& Maguire, J. (2017). College student self reported food insecurity and correlations with health and academic performance. Journal of Behavioral and Social Sciences, 4, 34-40.

Oved, O. S. (2017). Rethinking the place of love needs in Maslow's hierarchy of needs. Society, 54(6), 537-538. https://doi.org/https://doi.org/10.1007/s12115-017-0186-x

Paola, J., \& DeBate, R. (2018). Employing evaluation research to inform campus food pantry policy. Health Behavior Policy Review, 5(4), 83-94. https://doi.org/10.I4485/HBPR.5.4.9

Patton-López, M. M., López-Cevallos, D. F., Cancel-Tirado, D. I., \& Vazquez, L. (2014). Prevalence and correlates of food insecurity among students attending a midsize rural university in Oregon. Journal of Nutrition Education and Behavior, 46(3), 209-214. https://doi.org/10.1016/j.jneb.2013.10.007

Patton, M. Q. (2008). Utilization-focused evaluation. (V. Knight, S. Connelly, L. Habib, \& A. Virding, Eds.) (4th ed.). Thousand Oaks, CA: Sage Publications.

Payne-Sturges, D. C., Tjaden, A., Caldeira, K. M., Vincent, K. B., \& Arria, A. M. (2018). Student hunger on campus: Food insecurity among college students and implications for academic institutions. American Journal of Health Promotion, 32(2), 349-354. https://doi.org/10.1177/0890117117719620

Perrow, C. (2009). Organizational analysis: A sociological point of view. In H. L. Tosi (Ed.), Theories of Organization (pp. 123-131). Thousand Oaks, CA: Sage 
Publications.

Peterson, C., \& Park, N. (2010). What happened to self-actualization? Commentary on Kenrick et al. (2010). Perspectives on Psychological Science, 5(3), 320-322. https://doi.org/10.1177/1745691610369471

Ralston, K., Newman, C., Clauson, A., Guthrie, J., \& Buzby, J. (2008). The national school lunch program: Background, trends, and issues. Economic Research Report (United States. Dept. of Agriculture. Economic Research Service), 61(July), 1-56. Retrieved from http://files.eric.ed.gov/fulltext/ED502404.pdf

Ryan, F., Coughlan, M., \& Cronin, P. (2007). Step-by-step guide to critiquing research. Part 2: Qualitative research. British Journal of Nursing, 16(12), 738-744.

Schein, E. H. (2005). Defining organizational culture. In Jay M. Shafritz, J. S. Ott, \& S. J. Yong (Eds.), Classics of organizational theory (6th ed., pp. 360-367). Belmont, CA: Wadsworth.

Seidman, I. (2013). Interviewing as qualitative research: A guide for reserachers in education and the social sciences (4th ed.). New York, NY.

Severance-Weinert, S. (2016). The mother of the cupboard. The University of Central Missouri Magazing, 16(2), 4-9. Retrieved from ucmo.edu/ucmmagazine

Shen, J., \& Cooley, V. E. (2008). Critical issues in using data for decision-making. International Journal of Leadership in Education, 11(3), 319-329. https://doi.org/10.1080/13603120701721839

Shenton, A. K. (2004). Strategies for ensuring trustworthiness in qualitative research projects. Education for Information, 22, 63-75.

Silva, M. R., Kleinert, W. L., Sheppard, A. V., Cantrell, K. A., Freeman-Coppadge, D. J., 
Tsoy, E., ... Pearrow, M. (2017). The relationship between food security, housing stability, and school performance among college students in an urban university. Journal of College Student Retention: Research, Theory and Practice, 19(3), 284299. https://doi.org/10.1177/1521025115621918

Stake, R. E. (1995). Qualitative research: Studying how things work. New York, NY: The Guilford Press.

Tam, R., Yassa, B., Parker, H., O’Connor, H., \& Allman-Farinelli, M. (2017). University students' on-campus food purchasing behaviors, preferences, and opinions on food availability. Nutrition, 37, 7-13. https://doi.org/10.1016/j.nut.2016.07.007

Tay, L., \& Diener, E. (2011). Needs and subjective well-being around the world. Journal of Personality and Social Psychology, 101(2), 354-365. https://doi.org/10.1037/a0023779

Tierney, W. G. (2012). Creativity and organizational culture. In M. N. Bastedo (Ed.), The organization of higher education: Managing colleges for a new era (pp. 160-180). Baltimore, Maryland: The Johns Hopkins University Press.

Tikkanen, I. (2009). Maslow's hierarchy and pupils' suggestions for developing school meals. Nutrition and Food Science, 39(5), 534-543. https://doi.org/10.1108/00346650910992196

Tracy, S. J. (2010). Qualitative quality: Eight big-ten criteria for excellent qualitative research. Qualitative Inquiry, 16(10), 837-851. https://doi.org/10.1177/1077800410383121

Training, 360. (2019). Food Handler Training. Retrieved June 18, 2019, from https://www.learn2serve.com/food-handler- 
training?utm_source=google\&utm_medium=paidsearch\&utm_campaign=F\&B -L2S

-US-Food Handler\&utm_content=280868362205\&utm_term=food handler

class\&utm_source=google\&utm_medium=paidsearch\&utm_campaign=F\%26B -

L2S -US

Twill, S. E., Bergdahl, J., \& Fensler, R. (2016). Partnering to build a pantry: A university campus responds to student food insecurity. Journal of Poverty, 20(3), 340-358. https://doi.org/10.1080/10875549.2015.1094775

UCM Campus cupboard stats. (2018). Warrensburg, MO.

UCM mission and vision. (2019).

University of Central Missouri Fact Book. (2017a). University of Central Missouri Fact Book. Retrieved from https://issuu.com/usfucm2017/docs/ucm17030_fact_book_2017_issuu

University of Central Missouri Fact Book. (2017b). University of Central Missouri Fact Book.

US Department of Agriculture. (2019). Food and Nutrition Service. Retrieved October 15, 2019, from https://www.fns.usda.gov/snap/supplemental-nutrition-assistanceprogram

Vaterlaus, J. M., Cottle, N. M., Patten, E. V., \& Gibbons, R. (2018). Understanding Customers: The Jobs to Be Done Theory Applied in the Context of a Rural Food Pantry. Journal of the Academy of Nutrition and Dietetics, 118(10), 1895-1902. https://doi.org/10.1016/j.jand.2018.02.011

Watson, T. D., Malan, H., Glik, D., \& Martinez, S. M. (2017). College students identify university support for basic needs and life skills as key ingredient in addressing food 
insecurity on campus. California Agriculture, 71(3), 130-139.

https://doi.org/10.3733/ca.2017a0023

Weinfield, N. S., Mills, G., Borger, C., Gearning, M., Macaluso, T., Montaquila, J., \& Zedlewski, S. (2014). Hunger in America 2014. Feeding America. Retrieved from http://www.feedingamerica.org/hunger-in-america/our-research/hunger-in-america/

Wilson, N. (2016). When the cupboards are bare: Nudging food pantry clients to healthier foods. Journal of the Association for Consumer Research, 1(1), 125-133. https://doi.org/10.1086/684476

Wisconsin HOPE Lab. (2018). Basic needs security at the university of central missouri. Madison, WI.

Zein, A. El, Mathews, A. E., House, L., \& Shelnutt, K. P. (2018). Why are hungry college students not seeking help? Predictors of and barriers to using an on-campus food pantry. Nutrients, 10(1163), 1-14. https://doi.org/10.3390/nu10091163

Zizza, C. A., Duffy, P. A., \& Gerrior, S. A. (2008). Food insecurity is not associated with lower energy intakes. Obesity Journal, 16(8), 1908-1913. https://doi.org/10.1038/oby.2008.288 


\section{SECTION VI}

SCHOLARLY PRACTITIONER REFLECTION 


\section{Becoming a Scholarly Practitioner}

Taking full advantage of this opportunity to grow as a scholar and leader, I am excited to present this final product as a result of the hard work of my committee, and my family's sacrifice to achieve this milestone. Although it was my goal to complete a project that I could be proud of, there are three principle domains that guide this final scholarly reflection. First, I learned that this dissertation process is about the application of the previous two years' leadership coursework in practice. Second, I learned how to conduct thoughtful and meaningful research to aid my future career endeavors. Finally, third, I learned the importance of being a scholarly practitioner as I aim to begin a career in student affairs in higher education.

\section{Leadership}

Looking back, this dissertation process required a selfless effort by several individuals to help me complete this capstone project. I want to acknowledge the efforts of my dissertation committee, despite the severely limited benefits (if any). Although this dissertation was an important component of my academic career, the process provided an organic opportunity for me to experience a form of servant leadership that ultimately empowered me to reach my goal of earning a doctoral degree from the University of Missouri. Living the Northouse (2016) definition of servant leadership, I am extremely thankful for their inspiring altruistic nature; and I hope to pay their kindness forward one day as a future dissertation committee member.

Additionally, through this reflection I was reminded of my own leadership evolution. Particularly, this process highlighted a difficult balance between the determination to complete the project and my responsibility to for my dissertation 
committee. To explain, in agreement with Kofman and Senge's (1993) research, I hope this exercise in self-assessment produces a more accurate and useful understanding of who I am as a leader. For example, even though there were no catastrophes or mishaps, I felt writing this dissertation was an egocentric endeavor. My new commitment as an evolving leader will improve my efforts and my ability to balance prioritizing the wellbeing of those with whom I work with the responsibility of accomplishing a goal.

Another way this study shaped my leadership was observing the director of the UCM Student Recreation and Wellness Center. Because I was lucky enough to work on a study that focused on a philanthropic community service, it was easy to see the compassion and spirt of giving and enjoy its inspiring work environment; however, without the director of the Campus Cupboard, Beth Rutt, and her selflessness this project would not have the potential to help people complete their college degrees. For me, observing her leadership style solidified the importance of serving my community with the same empathy and commitment to improving the situation of those around me.

\section{Research}

I am excited to move forward with a newfound appreciation for research. In fact, the new role of research within my practice revolves around creating sustainable change, asking powerful questions, and ethically interpreting data. I now understand that any sustainable change or improvements in which I hope to invest requires a sound researchdriven approach. After this process, it is easy to link the appropriate use of data Shen and Cooley (2008) cite when referring to the "complexity of the teaching and learning process, and how data can help improve it" (p. 321). Serving as a nexus between my recent study and my future practice lies the heart of my interpretation of the power 
behind the data cycle. Specifically, as a result, exploring the complexity behind the numbers has crept into the focus of my new passion for research.

My commitment to ethical research will guide the sustainable change. I will create in my career. It is evident that people become set in their ways and often times do things based off of the lack of resistance instead of what is best. Johnson (2018) advocated, "the only way to change the outcome is to change how we see and play the game and, eventually, change the game itself and its paths of least resistance" (p. 73). I now understand research as the way to see and play the game differently, with the end of changing the game itself. I agree with Johnson (2018), "we can only choose how to be involved, whether to simply be a part of the problem or to also be a part of the solution. That is where our power lies, and our responsibility" (p. 75). Ethical research now plays a strong role in my work.

Asking questions is an important tool I have taken from this dissertation process. Specifically, I have learned a valuable skill in crafting questions that will evoke valuable information. More importantly however, I have learned how to listen and how to construct the reality of those I wish to serve.

One common misconception of the dissertation process emphasizes the output of the final product. However, after exploring the perceptions of food pantry clients, I have developed two skills that will no doubt serve me in my future career endeavors. Although I concede that writing this dissertation was a lengthy endeavor, I would argue the soul of research, like leadership, is a very receptive process focused on the art of listening, reading, and observing. Specifically, with new focus on my receptive skills as a 
researcher, I have learned that the art of asking questions connects leadership to research by serving as the foundation of all research inquiry and process improvement.

Because ethical leadership requires ethical research, I am focused on my ability to solve or address problems in the turbulent timeframe of fast moving big-data decisions. As a leader, an important aspect I now consider is wider accessibility to clean and appropriate data. Gill (2010) considered a shared vision, reflective inquiry, continuous measurement, and dialogue to be essential elements of a learning organization. This postulation aligns within the context of the conversation regarding data use. In agreement with Gill's (2010) study, another aspect I took from this dissertation process is allowing data to shape that shared vision for an organization's stakeholders. Drawing from the experience of a dissertation in practice, I can conclude that opening the food pantry to research essentially created a learning organization.

In a step further, Datnow and Park (2014) presented a similar point of view, emphasizing the need for open collaboration and trust to create an environment where teams can speak openly and honestly about data. In reflection, Rutt's leadership and transparency allowed for this exact conversation to take place. One day I hope to emulate her example in my own practice. Her trust in the process is no doubt a result of her own commitment to improvement.

\section{Scholarly practitioner}

In many ways the dissertation process symbolically solidified my transformation. I have a new awareness of how research, theory, and practice generate sustainable improvements for those without a voice. The resounding image I have from this dissertation process reflects how society views its leaders. For example, if we evaluate a 
leaders' impact by their moral reasoning, then the policies we write as leaders are the evidence we leave to support our claim to authentic leadership (Northouse, 2016). Specifically, I hope to lead a practice of scholarship that is driven by values derived from my conviction that all students deserve the best education their community can provide. I look forward to the trials of my future career knowing that I have been taught the effective framework to translate my values of ethical research and an adaptive educational data cycle into action (George et al., 2007).

Moreover, conducting my professional practice as a scholarly practitioner means I do not need to know every answer. As a result of this dissertation process, I am, however, confident in what I can bring to my new communities. Specifically, a professional curiosity and a specialized commitment to finding answers to questions that will improve people's lives. Ultimately, there is power behind being seen, included and accepted by other people. As an educator, I hope to use research in my career to protect those who are not seen by the current status quo. As a scholarly practitioner I see research as the tool to creating sustainable change (Johnson, 2018).

Another comparable understanding is that research alone does not guarantee an ethical practice. For example, Gagliardi, Parnell, and Carpenter-Hubin (2018) criticized that access to data, even when combined with high levels of analytical skills, does not guarantee sufficient understanding of analyses. After this process, I realize how the research involved in a dissertation in practice can help create a more dynamic learning organization. I realize creating access to data and empowering others to become translators and story tellers of data is a newfound goal of my practice. 
The process of a dissertation in practice allowed me to interact with an entire research project from start to finish. Although this was my first attempt at research, I loved the responsibility to a standard of ethics. Creating a study that allowed data to organically emerge and tell a truth for a large number of people was a fascinating experience. Although I am convinced my future efforts in research will produce a more refined experience, I am pleased with the final product of my first study. For me, completing the dissertation in practice sparked an opportunity to reflect on its impact regarding my own understanding of leadership. Not only do I love applying the scientific method to studying our practice as educational leaders, I now have a new understanding of the power behind ethical research. Lastly, the honor of becoming a scholarly practitioner goes beyond the regalia, and pomp and circumstance of becoming a doctor. It opens the door to my new responsibility.

In the beginning of my journey in this program I remember quoting William Butler Yates" "Education is not the filling of a pail, but the lighting of a fire." Now, as I write the final lines of this last reflection, in fulfilment of this honorable degree, I cannot help but reflect on that same quote. With the experience, and knowledge gained through this incredible journey, I have a new perspective. Yates' meaning never changed, I am just aware that the fire in the quote symbolizes my own curiosity and questions. And as a scholarly practitioner, I now hold the great responsibility to spark that fire in the dark future and cold unknown that await my next journey. Three years removed from that first reflection, to that same theme of fire I offer a parallelism from Jack London's To Build a Fire, reiterating the importance of fire's symbolism in my own practice: "He cherished the flame 
carefully and awkwardly. It meant life, and it must not perish." I look forward to my family's new adventure. 


\section{REFERENCES}

Beck, C. D. (2014). Antecedents of servant leadership: A Mixed methods study. Journal of Leadership \& Organizational Studies, 21(3), 299-314. https://doi.org/doi: $10.1177 / 1548051814529993$

Bemel, J. E., Brower, C., Chischillie, A., \& Shepherd, J. (2016). The impact of college student financial health on other dimensions of health. American Journal of Health Promotion, 30(4), 224-230. https://doi.org/10.1177/0890117116639562

Bennett, J., Greene, G., \& Schwartz-Barcott, D. (2013). Perceptions of emotional eating behavior. A qualitative study of college students. Appetite, 60(1), 187-192. https://doi.org/10.1016/j.appet.2012.09.023

Blagg, K., Gundersen, C., Whitmore Schanzenbach, D., \& Ziliak, J. P. (2017). Assessing food insecurity on campus: A national look at food insecurity among America's college students. Urban Institute, (August), 1-15. Retrieved from www.urban.org

Bolman, L. G., \& Deal, T. E. (2013). Reframing organizations: Artistry, choice, and leadership (5th ed.). San Francisco, CA: Jossey-Bass.

Bridwell, L. G., \& Wahba, M. A. (1976). Maslow reconsidered: A review of research on the need hierarchy theory. Organizational Behavior and Human Performance, 15(2), 212-240. https://doi.org/10.1016/0030-5073(76)90038-6

Broton, K., Frank, V., \& Goldrick-Rab, S. (2014). Safety, security, and college attainment: An investigation of undergraduates' basic needs and institutional response. Wisconsin Hope Lab. Madison, WI. Retrieved from http://wihopelab.com/publications/APPAM.Draft.10.28.2014.pdf

Broton, K., \& Goldrick-Rab, S. (2016). The dark side of college (un)affordability: Food 
and housing insecurity in higher education. Change, 48(1), 16-25.

https://doi.org/https://doi.org/10.1080/00091383.2016.1121081

Broton, K. M., \& Goldrick-Rab, S. (2017). Going without: An exploration of food and housing insecurity among undergraduates. Educational Researcher, 47(2). https://doi.org/10.3102/0013189X17741303

Broton, K., Weaver, K., \& Mai, M. (2018). Hunger in higher education: Experiences and correlates of food insecurity among Wisconsin undergraduates from low-income families. Social Sciences, 7(10), 1-25. https://doi.org/10.3390/socsci7100179

Brown, L. B., Dresen, R. K., \& Eggett, D. L. (2005). College students can benefit by participating in a prepaid meal plan. Journal of the American Dietetic Association, 105(3), 445-448. https://doi.org/10.1016/j.jada.2004.12.030

Bruening, M., Brennhofer, S., Van Woerden, I., Todd, M., \& Laska, M. (2016). Factors related to the high rates of food insecurity among diverse, urban college freshmen. Journal of the Academy of Nutrition and Dietetics, 116(9), 1450-1457. https://doi.org/10.1016/j.jand.2016.04.004

Byker Shanks, C. (2017). Promoting food pantry environments that encourage nutritious eating behaviors. Journal of the Academy of Nutrition and Dietetics, 117(4), 523525. https://doi.org/10.1016/j.jand.2016.12.020

Cady, C. L. (2014). Food insecurity as a student issue. Journal of College \& Character, 15(4), 265-271. https://doi.org/10.1515/jcc-2014-0031

Cafer, A., Chapman, D., Freeman, K., \& Rikoon, S. (2016). Missouri hunger atlas 2016. Columbia, MO. Retrieved from http://foodsecurity.missouri.edu Cafer, A., Foulkes, M., Heflin, C., Hermsen, J., Raedeke, N., \& Rikoon, S. (2013). 
Coping with hunger in 2013 : Food pantry clients and households in the service region of the food bank for central and northeast Missouri. Interdisciplinary Center for Food Security (Vol. 861). Columbia, MO. Retrieved from http://foodsecurity.missouri.edu

Campbell, E. C., Ross, M., \& Webb, K. L. (2013). Improving the nutritional quality of emergency food: A study of food bank organizational culture, capacity, and practices. Journal of Hunger and Environmental Nutrition, 8(3), 261-280. https://doi.org/10.1080/19320248.2013.816991

Campbell, E., Hudson, H., Webb, K., \& Crawford, P. B. (2011). Food preferences of users of the emergency food system. Journal of Hunger and Environmental Nutrition, 6(2), 179-187. https://doi.org/10.1080/19320248.2011.576589

Campus cupboard. (2019). Retrieved June 18, 2019, from https://www.ucmo.edu/currentstudents/student-services/campus-cupboard/index.php

Chaparro, M. P., Zaghloul, S. S., Holck, P., \& Dobbs, J. (2009a). Food insecurity prevalence among college students at the University of Hawaii at Mānoa. Public Health Nutrition, 12(11), 2097-2103. https://doi.org/10.1017/S1368980009990735

Chaparro, M. P., Zaghloul, S. S., Holck, P., \& Dobbs, J. (2009b). Food insecurity prevalence among college students at the University of Hawaii at Mānoa. Public Health Nutrition, 12(11), 2097-2103. https://doi.org/10.1017/S1368980009990735 Chen, M. (2018). University of Central Missouri Fact Book. Warrensburg, MO. Retrieved from https://www.google.com/url?sa=t\&rct=j\&q=\&esrc=s\&source=web\&cd=1\&ved=2ah UKEwiduZSknfbiAhUMW60KHXwHDisQFjAAegQIABAC\&url=https\%3A\%2F 
\%2Fwww.ucmo.edu\%2Foffices\%2Funiversity-analytics-and-institutionalresearch\%2Ffactbook.pdf\&usg=AOvVaw3nqe-bvydvcUzHtDivJL_j

Coleman-Jensen, A., Gregory, C., \& Singh, A. (2018). Household food security in the United States in 2017. Economic Research Report Number 256. https://doi.org/10.2139/ssrn.2504067

Coleman-Jensen, A., Rabbitt, M. P., \& Gregory, C. A. (2017). Examining an "experimental" food-security-status classification method for households with children. Economic Research Service (Vol. 1945). Retrieved from www.ers.usda.gov

Cooksey-Stowers, K., Read, M., Wolff, M., Martin, K. S., McCabe, M., \& Schwartz, M. (2018). Food pantry staff attitudes about using a nutrition rating system to guide client choice. Journal of Hunger \& Environmental Nutrition, 1-15. https://doi.org/10.1080/19320248.2018.1512930

Cooksey-Stowers, K., Read, M., Wolff, M., Martin, K. S., McCabe, M., \& Schwartz, M. (2019). Food pantry staff attitudes about using a nutrition rating system to guide client choice. Journal of Hunger and Environmental Nutrition, 14(1-2), 35-49. https://doi.org/10.1080/19320248.2018.1512930

Creswell, J. W. (2014). Researach Design (4th ed.). Thousand Oaks, California: Sage Publications.

Crutchfield, R., \& Maguire, J. (2018). Study of student basic needs. The California State University.

Datnow, A., \& Park, V. (2014). Data-driven leadership. San Francisco, CA: Jossey-Bass. Dubick, J., Mathews, B., \& Cady, C. L. (2016). Hunger on campus: The challenge of 
food insecurity for college students. CUFBA website. https://doi.org/10.5479/si.01960768.38.437

Dubick, J., Matthews, B., \& Cady, C. (2016). Hunger on campus: The challenge of food insecurity for college students. College and University Food Bank Alliance.

El Zein, A., Matthews, A.E., House, L., \& Shelnutt, K.P. (2018). Why ar hungrey college students not seeking help? Predictors of an barriers to using an on-campus food pantry. Nutrients, 10(9). https://doi.org/10.3390/nu10091163

Eisenberger, N. I., Lieberman, M. D., \& Williams, K. D. (2003). Does rejection hurt? An fMRI study of social exclusion. Science, 302(5643), 290-292. https://doi.org/10.1126/science.1089134

Farahbakhsh, J., Hanbazaza, M., Ball, G. D. C., Farmer, A. P., Maximova, K., \& Willows, N. D. (2016). Food insecure student clients of a university-based food bank have compromised health, dietary intake and academic quality. Nutrition \& Dietetics, 74(1), 67-73.

Farahbakhsh, J., Hanbazaza, M., Ball, G. D. C., Farmer, A. P., Maximova, K., \& Willows, N. D. (2017). Food insecure student clients of a university-based food bank have compromised health, dietary intake and academic quality. Nutrition and Dietetics, 74(1), 67-73. https://doi.org/10.1111/1747-0080.12307

Feeding America annual report. (2017). Chicago, Illinois. Retrieved from www.feedingamerica.org

Feeding America Annual Report. (2018). Chicago, Illinois. Retrieved from www.feedingamerica.org

Feeding America history. (2019). Retrieved January 20, 2019, from 
https://www.feedingamerica.org/about-us/our-history

Fink, A. (2017). How to conduct surveys: A step-by-step guide (6th ed.). Thousand Oaks, CA.: Sage Publications.

Food manners. (1955). Warrensburg, MO. Internal Report, Unpublished.

Food Research \& Action Center. (2019a). Profile of hunger, poverty, and federal nutrition programs. https://doi.org/10.4135/9781452276151.n284

Food Research \& Action Center. (2019b). Profile of hunger, poverty, and federal nutrition programs. https://doi.org/10.4135/9781452276151.n284

French, J. R. P., \& Raven, B. (2005). The bases of social power. In Jay M. Shafritz, S. J. Ott, \& Y. S. Jang (Eds.), Classics of organizational theory (6th ed., pp. 311-320). Belmont, CA.

Freudenberg, N., Manzo, L., Jones, H., Kwan, A., Tsui, E., \& Gagnon, M. (2011). Food insecurity at CUNY: Results from a survey of CUNY undergraduate students. New York. Retrieved from http://web.gc.cuny.edu/che/cunyfoodinsecurity.pdf

Fyall, R., \& Levine Daniel, J. (2018). Pantries and policy implementation: Using nonprofit priorities to understand variation in emergency food assistance. Nonprofit and Voluntary Sector Quarterly, 47(4_suppl), 11S-33S. https://doi.org/10.1177/0899764017753318

Gagliardi, J. S., Parnell, A., \& Carpenter-Hubin, J. (2018). The analytics revolution in higher education: Big data, organizational learning, and student success. Sterling, VA: Stylus.

Gaines, A., Robb, C. A., Knol, L. L., \& Sickler, S. (2014). Examining the role of financial factors, resources and skills in predicting food security status among 
college students. International Journal of Consumer Studies, 38(4), 374-384. https://doi.org/10.1111/ijcs.12110

Gallegos, D., Ramsey, R., \& Ong, K. W. (2014). Food insecurity: Is it an issue among tertiary students? Higher Education, 67(5), 497-510. https://doi.org/10.1007/s10734-013-9656-2

George, B., Sims, P., Mclean, A. N., George, B., Sims, P., Mclean, A. N., \& Mayer, D. (2007). Discovering your authentic leadership. Harvard Business Review, (February), 129-138.

Ghafoor, A. (2012). Active and Proactive Characteristics of Physiological Needs. Language in India, 12(7), 348-366. Retrieved from http://proxy.mul.missouri.edu/login?url=http://search.ebscohost.com/login.aspx?dire $\mathrm{ct}=$ true $\& \mathrm{db}=\mathrm{ufh} \& \mathrm{AN}=88819915 \&$ site $=$ eds-live $\&$ scope $=$ site

Gill, S. J. (2010). Developing a learning culture in nonprofit organizations. Thousand Oaks, CA: Sage Publications.

Goldrick-Rab, K., \& Broton, S. (2016). The Dark Side of College (Un) Affordability. College Teaching and Learning for Change: Students and Faculty Speak Out. Azusa, CA. https://doi.org/10.4324/9781315302393

Goldrick-Rab, S., Baker-Smith, C., Coca, V., Looker, E., \& Williams, T. (2019). College and university basic needs insecurity: A national \# realcollege survey report. Madison, WI. Retrieved from http://wihopelab.com/

Goldrick-Rab, S., \& Broton, K. (2013). Housing Instability among College Students, (October), 1-8. Retrieved from http://www.massresources.org/section8-financialeligibility.html 
Goldrick-Rab, S., Richardson, J., \& Hernandez, A. (2017). Hungry and homeless in college: Results from a a national study of basic needs insecuirty in higher education. Madison, WI. Retrieved from www.acct.org

Goldrick-Rab, S., Richardson, J., \& Hernandez, A. (2018). Hungry and homeless in college: Results from a national study of basic needs insecurity in higher education. Madison, WI. Retrieved from http://homelesshub.ca/resource/still-hungry-andhomeless-college

Goleman, D. (2011). What makes a leader? In Harvard Business Review 10 must reads on leaderhsip (Reprinted from June 1996) (pp. 1-21). Boston, Massachuttes: Harvard Business School Publishing Corporation.

Greenleaf, R. K. (1970). The servant as leader. Indianapolis, IN: Greenleaf Center. Gundersen, C. (2013). Food insecurity is an ongoing national concern. Advances in Nutrition: An International Review Journal, 4(1), 36-41. https://doi.org/10.3945/an.112.003244

Gundersen, Craig, \& Ziliak, J. P. (2018). Food insecurity research in the united states: Where we have been and where we need to go. Applied Economic Perspectives and Policy, 40(1), 119-135. https://doi.org/10.1093/aepp/ppx058

Ha, E. J., \& Caine-Bish, N. (2009). Effect of nutrition intervention using a general nutrition course for promoting fruit and vegetable consumption among college students. Journal of Nutrition Education and Behavior, 41(2), 103-109. https://doi.org/10.1016/j.jneb.2008.07.001

Hagedorn, R. L., \& Olfert, M. D. (2018). Food insecurity and behavioral characteristics for academic success in young adults attending an Appalachian university. 
Nutrients, 10(3), 361.

Hanbazaza, M., Ball, G. D. C., Farmer, A., Maximova, K., \& Willows, N. D. (2016).

Filling a Need: Sociodemographic and Educational Characteristics Among Student

Clients of a University-Based Campus Food Bank. Journal of Hunger and

Environmental Nutrition, 11(4), 569-577.

https://doi.org/10.1080/19320248.2015.1128864

Handforth, B., Hennink, M., \& Schwartz, M. B. (2013). A qualitative study of nutritionbased initiatives at selected food banks in the feeding America network. Journal of the Academy of Nutrition and Dietetics, 113(3), 411-415.

https://doi.org/10.1016/j.jand.2012.11.001

Helland, M. R., \& Winston, B. . (2005). Towards a deeper understanding of hope and leadership. Journal of Leadership \& Organizational Studies, 12(2), 42-54.

Henry, L. (2017). Understanding food insecurity among college students: Experience, motivation, and local solutions. Annals of Anthropological Practice, 41(1), 6-19. https://doi.org/10.1111/napa.12108

Hess, F. M., \& Lautzenheiser, Daniel, K. (2012). Putting the punch in parent power. American Enterprise Institute for Public Policy Research, August(5), 1-8. Retrieved from www.aei.org

Horner, J., \& Minifie, F. D. (2011). Research ethics I: Responsible conduct of research (RCR)-Historical and contemporary issues pertaining to human and animmal experimentation. Journal of Speech, Language, and Hearing Research, 54(February), S303-S329.

Hunger and poverty in Missouri: Map the meal gap. (2016). Retrieved from 
http://map.feedingamerica.org/county/2016/overall/missouri/county/johnson

Jablonski, B. R., McFadden, D. T., \& Colpaart, A. (2016). Analyzing the role of community and individual factors in food insecurity: Identifying diverse barriers across clustered community members. Journal of Community Health, 41(5), 910923. https://doi.org/10.1007/s10900-016-0171-0

Jansson, N. (2013). Organizational change as practice: A critical analysis. Journal of Organizational Change Management, 26(6), 1003-1019. https://doi.org/10.1108/JOCM-09-2012-0152

Johnson, A. G. (2018). Privilege, power, and difference (3rd ed.). New York: McGrawHill.

Kaiser, M. L., \& Cafer, A. M. (2017). Exploring long-term food pantry use: Differences between persistent and prolonged typologies of use. Journal of Hunger and Environmental Nutrition, 12(1), 46-63. https://doi.org/10.1080/19320248.2016.1157554

Karasar, B., \& Baytemir, K. (2018). Need for social approval and happiness in college students: The mediation role of social anxiety. Universal Journal of Educational Research, 6(5), 919-927. https://doi.org/10.13189/ujer.2018.060513

Kelchen, R., Goldrick-Rab, S., \& Hosch, B. (2017). The costs of college attendance: Examining variation and consistency in institutional living cost allowances. Journal of Higher Education, 88(6), 947-971. https://doi.org/10.1080/00221546.2016.1272092

Kenrick, D. T., Neuberg, S. L., Griskevicius, V., Becker, D., \& Schaller, M. (2010). Goal-driven cognition and functional behavior: The fundamental-motives 
framework. Current Directions in Psychological Science, 19(1), 63-67. https://doi.org/10.1177/0963721409359281

Kenrick, Douglads. (2011). Renovating the pyramid of built upon ancient foundations. Perspect Psychol Sci, 5(3), 292-314. https://doi.org/10.1177/1745691610369469.Renovating

Kenrick, Douglas. (2017). Self-actualization, human nature, and global social problems. Society, 54(6), 520-523.

Kofman, F., \& Senge, P. M. (1993). Communities of commitment: The heart of learning organizations. Organizational Dynamics, 4(12), 16-19. https://doi.org/10.1016/0090-2616(93)90050-B

Koltko-Rivera, M. E. (2006). Rediscovering the later version of Maslow's hierarchy of needs: Self-transcendence and opportunities for theory, research, and unification. Review of General Psychology, 10(4), 302-317. https://doi.org/10.1037/10892680.10.4.302

Krems, J. A., Kenrick, D. T., \& Neel, R. (2017). Individual perceptions of selfactualization: What functional motives are linked to fulfilling one's full potential? Personality and Social Psychology Bulletin, 43(9), 1337-1352. https://doi.org/10.1177/0146167217713191

Krueger, R. A., \& Casey, M. A. (2015). Focus groups: A practical guide for applied research. (H. Salmon, A. Villarruuel, T. Buyan, \& P. Schroeder, Eds.) (5th ed.). Thousand Oaks: Sage Publications.

Levi, D. (2017). Group dynamics for teams (5th ed.). Thousand Oaks, CA: Sage Publications. 
Lincoln, Y. S., \& Guba, E. G. (1985). Naturalistic inquiry. Newbury Park, CA: Sage Publications.

Manning, K. (2013). Organized anarchy. In Organizational theory in higher education (pp. 11-24). New York, NY: Routledge.

Martin, K. S., Wu, R., Wolff, M., Colantonio, A. G., \& Grady, J. (2013). A novel food pantry program: Food security, self-sufficiency, and diet-quality outcomes.

American Journal of Preventive Medicine, 45(5), 569-575.

https://doi.org/10.1016/j.amepre.2013.06.012

Maslow, A.H. (1943). A theory of human motivation. Psychological Review, 50, 370396. https://doi.org/10.1037/h0054346

Matthews, J. I., Doerr, L., \& Dworatzek, P. D. N. (2016). University students intend to eat better but lack coping self-efficacy and knowledge of dietary recommendations. Journal of Nutrition Education and Behavior, 48(1), 12-19. https://doi.org/10.1016/j.jneb.2015.08.005

McArthur, Laura H., Fasczewski, K. S., Wartinger, E., \& Miller, J. (2018). Freshman at a university in Appalachia experience higher rate of campus than family food insecurity. Journal of Community Health, (43), 969-976.

https://doi.org/10.1016/j.appet.2012.09.023

McArthur, Laura Helena, Ball, L., Danek, A. C., \& Holbert, D. (2018). A high prevalence of food insecurity among university students in Appalachia reflects a need for educational interventions and policy advocacy. Journal of Nutrition Education and Behavior, 50(6), 564-572. https://doi.org/10.1016/j.jneb.2017.10.011

Mcleod, B. S. (2017). Maslow's Hierarchy of Needs The expanded hierarchy of needs :, 
(December), 1-8.

Merriam, S. B., \& Bierema, L. L. (2014). Adult learning: Linking theory and practice. San Francisco, CA: John Wiley \& Sons, Inc.

Merriam, S. B., \& Tisdell, E. J. (2016). Qualitative research: A guide to design and implementation (4th ed.). San Francisco, CA.: Jossey-Bass.

Micevski, D. A., Thornton, L. E., \& Brockington, S. (2014). Food insecurity among university students in Victoria: A pilot study. Nutrition and Dietetics, 71(4), 258264. https://doi.org/10.1111/1747-0080.12097

Mintzberg, H. (2005). The five basic parts of the organization. (J.M. Shafritz, J. S. Ott, \& S. J. Yong, Eds.), Classics of organizational theory (Sixth, pp. 219-230). Belmont, CA.

Mirabitur, E., Peterson, K. E., Rathz, C., Matlen, S., \& Kasper, N. (2016). Predictors of college-student food security and fruit and vegetable intake differ by housing type. Journal of American College Health, 64(7), 555-564.

https://doi.org/10.1080/07448481.2016.1192543

Morris, L. M., Smith, S., Davis, J., \& Null, D. B. (2016). The prevalence of food security and insecurity among Illinois university tudents. Journal of Nutrition Education and Behavior, 48(6), 376-382. https://doi.org/10.1016/j.jneb.2016.03.013

Murphy, J. (2019). UCM announces changes in dining options as room and boards rates are set.Retreived from: https://www.ucmo.edu/news/university-news/posts/2019-0508-ucm-announces-changes-in-dining-options-as-room-and-boards-rates-are-set.php Newcomer, K., \& Hatry Harry, P. (2015). Handbook of practical program evaluation (4th ed.). Hoboken, New Jersey: John Wiley \& Sons, Inc. 
Nikolaus, C. J., Laurent, E., Loehmer, E., An, R., Khan, N., \& McCaffrey, J. (2018). Nutrition environment food pantry assessment tool (NEFPAT): Development and evaluation. Journal of Nutrition Education and Behavior, 50(7), 724-728.e1. https://doi.org/10.1016/j.jneb.2018.03.011

Noltemeyer, A., Bush, K., Patton, J., \& Bergen, D. (2012). The relationship among deficiency needs and growth needs: An empirical investigation of Maslow's theory. Children and Youth Services Review, 34(9), 1862-1867. https://doi.org/10.1016/j.childyouth.2012.05.021

Normal farm makes good. (1911, October). The Normal Student, p. 1 (Volume 2). Northouse, P. G. (2016). Leadership: Theory and practice (Seventh ed). Los Angeles: SAGE Publications, Inc.

O’Neill, M., \& Maguire, J. (2017). College student self reported food insecurity and correlations with health and academic performance. Journal of Behavioral and Social Sciences, 4, 34-40.

Oved, O. (2017). Rethinking the place of love needs in Maslow's hierarchy of needs. Society, 54(6), 537-538. Retrieved from http://proxy.mul.missouri.edu/login?url=http://search.ebscohost.com/login.aspx?dire $\mathrm{ct}=$ true $\& \mathrm{db}=\mathrm{s} 3 \mathrm{~h} \& \mathrm{AN}=126418107 \&$ site $=$ eds-live $\&$ scope $=$ site

Paola, J., \& DeBate, R. (2018). Employing evaluation research to inform campus food pantry policy. Health Behavior Policy Review, 5(4), 83-94. https://doi.org/10.I4485/HBPR.5.4.9

Patton-López, M. M., López-Cevallos, D. F., Cancel-Tirado, D. I., \& Vazquez, L. (2014). Prevalence and correlates of food insecurity among students attending a midsize 
rural university in Oregon. Journal of Nutrition Education and Behavior, 46(3), 209-214. https://doi.org/10.1016/j.jneb.2013.10.007

Patton, M. Q. (2008). Utilization-focused evaluation. (V. Knight, S. Connelly, L. Habib, \& A. Virding, Eds.) (4th ed.). Thousand Oaks, CA: Sage Publications.

Payne-Sturges, D. C., Tjaden, A., Caldeira, K. M., Vincent, K. B., \& Arria, A. M. (2018). Student hunger on campus: Food insecurity among college students and implications for academic institutions. American Journal of Health Promotion, 32(2), 349-354. https://doi.org/10.1177/0890117117719620

Perrow, C. (2009). Organizational analysis: A sociological point of view. In H. L. Tosi (Ed.), Theories of Organization (pp. 123-131). Thousand Oaks, CA: Sage Publications.

Peterson, C., \& Park, N. (2010). What happened to self-actualization? Commentary on Kenrick et al. (2010). Perspectives on Psychological Science, 5(3), 320-322. https://doi.org/10.1177/1745691610369471

Ralston, K., Newman, C., Clauson, A., Guthrie, J., \& Buzby, J. (2008). The national school lunch program : Background, trends, and issues. Economic Research Report (United States. Dept. of Agriculture. Economic Research Service), 61(July), 1-56. Retrieved from http://files.eric.ed.gov/fulltext/ED502404.pdf Ryan, F., Coughlan, M., \& Cronin, P. (2007). Step-by-step guide to critiquing research. Part 2: Qualitative research. British Journal of Nursing, 16(12), 738-744.

Schein, E. H. (2005). Defining organizational culture. In Jay M. Shafritz, J. S. Ott, \& S. J. Yong (Eds.), Classics of organizational theory (6th ed., pp. 360-367). Belmont, CA: Wadsworth. 
Seidman, I. (2013). Interviewing as qualitative research: A guide for reserachers in education and the social sciences (4th ed.). New York, NY.

Severance-Weinert, S. (2016). The mother of the cupboard. The University of Central Missouri Magazine, 16(2), 4-9. Retrieved from ucmo.edu/ucmmagazine

Shen, J., \& Cooley, V. E. (2008). Critical issues in using data for decision-making. International Journal of Leadership in Education, 11(3), 319-329. https://doi.org/10.1080/13603120701721839

Shenton, A. K. (2004). Strategies for ensuring trustworthiness in qualitative research projects. Education for Information, 22, 63-75.

Silva, M. R., Kleinert, W. L., Sheppard, A. V., Cantrell, K. A., Freeman-Coppadge, D. J., Tsoy, E., ... Pearrow, M. (2017). The relationship between food security, housing stability, and school performance among college students in an urban university. Journal of College Student Retention: Research, Theory and Practice, 19(3), 284299. https://doi.org/10.1177/1521025115621918

Stake, R. E. (1995). Qualitative research: Studying how things work. New York, NY: The Guilford Press.

Tam, R., Yassa, B., Parker, H., O’Connor, H., \& Allman-Farinelli, M. (2017). University students' on-campus food purchasing behaviors, preferences, and opinions on food availability. Nutrition, 37, 7-13. https://doi.org/10.1016/j.nut.2016.07.007

Tay, L., \& Diener, E. (2011). Needs and subjective well-being around the world. Journal of Personality and Social Psychology, 101(2), 354-365. https://doi.org/10.1037/a0023779

Tierney, W. G. (2012). Creativity and organizational culture. In M. N. Bastedo (Ed.), The 
organization of higher education: Managing colleges for a new era (pp. 160-180). Baltimore, Maryland: The Johns Hopkins University Press.

Tikkanen, I. (2009). Maslow's hierarchy and pupils' suggestions for developing school meals. Nutrition and Food Science, 39(5), 534-543.

https://doi.org/10.1108/00346650910992196

Tracy, S. J. (2010). Qualitative quality: Eight big-ten criteria for excellent qualitative research. Qualitative Inquiry, 16(10), 837-851.

https://doi.org/10.1177/1077800410383121

Training, 360. (2019). Food Handler Training. Retrieved June 18, 2019, from https://www.learn2serve.com/food-handlertraining?utm_source=google\&utm_medium=paidsearch\&utm_campaign=F\&B -L2S -US-Food Handler\&utm_content=280868362205\&utm_term=food handler class\&utm_source=google\&utm_medium=paidsearch\&utm_campaign=F\%26B L2S-US

Twill, S. E., Bergdahl, J., \& Fensler, R. (2016). Partnering to build a pantry: A university campus responds to student food insecurity. Journal of Poverty, 20(3), 340-358. https://doi.org/10.1080/10875549.2015.1094775

UCM Campus cupboard stats. (2018). Warrensburg, MO.

UCM mission and vision. (2019).

University of Central Missouri Fact Book. (2017). University of Central Missouri Fact Book.

US Department of Agriculture. (2019a). Food and Nutrition Service. Retrieved October 15, 2019, from https://www.fns.usda.gov/snap/supplemental-nutrition-assistance- 
program

US Department of Agriculture. (2019b). Special Supplemental Nutrition Program for Women, Infants, and Children (WIC). Retrieved from https://www.fns.usda.gov/wic Vaterlaus, J. M., Cottle, N. M., Patten, E. V., \& Gibbons, R. (2018). Understanding Customers: The Jobs to Be Done Theory Applied in the Context of a Rural Food Pantry. Journal of the Academy of Nutrition and Dietetics, 118(10), 1895-1902. https://doi.org/10.1016/j.jand.2018.02.011

Watson, T. D., Malan, H., Glik, D., \& Martinez, S. M. (2017). College students identify university support for basic needs and life skills as key ingredient in addressing food insecurity on campus. California Agriculture, 71(3), 130-139. https://doi.org/10.3733/ca.2017a0023

Weinfield, N. S., Mills, G., Borger, C., Gearning, M., Macaluso, T., Montaquila, J., \& Zedlewski, S. (2014). Hunger in America 2014. Feeding America. Retrieved from http://www.feedingamerica.org/hunger-in-america/our-research/hunger-in-america/

Wilson, N. (2016a). When the cupboards are bare: Nudging food pantry clients to healthier foods. Journal of the Association for Consumer Research, 1(1), 125-133. https://doi.org/10.1007/s10551-015-2769-z.For

Wilson, N. (2016b). When the cupboards are bare: Nudging food pantry clients to healthier foods. Journal of the Association for Consumer Research, 1(1), 125-133. https://doi.org/10.1086/684476

Wisconsin HOPE Lab. (2018). Basic needs security at the university of central missouri. Madison, WI.

Zein, A. El, Mathews, A. E., House, L., \& Shelnutt, K. P. (2018). Why are hungry 
college students not seeking help? Predictors of and barriers to using an on-campus food pantry. Nutrients, 10(1163), 1-14. https://doi.org/10.3390/nu10091163

Zizza, C. A., Duffy, P. A., \& Gerrior, S. A. (2008). Food insecurity is not associated with lower energy intakes. Obesity Journal, 16(8), 1908-1913.

https://doi.org/10.1038/oby.2008.288 


\section{APPENDIX A}

\section{INTERVIEW QUESTIONS: STAFF/ VOLUNTEERS}

1. What is your name? / How do you spell it?

2. Tell me about yourself (where you're from, major, things you're involved in on campus, if you have a job(s))?

3. How are you involved with UCM and the Campus Cupboard?

4. Regarding the Campus Cupboard, what would you say are some of your priorities are on a day to day, week to week basis?

5. What do you believe the clients the Campus Cupboard serves spend their money on?

6. What do you believe the stressors food pantry clientele experience as college students?

a. How do you believe they cope with these stressors?

b. What services does UCM provide for them to deal with these stressors?

7. How do you believe the clientele balance their education and other stressors?

8. Tell me about what a difficult day looks like for someone who uses the Campus Cupboard.

9. With all of these stressors-how does food fall into that? What are some of the things they might eat on a weekly basis?

10. Where do believe they get food? How often do they come to the food pantry? 11. Why do you think they choose to use the food pantry? How well do you think it fits into their schedule? How does the food the pantry offers compare to the food they want to eat.../ (GET AT THE TYPES OF FOOD THEIR EATING)? 
12. What would you want someone to know about college students who have to use the food pantry?

13. If you were talking to an administrator about food insecurity among college students, what are the recommendations or suggestions you would make about how to address this issue?

14. How do you think the perception of what a college student is compares to the experience of a college student who experiences food insecurity?

15. How do think they feel before going to the food pantry? How do you think they feel after? How do you believe clients feel the first time they go to the food pantry?

16. What really inspires you to be a part of this?

a. Have you ever gone hungry?

b. How does it feel when you have gone hungry?

17. Is there anything else I need to know? 


\section{APPENDIX B INTERVIEW QUESTIONS: FOOD PANTRY CLIENTELE}

1. What is your name? / How do you spell it?

2. Tell me about yourself (where you're from, major, things you're involved in on campus, if you have a job(s))?

3. What are you studying here at UCM?

4. What would you say are some of your priorities are, on a day to day, week to week basis?

5. What do you spend your money on?

6. What are stressors you experience as a college student?

a. How do you cope with these stressors?

b. What services does UCM provide for you to deal with these stressors?

7. How do you balance your education and other stressors?

8. Tell me what a difficult day looks like for you.

9. With all of these stressors-how does food fall into that?

a. What are some of the things you might eat on a weekly basis?

10. Where do you get food?

a. How often do you come to the food pantry?

11. Why do you choose to use the food pantry?

a. How well does it fit to your schedule?

b. How does the food you have to eat compare to the food you want to eat.../ (GET AT THE TYPES OF FOOD THEIR EATING)?

12. What would you want someone to know about you as a college student who has to use the food pantry? 
13. If you were talking to an administrator about food insecurity among college students, what are the recommendations or suggestions you would make about how to address this issue?

14. How do you think the perception of what a college student is compares to the experience of a college student who experiences food insecurity?

15. How do you feel before going to the food pantry?

a. How do you feel after?

b. Do you remember how it felt the first time you went to the pantry; if so, can you describe it?

16. Tell me about a time when you went hungry.

a. How does it feel when you have gone hungry?

17. Is there anything else I need to know? 


\section{APPENDIX C CONSENT FORM \\ CONSENT FORM}

Identification of Researchers: This research is being conducted by Michael

Verderaime, a doctoral student with the University of Central Missouri Cohort of the University of Missouri-Columbia Cooperative EdD Program.

Purpose of the Study: The purpose of this qualitative study is to explore the perspectives of food pantry clientele at UCM. The perspectives of food insecure clients of the food pantry will be generally defined as the outlooks of students struggling to meet their basic needs, including understanding additional services that can be offered to support students at UCM

Request for Participation: I am inviting you to participate in a study on the Campus Cupboard. It is up to you whether you would like to participate. If you decide not to participate, you will not be penalized in any way. You can also decide to stop at any time without penalty. If you do not wish to answer any of the questions, you may simply skip them. You may withdraw your data at the end of the study.

Description of Research Method: This study involves interviews. The interviews will ask you about your perceptions of and experiences with the University of Central Missouri's food pantry. The interviews will be audio recorded.

Privacy: All of the information we collect will be kept confidential. Your personal information will not be shared with anyone outside of the research team and our university advisor. After the interviews are completed, the information will be deidentified, and I will not keep your name on file. 
Questions: If you have any questions about this study, please contact my advisor Dr. Sandy Hutchinson at hutchinson@ucmo.edu or at (816) 405-9306. If you have any questions about your rights as a research participant, please contact the University of Missouri, Columbia Institutional Review board at (573) 882-3181. IRB@missouri.edu

If you would like to participate and agree to this informed consent, please sign below.

Signature

Date 


\section{APPENDIX D PERMISSION TO CONDUCT RESEARCH}

Email Title: Request to Conduct Research

Dear Mrs. Rutt:

I am requesting permission to conduct research at The University of Central Missouri Student Recreation and Wellness Center's Campus Cupboard Food Pantry as part of my study, (Exploring college food insecurity: A qualitative study of the perspectives of the University of Central Missouri food pantry clientele). I would need to be onsite from October 2019 to (March 2020. I have attached my IRB protocol approval letter to this email for your reference. Please let me know if you approve this request by response email, including your organization's name, your name, your position, and a statement providing permission for me to collect data at your location.

Should you need any additional information or have any questions or concerns, please let me know. Thank you for your consideration of this request.

Sincerely, Michael Verderaime (Doctoral Candidate)

(719)648-7464

Mav45610@ucmo.edu

University of Central Missouri Cohort

University of Missouri-Columbia 


\begin{abstract}
APPENDIX E RECRUITMENT SCRIPT
Identification of Researcher: This research is being conducted by doctoral student Michael Verderaime. I am with the University of Central Missouri Cohort of the MU Cooperative EdD Program.
\end{abstract}

Hello, my name is Mike Verderaime. I am a doctoral student from the University of Missouri Cooperative EdD program, with the University of Central Missouri cohort. I am conducting a study about the University of Central Missouri's Campus Cupboard food pantry and would like to invite you to interview with me regarding your thoughts about the Campus Cupboard. Participation is completely voluntary, and participant identities will be confidential. If you would be willing to help me, I would love to set up a time to meet at UCM and talk. Please let me know when a convenient time would be. 


\section{APPENDIX F RECRUITMENT EMAIL}

Email Title: Research Interview Request

Dear [Participant's Name]:

Hello, my name is Mike Verderaime. I am a doctoral student from the University of Missouri Cooperative EdD program, with the University of Central Missouri cohort. Beginning this fall semester 2019, I am conducting a study about the University of Central Missouri's Campus Cupboard food pantry and would like to invite you to interview with me regarding your thoughts about the Campus Cupboard. Participation is completely voluntary, and participant identities will be confidential. If you would be willing to help me, I would love to set up a time to meet at UCM and talk. Please let me know when a convenient time would be.

Sincerely,

Michael Verderaime (Doctoral Candidate)

(719)648-7464

Mav45610@ucmo.edu

University of Central Missouri Cohort

University of Missouri-Columbia 


\section{APPENDIX G RESEARCH QUESTIONS ASSOCIATED WITH \\ INTERVIEW QUESTIONS}

\section{RQ1: What are the perspectives of UCM food pantry clients?}

2. Tell me about yourself (where you're from, major, things you're involved in on campus, if you have a job(s))?

5. What do you believe the clients the Campus Cupboard serves spend their money on?

7. How do you believe the clientele balance their education and other stressors?

8. Tell me about what a difficult day looks like for someone who uses the Campus Cupboard.

9. With all of these stressors-how does food fall into that? What are some of the things they might eat on a weekly basis?

12. What would you want someone to know about college students who have to use the food pantry?

14. How do you think the perception of what a college student is compares to the experience of a college student who experiences food insecurity?

15. How do think they feel before going to the food pantry? How do you think they feel after? How do you believe clients feel the first time they go to the food pantry?

17. Is there anything else I need to know?

3. What are you studying here at UCM?

6. What are stressors you experience as a college student?

a. How do you cope with these stressors?

b. What services does UCM provide for you to deal with these stressors?"

16. Tell me about a time when you went hungry. 
a. How does it feel when you have gone hungry?"

\section{RQ2: What UCM food pantry services are most significant to clients?}

3. How are you involved with UCM and the Campus Cupboard?

10. Where do believe they get food? How often do they come to the food pantry?

4. What would you say are some of your priorities are, on a day to day, week to week basis?

11. Why do you think they choose to use the food pantry?

How well do you think it fits into their schedule? How does the food the pantry offers compare to the food they want to eat.../ (GET AT THE TYPES OF FOOD THEIR EATING)?"

11. Why do you choose to use the food pantry?

a. How well does it fit to your schedule?

b. How does the food you have to eat compare to the food you want to eat?

\section{RQ3: What additional food pantry services would be beneficial to its clients?}

4. Regarding the Campus Cupboard, what would you say are some of your priorities are on a day to day, week to week basis?

6. What do you believe the stressors food pantry clientele experience as college students?

a. How do you believe they cope with these stressors?

b. What services does UCM provide for them to deal with these stressors?"

Why do you think they choose to use the food pantry? How well do you think it fits into their schedule? How does the food the pantry offers compare to the food they want to eat.../ (GET AT THE TYPES OF FOOD THEIR EATING)? 
7. How do you balance your education and other stressors?

9. With all of these stressors-how does food fall into that?

a. What are some of the things you might eat on a weekly basis?"

13. If you were talking to an administrator about food insecurity among college students, what are the recommendations or suggestions you would make about how to address this issue? 


\section{APPENDIX H THEMES}

Several key themes emerged as a result of the coding process. The following section outlines the five key themes derived from the findings. Theme 1. UCM students are balancing multiple responsibilities with a variety of stresses. Theme 2: The Campus Cupboard clients had an array of successful strategies for making ends meet while in college. Theme 3: The reasons people use the Campus Cupboard vary from individual to individual. Theme 4: Clients care about the food and services offered by the Campus Cupboard, as well as their experience while they are there. Theme 5: Although the campus cupboard is focused on clientele, the volunteers and staff are the Campus Cupboard's greatest asset. They represent a variety of skills, abilities, knowledge, perspectives and resources for the cupboard and their clients.

\section{Theme 1: UCM students are balancing multiple responsibilities with a variety of} stresses

Several key concepts bubbled to the surface as the participants defined their stresses as students and staff at UCM. Some of these are self-care, busy schedules, financial stress, academic stress, family stress, and food stress. Besides school and work, clients also conveyed the importance of maintaining an emotionally healthy lifestyle. Some participants noted life in this transitional period between adolescence and adulthood. For example, Carly stated:

I think that one of the big things that stresses me out is just doing my best every day. You know every day I have to put on my shoes and then go to work, and then part of the stress is not only trying to be my best, but also remembering that I'm still a person. I have to take care of myself, you know. I have recently realized 
that I used to be an athlete, so I was very fit, and I recently realized that like you're not going to be able to just go to practice and you know, feel good about yourself, and get all of your work done.

\section{Self-Care}

The life of college is also a transitional period for students in terms of social life as well. In addition to being away from home, some participants noted life in this transition period between adolescence and adulthood. One staff member pointed out that some students do not enjoy the same luxuries as others in terms of access to social activities. For example, Simon shared:

Well, the biggest stressor I would feel is the academics, but right next to that is the whole social atmosphere. Everybody's social media, I think that is a big stressor is keeping up with people, social media, people here, people, people out there, and you see things that your friends are doing on Facebook and twitter and you want to keep up with the Jones', air quotes, and things of that nature.

Relationships can be stressful on students whether it's boyfriend, girlfriends, friends, and just really depending on where you're at in the semester. That's very stressful, and a lot of times holidays can be stressful and/or depressing for people as well depending on what their home life is.

Social Life. Because the media has been recently reporting on the rise of college food insecurity, several participants expressed their reactions to the general population's accusation that college is just a series of parties and a fun lifestyle. Specifically, Cindy rejected this notion, explaining how she navigates the environment: 
Actually, I came here all the way from Africa, like thousands of miles away, I don't think I'm going to come here and start living that life... But yeah, I see a lot of people, I have a lot of friends on snapchat that party and all, but you can't lead that life when you are a nursing student, I'll put it that way.

In general, participants expressed a similar perspective negating the generalization that college is similar to the laid-back lifestyle portrayed in movies. Specifically, Charlotte asserted:

Well, I've definitely met a lot of partyers. It's definitely here, but whether you necessarily want to be involved in it. Because I've also met a lot of people who are not involved in that and who do not care for that and I feel like there are a lot more of those than there are of the actual partyers.

Sophia addressed an important angle to consider when exploring food insecurity or public outreach programs in general:

And it's like a fair thing for people to ask about... it's like a really easy mindset to get into, I think, even for like people who are in a non-profit setting, who like see people at the lowest of low and like working really hard, and you want them to look a certain way, and I want you to never possibly have like any bad behaviors and like never get angry, and never react in certain ways to your situation and then just work really hard and then like it's going to be okay. Like that's a lot of times like the mindset we want to have, but then you see somebody and you see them pull up, and this is like a specific but general example, like you see somebody who is coming up to get food through Harvesters' or something and they have a really nice car that they're sitting in, and you're like there's no 
way you need help, like you're sitting in this like super nice car but you don't know if that person just like lost their job. Like they bought their car when they had like a really good job and they could afford it, or maybe they borrowed that car from somebody, and like they're using it so they could like go pick up goods, or there's like ten million things that could be going on in their lives and it's just you never know, I think it is so hard to create such a set way for people to be when they need help, and that's part of that mind set where like other people need it more because I do have a car, or other people need it more because I have enough money to at least pay for where I live. Well, like that's good but you know, we need to feel like we're safe and well taken care of or taken care of well enough that we can function day to day and maintain the set lives that we have sometimes. There's like a ton that goes into it, so, and it's easy. I know I've thought that way at times. So, it's just until you hear it from somebody or see it, it's kind of hard to completely be like okay, like you know they've got some stuff going on even though it doesn't look like it.

\section{Busy Schedules}

The majority of participants described busy schedules as the most difficult days. For example, Christopher said:

A difficult day would probably be, it's probably one where I have to work, and I have a ton of homework that I have to get done that day. Our hours, we used to only work 3:30-5 and then 5-8, like someone else would come and take your shift, 
but now it's just 3:30-8 and my classes get out around 1 and 2, so then I have like an hour break to do as much as I can, then go to work, try to do homework and like work and all that.

Likewise, these long busy days with strict schedules resulted in mealtimes having to be more flexible, Charlotte noted:

I think it's just long days. So, somedays it's like wake up at 6:30 go to work for four hours, have classes until like 4, then you go home and do homework and then if you have any extra curriculars you go to those, and so that accounts for a very long day. Socializing throughout the entire day because you can't really be away from people in college so just tiring, I think. It can be really easy to get worn down or burnt out.

Also, athletics added an additional component of difficulty to the already busy schedules of university life. Colton emphasized:

My busiest days are Monday, Tuesday and Wednesday because Mondays I have classes from 10 all the way to 4:45 so you know I have to miss actual practice and make it up in-between my class. So, I'm busy with that. Saturdays I usually spend doing homework, but now I'll be traveling with the team.

Similarly, one client expressed how her schedule dictated what she eat. Specifically, Carmyn indicated, "I don't have a time to cook a lot, then I cook a can of soup for lunch, or like a PB and J for dinner, stuff like that, anything that works." Of course, busy schedules were not limited to clients. Volunteers also expressed having to rely on fast food in between work and class to balance their responsibilities. For example, Violet said: 
Sometimes, I don't even have time or like I'm barely struggling to even get to McDonalds, and then get to work. I have a class that gets out at 2:30, and that day I start work at 3, and I usually have to be there like 10 min. early, so I just like have to be leaving and getting out of class, and that class gets out late sometimes, most times actually. I mean, somedays I forget to eat, and I don't have time to eat. Other days like about a weekish $[s i c]$ ago, I had work at 6 in the morning then class at 9, then I had to work on doing a quiz in between classes. Then I went to my next class and then I had to go to work and then I had a sorority event, and then I had to do some more quizzes and start working on writing a paper, and there was barely any time to eat so I think I ate twice that day. I didn't eat breakfast, I had like chicken nuggets for lunch and then I just snacked on popcorn when I was doing my homework.

This study found that budgeting time in college poses a certain amount of stress. For example, Clarissa reported:

I don't know if I'm really balancing it well, because I tend to get really stressed. I procrastinate a lot, and it's to the point where I don't feel like doing schoolwork anymore because I've been doing it for such a long time, that I'm kind of over it. I don't really know if I'm balancing it, to be honest.

\section{Academic Stress}

When asked about the academic stress of college, participants expressed different responsibilities, difficulties, and worries about their futures. Many participants expressed a variety of responsibilities when asked to outline their priorities. Among the most commonly reported were classes, and schoolwork. For example, Carol said, "My 
priorities would be homework, completing clinical rotation hours and sign offs, and then make sure that I have something to heat up at home for dinner, or to bring for lunch." Additionally, Colleen noted her two top priorities, "Passing my classes and staying financially stable". However, many clients indicated the difficulty in balancing difficult course loads, work and eating. Specifically, Caroline argued:

Homework is definitely number 1 , this semester more than any of them. I spend at least three to four hours every day doing homework, sometimes it's even more. I'd say that's my number one thing. This job is hit or miss, on like how many hours I spend doing it. I have a desk shift that I have to work for three hours a week, and then we have two-hour long staff meetings. If I'm on duty, then that takes up a lot more of the time, so like it just depends on how much of a priority this job is on a week to week basis. It just fluctuates.

Specifically, Cindy defined the dyadic relationship between working and school by linking the ultimate goal of graduating college:

Okay, one of my greatest priorities is, of course, getting into the nursing program because it is so competitive. And after getting into the nursing program, like finishing my program like excelling with my GPA to get a good job. Additionally, clients are stressed about the uncertainty the future holds, specifically, in terms of investing in an education with the hope of being able to support themselves financially after graduation. For example, Colton considered completing the transition between college and professional life as also stressful:

The future, the future, that is what stresses me out. You know I plan on going to grad school now, but sometimes I wonder if I should go to grad school right away 
or if I should wait, or if I even need it or anything like that. I guess another factor as to why I'm going to grad school is just because I don't know, I'm not ready for real life yet. I don't know what the future holds, so I guess graduate, stay in school for two more years, educate myself. You know, figure things out while I'm taking my master's. The future can be scary sometimes. You don't know what it has in store for you. It sounds like just trying to, you know, plan for that and prepare to get out and get into the real world. That's a stressor.

\section{Lack of family financial support}

Staff and clients alike acknowledged the level of stress revolving around studying at a university. Many participants indicated the financial stress of going to school. For example, two clients mentioned a similar stress stemming from low income families. First, Colton emphasized:

Um, yeah. So, my family isn't necessarily, I mean my family really struggles. Actually, last fall we moved in with our grandparents because we were unable to afford, my parents weren't able to afford where we used to live so we decided to move in with our grandparents, so that they could help us out. So, yeah, just growing up, we would have time when we were okay financially, but we would have seasons too when we were struggling. You know lights get shut off, water getting shut off, like eating hamburger helper for, we would have the stress of those financial burdens, so I know that's something that I know I'm really frugal with my money, at times, because I don't want to be in that situation. Okay, so I have a bill that has to be paid, but I don't have the money. I don't know I'd be like worrying and stressing about how things are going to play out. 
Second, not every participant has the same financial stability within their own family. Being away from family and losing family members increases stress for the participants. When asked about what stresses in her life affected her the most, Cindy indicated how losing her father affected her ability to study in the United States:

My tuition. Because I got here, and I lost my dad. Yeah, and he was like my major financial sponsor, and after I lost him and I'm from Africa and once the dad dies, his family gets to take his properties. So, it's like African culture where I come from. His family is like the owner of everything. So, it got difficult and everything, so I try to get loans, and try to pay my tuition. And work of course. I just try to save money. And that's part of the reason why I don't spend money on a lot of things. So yeah, that's part of what stresses me out. And school, it's not like school is really stressful, but it can get overwhelming at times.

She added that money was also a concern for her family back home, and even though she was in the middle of school, her ability to make money in the US was better than in her home country. When asked if she sent money home, Cindy replied: "Yeah, once in a while, maybe if my mom is really, really in need of money, and maybe if she's celebrating a birthday or if any of my siblings need to pay their fees." Other clients mentioned similar stress surrounding family: "Interviews with staff found that they were aware of the constant financial stress surrounding clients." For example, Stanley noted: Like I said, college is expensive. These are students who have school, they have work, they have like extra curriculars, so it's probably not easy for them to get a full-time job, make money and pay for all that. 
In fact, Simon noted the ability to make money with the time demanded by being a fulltime college student:

I think more of it is they just don't have very much money. I think that is more of it....So, if they are working, and they're not even guaranteed 20 hours, they may be working 10 hours a week getting $\$ 8.35$, and then they might have to pay for their cell phone bill. They have to pay for gas, I don't know there is a lot.

Obviously, the struggling college student is not a new concept. As Virginia pointed out: When I went to college 25 years ago, I was one of those that paid everything I could just to get into school. And my parents weren't helping me and I, I had a couple of days where I went, I did not have any food whatsoever and I did not eat, I just drank water for two or three. So, I got some more money to be able to buy some food. And I would live on rice and potatoes. I take a baked potato and take it to school and that's what I would eat, a cold potato at school, you know, that's what I was eating, I think. It would have been so nice to have something fresh. I'd always crave fresh vegetables or fruit. Something fresh to eat, you know, some meat maybe, you know.

Participants are stressed about food. Food was described as a unique stress affecting participants in this study. Participants defined food anxiety by citing lack of resources to purchase food, lack of time to prepare meals, critiquing the dining halls, and ultimately noting how their stress manifests in eating habits. Establishing a baseline for food insecurity proved difficult, due to hunger's ability to affect everyone differently. Participants revealed that time constraints, lack of resources, and anxiety caused by food illustrated how participants struggled to navigate the UCM Food Environment. 
The Campus Food Environment. One participant argued for addressing the food environment on campus by offering healthier items on a large scale. Specifically, Christopher contended:

More healthier food options. Things like, I know the dining halls are not the best. I don't know if you've seen them, but sometimes the food is just not right. It doesn't really taste the best. It might not be the healthiest option out there, but definitely if there were more healthier options, if it wasn't consistently the same stuff, that would be really nice. Opening up new options to different foods, that would be really nice too. That and like opening up to students, showing them that you kind of realize that it's a problem, because I don't think a lot of students know about food insecurity. Because I'm not going to lie, I never knew. Things like having the time to talk about that and pushing a program about that. In fact, knowing how to cook was a factor in how people can ultimately provide for themselves. For example, Clarissa summarized, "Meal wise, I probably eat like lunch and dinner, and I do some snacking. Yeah, I tend to make things that don't take a lot of skill or a lot of time, like Kraft Mac and Cheese." The options for food are limited on campus. Two competing points of view regarding how participants perceived the food environment affected their stress levels. The first one focused on the stress of having a meal plan. Specifically, Cali mentioned:

I think it would be better if I didn't have to buy the plan, because then I could just buy my own food, because I'm so sick of eating the same thing over and over again, so I will go buy other food sometimes, and that costs money on top of the other money that I paid for the plan. 
In the second point of view, Chloe stressed the anxiety of not having a meal plan:

It's just the idea of worrying, okay what do we have left to see if we can still make a meal with and I'll be honest, there were days when I would just skip a meal, because I was like you know what, I just don't feel like it today. I don't want to. There is nothing left in the cupboard that I feel like eating. So, it's not like I was starving myself or anything. Nothing like that. Just worrying about it makes you not want to eat.

Many participants agreed that the time to prepare meals in between studying and responsibilities is a point of concern. For example, Cynthia indicated the difficulties of being an international student:

We are from India, so we eat Indian food and sometimes there are assignments and study pressures, so we don't have time to cook. So, we don't have option outside, like Indian restaurants to eat so sometimes it's hard to manage that. Cooking and studying are a challenge for us.

In fact, time constraints added just as much stress as financial constraints. Specifically, Caroline noted:

It's more of like, not a stressor about how I'm going to afford it. It's more of like how am I going to work this out to what meals am I eating at the dining hall. And like planning my meals is a stressor, because I have to figure out what I'm going to eat, if I'm cooking it, when am I going to cook it, do I have the things I need to cook it. Is it worth it? I don't want to buy a whole pound of flour if I need a tablespoon. So like planning my meals is a big stressor, and figuring out what I'm going to eat. Because if I don't plan it then I won't eat. Which is not good. 
However, some clients did indicate the depth of the financial struggle, emphasizing the feeling of not having enough resources and commenting on their despair. For example, Chase highlighted: "Yeah, it's mostly just buying it. Food is expensive. It just adds up. I feel like I don't prepare enough. So, I end up spending more money on food." Violet reflected on struggling with time to prepare nutritious meals and money to purchase healthy food:

I mean, I have had to go without eating before for like writing a whole paper and I don't have time to stop writing to go get food. I've had days where I have \$12 in my bank account until Friday, it is Tuesday, I have to portion my money and where it goes, so those are the days where I'll have 2 meals a week and those are the days I will usually try to find a way to stop by at the dining hall.

The staff were particularly aware of the anxiety food can create for Cupboard Clientele. For example, Sophia explained:

Well, you kind of talk about our wellness overall. The really basic needs. I mean like sleep, food, that really play into our ability to function normally. When you're really focused on something so basic as getting food, then it's a wonder how some individuals are able to hold down grades. So like getting good grades because you're so focused on like I got to work so many hours so I have enough food so that I can pay for my education and pay for food and pay for my housing and I don't know. It just like plays into a whole bigger picture of it's not necessarily about the food but it's about getting the food and about also being able to maintain all these other things that we should have as human beings, like shelter and safety and education. 
Comparably, Simon agreed and added food adds complexity to an already stressful situation:

I think it's a big stressor. I think it can be a big stressor because it adds one more thing on top of everything else. So you've got an exam on Friday, you have a big paper, you got a big group project due, and half the group isn't pulling their weight, and you're fighting with your roommate, and you've barely got any food. I think it $[\mathrm{FOOD}]$ is just one extra thing that just builds and builds onto everything.

Limited Transportation. Many participants also spent money on transportation.

One client indicated her expense in traveling to Kansas City to buy produce from an African International Market. Specifically, Cindy emphasized:

Okay, I'll first say transportation. A lot of international students are in, some of them go to Lee's Summit and the bus cost like $\$ 12$ a day, to go to Lee's Summit, so that's a lot I feel. And you know going around some of them want to go to the hospitals on weekend, because the health center doesn't open on the weekends. One staff member noted the stress transportation plays in food insecurity. For example, many international students face this stress daily:

Like I've always had a car, and I've always had a way to get places, but if I didn't have a car, would I be able to keep my job, would I be able to go get things for myself. Like, that would be pretty challenging, and then to add on top of that, coming to a completely new culture, in a new place where you don't know anybody to reach out to and get support from. Like, so and that is from a standpoint of coming from a different country. 
Very similarly, Cindy reflected on the difficulties of being an international student during winter holiday breaks:

Um, yeah. Okay yeah, before I got a car, when the school was on break. And you know I don't think they're open those times, and I had to walk all the way to Walmart to get food. I can't forget that day. It was a sad day for me. And it was so cold. It was during December, and I didn't travel, I didn't go anywhere, and it was so cold, all my friends were not around. I was just like oh my god, I'm starving. I had to walk all the way to Walmart. I wore a lot of coats, sweatshirts and everything. It was so bad that day. When I came home, you know I was happy. Food is really good.

Similarly, Caroline indicated the importance of the food pantry for students with limited transportation:

But I also think a lot of international students use it, because they don't have transportation to get to food. Because there is no public transport in Warrensburg. So, I think you have a lot of students using it who don't have cars. Because it's groceries that they can get on campus without being up charged, because they have, it's not even groceries at the bookstore, but they have like little cereal cups but not like the boxes of cereal, but that stuff is like so up charged. Because it's convenience. So it's nice because it's close and it's on campus for students who don't have cars.

\section{Stress affects client dining practices}

The participants reported accessing food in a variety of ways, but maintained their reasoning focused on reducing the amount of stress surrounding food. Participants 
specified the fast food restaurants in the student union as one way to access food on campus. Some participants specifically choose to purchase tax free "dining dollars" to be spent in the on-campus restaurants over dining hall meal plans. For example, Charles indicated:

So, I didn't choose a specific meal plan. I added swipes onto my account so I could have those just in case. So, with those, I got those for a time when I have nothing else to eat, or in case I'm on campus and I know I'm not going to have time to eat at home later. So, I would just eat on campus then.

Additionally, some participants avoided the dining halls completely. Clarissa's response highlighted a common anxiety for college students having to dine on campus:

No, there were times my freshman year, where I just wouldn't go to the dining hall because of too many people. I just wouldn't eat because of like my nerves, and I was anxious, yeah.

This anxiety was actually quite common, as Veronica remembered:

I've never ate at the dining hall even when I lived in the dorms at K State, my freshman year for like a month. I think I ate there once just because I didn't get along with my dorm roommate, and I didn't like to eat by myself. I don't like to eat by myself, unless I'm like going somewhere and getting it, then I don't care. And I think the older I've gotten; I really just don't care. But boy, before I was like I can't be seen eating at the dorm as a freshman, by myself. I'm not going to eat here. Just not going to eat.

Other participants reported a stronger dependence on restaurants. For example, Violet confessed: "I will get like \$2 McDonald's sandwiches. I just eat at my dorm or in 
my car, depending on how much time I have."

Convenience. Around the campus, convenience often times takes the shape of Einstein's. For example, Cali reports, “The library at Einstein's bagels, because they have smoothies and bagels, and those are delicious." Participants also reported choosing meals and food based on convenience. For example, Clayton explained:

So [my girlfriend] and I are super consistent on what we eat, so we eat the same stuff all the time. Like we eat a lot of frozen stuff, and then I will also, it's frozen stuff but then I also get fruits a lot, or not a lot but I try to have a fruit on hand. For a while I was doing fruit cups exclusively because they're convenient and they don't really expire kind of thing and then threw in some bananas and we still have a thing of fruit cups but mostly frozen food. It's almost all frozen food, I would say.

Celeste agreed and added her preference for quick and easy items, "Sandwiches, like something small." Colton added his take on the importance of stress reducing convenience, but also nutrition:

Well one of those things I eat is like rotisserie chicken, um salads, spinach, I'll make. Um peanut butter and crackers, or peanut butter and apples or celery, stuff like that. Um, and then breakfast I'll have some eggs, toast, and then I'll probably get some fast food or something. But for the most part rotisserie chicken and salads and for breakfast like eggs and stuff. Ramen, frozen dinners, eat at a friend's place.

\section{Participants struggle to balance financial responsibilities}

Specifically, participants broke their concerns down into living expenses, 
academic costs, and loans and debt. Additionally, several financial decisions in the daily struggle that emerged as priorities for the participants such as transportation and visits home. Ultimately, for those participants living off campus, food was found to be a financial obligation that caused stress for the participants.

Fixed Living Expenses. Living expenses while attending the university were a concern for the participants in this study. Specifically, among the variety of fixed expenses, participants specified the financial responsibilities behind living in off-campus housing as a stress. For example, when clients were asked how they spent their money, they indicated fixed expenses like utilities and rent plagued their already low funds. For example, Chloe indicated:

We have to pay for, the lot rent covers trash, sewer and water. The gas bill is really pretty easy, it gets a little higher in winter because our heating is gas powered, but usually about $\$ 30$ a month throughout the normal year and it'll get up to probably about $\$ 70$ or $\$ 80$ even throughout the winter months even when we're running the heaters. The electric bill, that one is pretty constant too, because when we run the window units, that jumps up the electric bill over the summer too, but even that doesn't get much higher than $\$ 120$ a month during the summer months.

Volunteers and clients alike felt the stress of living costs. For example, Veronica breathed a sigh of relief when she found a new place to live: "Rent and bills like are the biggest stressor. My base bills, so since we just moved, we pay less, thank god... we pay way less than we use to pay, which is awesome." Participants indicated that paying bills was a large stressor. For example, Carly reported: 
Let's see, since I have different clients, I end up spending money on different activities that I have for them. Rent... of course is a big portion of my income, and then bills, I mean, I still have support from home. Like my parents help me with my car note, and you know insurance, things like that. But the big chunk is just surviving really.

Veronica agreed: "It is gross, awful, and I hate it. Let's see electricity. We had to switch from KCPL which has been a struggle ever since we moved up here, because it is expensive, electricity is."

Food. Spending money on nourishment rounded out top priorities for fixed expenses. This investigation found a variety of ways participants feed themselves, including budgeting for groceries, dining out at restaurants, meal plans, and fast food. Naturally, clients without meal plans spent higher amounts of money on groceries. For example, Chloe explained:

Food definitely on the weekly basis. I suppose between my husband and I we probably go through at least $\$ 150$ if not $\$ 200$ a week for food and so it kind of. And my job pays enough so we can cover all of our bills. But after my job we have maybe \$200 a month and that is not enough for food. So, he has to have a job and the short periods where he hasn't had a job, it's been stressful. That's when we used the Campus Cupboard, is when he didn't have a job.

Regardless of what participants budgeted, the stress of the financial responsibility was burdensome. Veronica shared:

Um, so I basically for the most, for the past couple of years, I've had to live paycheck to paycheck. So, that is a struggle. Having to prioritize, are you going 
to buy a lot of groceries? What groceries are you going to buy? Are you going to buy Great Value groceries? Or name brand groceries? Where are you going to go to buy them, because Walmart might be a little bit cheaper than Hyvee or Aldi's. So, I think, I probably will still struggle in nursing school until I have a grown-up job, because groceries are expensive. Everything is expensive.

Groceries. Regardless of where one lives, spending money on groceries was an unavoidable additional cost to university life. When asked, clients indicated different budgetary constraints, but overall frequently mentioned the added cost of groceries. For example, on the lower end of the spectrum Caroline reported:

I would say on average, I just went grocery shopping before you got here, so I probably don't spend more than $\$ 20$ a week on groceries, but sometimes I don’t have time to go grocery shopping. So sometimes it's like an every other week thing, and then it's like spend maybe $\$ 25$ or $\$ 30$. So, like $\$ 15$ a week, but it just depends. But when I don't have time to go grocery shopping, I don't because it's a pain. It takes a chunk of time to go get it, and like plan out what I want. Because every time I go grocery shopping, it's like what am I going to eat for the next week.

Some clients even looked to other forms of purchasing groceries to save money, including the commissary at nearby Whiteman Air Force Base. Clayton explained: I have personally not noticed, but like say I go there every once in a while and then, so I've been drilling on Whiteman for four years, and I've also spent way too long on Fort Sam Houston, so I've went to their commissary a bit, but most of the time I've never noticed a huge price difference. But if I do it is usually better 
at Walmart than it is at a commissary.

Grocery Stores. Participants indicated shopping at a variety of grocery stores when choosing where to shop, depending on location, price, and time. For example, Violet explained:

A lot of people, I know at least in my sorority, they go to actually, they don't usually go to Walmart, because it's far away from the campus. They will go to Dollar Tree, which is kind of weird, but it's cheap, because everything is a dollar there. But that's how people get their groceries. Sometimes I think they'll go to Cash Savers now. It used to be Woods but it's not anymore.

Walmart. Most participants rely on Walmart for their grocery shopping, even though some participants mentioned other areas, Walmart was their principle source for food. Cali said, "Aldi and Walmart. Aldi has some things that Walmart has for cheaper, and Walmart I always end up just buying great value stuff." Walmart does have some shortcomings, especially if people are looking for specific types of food. For example, Cynthia mentioned: "We go to Walmart for vegetables and fruits and rice. And for Indian groceries we go to Indian store in Lee's Summit or OP (Overland Park)." Some Campus Cupboard clients choose Walmart to supplement what they cannot find in the Cupboard. For example, Carly reported:

Well, they do have vegetables in there, but I don't get those vegetables. I'll get, so I usually compare the vegetables at Cash Saver to the ones at Walmart, and Walmart is usually cheaper, so I'll usually get the ones from there. I mean, it just depends on what is available. What's cheap, really.

Aldi's. Participants often shop at Aldi's. In particular, multiple participants 
indicated their preference for Aldi's. For example, Caroline explained:

Here, Aldi's is my number one go to. Because I think they have good prices, and I'm not a big fan of Walmart honestly. I don't think, I just like Aldi's better. Aldi's is where I grocery shop at home. Aldi's and Hyvee, so Aldi's is much more familiar. I like how they don't use plastic bags, because save the earth. But Aldi's is just where I find, I'm all about off brand. I buy off brand basically everything. And I find that Aldi's has everything I need there, so why go to Walmart when I can just go to Aldi's. It's easier, it's faster. And they have good prices.

Other participants in this study mentioned Aldi's as a top choice. For example, Colton indicated, "Aldi's or Walmart for the most part but we typically like to go to Aldi's because it's healthy it's fresh and its relatively cheap." Sophia also mentioned their preference for Aldi's, while highlighting some barriers that may prevent others from shopping there:

I love Aldi. I'm such an Aldi person but like if I didn't have a car, I would never go out there. That and Walmart are like right next to each other, and it's like they're kind of far away. They're on the outside of town really.

Yet other clients focused on using a variety of store options when preparing their meals. For example, Carol reported:

My family will go to like 5 different places in St. Louis and shop for sales, so we'll go to Soulard Farmers market, we'll go to Aldi, we'll go to Volki if it's a special occasion, although we know the owners. My sister is best friends with her son, so she can get a few things which is nice.

Family and support systems. Additionally, one participant in this study 
questioned family and support systems role in providing food for their students. Specifically, Veronica conjectured:

I would assume like grocery stores, their parents? Because I know a lot of people that live local, or the Kansas City area, so I'm sure a lot of people go home and get food. I mean, I do, when I have the chance. I'm like mom. Do you have food? Because I need it! That is where I would assume that most people do.

Restaurants/ Eating Out. Clients expressed a variety of reasons for frequenting restaurants, but regardless of the reason, participants reported dining out as a financial priority. For example, Christopher revealed:

I'd say most of my money goes to eating out kind of. I get lazy. So, I don't really cook that often, but when I do cook, I cook a lot. Second thing, probably climbing stuff. That's where most of the money goes.

\section{Financial Academic Obligations}

Among the daily priorities listed by participants, many focused on paying for school, financially stability, and managing fixed expenses. Many clients placed a significant importance on financial stability, illustrating the stress of the financial obligations many college students are facing. Cindy shared:

Um, I pay my tuition, so my tuition is like $\$ 9000$ a semester, and then my house rent. I hope to be out of debt. Yea, I hope to have enough. Yeah, and basically just have a good life and have enough, and like I don't want to be begging people for help, I want to be able to do things myself personally and take care of my family.

School. The investigation found that added academic costs also plagued participants. Specifically, participants mentioned the cost of books and Greek life added 
to their bills. Reserving a large amount of money for their books each semester was stressful. Simon indicated:

Oh, my god it's stupid how expensive they are. I mean you're looking three, four, five, six hundred books per semester, and then you can sell your books back... a book that you bought for $\$ 150$ bucks they'll give you five dollars for it, or they won't even buy it back, or there's a new version coming out. It's ridiculous.

Cali confirmed this high level of stress:

Well right now, I'm not sure how I'm going to buy my books for next semester. All of the money that I'm making goes towards all the stuff that I'm spending it on, so I have a budget to try and save a $\$ 1000$ buy the end of this year so I can buy my books. So, I don't know how well that it is going to work, but I'm trying to micromanage everything that I'm spending because books are really expensive, and I'm taking 18 credit hours. There will be a lot of books.

Because most courses require at least one book, clients stressed the importance of having additional academic costs beyond the price of tuition owed to the school. Clarissa made the case:

Depending on the class and how many books you need, it can go up. Like the last couple of semesters, some classes have needed like 2-3 books, and I'm like, I don't see why, but okay. They don't even talk about some of the other books sometimes.

Most participants indicated a level of frugalness when spending their money. For example, Charles argued:

The thing that people that I see spending their money on is probably on stuff they 
need throughout the school year, so like if they didn't buy a textbook that they thought they didn't need in the beginning of the semester, but then they need it around September, or let's say they need a pair of khakis for a job interview or a scholarship interview they need and they'll probably end up going to aa discount store or Walmart to pick those things up. It just all, I have not seen that to be the case for students, that they just blow their money on things that they don't need.

Greek Life. Greek life was also mentioned as targets of student spending. For example, volunteers and clients alike agreed that even though the financial commitments ranged, sororities were a financial focus of the participants. Regardless of the role the Cupboard plays in participants' lives, the participants reported the strain Greek life has on their checkbooks. Violet revealed, "Mostly sorority stuff. I mean I pay \$200 a month to [sorority], and then also food. Lots of food."

Tuition/loans and Debt. Many students acknowledged the stress behind having to turn to loans to pay their tuition. Clarissa clarified:

Um, the debt that I've built up, trying to find a good job that will help me pay for that. Some classes stress me out. Due to the workload and there's like one class that I'm taking and it's not the most organized and that stresses me out a lot. It's called career readiness. It's ran by career services, and the most bothersome thing to me is they like make you go to their events that they're holding. Like I did a mock interview last Friday, and I didn't really want to do it, but it felt like I was made to do it because it was worth like 50 points. I suppose it was good experience, but I didn't want to go.

This stress seemed to emerge towards the end of the semester when students were 
enrolling for the next semester. Violet revealed:

Yea, when I was trying to get enrolled for next semester, it was like super stressful, because my enrollment date came up and I still owed like \$700 and I was just trying to find somewhere to get all that money, and I figured it out, but it took me about a week. I ended up talking to my mom. She gave me a little money that I have to pay her back for, and then I used my \$200 that I had. Yeah, it was for sure stressful for that week. It was not fun. Academic debt was not the only form of debt that inflicts stress on students. For example, Veronica mentioned credit card debt as another stress:

Oh yeah, thank goodness I haven't had to pay a dime of student loans. I don't think you have to until a certain amount after you graduate. Thank goodness, but credit card debt. That is a fun one. I didn't have any credit cards until I worked for American Eagle Outfitters, that clothing store. When I went to K State, and I was like no, not doing it, and then after you know a year of working there, they were like you really should just get one, and I was like, you know what you're right. And that was dangerous, and I worked right next to a Victoria Secret. That kind of was a bad, yup. So, I went ahead and got a credit card for them, and I was like oooh, all my family is girls, so I'm like Christmas, birthdays, Christmas, and Nebraska Furniture Mart we got one to get new furniture with. That was fun, until you had to pay it. So, yeah, we're still paying. Because interest, and then you get in situations where, we've been in situations where it's like, what's more important? Paying your bills to live in your home or paying your credit cards off. So, then we would get really behind on credit, and then yeah, accruing interest 
yeah.

The Daily Struggle. First, money stresses clientele out in a couple distinct ways. Not only are people worried about the daily struggle to stay afloat, but also keenly aware of the extent of their debt and lack of savings. The daily struggle of staying afloat financially and academically seemed to take its toll on clients. Chloe indicated her biggest stress in addition to school was: "Paying our car and our regular bills." One international student working as a volunteer also noted the stress of living costs. Victoria shared:

Living in the US is expensive. If you have to pay bills, if you have to pay the rent, if you have to pay for your car, I think they budget for food, I can say it's stable, because you cannot eat more than what you can afford, but what I think stresses them out is to get what they want to eat. They probably don't' have money to eat outside, or to cook, so they turn to the campus cupboard to get some stuff. I think that... I don't know.

Some students have scholarships but pointed to how dependence on scholarships decreases the amount of time one has to dedicate towards earning extra money. Christina indicated:

Like keeping your scholarships, making sure your grades are high enough that you don't lose your scholarship money. It's hard to get a job and also be going to school. Because a lot of jobs don't work with school hours.

Additionally, Carol voiced various concerns regarding the reality of the struggle to make ends meet as a college student:

I know a lot of people appear that [they have parents that can pay for everything 
or that they're doing okay], but in reality they're working every moment that they're not in class or if they're in a sport they're working every moment that they're not there and then they're able to use that money, and they may have some scholarships or grants or parents helping, but I know a lot of people that are actually working to take a minimum number of credit hours here. And then some of them will come here for a full semester, take a semester off and keep doing that so that way they can save up money. I do know one of my friends actually had to move home at the end of my sophomore year. So that way she could save money so she could work.

While there is a distinction between food insecurity and caloric deficiency, some participants expressed navigating the stress of the low bank accounts many college students encounter. Cali shared:

I've had .20 cents in my bank account for a short block of time, so I would eat at the dining hall every day, I would go to the cupboard and I would get everything I could so I could have some sort of food yea. Yeah, I had no money for a while.

So, I used these resources and it's definitely helped.

\section{Vehicles, Insurance and Gas}

Participants suggested their vehicles and trips home to see their families also were a financial stress. Particularly, expressing they had to spend money on the cars themselves as well as gas. While some families were able to help more intensely than others, participants reported some level of stress surrounding their vehicles. This stress was prevalent for students who did not live in the general community. For example, Charles said: 
So, for me I'd say I go home at least once a month. It might be more just depending on what's going on, but like this semester I went home a few more times than I have in past semesters. Just a lot of stuff going on at home, that I have to go home for.

Insurance and car payments. Some participants mentioned vehicles as a shared responsibility, but regardless of how they interacted with the pantry, clients indicated that car insurance was also a financial responsibility for which students were responsible while in college. Veronica summarized:

A lot of people that I'm friends with in my classes or that I talk to have like newer cars, and they're paying hundreds of dollars for their car payment. I mean, my fiancé has a 2013 mustang, and his car payment is $\$ 300$ some dollars and then insurance is like $\$ 100$ something. So that's something for him, but we kind of just share bills, you know because we're here for each other so, his bills are my bills and my bills are his, so.

Gas. Whether it is to an off-campus employment or home to see their family during the weekends, having to purchase gasoline added to the participants' costs of university life. Cali reported:

Yeah, my gas and my other things that I have to buy, like normal toiletries stuff and any sort of like food that I can’t get at the pantry. Gas, my car takes like $\$ 40$ to fill up. Yeah, the toiletries stuff is a big thing, because I don't know how my roommates go through so much toilet paper, but we really have to buy a lot of toilet paper. Toilet paper, paper towels, Kleenex. We have to like buy cleaning supplies, and my suitemates don't clean anything, so we clean because it bothers 
us, so we clean.

Other clients expressed similar concerns. Charles indicated:

So, for the car that I have it has kind of a big tank, so I can run on that for a while.

So, I would say it's expensive after it runs out, but it can last me a while, but it takes me about $\$ 40$ to fill my tank up. And, the tank can last me like $2 \frac{1}{2} 2$ weeks. It kind of works along with the schedule that I have, so it's not that bad.

Ultimately, these daily struggles cause participants to scrape by in other areas. Many times, resulting in unhealthy food. For example, Veronica reported:

Gas obviously. Weird hours that I have to work. I mean I try to eat like an adult, but some weeks are work than others. Some weeks were like, oh my gosh we got all this money we get to meal plan and have all this awesome food, and then other weeks it's like Ramen Noodles, Mac and Cheese, and inexpensive things.

Additionally, Charlotte mentioned the connection between spending food money on gas:

So, if you spend a lot of time commuting whether because of family emergencies, or just because it's a holiday or something, then you do spend a lot of money on gas especially if you don't have like an economical car. And so you spend a lot of money on gas, which means you don't have a lot of money to spend on grocery items. Or food items or for people who do not have like an unlimited meal plan at the dining hall it's something that they can use to their advantage so they're not spending all of their meals at once, or only eating pizza for the rest of their lives.

Phones and entertainment. Many clients also reported phones and entertainment as financial priorities in addition to the basics. For example, Charles said: "So, typically of those who are probably staying in dorms, it's probably so like subscriptions they have 
to stuff, like Apple Music and Netflix.” Although students invest in different types of plans. Participants indicated phones are an important piece of their financial obligations. Veronica stressed, "our phone bills, a couple hundred dollars."

\section{Theme 2: The Campus Cupboard clients also shared an array of successful strategies for making ends meet while in college}

Specifically, participants reported strategies for budgeting and financial management, meal planning, engaging in supportive relationships, prioritizing goals, and using established campus resources as ways of navigating their financial situations.

\section{Budgeting/ Financial Management}

Employment. Many clients who participated in this study reported balancing a work schedule with their student course load. Most clients reported one 20-hour a week campus employment, while others worked two or three jobs off campus to earn money for school. For example, Chase said: "I have a 20 hour a week job, but I don't work 20 hours often, like 10-15 hours." The limited hours for work on campus force some participants to look for additional shifts. Caroline shared, "Sometimes on the weekdays it just depends. Like I'll pick up shifts if people need it. It's just a little extra money on the side, saving for grad school.”

Some placed more emphasis on their work than others. For example, Chloe reported:

Really just getting through day to day. I mean the job. I just definitely want to keep the job. So, the job is priority over classes. If my classes interfered with my job, I would choose my job first, because that is was keeps me going and what keeps our income stable. I work 40 hours a week. I think I'm hitting $\$ 24,000$ a 
year. I get about I want to say about $\$ 14$ or $\$ 1500$ a month.

Budgeting. Due to the variety of stresses and responsibility, this study found participants had various ways of monetarily coping with stress. In particular, some participants found managing their finances helped lower their stress. Specifically, some clients thoughtfully budgeted their money for the month while other participants relied on summer work to get them through the entire year. Caroline said:

So, I try not to let myself spend more than $\$ 88$ every two weeks. Because then I can limit myself to my stipend and all of my extra money is actually extra money and it's saved for like unexpected costs and like paying off my car. I need to get new tires, and stuff like that. So, I try to save that money, and that's my budget like $\$ 88$ for every two weeks.

Specifically, Clarissa mentioned struggling with personal finances and understanding loans:

I don't know. Maybe, looking back, I don't know. I think the biggest thing would be loans. I wasn't really told much about that at all. I wasn't taught properly how to do things like balance the check book, which people don't really use anymore, or like, it was just a poorly taught class. I feel like budgeting and all that kind of stuff was like not really, if it was taught, I don't really remember, so.

Other clients reported similar strategies. Charles focused on budgeting for their semester expenses:

So, to make sure that I pay the bills on time. To make sure that they work enough to get the money they need to pay their bills, and the little bit that's left on their college tuition outside of everything that is taken care of with loans and grants 
and scholarships and it's kind of hard to balance the actual class and trying to work on stuff outside the class and going to extra curriculars all at the same time. The investigation discovered that participants who were actively trying to save money found a way to balance their education with their stress. Carmyn explained: No, it's weird. I didn't grow up with much money, but we were always super frugal with it, and I would like I would chip in, but all of the money was like put towards education. But I still like worked to pay for stuff.

Savings. Some clients in particular reported saving money for life after college. Purposely focusing on saving money for financial emergencies, Cole delineated: The reason I've been able to save my money is because I save my money. I splurge every once in a while, and buy myself something cool or something I want, but mainly I save my money so the past three years I've been working at the local gas station and I've been able to make quite a mound for myself.

Charlotte reported the sometimes-difficult decisions required to not dig deeper in debt while enrolled in college:

Yeah, because I'm trying to save as much money as I can through college because when you're in college you're accumulating a lot of debt and you don't want to necessarily be stuck in that forever so spending all of your money is not the best idea and so I do find myself not wanting to go out like I don't really like going out to eat because that's just more money, or, buying a bunch of groceries at once or like you said going out to the movies or something like that.

Diet. Some participants reported successfully lowering stress by focusing on what they ate. Some clients found purchasing an individualized meal plan from the university 
was helpful. Even though many complained about the cost of the initial meal plans, some participants found being able to personalize them aided in lowering stress. On the flip side, Charlotte explained that stress manifested into negative coping strategies as well: "I usually eat around two meals a day, because I just don't normally eat breakfast, but I go to the dining hall once a day, at least." Some participants indicated purchasing dining hall meal swipes was helpful. For example, Charles said:

So, it all depends on where the student's money is at that moment, because the number of swipes that I got. In August I got about 50 swipes, so I figured that could last me in those emergency situations all throughout the semester. And so that was about $\$ 300$ and for some people that might not be as bad and for some people it's too pricy. It all depends on their financial situation.

Planning Meals. Like budgeting and prioritizing, this study found meal prepping is an additional way participant balance their education with their stress. Christopher shared:

Definitely, I know a lot of kids who meal prep. All my roommates we all meal prep. We all try and just half the time I get a rotisserie chicken and I just cut it up and put it in different boxes. It's really quick, and you know it's going to be a fresh meal. It's going to try and be some type of fresh meal and it's always going to be there, and you know it's healthy because you cooked it yourself, or it's from products that you got from the store or the pantry or stuff like that. So, yea, if people like gave out different ideas for that, like nutritionist came in and help with all that, it would be really useful.

Cynthia, an international student rationalized planning her cooking around busy class 
schedules: "When we have time we cook, and then if we have class and assignments then we cook rice only. We've got a [inaudible] and you have to add water and then you can eat it." Other students strategically plan when they visit grocery stores. For example, Cali added: "So, when I go to Walmart, my friends that I have usually plan to have like a nice dinner, where we have nice food. So yesterday we bought sweet potatoes, and broccoli, and a rotisserie chicken." Sharing food and expenses were helpful. Carmyn addressed sharing with her roommates:

We share two items. We share milk and then we share eggs. Because we get like these 60 things of eggs, so we just rotate. So if I bought it last time then someone else buys it next time, and then that's all we share.

Participants in this study also expressed preparing large amounts of food early on in the week in order to provide food for themselves for multiple days. For example, Charles explained:

So, typically I'll try to cook something on Monday that can at least last me until Wednesday. And so this week I made chili. I made that on Sunday, or did I make that on Monday? I think that I made it on Sunday, and it's still in the fridge everything and its lasted a while. And I made that mostly out of stuff that I've got out of the campus cupboard.

Similarly, Carly explained a similar meal prepping strategy for saving time and money:

Oh, I think my favorite thing to make is taco soup, because I can just put all of it in there, and then eat for days. I can just eat that. I know I'll be full. I know I'll be satisfied, and it's also relatively cheap, if I have to go buy it. So, it's convenient. I 
don't have to try and cook it all day.

Carmyn planned meals around a busy schedule, but highlighted meal prepping to save time:

Yeah, it's probably like two. Two on like a day where I don't have a lot going on. If it's like a full day for me, where I'm at school, and I wake up at 5 and then get back home at like midnight, then I will like eat three meals a day, because I'll just like meal prep, because I get hungry, because I'm doing so much. But if I'm just like, I do a little activity and then a little class and then a little homework, then I don't get too hungry. So it's like two meals a day.

Stress and anxiety surrounding saving money also manifested itself in harmful eating habits. These negative eating habits particularly formed when participants trying to save found cutting corners with food was the most easily accessible place to save money. This ultimately presented an additional layer of stress surrounding food. For example, stress caused by food also affected how, when, and where participants ate. Specifically, participants reported stress eating, forgetting to eat, and finding alternative methods to access food in order to manage their diets.

Several participants indicated stress caused them to overeat, or eat unhealthily, for example when asked how to manage stress, Colleen simply stated, "[I] Stress eat." Likewise, Carly added:

I mean, it's like sometimes with my stress, I'll stress eat, and then sometimes, like over the summer when I have my classes, I wasn't eating. So, like, it's also part of that self-care thing. I need to make sure that I take care of myself, and the Campus Cupboard helps me do that, because most of my money is going to, like I said, 
school and survival as far as like shelter, and water. So the Campus Cupboard has been a blessing, really, for me.

Several participants conveyed getting too busy throughout the day and then forgetting to eat. For example, Charles admitted:

So, in my personal experience I would tend to forget to eat. So say I'd be working on my homework for about three hours after I get out of my class at 3, and I would be trying to get that all finished up to have a little of my day left, and I might forget to eat that entire day, and I'd be running off the energy from a dinner I had the previous day at 8 at night. And it's also, another thing is that there is not a whole lot of college students that eat breakfast on campus. So, it's like not really a lot of people who have that energy in the beginning of the day to run off. And they're basically mostly out there running on fumes until lunch.

Other participants have to find alternative and stressful methods to navigate the food environment throughout the day. Colton reported:

Well, I'm trying to get better at this. I don't have a meal plan, but I'll ask my roommate or my friends if I can use their card to get into the cafe. But like honestly, I don't really meal prep which I need to start doing. Sometimes I'll be on campus and just stop at the vending machine or go to the food court and buy something to eat or I'll buy a or grab a piece of fruit or something and I'll just carry it around with me throughout the day and I'll eat it right before practice. Something to hold me over so I have enough energy to practice, but often times I don't eat like a real full meal until like dinner. Breakfast and dinner are the two times I eat like maybe an actual meal, but I don't really eat much. I snack. 
Support Systems. Additionally, participants reported coping with the difficulties of university life by building small support systems specifically relying on friends and family as well as creating relationships with faculty and staff members. To begin, participants who reported successfully coping with stress referenced building small groups of friends. Specifically, some clients reported bonding over the common goal of navigating the food environment. For example, Cynthia highlighted: "Yeah, we cook together. We cook for one day only and eat fresh food. So, cooking together is smart." Similarly, some clients even enjoyed the feeling of community. Christopher shared: "Hanging out with friends is a big one, kind of like getting myself away from the stressor, climbing, climbing is one of my main ones. Like running, I used to just, if I was mad at the world or something, stressed out, I would just go run and I'd be fine."

International Students in particular mentioned creativity in how they depend on their network of friend groups. For example, Cynthia explained:

Like we have a group. So all of the students are in that group, so we post like we need ride, and someone is available, so they give us ride. No, it's not UCM, it's a What's App group, and that we it's an Indian What's App group so those guys who have car, they reply that we are available, and we go with them.

Family. Some participants report families as a source of stress, others reported families as strong support systems. Of course, the level and type of family support varies greatly, but participants who can rely on their families found some relief. Carol stipulated:

Right now, no. I've gotten six thousand in scholarships, and then divide that in half for each semester, and then I do take out student loans and grants and that 
usually covers it. My parents help me out with rent because it's actually cheaper for them to help me out with that than live on campus.

Specifically, that support took many different forms. For example Caroline said: “so whenever I get home, I get jars of peanut butter... If I'm home for work, I usually will like take leftovers if they have them at home... But like as far as purchasing groceries, no. Just a few things at Costco that we get." Some participants found basic moral support from their family, and lending a friendly ear was helpful for lowering participant stress. Cali confessed:

I'll call in between classes, so most of my classes are far away in different buildings so I'll just call them in between and ask how their day's going. Well, I had never been to Warrensburg before. I came to school here, so I'm really just learning about the campus and stuff.

Faculty/staff Relationships. Participants relied on staff to help them manage stress. Two participants argued the importance of having a solid support system within the school. First, Cayden revealed: "I found support in the school system and most of my professors help with advice." Second, Simon mentioned the role faculty play as mentors for some students experiencing stress. He stated, "Students do confide in us all the time. About, whether they're stressed about school, ... we want to be nice, we want to be friendly to them, but we're still their supervisors. We don't just want to be their supervisor, but also their mentor as well to help them." Some clients also mentioned that same support. Carmyn commented:

They have, they're just really good people. Specifically, in education, I'm the only one out of the friend group here in the community who is an education 
major, and so when I share my professor stories, it's vastly different. Like, there was a time last semester. Where I didn't do anything for like 3 weeks. They like called me in, bought me food and was like it's okay. We'll work it all out, we'll get you back on pace, like they're definitely really good people in that department, who care a lot about their students.

Similarly, Carol considered a similar perspective:

Oh yeah, we have the counseling department, we also have teachers that if you feel comfortable, with most days you can go and talk to those teachers and some of them are mandated reporters, and green dot training, most teachers have it. It's really nice, and they'll help you and if they don't then they'll know who to go to.

\section{Self-Reliance and Prioritizing}

Although being self-reliant is a skill, there are some common shortcomings many participants shared. For example, Vanessa said:

Usually [students] just stress out, or freak out, or have panic attacks. They might over stress themselves and get a job while they're doing school and that just becomes a bigger stressor, I don't know. I think a lot of stuff is like mental things from at least me and my friends that I've seen.

Others, like Colleen, confirmed: "Hug my dog and find a way to get through." Other participants asserted managing their expectations helped them navigate the financial difficulties of college students. The flip side of that, of course, is committing to finding solutions for success. Other participants asserted managing their expectations helped them navigate the financial difficulties of college students, as Violet remarked:

Oh, yeah for sure. I knew for sure I would be a poor college student. I mean, I didn't 
have a job whenever I came in my first semester, and I knew that most jobs around here were going to be minimum wage working somewhere. So, I knew I wasn't going to have a lot of money.

Participants even claimed looking for creative ways of solving financial problems for themselves. Cali said:

I don't know. I just get really stressed out about it. Well in order to try and solve the problem, because then I'll feel better, so I've been selling my books and my clothing to try and make money back. The university website is actually really good for buying books because it will compare every single website that's out there, so it will show the Amazon prices on there. This is our price; this is Amazon's price. Even if you go searching on all these obscure websites that you've found, they will always be cheaper on the UCM Website. So, they're not tricking you. They're trying to give you good books.

Perhaps the most memorable quote of this entire study was made by an international student, who despite losing her father while going to school on the other side of the world, declared a focus for success that is seldom heard, but leaves no doubt that selfreliance fueled by motivation cannot be stopped. Cindy explained, "You know once you're determined to do something, you definitely find a way to cope."

Prioritizing. Like financially budgeting for the future, some participants in this study revealed prioritizing their responsibilities helped them cope with the hardships of university life. Charles noted the stress of being involved. "It's kind of hard to balance the actual class and trying to work on stuff outside the class and going to extra curriculars all at the same time." Another client reported prioritizing daily helped manage stress. 
Specifically, Carter indicated: "Like, if we do daily work, then we can balance the education and stress. If we divide the work and do some every day, we can reduce the stress." Others felt it was an easier decision. For example, Colleen stated: "Education is my priority, so it comes first." Likewise, other participants expressed prioritizing school over luxuries. Stanley indicated: "I mean I guess it depends on the individual, what they prioritize more. I guess they would use the facilities on campus more, they would probably just eat on campus and study in the library if they have to."

The investigation found that some students do not spend money wisely, Cali pointed out one extreme end of the spectrum:

I have noticed that a lot of people will put off everything and go party. I don't think they do their homework or eat or take care of themselves at all, and it's a little scary, but there are like polar opposites here. So, there's the people that will ignore everything and party and then there's the people [who] food and school and family, all that stuff is important to them.

However, Chloe who was drastically living on the other side of that spectrum:

My long-term goal would be, I'm going to take the classes really slowly because I don't want it to interfere with my work and I don't want it to stress me out. So even if it takes me 10 years for me to get my degree in anything, after that I plan to try hopefully to find another college where I can get that library science degree so I can become a librarian.

Using Resources. The university offers a variety of services and resources for students and staff who are experiencing hardships. Study participants are aware of a variety of resources that are designed to assist their community. Specifically, participants 
reported taking advantage of academic, nutritional, economic, health and wellness, emotional, and veteran services. Cayden indicated, "UCM has services in place that are accessible for dealing with stressors, student engagement, student counseling, student accessibility, and the GISS office."

Academic Help. Participants frequently acknowledged the tutoring center and writing center as key resources for academic help. Christina explained:

A lot. They give you free tutoring at the library. They have a writing center, and then people that volunteer their time to help you out in like math and stuff. They have counselors. I think it's after a certain amount of times, like you can only go like three or five times, before you have to start paying. So that's also an issue. Nutritional Help. Many acknowledge the Campus Cupboard as a resource provided to students to help them manage their nutrition. Staff, volunteers, and clients alike indicated the Campus Cupboard provided assistance for students struggling with nutrition. Caroline summarized:

I mean they have the campus cupboard, so what I used to do is like I would go to Campus Cupboard, and like find ingredients, if I found, like if they had a certain thing that week, and I would be like, ooh, this is going to be my base ingredient, and I would get that at Campus Cupboard, and then I would get that at Walmart, and I would base that off of the ingredient I got at Campus Cupboard, which was nice because then it gave me something to base what I was going to cook off of. So even though they don't have all of the little ingredients, it gave me an idea of like this is what I'm going to cook for the week. But as far as the food planning, other than Campus Cupboard, I don't think they have any resources. 
The support the Cupboard provides is largely individual, and some clients expressed the extent of how much they rely on the Cupboard as a resource. For example, Celeste confessed, "The best thing the cupboard has done for me is being able to provide me with food to eat to get me by most of each week."

Economic Help. Clients indicated both tuition and room and board were appealing resources for students. Specifically, Carter indicated, "Yeah, the UCM fee structure is less compared to other universities. The cost of living is also less." Likewise, Charles highlighted some economic benefits of the on-campus apartments:

For me since I stay at the university housing, so it's not completely off campus but it's kind of in that grey area in between, and so the rent that I have is included in the school bill for each semester, but I have to pay out of pocket the electricity and the gas, so that is an added expense that those in the dorms do not have. They do pay a little of a higher price because they do count as university housing.

Fitness and physical well-being. Some clients viewed the Student Recreation and Wellness Center as a campus-based resource for improving physical health and staying physically fit, while others focused on the UCM Health Clinic. Specifically, some participants focused on healthy exercise as a form of stress relief. Two clients specifically indicated working out at the student recreation and wellness center. First Carly said:

I want to feel good about myself, I have to go to the gym, or I have to you know, work out or something, so I end up going to the gym at 5:45 in the morning, which is okay, you know, but it was a big change. I had to learn to make that change for myself. 
Secondly, Cole indicated how staying fit is an important piece of his success:

So, we obviously pay for it but having the gym basically 24 hours a day available, which it closes at like 1 am I'm pretty sure, but always having that as an option just to kind of go out and escape things for a while is always nice.

Participants reported The UCM Health Clinic as the dominant campus resource for community physical health. Several volunteers specifically mentioned its services. For example, Valerie thought: "Um, I think maybe vaccinations, but most of those are free, maybe from our health place." This investigation also found some participants know how to navigate the system better than others. For example, Violet noted the subtleties in services provided at different locations:

Actually, this year, I got bronchitis, which was really stressful. I had to go to the off-campus hospital, because they're the ones that give us the sick notes. The on campus one doesn't, and in order to be excused from classes for the day you have to get a sick note. I had to pay the $\$ 35$ copay.

Emotional Help. Several participants indicated the counseling center was a useful resource for their emotional health. Sophia outlined:

Well UCM has a variety of services, I'm not as familiar with, we just had a restructuring, like last year or the year before that, I can't remember when it all took place, but I used to work in the MAPS Office, Mentoring, Advocacy and Peer Support, and I oversaw the students who would reach out academically to try and assist other students on campus. Whenever they were noticeably struggling with just different academic areas, just to offer just one on one support, and so that was a service that I think has been transitioned into something else. I don't 
know if they just absorbed that into like the learning commons. I'm not really familiar with the new layout for that, but I know that as far as academically there's support there. The counseling center is a really good source of support and they do the mental fitness. Which I think is really helpful, just coming from a counseling background I know that mental wellness is really important, but we don't always know the best way to be mentally well.

Clients were also quite aware of the services the counseling center offer.

Specifically, Cindy explained: "Um, the counseling center. I'd say the counseling center is helpful. I've used the counseling center a lot, it's really stressful. And also, the Campus Cupboard for food." Talking with professors was also reported as a useful resource. For example, Carmyn explained:

I think there's counseling, I think that's probably a big one. If I mainly go to my professors if I'm super stressed. Especially in education. They have, they're just really good people. Specifically, in education, I'm the only one out of the friend group here in the community who is in education major, and so when I share my professor stories, it's vastly different. Like, there was a time last semester, where I didn't do anything for like 3 weeks. They like called me in, bought me food and was like it's okay. We'll work it all out, we'll get you back on pace, like they're definitely really good people in that department, who care a lot about their students.

Clients were aware of resources focused on helping students create social events and community as well. For example, Vanessa stated:

Like just like counseling. I know I live in Nickerson Dorm on campus, and I 
know they do like either weekly or monthly like fun activities. So I think coming up is like a cupcake thing. They've tie dyed shirts. They've had ice cream. I think the atmosphere in the dorms are really like a good like de-stressor, because they have like different activities and stuff that can help de-stress.

Veteran Students. One veteran student noted the Whiteman Advantage as a resource for students. Colleen indicated her top services at UCM were, "The veterans' center, and the Campus Cupboard.”

\section{Theme 3: The reasons people use the Campus Cupboard vary from individual to individual}

Ultimately, clients have diverse backgrounds and needs and engage with the pantry on different levels based on that need. More importantly, participants indicated that they are looking for different ways to make ends meet, and the pantry helps navigate obstacles. The Campus Cupboard is a free and convenient resource, and participants felt

there is no judgment or stigma in using the pantry. Lastly, participants felt it is difficult to ask for help.

\section{Clients have diverse backgrounds as well as equally diverse needs}

It is difficult to categorize who needs help and who does not, but ultimately the Cupboard is there for everyone. Students' needs and backgrounds affect their ability to navigate the system. For example, participants' backgrounds define their need. Specifically, Charles remarked:

I'd probably say that you know, you never know someone's situation until you walk a mile in their shoes, right? So, it's not all college students have a great, I would say connection to like their home and everything so like they might not 
have a foundation that they're coming from, like once they get here, and sometimes you just got to do what you got to do to make sure that you make it by. One really interesting point emerged from the study. Specifically, Charlotte indicated that need was not a choice and, ultimately, food insecurity manifests from a variety of reasons:

I would probably say that just like, they didn't really choose to be food insecure and it doesn't necessarily mean that they were low on money but like sometimes that is as much as you can have because of a lot of different reasons.

On the other hand, some participants were in need of the food pantry. Cole emphasized: I think there kind of is a need base on that one, and you can kind of see like how they line up like $30 \mathrm{~min}$. before because they want the better stuff. So, I mean it's obviously a really cool thing. If you want to get stuff you might as well get there early. But yeah, it's a really cool thing.

\section{How students define normal affects their reasoning for using the Cupboard}

Because the word insecurity, by definition, deals with a given individual's feelings about their situation, it becomes difficult to gauge a baseline. In an effort to understand the disparity between what someone professes to feel, and the actual situation in which they find themselves, participants were asked to describe their personal experience with food insecurity. Participants revealed a range of responses. Many participants expressed a deeper understanding of the struggles that accompany the investment of higher education with the hope of a brighter future. For example, Carly spoke to her temporary struggles:

I think, I'm a normal college student. I feel like it's supposed to be hard in more 
than one way. My classes are hard, my clinic is hard. You know, life happens to everyone. Life doesn't just happen to you, it doesn't just happen to me. It's part of living, is that it's just hard. So, I mean, this is it. This is what I get, you know, and I just got to make the best of it. That's it.

On a similar note, Charles referred to the common perception that college students are supposed to struggle, but also pointed out the gravity of the situation:

So, it's kind of made into a joke. So it's always the running gag about how college students, how they live off of ramen noodles and stuff like that, and I mean it's funny but at the same time it's really true, because it's like a lot of college students can't afford to go to the grocery store every week, and by the time they're at the end of waiting for an influx of money, say it's from getting paid from their jobs or from money from their parents per say, they might actually just be living off of Spam and Ramen noodles a home.

Additionally, Cali expanded upon the common difficulties of being in college, but measured food security as the ability to buy the food one wants:

I don't think so. I think everyone is food insecure except for those people who have their parents pay for their college. Some people, or very few people, can afford to go out and buy whatever food they want, but I think everyone is using their resources here. I don't think everyone knows about the campus cupboard. Sam viewed the communal understanding of food insecurity, taking into consideration the accepted 'normal' around campus:

I would think the majority of people think that college kids eat Ramen, and just fast food because it's quick and it's cheap or whatever. So I think that kids who 
are actually going hungry here at school, are just looked at as just a normal college kid, and I think that's not good. I mean I don't I know any kids that are like legit going hungry, but I'm sure there are kids, and I feel like the normal thing for college kids is like, "yeah when I was in college all I had was Ramen, and I just, of course I went hungry I smeared peanut butter on one slice of bread and that was dinner" but like what nutritional value are you getting out of that, and there are some people who are going hungry.

Veronica analyzed her own struggles with not having enough money. Specifically, she compared her personal experience against the experience of other students with more financial resources:

I feel like a lot of people, yeah, it's like split up. There's this population of kids who do still reside at home when they are not at school and so their parents help them, and then there's people whose parents are like I don't want you to have a job, we'll help you with your finances, we want you to focus on school, and then there's people like me, who even before I was living with my fiancé and engaged, I still, even when I moved away from home, like as soon as I was out of the house, my mom was like okay, you need to start paying for this, this and this... Because you're an adult now, and then when you get just older, like you have more things to pay for and more responsibilities and then, you just kind of take the role of an adult even though you could still be a student. Mommy and daddy don't pay my bills, I have to unfortunately. So, it's stressful. It's so stressful, I wish I had thousands of dollars in the bank so I wouldn't have to worry about it, but I don't. 
One participant critiqued his own shortcomings with money management. Specifically, Chase admitted:

Okay, I would probably say that it's pretty typical because I feel that there's this generalization that I'm just a broke college kid. It [the Campus Cupboard] definitely helps because I'm awful at money management. I piss away money left and right. So, it's always good that I save it when I can. I feel like a lot of people are that way, like they know they're bad at money, but they keep pissing it away, but what are you going to do? I feel like there is a hole in my pocket, but I got to eat. I've got to do something to pass my time. I'm not going to sit in Warrensburg.

Sophia rejected the notion that if certain clients exhibited negative behaviors it diminishes their right to help:

I don't know but what I will say that it is really easy to see how somebody behaves in one part of their lives, and to create an assumption based on that behavior or based on how they are in that moment, but we never know what they're going through. I mean, you can never know like what they're struggling with. And so to assume that somebody who even is practicing those [negative] behaviors shouldn't be using some place like the cupboard. I mean, each person has their own opinion about how people should receive help, but I think to put someone into a box based on like one set of behaviors during a given time is really kind of ignorant. You know, it's just like very limiting to put someone into just one classification and say based on this you don't deserve any help, or you shouldn't be getting this help because you behave this way. I think that is really 
unfortunate to have such a limited view.

The dramatic spectrum of need affects how the clients engage with the food pantry. Some participants reported supplementing their diets with the food pantry, while others indicated a true necessity. Additionally, many students with meal plans still visit the pantry.

To begin, on one end of the spectrum some clients do not rely on the pantry but use it to supplement their food budget with the groceries they find in the Cupboard. Specifically, Chase delineated how he utilizes the pantry, I just kind of supplement it. I go shopping like multiple times a week, so I buy food like multiple times a week, and then having four roommates I end up at Walmart a couple of times a week.

Similarly, clients indicated the pantry helped them stretch their budget. Charles reported: So, I wasn't too worried about it. You know, I was, when I got to school I didn't even know about it until after the semester started, so I was able to afford all of the groceries that I needed and everything and it's just all like by the time I got done grocery shopping and paying for stuff that I need for that week or that month it wouldn't be a whole lot of money left. But after I discovered the pantry. It left me with a bit more of money to even have in my pocket for other things that I may or may not need.

Carol reported following a mutual respect policy while using the Cupboard. Carol explained:

I choose to go to the pantry to help minimize how much I spend each week at the grocery store. I know it's available. I try not to use it as much, because I know 
that other people need it more than I do. If I do go, I won't take the full number of items I need, I'll usually take two to three. So, I know I need canned beans and corn, I know they always have those in abundance, and I'll be able to get two cans.

Chloe reported strategically using food from the Cupboard to supplement their budget: My husband is the cook, so it would be like stew. We would buy the meat and just the meat and then with the vegetables we got from the Campus Cupboard we would make a big pot of stew and that would last us like three meals throughout the week. It went a long way, and spaghetti noodles, we eat spaghetti a lot. It's not the healthiest food, but man, it lasts. I mentioned the spaghetti. That one we always went back to, or goulash, or it's just the macaroni noodles with just meat and tomatoes. That's all it took, just a couple of cans of tomatoes, and we'd buy the hamburger itself, and we actually, my parents have a farm, sort of. They only have like 3 cows, so at one point they did have a cow butchered and gave us a lot of the meat and they would always help out, and my husband's parents were always good about that too. Giving us extra stuff if they went shopping and bought bulk stuff from Sam's Club or something. So, we always have our family to rely on in hard times.

Additionally, several participants referred to a common lack of financial resources as a key stress surrounding food. Highlighting high prices of healthier food, Stanley pointed out a trend in Campus Cupboard usage:

Things like meat, that cost a bit more, maybe they don't want to buy those at a grocery store. So, what I've noticed is that when we have chicken and that kind of 
stuff in the pantry, they tend to go fast, like people really want those, so I'm guessing that people really don't want to spend money to buy those.

On the other end of the spectrum, a number of participants expressed using the Cupboard out of a deep necessity for food. Specifically, several participants described their need behind using the Cupboard. One client indicated their weekly dependence on the Cupboard because they are bound to staying on campus. Specifically, Charlotte argued: We try to go like every Thursday because it's just a good source of food, especially since a lot of students don't have cars. They can just go there and get items that they might need, and if they don't want to spend a lot of money you can get food there.

Additionally, there was evidence to suggest the deeper need behind the usage of the Campus Cupboard. Specifically, Steve noted:

Some of the holiday breaks, our shipment may not be delivered from Harvesters and then we're actually just shut down, because we don't have the personnel here because the campus is shut down, and then you'll have kids coming over, oh I didn't really plan on that. So, looking them in the eye and telling them, I mean we do our very best. We have on occasion opened the facility up off hours for young people that show up and say, hey I just couldn't get here. I was in class, and I couldn't get here during those times, and we've gone down and opened up the room and said, get your products, you know. So, even though we do have posted hours, there are sometimes when the facility is open. We really don't want any young person walking out of here not feeling like we addressed their needs.

An additional staff member noted a similar perspective. Sam emphasized: 
Oh yeah, I have people come in all the time that are so grateful for us, and the first week I worked, I had a woman almost in tears because she had groceries for the week, and it's just amazing that we can provide that for people.

Surprisingly, a large number of clients use the Campus Cupboard despite paying for dining hall meal plans. There was an interesting relationship between the Campus Cupboard and clients with a meal plan. Specifically, the hours of operation, limited food options, forced meal plans, and price were among the top findings stressing out participants. For example, Violet noted:

I mean, they got rid of the best dining hall on campus last year, Fitzgerald. I don't know why. They had late night Fitz too, which I thought was successful, but I don't know. I think that they're actually doing something with the housing situation, I'm not really sure though. They're closing down a few of the buildings and renovating others. So, I think it might have played into that.

On a smaller scale, Valerie indicated frustration with the actual options for food within each hall:

I do. I mean the dining halls don't always have the best selection for all kinds. I know Fitzgerald usually had a vegetarian section and stuff that pretty much everyone would eat. I think Todd tries that, but it's not always like good.

For participants living on campus, the dining halls were the most frequent answer to how students access food. Many participants noted the dining hall meal plans as their principal source of nourishment, but also indicated the financial responsibilities associated with living on-campus. Although there are several plans that range in price, meal plans require a significant financial commitment. Vanessa supported this point of view, "Um, yes, just 
because I don't always like their food or their options, I think that their meal plans are very overpriced." The price of the dining hall meal plans also were the focus of participants' stress. Specifically, Christina critiqued:

I mean those dining plans are expensive. Like we have all access to the dining hall, but none of us are going to go that many times. Like last year you could choose how many swipes you wanted, so like I had 150 for each semester, and I only used like 80 of them. And this year it's all access but the prices went up.... you eat at the times that they have the food, or you go back to your dorm room and you eat goldfish, or you don't eat at all.

Community Advisors (CA's) were stuck in difficult positions regarding their meal plans. In particular, Caroline presented the difficulties for one specific group of students bound to campus:

I have a meal plan but it's provided by University Housing, and this is the first year they've done it, but all students at UCM now who live in the residence halls, they all have all access plans, which means they have unlimited swipes, so students who live on campus will do that, except for CA's because we get a partial meal plan, and it's provided by University Housing and you can like pay to upgrade, but it's really expensive, so most of us don't. So, I have 80 swipes this semester, which is about five a week, so five times a week I can go to the dining hall, and then I think we get 100 dining dollars, or it may be 150 , because they changed our meal plans. So, they've improved them from what they were the past few years. I don't eat out a lot. I use my dining dollars. I actually got extra dining dollars this semester because some students, like they scheduled us for shifts 
during training, like whenever we were opening the residence halls for people to move in, and I had to do lofts which is like technically part of our job description and it's this super big pain, so they gave us like 50 extra dining dollars. So this year I have extra dining dollars to spend which has been nice, so I'm not spending my money. I'm spending dining dollars, but I don't really like the on campus dining options. Like, Chick Fil-A, Taco Bell, it's really hard to eat healthy. So, I like to eat there, but not a ton. As a CA we're technically supposed to be pro Sodexo and pro housing, and we're not supposed to attack these things, but there's like a huge gap and we're kind of just left here without.

Specifically, Community Advisors are only given five meals a week as part of their compensation. Caroline went on to explain the difficulties the lack of swipes causes for CA's forced to stay on campus during their shifts. Specifically, Caroline shared:

Five swipes a week is what I can, so if you're eating 3 meals a day, 7 days a week that's 21 meals. I can only eat five of those in the dining hall. That means I better have food in my room, so if I don't have food in my room, because we don't have a dining hall in this building, we used to, but I'm allowed to take, so I have a phone and I'm allowed to take the duty phone over to Todd and eat at the dining hall, but that's the only place I can go with the duty phone, so if I don't have food in my room, and I'm not eating at the dining hall, you're probably not eating when you're on duty, because you have to have food in your room.

She continued with the importance of having to budget meal plans:

So, you kind of have to plan your swipes out, because I've saved enough swipes, because I haven't used a lot this week, so now I can make sure I eat there on the 
weekends. So, you have to space them out. So, I know at the end of the semester I don't have much time to cook because I'm too busy with projects and papers, so like, I don't eat at the dining hall very much for like the first 8-10 weeks of the semester, like I haven't even used half of my meals yet, and we're like well over half way through the semester. So, like I save them because then I know I can eat at the end of the year, whenever I don't have time to cook.

Ultimately, clients are looking for different ways to make ends meet. Cole summarized that due to the difficulty of defining need, food just seemed to be one area where participants could manage to save money:

Like I said, we don't know who can and can't afford things on the dining plans, but there might be people who are spending quite a bit on rent and their just education in general, that they might not have a lot of money for extra food or extra snacks. So, this is a great resource from the university to give back a little bit.

Likewise, defining the obstacles people have to overcome differs for everyone. Valerie indicated, “...they're just trying to stay healthy to begin with and be able to have all of their basic needs provided for people who can provide them." Another interesting finding was that the cupboard is not limited to just students within the community looking to make ends meet. The need and service extends to staff as well. For example, Steve shared:

Yes, one of the main things too. Over the past few semesters, or the last year or so is what we have seen is we've had an increase in staff members using our facility. We did open the campus cupboard to any of our staff, and with the times being 
kind of tough, we have seen that and you know, they're very, very, again, understanding of hey, this is very important for us. So not only are we taking care of the student body, but some of our staff members here on campus also have access to that facility. Anyone with an ID card, we swipe them in and that is tracked through our Tutor Track System. So, of course you know, we keep confidential who, but we can do an aggregate data of you know, unique visit, or repeat people, or those are the type of things that we track and everything. So when we say four to five hundred, you know that also includes some of our full time staff members.

Making ends meet sometimes means cutting corners wherever one can. Specifically, Chase remarked:

Probably just that it does help. Like sometimes there's not much there. But even one item a week that's just like $\$ 10$ that I can save later on down the week. You know, like the chicken I got the other day, it's like a couple of days expired. I might as well use it.

For many participants, the Campus Cupboard represents a way to save money. For example, Cindy explained:

I like to save money a lot, because I have a lot of responsibilities. So the Campus Cupboard is a really good place that helps me as a college student to save money. It helps me to not drive all the way with my gas, and I can literally just leave my class, pick food and then go to my house. I stay right across the campus.

Charles summarized the role the Campus Cupboard plays in his education: And in the regards of making ends meet, I would not say that I know people 
specifically who struggle to make it. That is something that they might not share with people. But as it is for college students, it's always hard to come by some money exactly whenever you need it, and so that's why it's always good to receive help when it's there in spots that you can.

Ultimately, clients are looking for any way to make ends meet because of a certain level of comfortability that Chloe highlighted, "Getting by means you pay your bills, you get enough food to last you, and that's it. You don't get to enjoy any of the money you're making."

\section{The Campus Cupboard helps clients navigate other obstacles. Campus}

Cupboard helps clients navigate other obstacles in their lives by helping them save money on food so they can use that resource elsewhere. For example, Vanessa noted:

More than likely, that it is a really good resource on campus and that if you're struggling, or if you just need a snack, it's definitely something that you should use and utilize and they have a wide variety of different foods and I think it meets a lot of different needs for people and I think they have lots of toiletries in there, and I think they have fruits and veggies and breads, and carbs, just a lot of different things, that if you may be lacking you can go and get.

To help define this perspective, Cindy explained how she used the cupboard to help her regain finances she had to spend on clothes.

Beds, what do I call it, clothes for winter, because where I come from, we don't have snow. It's just hot weather all the way through, so yeah, I got here, and I had to spend a lot of money to buy clothes for winter and all.

Other participants commented on international students having to spend their money on 
clothes for winter. Specifically, Caroline mentioned:

Exactly, they don't have coats. Especially, I know an international student from Malesia. He never experienced winter like this before, and so like they don't have any of these resources, yet so many people throw out this stuff. And so some schools, Harvard was a great example that I found. They take donations at the end of the year and they're stored and then it is opened up for students, they might charge some, but like a very discounted rate of like, here is bedding you can buy, storage containers, anything and everything, shower caddies, or little necessities that people don't think about.

Likewise, Victoria, thankfully highlighted how donations helped her with settling into the United States for school:

So coming from Tunisia, and it took me like 20 maybe 24 hours to get here, with the transit and the layovers and something. So, it's long distance, and you cannot bring with you, you cannot exceed a certain kilogram when it comes to luggage. So for me when I was packing, I really wanted to bring many things, like for example food, like you can cook yourself here, and I couldn't bring that because I had to be careful with what I bring, because in the airport they can pull you over and especially if you are bringing some things, they think it's maybe a drug or anything, so a lot of things I wanted to bring, I was not able to bring it with me. And as I told you, you shouldn't exceed a certain kilograms, otherwise you have to pay for if it exceeds that, and you have to pay a huge amount of money, and when I got here, I entered the room, my dorm and I don't have the mattress or the thing that I can decorate my room with so I have to buy it and that can be 
expensive. But the good thing is there was this donation and I actually got some mattress from there, and I got some pillows, I got some stuff to decorate my room with, and that's truly helpful that some people take into consideration that people come from other countries and they cannot bring a lot of stuff from their home so yeah, they provide us with many things that are really helpful, and I found that amazing.

In addition to money, time was another resource with which students struggled. Caroline shared:

Time is a huge restraint, and I think that the busier you are the less time you have to cook. Also, when people think that college students have money, so UCM serves a lot of low income, first generation, and minority students, so that's who we cater to. So a lot of those students do take student loans out, and like student loans don't pay for these extra things. Like student loans don't pay for your grocery bill every month, and so people don't understand that. And so I think that is what I would want people to know, because I've actually done some research myself. So in addition to food insecurity, a lot of our students don't have stuff to furnish their rooms, like for on campus housing, because when we close at the end of the year, we walk through their rooms and some of them don't have sheets, like it's a real need, like students don't have what they need here. So even beyond food, but student loans don't buy you bedding, they don't buy you stuff to furnish your dorm room.

Similarly, Cindy shared a personal story regarding how she had to make ends meet as a student new to the school, community, and country: 
Also all the things that we can do, of course beddings, when I got here I didn't' have a bed. A friend of mine had to give me one of these because he uses two, so he gave me one and later on my boss at work gave me a queen bed size, so yea. I used to work for Sodexo then when I first got here. He was leaving. He had a job in Kentucky with his wife. So, it's like Cindy, do you mind a bed? I was so happy. He brought it to my house, and you know beds are expensive. I couldn't afford a bed when I got here. So, I was just thinking about things to buy.

One bottom line that can be drawn is that clients are looking for different ways to make ends meet and the Campus Cupboard helps clientele navigate other obstacles. Carly explained: "I'm 12 hours from home. I fly home for Christmas, I go home twice a year, so far."

\section{The Campus Cupboard is a free and convenient resource available to students and staff}

Several participants focused on the convenience aspect behind their usage of the Cupboard. Specifically, Carly stated:

I mean, it's just convenient for me. It helps me out, you know. Like, it feels like somewhere that is comfortable for me to go, and I feel like it's there for me, for me as a student it is here to help me, and I don't feel bad about using it, because they know. The school knows that I need it.

Christopher referred to the convenience of the pantry:

That's what I actually use the cupboard for. A lot of the time that's usually where I get all of my vegetables from, just because it's more convenient. But, all of my fruit is fresh. Sometimes I'll get like fresh broccoli or get a head of lettuce and I'll 
make my own salad and stuff like that, but most of the time it's probably canned. Caroline referred to the convenient location, as well as the convenience for their pocketbook:

It's convenient, it's on campus and it's kind of like, makes you stretch. Like if I'm sticking to my $\$ 88$ every two weeks, it like makes it stretch, so if I can just avoid like, one of my favorite things that I took was like, I can have a crockpot, so I can do chicken and dumplings in there. So if I can get the canned goods that I need for that, Campus Cupboard, then all I have to do or buy at the grocery store is like one or two other ingredients and so it like really stretches your budget. So, it's not like I didn't have the money to do it, but it really stretches my money so much farther than it would have gone without it.

Sophia believed convenience was a primary reason for pantry usage: Yeah, so primarily I want to say probably convenience. Like it's built to be convenient and it probably should be that way. I also want to say that the fact that we don't, so like when you go over to the food center or whatever I'm pretty positive you like have to prove you have a need. And like we don't do that here. You literally your ID Card is all you have to bring in order to bring food to the food pantry. And I think that cuts down on some of the stigma. You don't have to bring in the income and say here you go. I really need some extra food right now, and here is all my information, and that is one of the really hard things that I know that was always like the most uncomfortable thing working at an agency that is something you have to ask for.

Sam presented a similar perspective. Specifically, stating: 
Yeah, I think it's just convenient. We're not in like the best location, but it is convenient to get snacks, or we do get food from the dining hall every now and then. This week we had like macaroni and turkey pasta and that seemed to fly off, because it was in these little individual containers and people could just warm it up and it was like an actual meal to eat. So, you can come in and get a quick meal. It's like a microwave meal and it's just simple like that. So, and then we do get occasionally protein and stuff, we have a lot of hamburger right now and a lot of bacon. So, before like I worked here, they told me about it on my visit, so when I toured campus they brought us down and showed us the Cupboard, and I would come to the rec a lot and if it was open that day, I would be like oh, yea the Cupboard is open so I would just run in and grab something.

Additionally, some participants noted the role the university played in offering this resource to its community. Specifically, Charlotte stated:

It's a resource that campus has given to the students. So, one, why wouldn't you choose to go there because it's something that you have access to, and I do not always have money to go to the store to buy food, and especially since the dining halls are closed. Late on the weekends, if I want any food, I'm going to have to make it myself. So, I like to be able to have items that I can cook.

This perspective was commonly shared by clients. For example, Colton confirmed: Because it's there and it's available, and it helps saves money, they have good food, like eggs, and the big portions of your meal. It's got good protein and stuff like that. They have chicken, lunch meat, eggs, those are like the essentials, for your meal and so using the food pantry not only helps save money but it's a good 
resource to get some food and stuff like that.

To help put the role of the Campus Cupboard in perspective, Christina confirmed:

It's kind of like the on campus tutoring that's free. It's like that is provided, you're going to UCM, so why don't you use it. You might as well go to the places and get what you're paying for type of thing.

Ultimately Christina summarized the notion that any savings while in college ultimately helps pay for college:

I'd say it's inexpensive, like personally I know people that they don't have a car here. Their family can't help them even pay for college, yet alone even pay for food, and so like something like this is helpful for them.

\section{Judgment and Stigma}

Perhaps most powerfully, another reason clients chose to use the food pantry was that they felt no judgement or stigma there. The judgement free environment in which the Campus Cupboard operates was attractive to its clients. Specifically, Sophia stated:

Well, you just think about all the other obstacles that people encounter when they seek out help. And I think we've done, like just the way we're set up makes us like a really effective source for people to come to in order to get their needs met without feeling like they have to be called out for what they're struggling with, be that finances or transportation.

Additionally, several participants indicated how clients navigate the fear of negative stigma surrounding free food programs. Specifically, Sam argued:

No one is looked down upon by going to the Cupboard. It's not, I feel like food stamps and stuff have a negative stigma, but this isn't a charity. We're providing a 
service for our students. So, you can come in and take what you need and then leave. We're there to help the students and faculty.

Clients overwhelmingly understood this claim and supported the idea behind having to use the food pantry. Ultimately, Carly emphasizes the spirit of endeavor:

I think that people should know that it doesn't mean that you're not trying. Like, I have two jobs, and I'm a billion miles from home. So, I mean just because you aren't doing the same thing I'm doing, or I'm not doing the same thing you're doing, doesn't mean that it's not there for both of us.

Staff members mentioned the culture surrounding the Campus Cupboard as well. For example, Sam reasoned:

It just depends on the person; I don't think they're ever ashamed. I don't think anyone is ever ashamed to come into the cupboard, it's not like we're ever making it demeaning. It's just that we're just there. So, I don't think anyone is ever stressed about going to the Cupboard, they're just going to the Cupboard.

\section{It is difficult to ask for help}

Additionally, it is difficult for participants to ask for help. In the end, clients are using the cupboard because the staff makes it easy to not have to ask. Specifically, Veronica outlined this finding:

Definitely to know that rarely is somebody going to come to you about it, I'm sure. And it's going to be hard to probably spark up a topic, like if you maybe suspect something, or you want to ask about it. That is probably hard, as well as the student themselves being honest with you. So, I guess it's probably important to like maybe be educated about it and maybe learn the best ways to go about it. 
Because, it's a big thing, I just I mean, I don't know. And like, a lot of people hide it well. So... you don't know.

Others felt similarly. For example, Colleen stated: "If you look at a student you don't know if they use a food pantry. No student is going to be like oh yeah, I'm broke and can't eat." Likewise, someone needing help does not always meet our own personal requirements for what "need" looks like. The participants communicated a wide variety of perspectives when asked what they wanted people to know about the clients of the food pantry. Simply put, Sophia expressed:

Probably just that they're doing their best and they're working the hardest that they can to stay where they're at just to stay at college, or just to maintain their grades, or I don't know just to like, live the best life that they can, honestly. They're just like everybody else, like they are, I mean, it's just that they maybe have more obstacles than maybe other students do, and they are actively seeking out ways to resolve that or to meet those needs, which should really be considered a strength in the long run because really we should be there for one another, like we as a community, and we as people we should be there for one another, and we should encourage people to identify their needs so that we can help meet those.

Part of the trouble with asking for help is knowing that one needs help. Specifically referring to the dangers of living in a food swamp on college campuses, Colleen made an important case:

I think we're either, a lot of people are numb to what it looks like, because we think of someone walking around who, we think of emaciated people, people who are food insecure, that kind of thing and reality is, I think it looks like the exact 
opposite. I think it looks like people who don't have a balanced diet not people who don't have no diet at all, and I think when you see it, you don't notice it when you see it around, at least here specifically it looks like a lack of a balanced diet so much as a lack of any diet at all.

Vanessa reported a struggle between education and food was more of a fight or flight situation than one where she could ask for help:

I don't know. I think food is a necessity that you have to have it to survive, and if I was in that situation I would debate whether or not I wanted to go to school, because surviving or getting an education, I would probably go survival, it's probably a really big stressor.

A similar perspective regarding the quantification of need before someone could use the pantry was also expressed by a client. Specifically, Colton suggested:

Go look and see what they have to offer. It's free to use, and going to the pantry doesn't necessarily mean that you're struggling and in need, and ideally that's who it's for, people who can't afford to buy foods and things like that, but you try to be frugal with your money and things like that. It's a great place to go for some food and like I mentioned it's free. It has a bunch of different options like that, and it's really a smart resource to use, because there's only good things that you can get out of it, nothing bad.

Similarly, Sophia supported a similar perspective, but highlighted the mindset behind people who are in need:

Um, so I want to say that the individuals that, and I have not honestly been in the pantry in a while myself, so I can't completely speak to this, but kind of coming 
from the mindset of someone who is willing to go and stand in line for something for a need they have regardless of whether or not it's a super big need, but like you know I'm not going to make it off campus today to go to the store, and it would be a really good idea for me to go and get some things. So, they have them. But I think that it's likely that the individuals who are going to the cupboard are in a head space or a mindset that they are more willing to seek out services and support, because that is a really hard thing to do. Like regardless of how accessible programs are, I can't tell you how many times I talked to people when I worked at like Salvation Army where every time we would sit down with them we were able to do financial support and sometimes it was some goods that we needed and it was probably like $75 \%$ of the people I sat down with were like, "I just did not want to ask for any help but this is like my last resort and this is all I can do to help myself." I mean it takes a lot of courage to step up and ask people for assistance and to go and do that. I would say that there is probably a lot of people on campus who really need us, but they think other people probably need it more, or it's just a really, really embarrassing thing for them to think that they need help but they don't want to go and show everyone that they need help. So it is, it messes with people's minds, because that's like the type of society we live in, like you don't ask for help. Except there are so many people who need it. So, and that's just unfortunately a part of life. I want to say there is a point in everyone's life where they need some kind of assistance, where they struggle with mental health, or they struggle with getting food or you know, I just want to say that honestly in my opinion there's just probably a time in everyone's life where 
they needed some type of support that they have to ask for or that is possibly given to them that they didn't want to ask for.

\section{Theme 4: Clients care about what the food and services the Campus Cupboard offers as well as their experience while they are in there \\ Practices}

Food Distribution. The Campus Cupboard prioritizes ensuring that clients have equitable access to products by focusing their policies around distributing items equally. However, there is a fine balance between making sure everyone has at least something, but also making sure the pantry is able to support students who really need it. For example, Sophia highlighted the steps the Cupboard takes to prioritize equitable food distribution:

Well the Campus Cupboard has like a set policy that was put in place before this started, and I think it's been in the rules since they've opened. But, students, staff and faculty, all can take ten items, and typically we say that those need to be ten different items, because typically we don't want people taking like ten things of bacon or ten meat items or proteins. So, the rule for that is mainly geared around like, we want to make sure everybody gets something of what we've got. So that prevents people from getting a little overzealous with those goods. But, because of how many individuals we serve, it's important we put policies in place to make sure that things get evenly distributed as best as possible.

The maybe unintended consequence of this policy is confusion and then of course limiting food for clients who need it. Specifically, Carly explained:

The only time I've been confused about what I could get was this previous time. 
Because they say you can get, it was different. I was used to it being one way, and it wasn't this way. It was like you can have two cans of this, but you can only have one can of this. But you can't have two cans of like, I think it was like soup. You can't have two soups, but you can have two vegetables, or you can have one vegetable and one soup. Or something like that, and I was like, I don't know what this mean [laughter].

Several clients reacted to the policies of the Campus Cupboard in a variety of ways. Specifically, Colton explicated a general understanding of the policies:

No, mostly all of them make sense to me, especially like grabbing one meat item of bagged chicken because if you could grab whatever you want I would grab like ten bags of chicken in one week and I'd be set for the whole semester, but there has to be enough for everybody you know. I think that's a good policy that is in place. Now there is one policy and it's about the eggs, and it says please do not remove eggs from the carton or anything like that. I check my eggs before I buy them, if there's a cracked egg, I'm not going to take a cracked egg, I want all my eggs to be good, so I wonder if there's something that I can ask like hey this has a cracked egg in it, can I replace it?

Similarly, Carmyn shared her perspective on the policies:

They didn't used to have such strict ones, but I guess they impose them because people were abusing it somehow or something. It definitely, I was sad about it because, since I used to be able to get as much as I could, and as much as I like needed for the week, because right now you can only get like two cans of the green beans, peas and corn like a week, and I used to have that like three or four 
times a week. Or like three times a week, and so it was nice to get that more, and then the meat, they're now like packaging a lot bigger stuff, and it will last you a week, but you still only get one thing of meat, so you can only pick one meat you want to eat a week, and so it would be nice if you could get more than one, so you can mix it up so you're having more of a variety, but at the end of the day, it's like free food so it's fine.

\section{Clientele cooking facilities and access to utensils affect how they use the Cupboard}

The Cupboard's clients' facilities limited the extent of the items they found useful. For example, Sam revealed:

When I worked there, and I would go, I would just kind of see it as a way to just get snack stuff, just a way to get stuff in my dorm where if the dining hall was closed, I could just munch on something. I would never take like big bulky like proteins and like actual meals because I had a mini-fridge and a microwave. So, it's not like I could cook actually. So, I was just getting like cupcakes, because one time I needed to provide a food for like an event or something so I got cupcakes, and I would get the chips and I would get the cereal because I could always eat dry cereal.

Although a point of constant critique, participants mentioned seeing the dorm kitchen facilities as support for improving the nutritional health of the UCM community. Caroline critiqued:

They're nice, but some of the times, so you can check out supplies at the front desk, so all of the front desks have kitchen supplies that you can check out, which is really nice because I don't keep pots and pans in my room, but sometimes 
they're like gross. So, I don't use our pot to boil like water. So, if I know I'm going to cook something like pasta I like bring a pot from home because it like gets black flakes in your food and it is really gross. So we need to replace ours here. But they'll have kitchen supplies, but it is such an inconvenience. Like imagine having to take all of your kitchen supplies up a whole flight of stairs every time you wanted to cook. It's a pain. It's not that I mind, it just adds a whole, like what I can cook in $30 \mathrm{~min}$. at home, probably takes at least an hour here because of all of the extra steps of bringing my stuff up, and checking stuff out, washing it, putting there, and then bringing everything back down, so it adds at least $30 \mathrm{~min}$. on every time you want to cook. So, whenever I cook, I cook a lot of food and then I just eat the same thing, like all week. Which gets really old, but it's easier that way. It's also hard to cook for one. So, I just eat the same thing all week.

Even though scheduling conflicts could arise, the kitchenettes were a way for students to cook their own food. Charlotte reported:

There is a kitchen in our dorm hall. There's one on the second and the fourth floor or on the third floor. And so, we do use it sometimes, but it is open to everyone else and so you do have to schedule around those, too.

Students seldom use the kitchenettes though. In fact, food that could be stored in a dorm room was also important in choosing convenient food. Specifically, Christina explained how having to eat in the dorms limits choices. For example, Christina said: "Chips and salsa, pizza rolls, anything you can fit into a tiny fridge, pretty much like yogurt, pretzels, sometimes I buy cuties, sometimes veggie trays if you want something good." Similarly, 
Valerie alluded to the popularity behind easy to make items for college students:

We usually have food in our rooms, that we just can eat. Like noodles to warm up in the microwave, just like spirally noodles in a bag... We have a lot of easy stuff like yogurt and fruit in our fridge, like grab and go stuff.

Christina indicated the struggle behind being able to cook in Panhellenic Hall, "You have to go downstairs and check out items, like pots and pans, and if someone else is there then you have to wait. It's hard to cook anything." However, this struggle was not limited to one certain residence on campus. Many clients indicated this very struggle regardless of where they lived. For example, Cindy said:

We have a kitchen that we all use, and we all make our food and we use the same plate because it's not a lot of space. It's just small, you know, and in the dorms too, they have a whole building of kitchen stuff, but the kitchen is on the last floor. Like four floors can have just one kitchen on the first floor, so most people who sometimes want to cook, but I have a friend that lives on the fourth floor in Todd, and she can basically say okay I want to go all the way down to cook and bring my foods all the way up again, and in some buildings they don't have an elevator, and I feel like they should work on that. I know having, if they have kitchens on every floor, like some people can, it can cause some hazards, maybe fires or something. But yeah, they should try to work on that, and also time, like I said earlier for the campus cupboard sometimes it doesn't match with the time that I have to go to class. And sometimes I want to get food and then go to class. It's the primary reason why I'm here, if they can work on a time, that maybe it's just fill out a form online, and just put anytime you're available and you just 
check all the times, and say like maybe make an appointment...So not like a fixed time, so say the Campus Cupboard opens from 3-6 so you can just go online and make an appointment for all the times that are available, for that other people are going to come.

Likewise, Carmyn confirmed:

I went freshman year the first time, the first day it was open, and I was super pumped about it. We got a bunch of stuff, and then I went a little bit after that, and it wasn't super applicable for me, being a freshman because I didn't have a stove. I didn't have a place to store any food. It wasn't like super realistic for me because I was forced to get a meal plan, and I had unlimited swipes so I didn't really need to cook or buy food. So, I didn't use it my freshman year, and then I used it a lot my sophomore year, and then a lot this year. But I felt fine going to it. Likewise, simple snacks while living in the dorms also proved difficult. For example, Cali stated: "That is my favorite thing, but I don't know how to make grilled cheese in my dorm."

Although kitchen facilities were reported as a resource the university provides to combat food insecurity, difficulties in accessing the kitchenettes was stressful. For example, Cali complained: "We have one kitchen in the building. It's supposed to have two, but the other one, the oven broke, and there's like nothing else in there, so it's no point."

Creating Community. Participants expressed looking for others who were in the same situation. Whether it was not wanting to eat alone or merely looking for likeminded individuals, visiting the Campus Cupboard appeared to be a very communal 
activity. With this in mind, some participants suggested building community through a variety of ways. Likewise, Sophia indicated the importance they place on treating people with dignity:

I would say it's a large part of it, yeah. I mean, that and from what I've heard of my student workers, they're also like very welcoming and consistent in the way that they treat people. That is really important too, that when you go to a place like that, you feel like a normal person, like you're a normal person, like going to get some food. Because, I would imagine that, that is not everyone's experience when they seek out help. And that is partially why they do not seek out help as often as they need to because they don't feel like a person and that's not how it should be.

Other participants also mentioned creating a community buzz around food insecurity. For example, Carly suggested:

Hmm. I think that there should be more information available to students, and I don't mean just send out an email, because we don't want all them emails. We don't want long hours' worth of classes. I mean just you know incorporate it into the things you see us doing, like in the union, I bet you everyone knows where that Starbucks is, right? Why can't you incorporate something about budgeting in the Starbuck's line or something, because that line gets long sometimes, you know. And I don't even drink coffee. I've never even been there, but I know that people are there, I walk right by it. I'm in the Taco Bell line, why can't we just incorporate more knowledge to students about it. But I would also thank them, for keeping the thought in mind to have the Campus Cupboard and making that 
possible. I mean there's always room for growth.

The participants in this study view the Cupboard in different ways. Carmyn summarized her perspective that emphasizes community:

Oh, I definitely know a lot of people that do what I do. And, use the cupboard to grocery shop. Most people in my house do because I'll come home and be like, this is at the cupboard. And I'll be like sweet, I'm going to go get it too. Like we had bacon the other day, and that's because we got it at the Cupboard. I feel like the people I surround myself with, it's pretty similar. I know people who pay for more of their college than I do, and I know people who pay for less of it. So, I feel like, I definitely know people in my classes who don't have to work to make ends meet.

Clarissa pointed out the feeling of community that the Cupboard creates: I've seen other people going, I've seen faces like almost like every time we go. Like a silent comradery, I guess, like other people do it, they do it consistently, like us. Sometimes we don't go, that happens, but just feels like oh, it's an okay thing to do because we're not the only ones doing it, I guess.

Additionally, participants shared how clients are hearing about the Cupboard and its reputation around the community. Specifically, Cali noted her older family member encouraged her to go:

My roommate, her sister went here, so she used that while she was here and so she told her little sister and she told me otherwise I would have no idea, because no one talks about it. When I went there yesterday, there was like no one there. So, I think that if you made a poster, I mean people look at posters. I think if 
people knew about it, they would use it way more.

Social media also plays an important role in how and when clients visit the Cupboard.

For example, Christina said: "One of our sisters texted that they were going to have more food than normal today, like this week. Last time we came in they had like nothing." Word of mouth is by and large the predominant way clients find out about the Cupboard. For example, Charlotte explained:

It was a couple of months ago, and me and my roommate were going with someone else, I can't remember who, and he was like yeah you should come, and you should check it out. And so, we went, and we looked around, and we grabbed some food and were like this is a really cool resource. We should start coming here more often, so we can get a better, some better foods to eat. And we'll be able to keep our pantries a little fuller.

Educational Services. Some clients also stressed a need for learning how to navigate food insecurity through cooking and accessing raw foods at an affordable price. Several clients indicated confusion on the hours of the pantry. For example, some clients made the case that knowing how to most effectively use the cupboard would be beneficial. Admittedly, some clients were confused by the food or products offered in the cupboard which bolsters the case for education. Specifically, Cali's comment serves as a basis for understanding this particular need:

I think it would be very cool if you could actually survive off of it, because I know people that do and they're not getting the stuff for their body that they need, so if there was like every food group in there, like protein, and like grains, and I don't know. If there was everything in there that would be a lot easier to live than 
if there were a bunch of frozen chickens. Those frozen chickens I would also like to leave. It's gross, and a little scary. I didn't see them in there yesterday, but they had like 20 packages of flour the other day, or biscuit mix. They had huge packages of biscuit mix, and I'm not going to make biscuits. I think you needed eggs and milk and stuff too, and I don't have those, so it was just a bunch of biscuit mix. They have like 40 cans of cream of mushroom soup right now. It's a lot of things that you need other things for, like it's lasagna noodles, but there's no sauce, no cheese. I don't have dishes to make lasagna, so it's a lot of missing parts.

Carol responded with a simple example of educating clients on the fly:

I really like that they have clear signs of what is in the freezer, so people aren't constantly opening the freezer every single time. Sometimes they are not updated quickly but it does help. So, the list of what is in the freezer is important. I like that they label the dates of when everything comes in. It is very helpful. It lets me know that okay, I will definitely grab this, it just came in. They are really good about dumping it and rotating it.

Although several clients express opposing points of view, those students with higher levels of cooking experience and knowledge saw the raw ingredients that others didn't know how to cook or know what to do with as a priority. Specifically, Carmyn concurred:

Probably something I could make a meal out of because I feel fuller if it's not just a breakfast sandwich type of thing. Like I always go in and grab the peas, and the green beans and the corn and stuff like that if I can. That's probably, I usually 
cook that and then a dollar thing of rice from Walmart, and then like a meat, because I get frozen chicken as well.

Likewise, Chloe found those canned vegetables to be a great resource:

Okay, the canned vegetables, definitely, I am very grateful that they always had those canned vegetables. Maybe if they had more selections on noodles, because I did get noodles a couple of times from there, but they would have these little tiny portions of noodles that would maybe make a meal for me, and my husband is a big guy, so it wouldn't have made enough for him at all. But, I'm not going to say that they should have the meat, because I realize that would be hard to keep in good condition, and be able to give that out for free. But I guess maybe more of the cheap everyday things, like noodles and bread, so more of that.

With an arguably higher level of cooking knowledge, the items found within the cupboard can open more possibilities. Charles explained:

I actually do not find it too hard to make stuff out of things I find at the Panty. So, each week they kind of offer some things you can make stuff out of. So they offer a bunch of canned vegetables and everything. They have some rotisseries chickens, they have bagels and all of that, but one of the main things I do is I grab rotisserie chicken and I'll end up having some vegetables and depending on what they have in there that might vary, so say that it could be potatoes and this last time I went, it was a couple of weeks ago, and they had potatoes, and I ended up making biscuits and gravy.

Other suggested methods of educating the Campus Cupboard community took more modern forms. For example, Charlotte furnished one exciting idea: "Well, this is still 
food, but like some meal kits, so if people did want to start cooking, either purchase or get one of those meal kits." Other clients suggested just connecting with existing efforts that are already being offered within the Student Recreation and Wellness Center. Specifically, Carol proposed:

I know that we have a class, a health class, where in that class you ware taught to plan meals, a healthy diet, figure out calorie intake, what is nutritious, and then different ways of cooking quick meals. So, it would help, and it's a class you can take here at UCM, so it's a 1000 level course. I know the rec has healthier U like sessions where you can come and learn about how to create healthy diet, or healthy work out plans, things like that. I haven't seen one put on in a little while, but I haven't been looking at all of the advertisements as much.

Education can take many forms, but some clients traced food insecurity back to cooking knowledge. For example, Charles observed:

So, something that they could do is offer a simple cook book, and I would not know exactly how to go about that, but I would say that is something around 15 to 20 pages and has a variety of simple and healthy meals, the kind that students could make and they could offer that with every cloth bag that they hand out for students.

Hours of Operation. Participants had different points of view surrounding the hours of the Campus Cupboard. While some had conflict with the current hours, some found no issue, and others were confused on when the Cupboard was actually open. More importantly, holidays and vacation breaks posed difficult for clients. Specifically, Cindy mentioned: 
Yeah, I think there was a day that I came here in the summer. So, I came here on Sunday, trying to get some food, but they weren't open, and I tried calling her. And then later on I saw a number on the school website and the person was basically yelling at me, like I'm not Beth. And I was like do you work here at the university? They said yes, I'm a professor but quit calling me. I'm like okay sorry, I'm so sorry. I just hung up, and I saw the number on the website.

The business hours during the school year posed some conflict for clients. Specifically, Christina stated:

I mean, it's good for my schedule this year, but if I had like work right after class like last semester it wouldn't be. There are a lot of students that take night classes too or have meetings and stuff. Like there's meetings or they work, or they don't get out of class until really late. It just kind of depends. Like if they had like a morning time. It kind of goes back to that market thing. Like if you had that open during the day, you could hit that during class and stuff. Like if there was a morning shift and a night shift, like if they were open like 9-noon or something. Like I may not be up that early, but people could be.

One participant pointed out a potential conflict. Specifically, Valerie stated: "I would say probably, but depending on their schedule, because the Cupboard is only open 3 days out of the week, and certain times, I think they're good times, but some people have night classes." Busy schedules made the first come first serve policy difficult for some clients. Specifically, Steve indicated:

I think the saddest thing for me to see are some of those young people who show up and we're running low on some things, or some things we run out of, and just 
seeing the look on their face, you know, I was really counting on this, and that is hard for us.

Balancing work and education likewise created extremely difficult days for clients. Specifically, Caroline mentioned:

Well, it just hasn't been, the hours aren't advertised well anymore. They changed them, like the first 5 weeks they were like okay these are our hours, and then they were like okay, just kidding, we can't, they didn't have enough volunteers was my understanding so they like changed them, and then they changed them again, and now the last I heard they were only open on Thursdays but I don't know if that's accurate. So, and then when you do go, because they have such limited hours, the line is so long to get in, and I don't have time for that so, we don't really go anymore. Because there used to be a line, like they used to be open Sunday, Tuesday, Wednesday, and Thursday last fall. From 3-6, and so like Sunday's most people didn't go, because it was the weekend and again we're a suitcase town so people aren't here. so you had a lot of international students on Sundays go, but like Tuesday at 3 o'clock is the busiest time because Tuesdays are when you are going to get the good food, because they get their shipments and donations leading up to that. So if you go on a Thursday around like 5, you're getting the picked over stuff, you're not getting the good stuff, so you have to go Tuesday early, but that's when the line would be usually, but it was much more manageable when they were open four days a week. But now when they're open one day a week, at least my understanding, I don't know if that is the correct hours, so you'd have to check on that, but like the line is so long, it's just not, it 
goes all the way up the hallway and like...

The wait in line was a reason to be familiar with the hours. Specifically, Caroline added: Um, well we used to get there like when it opened so we would like to be in line before they opened. I probably never waited more than 15 minutes, I would say, but I would say there are students who do wait. But it isn't, honestly, I have yet to show up there this year when they're open. Like every time I've gone, they are not open. So, I have not gone at all this semester. It's not like I go, and oh, the lines too long and I leave. Like I've literally not seen them open in the times that I've went there this year.

One staff member referred to the clients' frequent visits. Specifically, Simon reported: Every week, because there's always a line. Like the ones who have come before they're smart and they know that we get the delivery Tuesday, so they are here for the first time, we used to be open Tuesdays now we're open Wednesdays...Every single Wednesday now there is always a line... And you know we have a lot of returners, because we have those bags that we've purchased that we've given out so they're coming back because they're bringing those bags again.

Additionally, Charles spoke to the hours of the Cupboard when asked how to address food insecurity.

The main thing for me I would probably say is to extend the hours a tad bit, and I know that's kind of asking for a lot because they're understaffed a bit, but I would say extend the hours a bit, that would be great.

Christina also shared a similar perspective:

I feel like you couldn't get the nutrients you need as a growing person from the 
food pantry. Like they have vegetables down there, but again, they could be getting close to begin bad, like the bread sometimes like molds within a couple of days. And you can only get them within a week, so by the time things get old, you can't even get more food and they're open weird hours of the week. It's like 3:306, like Wednesday, Thursday, Saturday, something like that. Three days a week, three hours a day.

\section{Products}

The clients care about the freshness of products. Because the Campus

Cupboard works with donated food, volunteers and staff alike prioritized checking the expiration dates of the products on the shelves. When asked about the food clients were looking for, many participants expressed a concern surrounding the expired goods offered in the pantry. However, how much the expired food affected each client largely depended on the individual. Specifically, many clients reported not grabbing the produce that looked bad. For example, Colton stated that while he understood the items were donated, the spoiled food affected his choices:

So, sometimes, now I only usually get eggs or the frozen meats or like canned vegetables, because I would like to eat more vegetables, like salads and fresh vegetables from there, but typically in the food pantry the lettuce or the salad and the stuff that they have it goes bad rather quickly, so I typically don't get that because I want to eat like food that's not expired but food that is on its way to being bad very soon. So, I do wish they had like more fresher vegetables. Once again, those foods are donated.

In fact, fresh produce to be an important aspect of their perspective. For example, 
because the Cupboard is only open 3 days a week, Cayden suggested organizing an effort to distribute the less fresh produce before it goes bad:

Also, if possible, call out to student to come around for pick up on items that have less validity time before they go bad, in between when the pantry is close, this has to be monitored to achieve. If it can be allowed up to twice in a week and also more of the perishable things out for those who want more so as not to get bad in the pantry without anyone having them.

The bread was also a concern for the clients. Specifically, Colton indicated how she utilized the word of mouth:

Yeah, their bread. Their bread it's like sometimes I'll get a bag of croissants or something, and they'll be on top of my refrigerator for like two days and I'll go to eat one and it's already molded, and I'm like that is disgusting and I don't get food from the pantry anymore. And I typically tell people not to get bread from the pantry because it may be good while it's there but it is really short lived, and like if you don't eat it right away food is going to go bad, if it can't last longer than like three days, it's not worth getting or risking.

Additionally, Stanley noted this concern:

Well, I am kind of sensitive about the expiration dates on some of the items. I try and keep a close eye on those. Because like I said, especially the food from the dining halls, because those can go bad because they are already cooked. So, I just keep an eye on those and if they're expired, I just got to throw them away. I would say that is a priority.

Overall, there was a general understanding that the food at the Campus Cupboard was 
donated because it was close to or passed the expiration date. Specifically, Cindy reported:

Okay, so the food in the Campus Cupboard sometimes, they are close to the expiration date, so you have to eat it right away. Sometimes you cannot store it. Let's say I buy food at Walmart, I can store it as long as I want, you know, but the ones in the Campus Cupboard you have to eat them as soon as possible so it doesn't get expired.

The leeway on expiration one could allow per item also varied. Specifically, Carmyn found:

There was like milk, and I got super pumped because we're out of it at home, and I needed to buy some. But then I saw that it expired November 4th, and I was like, is that okay? Can I eat that? So, I put it back.... Like fruit is expensive, and I love fruit. But I know that because of where the Cupboard gets their food, and what the Cupboard is, it's not really possible. And the fruit that they do have sometimes, is like really old. Obviously, since it's donations, it doesn't taste that good.

Likewise, Cynthia argued working around her ability to work around expiration dates: Sometimes it's good, like the fruits are sometimes good but the vegetables are not that good. It is expired or spoiled most of the time, like I took tomatoes, they are good. So, what I do when I take anything like vegetables from here, I cook on the same day or the next day, because if keep it for more times it will get spoiled. They should not keep the expired products there. Like we can eat bread, they give bread also, and it's not exactly bread but it's like a roll or a bun, we can eat it after it's expired, but not the vegetables or the fruits. 
The staff also are aware of the expiration dates. Sam pointed out:

We do get a variety of foods, we get breads and vegetables and all that. The problem is that it may not be the best quality. It's edible, I won't say that it's not, it's just not, it's the stuff that Walmart and Aldi's doesn't want. Like they can't sell it, and it may be some of it may be brown, or squishier than normal, so it's just a matter of I wouldn't say lowering your standards, but it is just a matter of hey, do you mind eating this whether, because it's free. You know what I mean? So...

Offering a variety of options within the Campus Cupboard is important for the clients. In general, variety can be defined in a variety of ways, but specifically some clients expressed an interest in what they considered to be basic items. For example, Carmyn stated:

I mean the cans are always there, so that's always convenient. Like I would buy that straight from Walmart. The cans of like corn and green beans and peas, as far as like the other random stuff, it's fine, yeah.

Additionally, an understanding of one's own budget constraints in conjunction with the actual cost of the food item within the pantry can lead to excitement. For example, Carly exclaimed:

Man, they had bacon there last weekend! I was like, woah! Bacon is expensive! They have meat! Meat is expensive! I'm not the type to like vegetables that much, but they do have vegetables too, and I know I need that, so self-care, right? [laughter].

When working with donated items, the variety can be so great that once in a while the 
donations will be exactly what one needs. Clients were also truly cognizant of other's needs as well. Carly shared:

I think they have a wide variety, sometimes, I'll go, and I'll wish I had gotten more of something, because I try not to be greedy when I go. Like I have yet to get all 10 items in one go, because I feel like I'm just one person, you know. I don't need to be getting all the stuff. So, like one day they had binders, and I think I got two binders, and I was like I should have got more of these.

Fruits and Vegetables. Participants in this study also referred to the amount of fresh fruits and vegetables the Cupboard was able to provide, politely suggesting they would like to see more. Cindy suggested:

I'd say for example in the Campus Cupboard, how to give food, that is probably not close to expiration date. Because trust me a lot of us just take the food, we don't eat it all at once, and sometimes whenever you hungry you definitely forget to check the expiration date, and you would not know that it expired. You know, because sometimes we pick food and we see that it is a week to expired, but it's like okay it's just a week, I'll eat it before then, but when you get home you save it, because you can't eat it all at once.

Cindy agreed and advocated for international students who use the cupboard when asked about the variety:

They have a lot of variety of food actually. I think they have like less for the Indians, I have a friend who is Indian, she doesn't eat like pork, you know beef, I think they have like a specific spice that the Indians take, and I find that really good. So they have different variety of food, if it's like American food or 
something that is maybe for the Indians or Africans or you know, there's quite a lot. Because once we see food stuff and we pack a lot of them, and we keep for later on, and by that time it may be expired. But we still eat it.

Even though others felt that more fresh produce would be helpful, Cali admitted to the difficulties behind providing fresh produce:

I don't know how well this would work, but like fresh fruits and vegetables and stuff. I'm not sure they could do that because on weekends, I don't know if they're open on weekends I don't know.

The most popular item in the Cupboard, and perhaps the most talked about was canned soup. Many, if not all of the participants, mentioned soup. There were varying perspectives, but most clients really appreciated canned soup. For example, Simon confirmed:

Yeah, I think most if not all of them, I think on every floor have a little kitchenette type thing, but I'm pretty sure all of them can have microwaves. They do have a microwave in their room, so they're allowed to have a little mini-fridge and a microwave in their room, so soups or ramen noodles or easy macs or quick things that could can just throw in a microwave.

Because of its popularity, Simon even mentioned the importance of keeping more cans of soup in stock:

I'd say it's probably lacking, because we do get a lot of corn, we do get a lot of green beans, what the students want are their soups, the soups, that's the simplest thing, but we don't get enough of those. I know that for a fact, because when we get soups it's gone. They go so quick and we have a limit, one soup per person, 
but it just flies off the shelves.

Additionally, Caroline explained one angle behind the popularity of soup. Specifically, she highlighted:

Those were more of like a supplemental thing for me rather than like this is all I'm eating. So the canned soup, like even I would use like condensed soup to make the chicken and dumplings, but if they just have like cans of soup, that is super nice because it is super-fast, like I can heat that up in the microwave, or like put it in a to go container and like take it with me and eat it for lunch at the union or whatever, so I really liked those. I think for the most part, it's hard to say like what I want to eat, I don't really eat what I want to eat when I'm at school, because when I'm eating here, I'm eating to like live. I don't eat for pleasure, like the dining hall is not good. When I'm cooking, I don't have everything I want to cook, so you just kind of eat to fill a hole, like you don't always, like whenever I'm at home I like to cook this, so I'm a big cooker. So, I like to go all out, but I don't do that here. So, like when I'm eating here, I'm eating because I need to. Personal Hygiene Products. Students also suggested that offering personal hygiene products would have an indirect effect on freeing up resources for purchasing food. Specifically, Charlotte recommended:

I notice that they have some like deodorant or tooth paste for people who can't get off campus and they need this sort of thing, so maybe like some shampoo or conditioner or something like that. Or, if again for low income people who can't afford like some notebooks or stuff like that.

Likewise, Cole generalized, “So, if people don't have money for food, then they don't 
have money for other things like toiletries." These additional products were quite popular among the participants. Cynthia said, "Yes, like toothbrush, toothpaste, and sanitary pads, tampons, and sometimes shampoos, creams, moisturizing creams."

\section{Perspectives}

Some of the missing pieces did not necessarily refer to the food the pantry offers. For example, Christina mentioned how advertising is not only important for people searching for food, but for those willing to donate as well. Specifically, Christina argued: The biggest problem with that is like nobody knows about it. A lot of people at UCM don't even know that this exists. So, like some people might want to donate it but they don't know it's there. Yea, because like the beginning of the year last year they said like any left-over food you have that is non-perishable you can donate to the campus cupboard. I had like a bunch of left-over cans and granola bars and stuff that I donated last year. Awareness too. Like so if people can give help if they can, like if they have stuff to donate, because some people do, their parents like send them gift baskets and like stuff in the mail and they don't want to eat it and they like don't know where to donate, like where to go or how to do it. Like I don't know how to donate food here. And Greek life. Like usually it's a requirement that you give service back to the community. So that would be a great way that people could take advantage of doing that for their service hours. Like if it was able for us to volunteer in the Campus Cupboard, like I'm sure a lot of girls would definitely do that. I think you can in like two hours increments, and you can donate food.

This perspective was actually common among participants. Victoria agreed: 
Um, okay so most of the students here at UCM don't even know that the Campus Cupboard exists. For me, I wouldn't have heard of it if it's not for the volunteering hours that I have to do. And I found this without having to know of it. But, for international students I would take into consideration that there is for example, for me as a Muslim I cannot eat certain stuff, and it would be great if they could provide it at the Campus Cupboard, or like the Indian students, if they could get dried rice, or they can provide it at the Cupboard, or if there was someone who was willing to donate, say can give the Campus Cupboard dried rice that would be good for the Indian students to get that from the Campus Cupboard, so I would say to take into consideration how culturally different we are, and sometimes we have special things that we need in order to make our food or yeah. I think that is it.

One important perspective to consider is the wait time outside the pantry. Celeste suggested an interesting point of view: "The pantry needs more options or have a list or a heads up before you go in there." Clients expressed their need for healthier items. For example, Chloe indicated:

They didn't have carrots often enough. Because I was always looking for the canned vegetables, so I would get two corn, two green beans, two peas, half of the time they were missing the carrots, they didn't have any sliced carrots, but I wasn't really looking for anything when I went there, other than the canned vegetables or whatever was there. Free food, I'm not going to be picky about it. Additionally, participants expressed an interest in dried goods as well. For example, Chloe stated: 
Rice, definitely, rice can make a meal stretch quite far, sometimes when he made that stew, I would cook up some rice with it and you get twice the meal, or you could make that stew last a little bit longer.

Due to the high frequency of international students that use the Cupboard, several clients expressed a desire to see more traditional basics available. For example, Cindy stated: We eat rice a lot in Africa. Where I come from in Nigeria, we eat beans, but it's like peas. Not beans, it's like peas, like a lentil. We eat something back at home called a yam. Yam is a tuba. It's like potato but a bigger version of a potato. It's big, really big, so we cook that and eat it with egg, so it's my favorite meal. I drive all the way to Kansas City to get it in an African store. I would be so happy. And also, we don't eat the same vegetables that Americans eat. So... we eat, how do I say, I don't know the name but it's something like spinach, but it's not spinach, it's a green leaf. We use it to make soup...

Other participants mentioned less exotic, but equally expensive, items. Specifically cooking oils. For example, Cynthia remarked: "Oil, like vegetable oil. We also have peanut oil. But peanut is a little expensive." Likewise, Stanley confirmed this need for culturally sensitive items:

So, going back to that question having Halal meat would help those Muslim students and even like vegetarian options because I know quite a few of the Indian students, from India they are vegetarian as like a cultural thing too and they come in there and ask me, actually like just today one of the guys, he saw the pasta sauce and he wanted to know whether there was meat in there. So, I'm just saying that vegetarian options too. It would be nice if we could be set up like a grocery 
store, and have like a vegetarian section and everything else, that kind of thing. But first of all, what we need first is room before we can start any of that. Like actual physical room.

Food Recovery Program sparks mixed feelings. In addition to the nutritional value of food, the food recovery program also provoked mixed reviews. Steve explained: So, Sodexo is another one of our primary partners in that. For instance, we've been repackaging the bagels, or the pastries, that instead of them throwing it out we can repackage it and we can offer it up through our Campus Cupboard. So that food recovery program on campus has been a vital component also. There has been a couple of other colleges actually, that have toured our facility and checked out how that's handled and how we do that, because they want to replicate that on their campus also.

On one hand participants really found benefit in the collaborative project, while on the other hand the partnership received harsh criticism. For example, some clients purposefully watched the menu of the dining halls, so they knew when to visit the Campus Cupboard. For example, Caroline emphasized:

At the dining hall at the end of the night, if they have left over food that they're not going to reheat, they box it up and portion it out and you can get dining hall food, so you can have already prepared mashed potatoes or turkey, so sometimes we pay attention to the dining hall menu, and okay we had turkey on Monday which means we're probably going to have left over turkey and mashed potatoes at the Campus Cupboard on Tuesday. So if you watch the menu you can kind of guess what's going to be there, and so if you like something that they serve at the 
dining hall, which is like once in a blue moon, you can actually, there's a chance you're going to get more of that at the Campus Cupboard.

While some people appreciated the options in recovered food, others, like Clarissa did not, expressing discontent for repackaged Sodexo food:

About the only thing that I can kind of trust is like a cupcake, because the food isn't really that good. We don't understand why. Like, if you don't swipe in the dining hall, it's like $\$ 10$ or $\$ 13$ otherwise. It's like it's not worth it, we're not the biggest fans of the Sodexo food. Like last time, I've never had bread pudding, and so I got it to try it, and it was... I imagine it was better elsewhere.... I don't really know. I just know what I don't like. Usually, it's from the dining halls. The Sodexo, that food usually isn't the best. We both know that they're just doing it for a tax write off.

Additionally, Virginia communicated her perspective on cutting down food waste on campus:

I think it's great because otherwise they'd just be tossed in the food and this way other people can get, cause we've repackaged how many things stuff we read back, it's bad all day goes and spaghetti and we're taking the big trays and putting in little containers and labeling it. We do that all the time.

Nutritional Value. Clients, volunteers, and staff expressed varying perspectives on the importance of the nutritional value of the food in the Cupboard. To begin, participants were quick to point out the less than healthy options that were easy to find in the Cupboard. Christopher acknowledged the importance of eating healthy, but also rationalized grabbing for the less healthy options available in the Cupboard: 
Vegetables are probably my number one thing. I try and not eat too many sweets, but if there is something sweet in there then I try and grab it because it is free. I try and look for pastas and high carb stuff. I haven't really gotten meats from there because I'm not a huge after the date type of person, but yeah, that's mainly what I go for, and then they just now started putting medicines and stuff in there, and that's a huge help because that stuff gets expensive real quick. So, having that in there is really, really nice, especially for me because I get sick a lot.

Similar perspectives from multiple participants. In another example, Cole rated the Cupboard with a fairly mediocre assessment, "On like a healthy $1-10$, I would say like a 6 or a 7." In some cases, clients appreciate food of higher nutritional value, but referenced the temptations of less healthy items in the Pantry. Caroline outlined:

I definitely try to eat healthy as much as possible, which is not easy to do whenever you don't have a kitchen and the dining hall isn't always super healthy. I don't think they have a lot of healthy options because most of the donations they get are like all the soups are condensed soups, so like it's not, most people don't eat condensed soup anymore, they just use it for cooking. You get a lot of chips, there's usually a lot of pasta there, which is fine, I like the pasta, they have a lot of soda. When they serve the dining hall food, that's definitely not healthy options. The fruit and veggies that they would get it's like sometimes they would have the prepackaged trays from Walmart and so they would like get them in when they expire, and they've past their best buy date and so Walmart can't use them, but like you get them and they like smell gross because it's old food. So, I definitely never relied on Campus Cupboard for healthy options, because the few healthy 
options they do have there are old and gross.

The other side of that coin contends unhealthier options are better than no options at all. For example, Vanessa pointed out:

No. I think whatever they provide is good. I think it's more beneficial to the college population if it's healthier, because I feel like most cheap things are going to be probably unhealthy, I'm trying to think of an example. Like, McDonalds and Taco Bell are fairly cheap, and they're not exactly the most nutritional, but when you go to Walmart and something, and you look at fruits and veggies, they're going to be a little more costly, so I think probably more nutritional things would be better, but anything would help so.

Lower Nutritional Snack Food. The participants expressed different opinions over the lower nutritional snack food the Cupboard also offers. Sam highlighted the essential problem when working with strictly donated items from Harvesters. Ultimately the Pantry will have to make a decision regarding the healthy options it gives to its clients. Sam shared:

We can't really control it. I guess I could tell the people in the truck, hey we don't want to take this, but then it may not be that full that week. You know what I mean? I just kind of take what the truck gives us and then I put it on the shelves. I feel like it's always good to have snack foods. Just because people may not be able to buy them, so they just may want to go in and take some, and I know they don't have the best nutritional value and there is obesity in America and all that, but like there's nothing wrong with indulging yourself if you keep it in check.

Several clients pointed out the variety of unhealthy options the Campus Cupboard offers. 
Specifically, Cole mentioned the soda:

There's' quite a bit of canned foods, so like vegetables and stuff so I would say on average there is more healthy food, but there is quite a bit of soda. Like they had like an entire rack full of soda and obviously the snacks that I was taking advantage of, so.

Some participants mentioned the candy, and soda, and sugar, but other clients pointed to the food that does not take long to prepare, specifically pointing out their lack of nutrients. Valerie indicated:

Just like easy microwaveable stuff that's not always the healthiest. I noticed there's a lot of candy in there right now, but I think that's because Halloween. They have a lot of Kit Kats in there.

However, from the staff perspectives, the unhealthier items seem to be a priority. Specifically, Stanley refuted:

Well, to be honest, I think the students just want the fun unhealthy snacks, like sodas and chips, those tend to go like really quick. I think you saw me do the tally sheets. Those would like to fill up so quick. And then stuff like the dining hall food, I don't think they're as popular as the chips and soda.

Virginia, who holds experience in the health care industry spoke to the importance of less healthy items within the Cupboard. She argued, "the idea is to sustain life, but so physically, but emotionally, some of those types of foods sustain them emotionally."

Location. In making suggestions for how to address food insecurity on campus, some clients addressed the policies, hours, and size and location of the Campus Cupboard. An additional client suggested the philanthropic nature of the university and 
connecting volunteerism to graduation. Specifically, Caroline suggested:

Well I think right now, from my understanding the biggest problem is that they don't have volunteers to work it, so it's not that they're not getting food in there and they can only serve so many students, but they need volunteers, so how you do that? I don't know. Because I know a lot of sorority chapter have like mandatory volunteer hours, and I'm pretty sure people who are dietetics majors are required to work so many hours, at least it's been my understanding, is that they have to work so many hours there. To provide volunteers, I think other majors can honestly do it, like social work, this is social work stuff too. If you were just required to do even 15 hours in a whole semester, like everyone can give a little bit more of their time, so like making it more of instead of random people volunteering, like building it into the curriculum, like what if UCM had, like my high school you had to have 10 service hours to graduate. Like what if UCM implemented something like that. If every student gave 15 hours, like what if you did something like that. I don't know, service is really important to me, so I feel like if you just made it a part of like your graduation requirement. Or just program requirements, that could bring volunteers in.

For example, Clarissa suggested adverting its existence to help people talk about it: I don't think that the Campus Cupboard is advertised well enough, I feel like there are people on campus that don't know about it. Um, maybe the location is a bit far off because there are more dorms over that way, and it's a farther walk over here. It's probably more, so a thing, if you don't have a meal plan, which I never liked how they made you have one anyway, because it's very expensive to have a meal 
plan and live in a dorm, but, maybe the people that choose to live in an on or off campus apartment, through the university, should know about it [Campus Cupboard] more, because I've heard lots of times, they're like, it's going to be spaghetti again tonight, I've got noodles and pasta sauce.

Conversely, several clients addressed the size of the food pantry. Specifically, Valerie suggested finding a bigger location:

No, I mean I think a bigger space would be awesome for them. I mean, I don't know how many people go there on like a regular day, but I'm sure it gets kind of packed on the inside. I think only so many people can go in at a time.

Interestingly, Stanley argued the location of items within the cupboard could make a difference:

Probably set up like, really just categorize everything like a vegetable section, a variety of vegetables, meat section, variety of meats, and then like some stuff that is just for fun, make it like a smaller section maybe set certain limits on that.

Lastly, Vanessa indicated the location was difficult for people to find:

I don't think it's a great location honestly. I had no idea how to find it last year, I went with a senior to find it. It could be better, more signs, more open, but, it's a spot, so... Honestly not really. I think it is very well organized.

Increasing access to affordable raw food. Some clients demonstrated an interest in transforming or adding a small marketplace to the cupboard in addition to free food. Specifically, Chloe indicated:

Food is expensive, fruits are not cheap, and they taste amazing, and I like vegetables, I love vegetables, but fresh vegetables are not cheap, and it's hard to 
get them fresh too. So, canned foods, canned vegetables may not be as good for you, but they're cheaper, and that's the other thing we would do too. The canned meals, canned meals or frozen meals, because those are really cheap so when my husband didn't have a job, we were just buying those things.

Likewise, when referring to a low-cost food market on campus, Charlotte said: I think that would be a good option too, kind of having a more marketable, like produce can be very expensive so they don't necessarily want to, if they lose a bunch of money, and so I think it would be a great idea to have it more like a small produce market or something. Just because it can be very hard to get to other locations if you did want produce and you can't get off campus, or if it was cheaper on campus because a lot of college students are very low-income people. Finally, Cindy expressed her ability to navigate the food environments, as well as the hurdles of college and higher education:

I would say I'm a pretty determined young woman, I've been through a lot, but I just keep going because I feel like it's going to be worth it at the end. Getting my nursing degree and furthering my education. I actually want to be a surgeon, so I plan on going to medical school in the Caribbean and getting my medical degree. In addition to the actual food that the Cupboard provides, some clients specifically mentioned adding services as well. One client suggested offering items that were of little cost, not to make profit, but to improve the food environment. For example, Cali suggested:

I think that would be great because I'm sure the prices would still be better than a lot of other places. It's not that people don't have money, it's that things are 
expensive. So, if they could buy that, that's great. Like I know on campus we have like the cheapest Advil you can buy anywhere over at the health center, so people will go there to buy Advil, so people would go to the campus cupboard to buy whatever the campus cupboard had if it costs.

Some participants even compared a low-price market to the student health clinic. Specifically, Charles stated:

So, I would say that they might be able to offer some more services that aren't available to all college students. I know there is a clinic that is on campus. I personally have not been to it before, but I do know that there are a few college students on campus that don't have health insurance and so it's kind of a dangerous game, just waiting on something to happen where you have to go to the hospital and you have an $\$ 800$ bill that you need to pay, but you have your rent coming up and you need to pay a certain part of your tuition before this date before you sign up for spring semester classes, and it would kind of throw a wrench in the whole thing, So it would be great for the university to offer. Additionally, adding guides or more personable relationships to the clients would be beneficial. Valerie recommended:

I think obviously they have their usual, and they could get more personable with them and see their basic needs. Because I know like for my issues, it would probably be a little hard for me to find everything to balance all of my nutrients and stuff. 


\section{Theme 5: Although the campus cupboard is focused on clientele, the volunteers and staff are the Campus Cupboard's greatest asset}

The staff and volunteers who work with the Cupboard are an additional asset to the community. They bring a unique wealth of experience, knowledge and experiences that is important to note. Specifically, the study explored what inspired volunteers and staff to be a part of the Campus Cupboard. They reported several experiences worth noting. For example, Valerie stated:

Yeah, I mean I work at a hospital so I could have just volunteered there, and did my normal thing, but it doesn't really mean anything then. I really think it helps people, and obviously I want to be a nurse, so I want to help people, and me being able to do that drives me to want to do it, motivates me.

Other staff members referred to needing work experience for their field, but also taking pride and joy in their ability to help people. Specifically, Stanley said:

The reason I got a job here is because I needed work experience in my field, for my major but you know being there I can give a specific example, like just today you saw all the vitamins and what not, we don't always have those and it's like a fluke thing. And some people came in today and said they needed something to help them with their bones, and I would just like find stuff with calcium for them. So, yea, it was pretty exciting to use what I've learned to help these people.

Some staff members also acknowledged the difficulties of attending college and noted the affect their university had on their own life, so they wanted to give back. For example, Steve said:

I personally am a first-generation college student and I know how it impacted my 
life versus my family that was just blue collar that just went to work and didn't pursue that avenue. I know the difference it has made in my life, in every aspect. Likewise, Simon recalled a very personal experience that he has transformed into a desire to help others:

I graduated in 2008, and to my knowledge we didn't have anything like that. I'll never ever forget, man I didn't have much money in college, and this is why I want to help with the pantry. I went to Kroger, I thought I had like \$10 on my credit card, not even my debit card, but on my credit card I bought literally like a gallon of milk, ramen noodles, and easy mac and I went to the self-checkout thing and credit card was declined. I didn't have, so I literally just said I'm sorry and I just had to leave it there and leave. So, I'll never, ever forget that so that's why I want to help and like helping with the pantry and I do think it's very important. It sucks more because you felt, kind of useless, I felt useless, and worthless when that happened.

Sam just enjoyed the experience of helping others:

I mentioned it before, I just really like what we're doing. I like the people. The volunteers that always come in are always curious, and they always ask me this. Like how you got involved, and it's just fun. It's a fun environment, we provide food, people get excited about the food, they're very thankful for the food and it's just a great environment. I wish we could help more people. That's why I need to mention the Twitter thing to Sophia, to just reach out.

Many of the volunteers come from philanthropic requirements from their courses; specifically, the nursing program's Culture and Sustainability in Health Course. So, in 
addition to providing food for students in need, the Campus Cupboard also provides a place for community members needing volunteer hours. Many volunteers provided similar responses when asked about their participation in the Cupboard. Veronica shared:

So, I'm taking an online nursing prerequisite course, it's called Culture and Sustainability, and one of our requirements is to do community service, 12 hours for the 8-week course, so for that 8 weeks. And, I have done community service with the food service and stuff before, so I'm comfortable with it, and it's close, since I'm just living in town, and I really like the idea of giving back to people in such an important way So I was like hey, that is a good idea, and I want to do that.

Defining their role. Although the employees and volunteers complete a variety of work for the cupboard, they define their roles within the Campus Cupboard in a variety of ways. First, this investigation found that the Campus Cupboard prioritizes ensuring that clients have equal access to products by focusing their policies around distributing items equally. Specifically, three volunteers pointed out the Cupboard's commitment. First Vanessa indicated:

Um, just kind of taking care of the well-being of the community of UCM. I think it's really helpful towards the people or the students here that might not be able to get snacks or food and so, it's really good for the students and the faculty on campus. Um, probably just like they're trying to make sure that there is enough for everybody that needs help. So, they're trying to like limit, but also give enough to help support people throughout the week.

Second, this same sentiment held true for other volunteers as well. Violet highlighted the steps the Cupboard takes to prioritize equitable food distribution: 
I mean, definitely giving enough food to everyone. So whenever portioning everything, they really care about making sure everything is filled very well. Because you're only allowed to take 10 items every week, I think it is, so whenever you go in, you want to get the most out of your 10 items. So, I think it's good that they're making the portion sizes that you can get from it really big. Just getting as much things as they can to give people is a big priority.

Volunteers and staff agreed that the Campus Cupboard ranks repackaging food, organizing donations, and filling the shelves of the food pantry as a top priority. Specifically, two staff members reported this as a priority. First Sam shared:

So, we get food shipment deliveries from Harvesters every Tuesday and Thursday, and so we bring that in, and then we provide food for students. So, there's food and sometimes there's also toiletries and stuff, and we provide that for students.

Second, Sophia pointed out the difficulty in balancing a full pantry with desirable product:

I think we always have food, it's just like the types of food we get. So like I believe we pay Harvesters to bring in the goods that they bring in for us, so those are like produce items, or just items that are getting moved out of stores for one reason or another. Many times, it's because they're getting close to their best buy date, but it really just depends on what is coming out of the stores. A lot of times, dry goods, we're typically doing pretty good on. But I would say it's really touch and go with the products like meats. So, like proteins, like right now I know we have like bacon, and we probably have had bacon for a week or two, but stuff like 
that just goes so quickly that it's a pretty quick turnaround for us to run out of something like that. So we always have food, it's just not always things that people want, or would prefer, I think is a good way to put it.

Likewise, Valerie mentioned packaging, labeling, and storing food appropriately: What we've done recently is packaging all the food we get from dining halls, or their director donated a bunch of food from a wedding she went to that was left over, so we packaged all the foods, labeled it, put it in the fridge. We'll unbox toothpaste and things and then we recycle those, the boxes, and then after a week, we have to get rid of the food from the Campus Cupboard so we donated that to the FPO, where the janitors can grab it if they need it.

Similarly, volunteers play an important role in correctly placing items in the pantry. Vanessa stated, “Um, mostly just like repackaging foods. I’ve organized foods, kind of organized cans on where they go, labeling foods, just kind of stuff like that."

Creating Strategic Partnerships. The Campus Cupboard works diligently with a variety of partners within the local community and region to ensure the pantry's stability, Harvesters, local groceries, and faculty members create this network of support. The staff found creating these local partnerships to be a priority. For example, Steve said:

With the Cupboard we have a partnership also with some of the local community food pantry and on Tuesdays they go up to Harvesters in Kansas City. We actually have an account with Harvesters, and they get produce, they get commodities, and each week that is different. So, on Tuesdays I am here to unload that truck and move it into our facility and then help organize that as needed. We do have a volunteer staff that comes in and they also help with that. 
Working with them, making sure that things are handled in a proper manner and then storage. We also get locally; Walmart and I think now Aldi's is now coming on board so some of their discontinued products or produce and things. They're getting that in the rotation now. So, we get two deliveries on Tuesday and then we normally get a Thursday delivery. So, helping make sure that it's handled correctly and unloaded and keep that relationship with those guys. So, liaison, I guess between those guys and our facility.

Additionally, Steve spoke about the importance of the Cupboard's connection with the UCM Faculty:

So, there are staff members they're community members here on campus and in the community that have reached out to us and have said, you let us know what you need. We will make sure you have it. We'll get a call, an anonymous donor will just back their van up and they'll say I was at the store and I picked up extra so these kids could have some extra. So, whenever we do run low on things it's really important, it's imperative that we make sure that we have something for everyone. It might not be everything that they're really looking for, but I mean we need to have something down there. I mean, on a number of occasions, I've spread the word, hey guys we're running low on soup. And, you know we'll have people that will just anonymously show up at the front counter of our rec-center, drop off ten or twelve cans of soup. They don't care to be acknowledged, they know that we're doing the right thing, but as far as our clients, that's probably some of the toughest times.

Likewise, Virgil argued the importance of relationships: 
You know relationships are the wellspring of all of humanitarian service and different opportunities. And so, as you, I think that there's probably an opportunity to look at local stores, local farmers. I think that there's probably an opportunity to serve as and interact more with the students. Say, okay, what, you know, you've got this food insecurity, so what actually helps? You know, do you need more fresh produce... And then can we find a resource that has, uh, you know, that and make a partnership or a contribution there. You know, and I don't know, but is there somebody just tossing things that you know, could have at one to three-day shelf life that would be a great surface or one to 10 days shelf life or whatever. That wouldn't be a good service then. And I and I, and honestly cause I haven't talked about that, I have no idea how much, you know, survey work and needs analysis have been done with the students that are coming. Not in terms of just volume but also type, um, and frequency and whatnot. But you know, maybe there's a, maybe there's an opportunity to dial that over and maybe it's already been done. I don't know.

The report found that the food recovery program with Sodexo is an important partnership in offering clientele a variety of food options. Veronica emphasized the important yield of this partnership:

Um, I think they just strive to help out others who are in need, just like we're doing with Campus Cupboard. Um, just like trying to do their best. I saw online that they go and get food from the dining cafeteria stuff, because I know a lot of food gets wasted, and it's just like a thing. I think that's awesome that instead of letting that go to waste, they put use to that, to people who are in need. There is so 
many homeless people, everywhere and then just people, yeah, who are jobless, or who don't make anything for money, and students. We can't work full time, there are people who are doing it, and like kudos to them, but like I just can't do it. Yeah, so...

On a similar note, Victoria stated: I think their priority is to get food from places nearby, and then they put it into bags, and then students can come in, not only students, but faculty too can get up to 3 free items. So, I think for people who are in need of food or anything else, they can go to the Campus Cupboard, so I think that many people who are going through some financial difficulties, so this is a great way to help provide some assistance to students and faculty here.

Communication. The Campus Cupboard staff and volunteers take several approaches to communicating their services to the community. For example, Steve indicated:

Yes, we use a number of ways. We use social media, we get it out through Instagram, Facebook, Snapchat, we have flyers, we post flyers around and then once the kids, and once people come in and start using it, we say tell your friends. I know I've been down there a number of occasions and some of our students say, I heard this from such and such and I wanted to come over and try it out. So, word of mouth is a big one here on campus. We are a small, smaller unit as far as a college campus goes and so that helps us. I think our office of sustainability does a nice job of getting the word out, that this is available. We've worked very hard on our signage. It's that component that we want everyone to know that this is 
available to you.

Virgil indicated the importance of communication within the community, arguing for strategic communication to more effectively aid the effort moving forward:

Yeah, it is, uh, you know, again, being in the business that I am, that the challenge of communicating to both on a massive scale and a pinpointed scale. Like, so getting to the right person. Um, even on a college campus... So, you know, maybe one of the other ways to dial that in is finding systems and community communication channels to effectively target and communicate with students. And the two-way communication will know what their means are and is there a way to dial in that the campus is covered more effectively, and it's a more personal one-on-one.

Staff and volunteers both expressed the importance of communication between workers as a principal priority. To further explain, as a result of isolated shifts and busy schedules, coordinating responsibilities and workflow is a legitimate concern for the staff. Sophia clarified:

I would say communication is a huge, I want to say that's number one, I want to think of something else that is like really important too, but I would say communication between like me and then Sam and Stanley so my student workers as well as like our director, if we're, since they really manage themselves within their shifts, largely our communication happens through email. I have them do end of shift reports every day, and so that follows up there, so if they're working in the pantry for a shift, like if they're working during open hours or if they're working during food recovery, which is when we do a lot of cleaning, and 
repackaging and picking up food and all that good stuff. So I would say if we did not have that communication in place, where they were doing those end of shift reports and texting me when they had more immediate questions, then we would really struggle to be productive about getting things done, that like need to be done now versus like things that can wait. So, I would say communication is a huge priority.

Advocacy and Outreach. Several volunteers as well as staff members defined their role in advocating for their clientele by providing thoughtful outreach programs and useable products was also a priority for the Campus Cupboard. The majority of staff members individually confirmed the importance of outreach and client advocacy as well as acknowledged how clients depend on Campus Cupboard. For example, Steve mentioned:

Well, I think what the Campus Cupboard provides is that outlet you know, you're going to be, we understand your needs, we're taking care of people's needs, not just their wants. You know, when you look at the old psychologist, Maslow's Hierarchy of Needs, you know the food clothing and shelter, and you know that is, we're going to try and make sure, that if those components are not addressed, how are we going to expect them to have success in other areas of their academic pursuits, so I think looking at the clientele again, like I said, there's a larger need than just the want, well I want a soda, but these people need sustenance because of their situations, so we do not want anyone to feel like they're not being taken care of, and that's a holistic approach that we take here on campus, at Central Missouri. 
On the other hand, one volunteer mentioned how easy it would be to incorporate an educational experience while clients wait to enter the cupboard. Virgil commented:

So it's, and this could be, this could be as easy as this, you know, in some regards it's not as personalized, but it could be. It could be as simple as sitting down and putting together five or 10, five or 10 minute videos and posting them and saying, Hey, uh, you're here at the food pantry. Look, scan this QR code. Oh, watch this five-minute video. You know, fill out a little assessment and get it just for your own personal sake and get a feel for where you're at and how you're spending money, what you're doing and um, you know, and just, and then here's a set of online resources that will walk you through step by step, how to manage your money better. How to, um, deal with, you know, different things. What are the other things that we see as we've talked to different people, as, in my opinion, what are the challenges with the food pantry is a lot of these guys have no idea how to cook, right? Um, and especially the huge international population we've got over here. You know, a lot of them come from a variety of different families. Volunteers and employees of the Campus Cupboard also provide unique perspectives that are valuable to the culture and sustainability of the Campus Cupboard. Among the variety of services that the Campus Cupboard provides, the highest priority is alleviating hunger by offering a variety of nutritious options. When given the opportunity to speak about the Campus Cupboard's priorities, several staff and volunteers presented similar perspectives. For example, Stanley reported: "Part of our mission is to provide students with good nutrition as well. So that is why we're figuring we shouldn't be giving out whole sheet cakes to a student." Additionally, Sophia confirmed: 
We really want to make sure that we're ideally providing a really well-rounded like meal type experience, where people can get like fruits, vegetables, like a treat here and there, but someone's not getting like a whole cake every single time they come in, because we really want to make sure that people are getting like nutrient enriched foods. Not just like junk food, because we want to make sure that we're being as healthy as they can be.

Several volunteers as well as staff members believed advocating for their clientele by providing thoughtful outreach programs and useable products was also a priority for the Campus Cupboard. The majority of staff members individually confirmed the importance of outreach and client advocacy. For example, Sophia argued:

And then you think about, how much storage can people have in their rooms? Like, I don't know, like a mini fridge maybe, if it's like a dry good then it's still probably kind of limited, but maybe not as much. So, yea, it's limited.

Likewise, staff noted the importance of connecting with clients and argued reaching out to those struggling creates the Cupboard's holistic approach. For example, Virgil suggested extending the outreach to communicate more individually with their clients: So, so there's a, uh, but there's, there's even less than this or that. But I think that the communication channel of great idea of who really is, uh, you know, struggling, what does that person look like? And you know, without, without stereotyping or inappropriate ways. But I think that that's a significant issue. And I think the two-way communication channel with technology should be totally feasible.

In fact, Sam pointed out one example of what communication can create: 
I'd say it's to provide for our community, like for the UCM Community. I've been told that some of the UCM janitors make like 20 thousand a year, which is below the poverty line for families, so they can come in and get food, and I think it also just helps college kids because they might, may not be going hungry, because I think most of them are required to get a food plan, but just sometimes you just don't want to eat that food, so we'll get snacks all the time, we'll get sodas most of the time, so it's just snack stuff all the time, we'll get sodas most of the time, so it's just snack stuff that people can come in and grab that aren't necessarily necessities, but like it's nice to have. We'll also get like bag vegetables and stuff, so if you don't want to go out and buy vegetables, because they're expensive at Wal-Mart and Aldi and whatever, then you can get some there.

Some volunteers stressed the importance of how just reaching out to the community could be the most important role the Cupboard plays. For example, Virgil and Virginia highlighted:

Yeah. I, uh, so in all my years of church extremes where I've dealt with a lot of poverty, a lot of poverty um, I, generally had a philosophy to err on the side of just compassion. And just be like, I never, I've never felt, on the one hand there, there is a, like in my church leadership position, there is an obligation to be responsible and respectful of sacred funds and resources that we consider sacred. Right? Like, like, Hey, I know that there's families out there that didn't eat to give up that food and money for that person. Right. So, there's a responsibility to be wise with it. On the other hand, I'm not sure God, and I'm speaking to religious. 
There are, I'm sure God wants us to be like the police authority of what's of someone's food and what they consider enough and not enough, and you know like, like, like, Oh, you're abused. Again, I haven't seen someone who legitimately is abusing systems. I know that they're out there, but as a general, people are good people are good people, they're really good people and they're, they're just trying to get by, and they don't have the same perspective on nutrition and food and drink as we do have. Is it really my job to conform them to my perspective on that? Or could I instead to say, I'm just going to love you and serve you.

Volunteer and staff perspectives on the role of nutrition. Likewise, because the Campus Cupboard works with donated food, volunteers and staff alike prioritized checking the expiration dates of the products on the shelves. Valerie noted, "I know they threw away old stuff. Like we had lettuce the other day that was brown, so we had to go through that and throw it away."

In addition to providing healthy food choices the Campus Cupboard also focuses on alleviating financial burdens. Steve highlighted:

One thing that with our clients that use our Campus Cupboard, we want to make sure we offer protein on a regular basis. That is something that is really important. Whether that comes in the form of a canned good or beef, or we just got a shipment of bacon in this last week. Sometimes, we get other things, so having that variety. We do serve a number of international students with our cupboard and their taste and their needs from their culture might be a little different than, you know American students, our US Students. So, we really concentrate on trying to offer a variety, the packaging, and then of course taking care of it for 
distribution.

Ultimately, the Campus Cupboard does focus on nutrition but in the end Virgil summed up their mission:

I think the answer is, we're just going to love you and serve you and if you get too much Mountain Dew, it's not our responsibility to keep you healthy. We're just going to love and serve you.

Structure of the Campus Cupboard. Regarding how to address food insecurity on campus, clients addressed the policies, hours, and size and location of the Campus Cupboard. When asked, some participants directly spoke to directing funds towards what is obviously a campus wide issue. Specifically, Simon said:

I would ask for more of a budget to not just rely on donations. I mean, the donations are great, but if we were able to spend some money we could go and purchase more soups or more whatever that we want. I don't know, I think it's run pretty well right now, but if we had some more resources to stock it more fully and more consistently, because some weeks we get a large delivery and it's full, but other weeks we barely get anything and it's bare, and sometimes we don't get any deliveries. For example, last week, of the three deliveries we normally get, we got one, and it was really, really small, so we didn't have much of anything last week.

Additionally, teaching their clientele how to feed themselves could ultimately be the best form of outreach. For example, Virgil suggested:

Let's see if it's, if it's connected, see because they can go to, there's all kinds of recipe things online, but it's the, it's the context, right? So maybe, and I don't 
know, I'm purely speculating there, but like if they, if they have a communication channel or a little barcode or something there that just said, Hey, this item can be made in five ways, click on this to get a couple of recipes that can be done in five or 10 minutes. Because again, students don't have time to sit around and make a whole bunch of things. Like we've learned this with our missionaries, right? So, we sent them off to Brazil or Idaho or wherever they've got, you know, they run 14 to 18 -hour days, missionaries where they got to stay, they got to stay healthy, so they can't just eat out or, you know. Right. And so how do you give them recipes that are quick, easy, simplified, but still give them nutrition? That's what these college students need in my opinion. 


\section{VITA}

Michael (Mike) Verderaime was born in Pueblo, Colorado, but spent the earliest part of his life in Trinidad, Colorado. He completed high school in Colorado Springs, Colorado. After high school, Mike attended Adams State College in Alamosa, Colorado. He majored in Spanish, with an associate degree in Business Administration. As a member of the football and wrestling teams, he experienced the importance of athletics which ultimately fueled him to become a teacher.

In 2003, Mike began his career as a public education teacher and coach. Over the course of his 15-year public education career Mike worked with a wide variety of students of all ages and backgrounds. These years of teaching and coaching in three different public high schools would ultimately set the stage for understanding the importance of the National School Lunch Program (NSLP) in creating a balanced playing field for lower economic communities.

Mike received an MA in education emphasizing in Spanish Language pedagogy, history and literature. While at Doherty High School he assisted in a field studies program that focused on an experiential learning environment in Colorado, Utah, New Mexico and Peru. Focusing on the natural, biological social, and political importance of water. Specifically, Mike focused on drought's role in immigration and on lowereconomic communities in the West, he also helped create an international program that helped doctors with health clinics in the Peruvian Amazon.

He was hired by Colorado Community Colleges in 2010. He continues to serve students, families, and his department as the World Language and Communication Department Chair at the Colorado Community College System. While teaching at 
Colorado Community College Online, Mike completed the Doctorate in Educational Leadership and Policy Analysis program through the University of Missouri in Columbia, Missouri in May of 2020. 